Routledge Studies in Media, Communication, and Politics

\title{
SOLIDARITY IN THE MEDIA \\ AND PUBLIC CONTENTION \\ OVER REFUGEES IN EUROPE
}

Manlio Cinalli, Hans-Jörg Trenz,

Verena K. Brändle, Olga Eisele

and Christian Lahusen
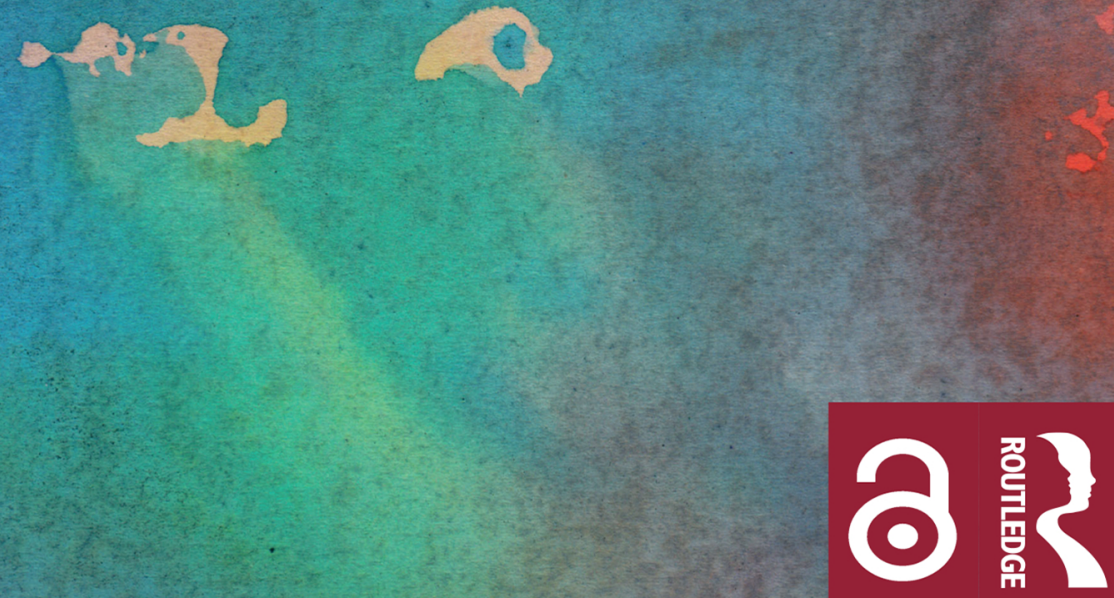


\section{Solidarity in the Media and Public Contention over Refugees in Europe}

This book examines the 'European refugee crisis', offering an in-depth comparative analysis of how public attitudes towards refugees and humanitarian dispositions are shaped by political news coverage.

An international team of authors address the role of the media in contesting solidarity towards refugees from a variety of disciplinary perspectives. Focusing on the public sphere, the book follows the assumption that solidarity is a social value, political concept and legal principle that is discursively constructed in public contentions. The analysis refers systematically and comparatively to eight European countries, namely, Denmark, France, Germany, Greece, Italy, Poland, Switzerland and the United Kingdom. Treatment of data is also original in the way it deals with variations of public spheres by combining a news media claims-making analysis with a social media reception analysis. In particular, the book highlights the prominent role of the mass media in shaping national and transnational solidarity, while exploring the readiness of the mass media to extend thick conceptions of solidarity to non-members. It proposes a research design for the comparative analysis of online news reception and considers the innovative potential of this method in relation to established public opinion research.

The book is of particular interest for scholars who are interested in the fields of European solidarity, migration and refugees, contentious politics, while providing an approach that talks to scholars of journalism and political communication studies, as well as digital journalism and online news reception.

Manlio Cinalli holds a Chair of Sociology at the University of Milan and is Associate Research Director at CEVIPOF (CNRS - UMR 7048), Sciences Po Paris. He is the author of Political Integration of Muslims in France (Palgrave, 2017), and has published widely on citizenship in international journals.

Hans-Jörg Trenz is Professor at the Department of Communication at the University of Copenhagen and at ARENA - Centre for European Studies, University of Oslo. His main field of interests are European media and the public sphere, migration and ethnic minorities, cultural and political sociology.

Verena K. Brändle is a Senior Research Fellow at the Department of Communication, University of Vienna and recipient of an International Postdoctoral Grant by the Independent Research Fund Denmark. Her main research interests focus on critical migration studies and political communication.

Olga Eisele is a postdoctoral researcher at Vienna University. In her work, she focusses on media discourses, the European Union, crisis communication and the relationship and mutual influence of media and politics.

Christian Lahusen holds a Chair of Sociology in the Faculty of Arts at Siegen University, Germany. His research interests include social theories, political sociology and the sociology of European societies and European integration. 


\section{Routledge Studies in Media, Communication, and Politics}

\section{Digitizing Democracy}

Edited by Aljosha Karim Schapals, Axel Bruns, and Brian McNair

\section{Communicating Populism}

Comparing Actor Perceptions, Media Coverage, and Effects on Citizens in Europe Edited by Carsten Reinemann, James Stanyer, Toril Aalberg, Frank Esser, and Claes H. de Vreese

Human Rights, Iranian Migrants, and State Media

From Media Portrayal to Civil Reality

Shabnam Moinipour

Threat Communication and the US Order after 9/11

Medial Reflections

Edited by Vanessa Ossa, David Scheu and Lukas R.A. Wilde

Rhetoric, Fantasy, and the War on Terror

Vaheed Ramazani

Generational Gaps in Political Information Use and Civic Engagement From Baby Boomers to Generation Z

Kim Andersen, Jakob Ohme, Camilla Bjarnøe, Mats Joe Bordacconi, Erik Albaek, and Claes de Vreese

Solidarity in the Media and Public Contention over Refugees in Europe Edited by Manlio Cinalli, Hans-Joerg Trenz, Verena Brändle, Olga Eisele and Christian Lahusen 


\section{Solidarity in the Media and Public Contention over Refugees in Europe}

Manlio Cinalli, Hans-Jörg Trenz, Verena K. Brändle, Olga Eisele and Christian Lahusen 
First published 2021

by Routledge

2 Park Square, Milton Park, Abingdon, Oxon OX14 4RN

and by Routledge

52 Vanderbilt Avenue, New York, NY 10017

Routledge is an imprint of the Taylor \& Francis Group, an informa business

(C) 2021 Manlio Cinalli, Hans-Jörg Trenz, Verena Brändle, Olga Eisele and Christian Lahusen

The right of Manlio Cinalli, Hans-Joerg Trenz, Verena Brändle, Olga Eisele and Christian Lahusen to be identified as authors of this work has been asserted by them in accordance with sections 77 and 78 of the Copyright, Designs and Patents Act 1988.

The Open Access version of this book, available at www.taylorfrancis.com, has been made available under a Creative Commons Attribution-Non Commercial-No Derivatives 4.0 license.

Trademark notice: Product or corporate names may be trademarks or registered trademarks, and are used only for identification and explanation without intent to infringe.

British Library Cataloguing-in-Publication Data

A catalogue record for this book is available from the British Library

Library of Congress Cataloging-in-Publication Data

Names: Cinalli, Manlio, author. | Trenz, Hans-Jörg, author. | Brändle, Verena K., author. | Eisele, Olga, author.|Lahusen, Christian, author.

Title: Solidarity in the media and public contention over refugees in Europe /

Manlio Cinalli, Hans-Jörg Trenz, Verena K. Brandle, Olga Eisele, Christian

Lahusen.

Description: Abingdon, Oxon ; New York : Routledge, 2021. |

Series: Routledge studies in media, communication and politics |

Includes bibliographical references and index.

Identifiers: LCCN 2020047345 (print) | LCCN 2020047346 (ebook) |

ISBN 9780367419950 (hardback) | ISBN 9780367817169 (ebook)

Subjects: LCSH: Mass media and immigrants-Europe. | Refugees-Europe-

Public opinion. | Refugees-Press coverage-Europe. | Solidarity-Europe.

Classification: LCC P94.5.I482 C56 2021 (print) | LCC P94.5.I482 (ebook) |

DDC 302.23086/912-dc23

LC record available at https://ccn.loc.gov/2020047345

LC ebook record available at https://lccn.loc.gov/2020047346

ISBN: 978-0-367-41995-0 (hbk)

ISBN: 978-0-367-75322-1 (pbk)

ISBN: 978-0-367-81716-9 (ebk)

Typeset in Sabon

by Taylor \& Francis Books 


\section{Contents}

List of illustrations vii

List of contributors ix

Acknowledgements $\quad$ xi

1 Introduction: A divided Europe? Solidarity contestation in the 1 public domain

2 Debating solidarity across borders: The public sphere and role of the media

3 Claims-making analysis and its applications in media and communication studies

4 Solidarity under siege: The 'refugee crisis' in the news media

5 Bottom-up solidarity contestation through social media: How Facebook users respond to political news

PART II

6 Solidarity contestation in Switzerland - fragmented news, fragmented solidarity?

7 Solidarity contestation in Germany - 'Can we really do it?': Refugee solidarity in the German context

8 Solidarity contestation in Denmark: A national escape from transnational crisis

9 Solidarity contestation in France: Bottom-up polarisation and segmentation 
vi Contents

10 Solidarity contestation in Greece: Standing on the verge of emergency

11 Solidarity contestation in Italy: A dual debate between regulatory and confrontational discussions

12 Solidarity contestation in Poland: The categorical denial of responsibility

13 Solidarity contestation in the UK: Reluctance during political uncertainty

Conclusion: The divided Europe of solidarity contestation

References

Index 


\section{Illustrations}

\section{Figures}

4.1 Total number of articles over sample time period 66

4.2 Total number of claims over sample time period 67

4.3 Number of first time asylum applicants during the 'refugee crisis' 68

4.4 Average positions ( -1 negative to 1 positive) across countries and actor types $\quad 75$

4.5 Justifications in claims by country 77

4.6 Average tone of claims and solidarity justifications across broadsheet/tabloid newspapers $\quad 79$

4.7 Average position of actors by scope across all countries over time $\quad 80$

4.8 Average positioning of claimants by country/scope 81

5.1 Average tone of claims regarding solidarity with refugees in articles posted on Facebook 90

5.2 Overview of user engagement across countries and reactions (types of comments in frequencies) 91

5.3 Overview of issues discussed in articles posted on Facebook 92

5.4 Average stance towards refugees in comments 96

5.5 Justification versus no justification in comments with tonality

5.6 Justifications of solidarity of negative and positive comments
compared

5.7 Average position in broadsheets and tabloids in relation to $\begin{array}{ll}\text { justifications } & 100\end{array}$

\section{Tables}

3.1 Examples for coding of claims-making 48

3.2 Claims sample size across countries and newspapers 52

3.3 Comment sample size across countries and Facebook pages of newspapers 58

4.1 Actors of claims by country 69

4.2 Issues of claims about the 'refugee crisis' by country (percentages) 71 
viii List of illustrations

4.3 Position across countries (distribution in \% and average -1 to 1 ) 72

4.4 Pairwise comparison of claimants' positions across countries

4.5 Five most frequent claims based on actor-issue-position combinations

4.6 Percentages of justifications $(n=5948)$ in all claims by position and claimant

5.1 The type of comment by position of commenter towards the issue/ claim in the posted article (frequencies in brackets) ${ }^{2}$

5.2 Cross-country distribution of issues in comments

5.3 Subsampling comments with position regarding refugee solidarity $($ Object $=$ Yes $)$

5.4 Percentage of positive, neutral, and negative claims and comments across countries

5.5 Issues in comments with negative stance towards refugees

5.6 Issues in comments with positive stance towards refugees

9.1 Solidarity frames across newspapers 


\section{Contributors}

Verena K. Brändle is a Senior Research Fellow at the Department of Communication, University of Vienna, and recipient of an International Postdoctoral Grant by the Independent Research Fund Denmark (DFF). Since 2020 she is Principal Investigator of the DFF-funded project 'Informing to Dissuade? Governments' Digital Information Campaigns for Migrants as Bordering Practices'. Her research is located at the intersection of critical migration/ border studies, political communication and migration governance. She is further interested in the role of the state in internet infrastructure regulation.

Manlio Cinalli holds a Chair of Sociology at the University of Milan and is Associate Research Director at CEVIPOF (CNRS - UMR 7048), Sciences Po Paris. He has delivered teaching and research in various leading universities and institutes across Europe and the USA including, among others, Columbia University, the EUI and the University of Oxford. He has many large grant awards, and has been publishing widely on citizenship and political integration. His research relies on a multidisciplinary approach that combines contentious politics, political behaviour and policy studies.

Olga Eisele is a postdoctoral researcher at the University of Vienna. Her research interests lie in the broader area of political communication with a focus on media coverage, European integration (especially during crisis) and the relationship of media and politics. She obtained her $\mathrm{PhD}$ from Vienna University in 2017; she then joined the TransSOL project as a postdoctoral researcher and is now Principal Investigator of the project 'Tango on a Tightrope - An Investigation of Media-Politics Dynamics in EU Crisis Management'.

Christian Lahusen holds a Chair of Sociology at the Department of Social Sciences, University of Siegen, Germany. He studied at the European University Institute (Florence) and obtained his habilitation from the University of Bamberg. His research interests include social theories, political sociology, and the sociology of European societies. He has directed and participated in research projects on topics relating to contentious politics, civil society and social exclusion. 


\section{$\mathrm{x}$ List of contributors}

Hans-Jörg Trenz is Professor at the Department of Communication at the University of Copenhagen and Research Professor at ARENA - Centre for European Studies, University of Oslo. He studied at the European University Institute (Florence) and obtained his habilitation from Humboldt University of Berlin. His main fields of interest are the emergence of a European public sphere and of European civil society, European civilisation and identity, migration and ethnic minorities, cultural and political sociology, and social and political theory. 


\section{Acknowledgements}

Results presented in this book have been obtained through the project 'European Paths to Transnational Solidarity at Times of Crisis: Conditions, Forms, Role-models and Policy Responses' (TransSOL). This project was funded by the European Commission under the Horizon 2020 research and innovation programme (grant agreement No. 649435). The TransSOL consortium was coordinated by the University of Siegen (Germany), and comprised the Université de Genève (Switzerland), the Fondation Nationale des Sciences Politiques (France), Glasgow Caledonian University (United Kingdom), the Panepistimio Kritis (Greece), the University of Florence (Italy), the University of Warsaw (Poland), the University of Copenhagen (Denmark), the University of Sheffield (United Kingdom), and European Alternatives Ltd (Germany and United Kingdom). We thank all members of the TransSOL research consortium for their contributions to the project. In particular, we would like to thank our coders of claims and comments on whose diligent empirical analysis this book is based. Their individual contribution is gratefully acknowledged in each country chapter of Part II of this book. 
$\Longrightarrow$ Taylor \& Francis

Taylor \& Francis Group

http://taylorandfrancis.com 


\section{Introduction}

\section{A divided Europe? Solidarity contestation in the public domain}

Of the many crises that Europe faces today, the so-called 'refugee crisis' is the one that has had a profound impact on public debates about solidarity, reinvigorating contestations and divisions within and between European member countries (Krastev, 2017b). Since 2015, huge fault lines have opened up across the European Union about the question of how this 'crisis' should be handled and what the responsibility of European countries and populations is in regard to the provision of humanitarian aid and assistance. While most research has focused on migration movements and policy and security implications, there has been little sustained and comparative analysis of how public attitudes towards refugees and humanitarian dispositions are shaped within the public sphere by political news coverage of the 'crisis' (Agustín and Jørgensen, 2018; Barlai et al., 2017). Sociological research in the field of communication studies, in turn, has mainly focused on the representation of refugees in the media, but less on how discourses and contestations of solidarity in European receiving countries inform, through the media, policy responses and public attitudes towards refugees (Eberl et al., 2018).

This volume, composed of results from comparative media analyses about transnational solidarity contestation in the public sphere in response to the socalled 'refugee crisis', aims to provide systematic empirical data and theoretical reflections about public contestations, and thus propose answers to the vital, yet understudied question of the role of the media in contesting (promoting or rejecting) solidarity towards refugees. To enhance such an understanding, we propose a public sphere framework of solidarity contestation. The public sphere is conceptualised as a place of political struggle (Cinalli and Giugni, 2013a, 2016a; Della Porta and Caiani, 2009; Koopmans et al., 2005), but at the same time, as a space where the boundaries of solidarity are defined (Calhoun, 2002; Enjolras, 2017). We argue that such solidarity contestations in the public sphere are not solely about the standing of Europeans vis-à-vis refugees and migrants more broadly. They are also about a broader notion of European solidarity among the member states and among the people of Europe in dealing with the 'crisis', e.g., in terms of shared responsibilities and activities of mutual assistance in sheltering refugees. In analysing the 'refugee crisis' as a media event, we learn as much about the conditions necessary to construct solidarity 


\section{Introduction: A divided Europe?}

towards 'others' (the refugees) as we learn about the way we grant solidarity among 'us' as Europeans.

Additionally, we argue that an accurate understanding of solidarity contestations has to do justice to the complexity of mass mediated public debates by addressing the relations between news coverage and citizens' comments. In fact, the mass media provide an important arena of public contentions that is highly patterned by news coverage routines and journalistic practices, thus privileging representatives of corporate actors (e.g., public authorities, interest groups, scientific communities). However, online media have conquered the public sphere, and this means that news audiences and consumers have become part and parcel of the media system and mass mediated public contentions. The analysis of public debates about solidarity with refugees has to acknowledge this structural transformation of public contentions by focusing on both the way public claims makers define and assess solidarity within the news, and how citizens who read and comment on these news delineate what solidarity with refugees means to them. The added-value of this dual approach is not only tied to the empirical insights of two interlocked arenas of solidarity contestation: claims-making by public, mainly organised actors vs. commenting by readers and media consumers; this approach also enables us to learn more about the relations between two distinct forms of public contestations that both have an effect on the way solidarity with refugees is shaped, promoted or eroded in the various countries.

Analysing public responses to the mass arrival of refugees in the European Union from a comparative media perspective is timely and will allow us to better understand why member states have reacted in very different, and often contradictory ways to the challenges of migration, humanitarian aid and political integration. The main aim was to survey mass mediated public debates in very different national backgrounds - including the south, north, east and west of Europe - in order to systematically map differences in the perception and reception of refugees, and link them to differences in respective public debates across Europe. Altogether, this will allow us to explain not only the variety of public responses, but also to address broader questions about the role of the media in their treatment of refugees and the respect of human rights, especially at a time when media are considered to be responsible for spreading antimigrant sentiments. Our book thus also contributes to the current discussion about the responsibility and accountability of journalism in important ways (Gemi et al., 2013; Wahl-Jorgensen et al., 2016; Waisbord, 2013).

What is more, the so-called 'refugee crisis' is the one that has had a profound impact on the self-understanding of the European Union (EU) as a community of values based on the respect of human rights and global solidarity. For a long time in history, Europe has been a promoter of values that are held to be universally valid. In this tradition, the EU has also been built on a set of fundamental values such as 'respect for human dignity, freedom, democracy, equality, the rule of law and respect for human rights' (Art. 2 Treaty on European Union). These values are meant to unite all member states. It is the goal of the 
European Union to defend and promote them both in its internal and external action. As we will argue, beyond the lack of solidarity, the events that led to the so-called refugee crisis in 2015 and 2016 stand for a clash of solidarities within and across established member states, a clash about our moral and legal obligations towards refugees and migrants, as well as a clash in our relationships among our members, and with regard to the moral foundations of our community of states and citizens (Krastev, 2017a and b).

Raising such normative questions requires, however, a stock-taking exercise to unveil a large array of variations in the public sphere, especially in terms of how the news media actually cover humanitarian crises, inform about the needs of those affected by them and involve readers and audiences in normative debates.

\section{The European field of solidarity contestation}

Our analyses shall help to develop a better understanding of the constitutive role of (mass) media communication in the construction or erosion of solidarity in modern society. We wish to raise awareness of the central contribution of the mass media in channelling contestation of solidarity among citizens across time and space. Solidarity in modern society can no longer rely solely on face-to face encounters of intimate relationships, such as the family, but needs to be built on the mediated relationships among distant people who begin to negotiate responsibilities between each other. In historical terms, the construction of solidarity relationships among distant people unfolded as part of the nation-building process (Rokkan, 1999; Stråth, 2017) and was strongly attached to the idea of solidarity among citizens sharing equal (civic, political and social) rights (Banting and Kymlicka, 2017). The establishment of a public sphere, primarily by means of mass media, played a crucial role in promoting national identities and a sense of national solidarity. This role has not lost power, given that feelings of belongingness and claims for solidarity among co-nationals are constantly reproduced and reaffirmed in the public sphere. The mass media are still held responsible for strengthening bonds of national solidarity among members of a political community (Waisbord, 2004).

However, the mass media cannot be reduced to a functional instrument in the promotion and stabilisation of national solidarity, given that the mass media have fuelled public debates that have qualified, and in part even contested, national solidarities in the name of international, humanitarian or cosmopolitan visions. Public debates within the mass media are thus shaped by particularistic and universalistic notions of solidarity. On the one hand, mass media systems are structured primarily along national divisions, impacting on patterns of news coverage and public discourse. Scholarly writing has provided ample evidence on the ways mass media contribute to the reproduction of national identities (Calabrese and Burke, 1992), and how news coverage of national and international events is driven by national media systems, interests and sensitivities (Aalberg et al., 2013; Van Dijk, 1988). This affects the mass media's approach 


\section{Introduction: A divided Europe?}

in addressing solidarity within and beyond the nation-state, because relations with co-nationals are dealt with differently than those towards distant others. According to Walzer (1994), solidarity relationships as established within a membership community of equals are described as thick or reciprocal, whereas the support that is granted to distant strangers is often reduced to forms of charity in a thin and non-reciprocal relationship of inequality.

Additionally, solidarity with distant 'others' is subjected to a strong sense of conditionality, given that support depends on the assumed neediness, deservingness or proximity of potential recipients (Van Oorschot, 2000, 2006). Non-members of a national community might thus not apply or even discredit themselves as legitimate targets of support. This limits the readiness of the mass media to extend thick conceptions of solidarity to Europeans and European member states, as evidenced by public debates during the Great Recession. Since 2008, the economic crisis has placed fiscal solidarity on top of the policy agenda. However, news coverage in member states has emphasised conflicts between different governments about the necessary measures to combat the (budgetary, economic, and social) consequences of the crisis (De Wilde et al., 2013), in part questioning the legitimacy of the Greek governments' claims for European assistance (Mylonas, 2012; Papathanassopoulos, 2015). Conditionality seems to be even stronger in regard to non-Europeans, as the experience of public debates during the so-called 'refugee crisis' of 2015 and 2016 showed. While the mass media were initially quite receptive to public solidarity towards the needs of refugees, this momentum was overlaid by public debates stressing risks (security issues, integration problems, social costs, cultural menaces), and qualifying deservingness publicly (Georgiou and Zaborowski, 2017).

The mass media tend to reproduce national solidarity, because the latter is firmly institutionalised by the modern nation-state in terms of constitutional rights, policies and public oratories. However, public debates within the mass media are not exclusively constrained to particularistic solidarities. On the other hand, there is evidence that the mass media provide a voice to transnational, cosmopolitan or universalistic notions of solidarity. The mass media raise questions of global solidarity and justice towards non-nationals. Through the coverage of distant suffering, they confront audiences with their moral responsibility to provide assistance to strangers (Kyriakidou, 2009, 2015; Nash, 2008), even if these debates are marked and guided by national agendas and interests. The notion of global solidarity is therefore not only an abstract normative and legalistic principle. Following Tönnies' (2002) distinction between community and society, it is also linked to different forms of sociation, and here in particular it is tied to the expansive logic of solidarity relationships within modern society as an association of strangers. The transition from solidarity, as enshrined in the private relationships of kinship, to solidarity as a public relationship among strangers underlies the social struggles for an expansion of rights, citizenship and equality. This contraposition of thick and thin, communal and associational forms of solidarity is more often than not also associated with liberal-cosmopolitan and exclusive communitarian values (Brändle et al., 2019), and is a constant source of public contentions. 
The mass media thus play an ambivalent role in public debates about (transnational) solidarity. This book aims to shed more light on this ambivalence by focusing on solidarity contestations in regard to the so-called 'refugee crisis'. The empirical and theoretical analyses will be devoted to a number of questions. What are the main topics, ideas and beliefs associated with solidarity with refugees? Which actors are involved in these debates and who can be considered as promoting and questioning solidarity towards refugees? How do these contentions develop across time, and what are the main drivers of public contention? How are citizens' comments related to claims-making within the news coverage, and can we speak of dissociated or integrated public debates? What role do the mass media play in the construction of antagonistic visions of solidarity, and are they receptive to discourses about transnational solidarity?

The book also aims to map the public solidarity contestations in a number of European countries and wishes to advance our knowledge about the patterns, drivers and implications of these solidarity contentions. Additionally, it wishes to assess whether the needs and concerns of the others can be communicated in such a way as to formulate reciprocal commitments between strangers. It is here that we wish to contribute an original theory of the public sphere and the media as open spaces for solidarity contestation through which our moral responsibilities towards others are negotiated nationally, at a European level, and globally.

The empirical data and theoretical reflections presented in this book emanate from a research project funded by the European Union under the Research and Innovation Programme, Horizon 2020. The project was devoted to the analysis of 'Transnational Solidarity at Times of Crisis' (TransSol, available at www. transsol.eu), and was conducted in eight European countries (Denmark, France, Germany, Greece, Italy, Poland, Switzerland and the United Kingdom). These countries are representative of the broader European landscape, displaying very different attitudes with regard to the question of transnational solidarity and whether hospitality should be granted to the incoming refugees. TransSOL followed a multidimensional approach and was interested in forms, drivers and implications of (transnational) solidarity at the level of individual citizens (Lahusen and Grasso, 2018), the organised civil society (Lahusen et al., 2021), public policies (Federico and Lahusen, 2018) and the public sphere. The focus on the public sphere was motivated by the assumption that solidarity is a social value, political concept and legal principle that is discursively constructed in public contentions. And this means that individual, organised and institutional forms of (social, political and legal) solidarity are highly dependent on public justifications and/or susceptible to public criticism. In this sense, this book complements previous publications of the project, highlighting the prominent role of the mass media in shaping national and transnational solidarity.

TransSol is also original in the way it deals with variations of public spheres by combining a news media claims-making analysis with a social media reception analysis. On the one hand, comparative insights on solidarity contestation are gained through standard claims-making analysis of a number of variables 


\section{Introduction: A divided Europe?}

such as main contestants, issues, attitudes towards refugees, forms of actions, polarisations, degrees of Europeanisation, justifications and ascriptions of responsibility. On the other hand, TransSOL innovates through an exploratory user reception analysis and inductive coding of citizens' attitudes towards refugees expressed on social media (Facebook). This latter analysis offers promising results on the dynamics of social media contestation, and in particular, the expression of pro- and anti-refugee sentiments by citizens-users, and the way such sentiments are translated into political mobilisation in support and/or rejection of solidarity.

\section{Outline of the book}

Given the expected differences in terms of public responses to the mass arrival of refugees, this volume has four main objectives. First, we identify the extent to which acts of solidarity towards refugees were granted public awareness in national public spheres and what claims on behalf of or against hospitality towards refugees were made, and by whom. Secondly, we reconstruct the dynamics of solidarity contestation in the public sphere in terms of competing interests and interpretations between EU-member states, their main lines of division and allegiances. Thirdly, we examine the discursive construction of European solidarity in terms of its underlying conceptions, ideas and norms that drive public debate, and how such different notions of solidarity are used in contestations between various allegiances (e.g., proponents and opponents of humanitarian solidarity, of national exclusive notions of solidarity, or of populism and xenophobia). Fourthly, we trace the different dynamics of media-driven solidarity contestation from the perspective of public claims makers in the media who make it into the news, as well as from the perspective of citizens who read and comment on the news.

The chapters of this volume contribute to these objectives by providing theoretical and empirical insights into the dynamics and structures of solidarity contestations in eight European countries. Our journey starts with a conceptual and theoretical reflection of the role of the mass media in public debates about solidarity. In this theoretical chapter, we argue that European integration has expanded the field of solidarity contestation and opened up the spaces of media communication through which we define our moral responsibilities towards others. The expanded space of solidarity contestation is European, but at the same time is open towards the global and segmented towards the national. We argue therefore that our empirical analyses require an approach that examines the European field of solidarity contestations in its relationships to alternative national or transnational (global) notions of solidarity. Media contestations of refugees and migrants suggest a tension between exclusive nationalist notions of solidarity that are often defended by populist parties, an extended notion of European solidarity among the member states of the EU in handling the 'crisis' propagated by some policy actors, and an inclusive conception of humanitarian solidarity upheld by civil society organisations. In this regard, we propose to 
treat the mass media as a public space of (trans-)national solidarity contestation that allow us to empirically analyse how this tension between national, European and trans-national-global dimensions of solidarity translates into discursive struggles that play out in the public sphere. Our approach moves beyond the more traditional focus on the public sphere, because we contend that an analysis of the mainstream media needs to be carried out by inquiring into contestation within the social media. On this basis, we also introduce a revised and extended conceptualisation of 'media events' to advance our case: the so-called 'refugee crisis' of 2015 and 2016.

Based on these conceptual and theoretical insights, Chapter 3 addresses methodological issues by discussing claims-making analysis and its applications in mass media and communication studies. The focus of this chapter is on methodological choices taken during the development of the comparative research designs used for the analyses of this book. The aim is not only to document our methodology in a way that our own research becomes transparent and replicable. We also wish to give guidance on very concrete questions (e.g., sampling strategies, coding practices and necessary steps to safeguard the reliability of data) so that our research can become a source of inspiration for other scholars. Our methodology draws on two methods of comparative media analysis that are applicable to news media and to social media: the method of media claims-making in news content and the method of social media commenting analysis regarding news reception. Overall, we will demonstrate in this chapter how questions related to media functions and responsibilities in the public sphere, which are derived from normative political theory and theory of democracy, can be operationalised and turned into empirically measurable and reliable indicators.

Before the backdrop of these theoretical and methodological reflections, we will move to the presentation of our main empirical findings. In Part I, we will engage in comparative analyses, both of the claims-making and the social media commenting datasets. Chapter 4, on the one hand, takes a closer look at solidarity contestation in print media by analysing political claims covered by national newspapers. The comparative analysis assesses the extent to which claims of solidarity over the refugee crisis were granted public awareness, as well as looking at the main characteristics of claims on behalf of or against refugees, the dynamics of solidarity contestation, and the underlying contentiousness in terms of values and justifications. We also consider the diachronic development of claims-making across the eight countries in order to assess the extent to which claims follow (or not) a similar cross-national pattern over time. The chapter also assesses whether potential (mis)matching across countries can be related to some particular explanatory factors. We consider variations of 'grievance-based' factors, such as the number of asylum applicants, as well as the potential impact of other domestic-based factors linked to national political spaces and policies in the field. In so doing, we engage with a longstanding tradition of scholarly debate that opposes 'grievance' and 'opportunity' theories in the field of contentious politics. From this viewpoint, given the nature 


\section{Introduction: A divided Europe?}

of the 'refugee crisis' and its transnational implications, we aim to probe into the relationship between Europeanisation and 're-nationalisation' of solidarity contestations beyond an initial appraisal of similarities of debates across countries in terms of attention cycles.

Chapter 5 shifts attention away from claims-making within news coverage and centres on news readers' comments of publicised newspaper articles in order to analyse bottom-up solidarity contestations on social media. It is primarily interested in the way social media dynamics influence and pattern the mobilisation of support or opposition towards refugees. While the comparative study of claims-making has allowed us to map the voice of organised publics and powerful stakeholders capable of leading politics, our analysis of online commenting by news readers allows us to shed light on the more hidden side of the public sphere, where people seize the chance to express emotions and opinions, and translate them into political action. This is particularly interesting because the case of solidarity with refugees has divided public opinion throughout Europe with advocates of human rights and open borders opposing supporters of exclusive national communities and welfare chauvinism. We analyse how bottom-up contestation of refugee solidarity was triggered by a particular succession of events and their interpretation in the media: the humanitarian disasters at Europe's external borders that unfolded during September 2015. The chapter presents findings from a comparative analysis of online commenting on Facebook news sites in order to see how citizens 'took sides'. In particular, we will show how they advocated for solidarity with refugees or opposed any support, how they voiced and justified their opinions, and in which ways they critically engaged with the issues and claims reported in the news articles posted on the Facebook sites. On these grounds, we are able to describe the tonality and structure of solidarity contestations among news readers, and the way these debates are interrelated with traditional news coverage in the national print media.

The two comparative chapters highlight important similarities and differences between the eight countries under analysis, thus contributing to the identification of key dimensions and factors of solidarity contestations within the public sphere. These analyses, however, provide only a very rough picture of the specificities of each of the eight countries. Part II of our book complements the comparative chapters by zooming in on each of the cases under study. Chapters 6 to 13 are devoted to a focused analysis of the discursive context of solidarity contestations and the main features of public debates in terms of claims-making and news commenting. Each of our eight country chapters addresses the specific exposure of the country to the events of late 2015 and early 2016, the way the 'refugee crisis' made its appearance in the public sphere and how the mass media contributed to its construction. A closer look at the structure of the print media is provided in order to indicate the potential imprint of the country's national media systems on public contentions, in particular by highlighting the potential impact of political divisions between newspapers, the role of political tutelage and party allegiances. Against this 
backdrop, core findings of the claims-making and Facebook comments analysis are presented in order to highlight the main lines of contention, the general inclination of public debates and the role of key actors in shaping the tonality and orientation of these discussions. These chapters underline the substantial differences between the countries under analysis by identifying more hostile and more moderate publicised public opinions, by highlighting the strong impact of political parallelism between newspapers and political forces in some countries, and by indicating the specific contribution state-actors play as key definers of public debates, when compared to other, more marginalised actors, such as civil society groups and the refugees themselves. Special attention is also given to the relation between claims-making within the print media's news coverage and the news readers' comments on the newspapers' Facebook sites, in order to assess possible linkages and the degree of fragmentation of public contestations about solidarity with refugees.

The concluding Chapter 14 finally highlights the main findings of our analysis and engages in a discussion with important implications. On the one hand, we reflect on the role and responsibility of newspapers and the social media in triggering conflicts about refugee solidarity. In so doing, we aim to address broader questions about our public sphere framework of solidarity contestation, focussing on the role of the media in the treatment of refugees and the respect of human rights (especially at a time when the media are considered to be responsible for spreading anti-migration sentiments). Against the standard argument about the responsibility and negative impact of journalism, and social media more generally, we maintain that the media cannot be held solely responsible for promoting anti-solidarity and anti-refugee feelings, frames and positions in the public sphere. Mass and social media also contributed to the spread of news, statements and discussions favourable to refugees, and they actively contributed to the momentum of European solidarity that made its appearance during September 2015 throughout Europe. The chapter discusses this ambivalent role of the mass media and highlights those factors that tend to encourage and limit the mobilisation of solidarity. On the other hand, we reflect about the implications of public debates within the mass media on the formation or erosion of solidarity in the public sphere. We discuss how public debates amplify certain developments within political debates among European institutions and member states in regard to the essence and future of solidarity, underlining the particular importance the principle of solidarity has and is still playing in the architecture of the European Union. We critically examine political developments that tend to debilitate the notion of solidarity among European citizens and European member states, and indicate the importance of solidarity contestations - and the moment of generalised European solidarity during late 2015 - in the constant reproduction of this principle. 
$\Longrightarrow$ Taylor \& Francis

Taylor \& Francis Group

http://taylorandfrancis.com 
Part I 
$\Longrightarrow$ Taylor \& Francis

Taylor \& Francis Group

http://taylorandfrancis.com 


\section{Debating solidarity across borders The public sphere and role of the media}

\section{Introduction: the public sphere as locus of contestations}

Since the foundational work by Habermas on the 'public sphere' (Habermas, 1989, orig. 1962), the idea that democracy is grounded in relational spaces of bottom-up communication - by which citizens intervene through their public interactions on the largest array of issues and daily concerns - has stood out as a new and more meaningful framework guiding much sociological research on citizenship, including their relationships of contestation and solidarity, beyond the more traditional attention to main institutional actors and processes. Habermas himself took his first steps within the disciplinary field of 'critical theory', drawing on the astonishing technological progress in communication systems from the 1950s onwards, and hence, the expanding media-based 'culture industry' (Adorno, 2001; Adorno and Horkheimer, 2002). Accordingly, sociological research on the public sphere has been developed side by side with the most extensive reflection over the functions of the mass media in modern society, to the point that today, the way the mass media contribute to the shaping of contestation of solidarity among citizens in a large scale and anonymous society is a consolidated topic of sociological inquiry (Lasswell, 1948; Wright, 1960). This strand of research has extended the focus of attention from the public to the policy sphere, and to the relations between them (Ambrosini et al., 2020).

In any large democracy, it is impossible for everyone to engage discursively together in a single physical space. Consequently, individuals must rely to a considerable extent on the mass media to make information available to them and to debate over different positions, issues and choices within the sphere of politics (Cinalli and O'Flynn, 2014). In turn, individuals contribute to democratic life by engaging in public discourses within the mass media and the communicative interactions these entail, irrespective of whether these interactions are conflictual or consensual. This also applies to this book's field of study: public contentions about solidarity with refugees. The mass media play a decisive role in providing individual and organised actors with information on related events and developments, but they also host public debates regarding how the issue of immigration should be dealt with and the extent to which solidarity should be granted to refugees. In fact, the number of organised actors engaged in public debates about 
solidarity towards refugees is large, including political parties, unions, churches, as well as a range of charities, NGOs, social movements and groups of refugees themselves. A comprehensive investigation of public debates thus allows us to identify the conflictual or consensual relations of these actors over issues of solidarity. It thus enables us to study 'national publics' that are the object of policy-making (Cinalli, 2004 and 2007; Gray and Statham, 2005) in connection with the policy sphere, which is composed of institutions and main political elites that lead processes of decision-making (Ambrosini et al., 2020; Cinalli, 2017).

While there is a growing body of research that seeks to assess in detail this complex relationship between public and policy spheres on the one hand, and, on the other, their display in the media (Cinalli and Giugni, 2013a, 2016a; Dolezal et al., 2010; Ferree et al., 2002; Page, 1996; Wessler et al., 2008), the process does not remain private but claims generalised validity (Calhoun, 2002). To assume that discourse in the media can be understood as a form of 'engagement' and mutual 'challenge' among a panoply of actors endowed with different opinions and strategic aims in terms of policy choices might seem controversial or counter-intuitive, as the media and journalism are first and foremost meant to be fact-based, objective and neutral (Löffelholz and Weaver, 2008). Yet this assumption is consistent with the idea that the public sphere is an arena of relational exchanges over the definition of the main issues of public relevance, within which individuals and actors of different kinds negotiate (and fight for) different meanings, construct political issues and nurture public controversies. Accordingly, the mass media provide spaces for a continuous and contentious process of communication through which the participants create their preferred frames to understand social reality and try to impose the way they see it onto others (Goffman, 1974; Nelson et al., 1997).

Moreover, in Western liberal societies, journalism and democracy have entered a symbiotic relationship where news representation and critique are interwoven (Habermas, 1989; McNair, 2000). This is important for our understanding of how the media shape contestation over solidarity, because it helps us to see the variable way in which they represent human suffering with normative critique and justification (Ambrosini et al., 2020; Boltanski, 1999). In the public sphere, the moral mechanism of this form of engagement applies to social relationships established by anonymity and distance (Habermas, 1989). Public discourse is used to exchange information about the needs of others and the moral obligations and commitments that follow on from it from a perspective of social justice (Brunkhorst, 2005). Hence, the main point to retain is that in any modern pluralistic society, different individuals will tend to see the world in different ways. In turn, this opens the possibility of communicating (or denying) experiences of injustice of people who are not present, or who even live at a distance but who are nevertheless included in a discourse of moral commitment (or disengagement) and are thus recognised (or not) as carriers of rights and legal subjects. 


\section{Conceptualising the mass media as interlocked arenas of solidarity contestation}

The mass media play a crucial role in constructing solidarity. This has been evidenced repeatedly in regard to the national level, where nationally structured systems of news coverage facilitate public debates about national solidarity (Aalberg et al., 2013; Calabrese and Burke, 1992; Van Dijk, 1988). Even here, solidarity remains a contested object, as will be explained below, given the diverse views and interests associated with the principle of solidarity. Contestations within the public sphere develop more complexity once we move to transnational solidarity. Mass mediated arenas are structured into national compartments, thus addressing transnational solidarity - e.g., within Europe - from the perspective of national agendas, preconceptions and interests. However, this does not necessarily hold true for the public debates they facilitate and guide. Particularly in regard to debates about European solidarity towards refugees and asylum seekers, we see an interlocking of national arenas of solidarity contestations. Not only do they host debates about the readiness of national governments and fellow citizens to act in support of refugees, but also expedite deliberations about each other's readiness to engage in mutual support within the EU. Solidarity contestation thus develops a relational aspect that transcends national borders (see also Lahusen, 2021).

Driven by the expansive logic of the public sphere, solidarity engagement has a potential to become transnational. To the extent that such external linkages become institutionalised and translate into solidarity practices beyond the national, we can speak of transnational solidarity as discursive links that define commitments among distant groups of people. Such a widening of our horizon of moral commitment relies on the availability of a mediating infrastructure that helps to bring distant events to our attention and make them relevant to us. The solidarity of the public sphere builds on the mass media, which are not just a neutral transmitter of information about what is happening at a distance, but also a forum of critique and of normative debate about the interpretation of these events and their relevance for our moral self-understanding.

This transgression of a national frame of reference is partly due to the normative underpinnings of the principle of solidarity. Solidarity can be defined as a disposition and practice of support towards others (Bayertz, 1999; Deken et al., 2009; Stjernø, 2012: 88). Solidarity is practiced at the level of individuals within kindship or friendship relationships (Komter, 2005), organised at the level of civil societies in terms of philanthropic organisations, welfare associations or advocacy groups (Giugni and Passy 2001; Lahusen et al., 2021; Smith et al., 1997; Zschache et al. 2020), and institutionalised within the welfare states through constitutional principles and public policies of redistribution (Banting and Kymlicka, 2017; Federico and Lahusen, 2018). Solidarity contestations within the public sphere are essential for all these forms of lived solidarity, given that the mass media provide a highly patterned arena of voicing and debating ideas and claims about the content and scope of solidarity. In this sense, one element merits special attention: the notion of group-bound rights and obligations of mutual support. In fact, 
solidarity as a norm or rule transcends the unilateral orientation of concepts such as care, empathy or altruism, because it is more strictly tied to the idea of reciprocity. Solidarity does not only entail the idea of (personal, organisational or institutional) obligations to help others in need, but also the notion of rights of recipients to be helped by others. Solidarity might be restricted to national communities (particularistic solidarity) that exclude outsiders (e.g., migrants), but solidarity can also refer to a wider community of equals (e.g., humankind universalistic solidarity) that questions the distinction between insiders and outsiders, and promotes the idea of shared rights and obligations among all humans. Overall, the different conceptions of solidarity converge in a political component that stresses the notion of shared rights, responsibilities and obligations (Lahusen, 2020) to be applied to particular and/or universal groups.

The mass media provide us with the communicative infrastructure that allows for the formulation of mutual obligations and responsibilities among individuals, and for the validation of claims for (or against) particular or universal solidarity. This mediating role relates to different dimensions of solidarity contestations. The public sphere of the mass media facilitates an almost instant and global dissemination of distant events, but also turns this information into news that is discussed by underlying common criteria of relevance (Michailidou and Trenz 2014; Neidhardt, 1994; Risse, 2014). The shared world of news is in this sense also a world of shared concern and commitment. Responses to images of the pain of distant others, and their translation into a political language of commitment, follows established and institutionalised narratives that structure our social relationships to strangers and justify our moral stance towards them (Boltanski, 1999). Solidarity debates in the news therefore follow established narrating structures that are held valid over time and across social context.

In this regard, it is important to highlight that the mass media do not confine solidarity relationships to national communities of citizens (Habermas, 1996), but they also continuously confront us with the suffering and the needs of distant people, who are primarily defined as strangers (Bohman, 1998). As such, they unfold a critical force to put to the test established solidarity relationships within this horizon of (global) social justice (Boltanski, 1999; Chouliaraki, 2013; Silverstone, 2006). In this sense, they also play a crucial role with regard to European solidarity. On the one hand, the coverage of European news can be a discursive challenge, because it can provoke an engagement with the needs of others. On the other side, it facilitates contestations about the extent to which solidarity in Europe and among Europeans should be either promoted or opposed. For these reasons, it is advisable to focus attention on these extensive interactions across Europe, its states and regions, with the aim to uncover, if any, evidence of Europeanising synergies across very distinct national publics, which would otherwise remain apart owing to differences in geographical distribution, language, and cultural and political conceptions.

The analyses of this book underline the necessity to transcend the nation state as the only pertinent arena of solidarity contestation. Seminal studies on 
immigrants and policy-making have tended to privilege a national framework, for example, by highlighting the strength of policy actors and institutions (Freeman, 1998; Joppke, 1996), and by looking at the ways national publics have had an impact on policy actors and decision-making (Faist, 1994; Husbands, 1994). In this sense, scholarly research has put emphasis on the prominence of nationally based mass media, institutions and policy elites since the alternative notion of a pan-European policy domain with an integrated European-wide public sphere is still unrealistic (Chabanet, 2008; Hooghe, 2008). However, interest has been growing for the two-way interaction between national and European public spheres, given that both arenas of public and policy debate are interlocked, for instance, in terms of actors, issues and claims. In fact, studies have unveiled that the divide between dominant and marginal actors within public debates runs across the national and supranational arenas of contestation. Some inquiries have centred on top-down relations between discourse participants by emphasising the impact of EU institutions, policy elites and their interventions on public debates at the national or local level (Favell, 1998). In this case, scholars have gone beyond the limits of the migration field, engaging with both normative and empirical analyses (Curtin, 2006; Maloney and van Deth, 2008; Smismans, 2006). Others have insisted on bottom-up relations between discourse participants, for instance, when addressing the role of European civil society in the public sphere (della Porta and Caiani, 2009; Ruzza, 2006) and its ability to raise a voice of solidarity with refugees (della Porta, 2018). In particular, investigations have focused on the inclusion of a European civil society within the new modes of EU governance (Armstrong, 2002; della Porta, 2008), even though some studies have called into question the tight relationship between the public and the policy spheres in Europe (Magnette, 2003; Saurugger, 2008), showing that governance dynamics in Europe are not necessarily inclusive of weaker interests (Beyers, 2004; Eising, 2004).

Out of this flourishing field of scholarship inquiring across the national and the transnational level, our book takes a prudent stance that acknowledges the importance of national arenas of solidarity contestations, while inquiring into potential intersections and interrelations. Here, we follow evidence generated by studies of contentious politics that has insisted on the ability of political activists and protest groups to unleash dynamics of mobilisation across the national and the transnational levels (Balme et al., 2002; della Porta and Tarrow, 2005; Imig and Tarrow, 2001; Smith et al., 1997), as shown also by studies dealing specifically with the migrants and refugees (Giugni and Passy, 2000, 2002; della Porta, 2018; Lahusen et al., 2021).

Beyond social movement analysis, scholarship with a bottom-up approach has also testified to the increasing use of transnational frames and justifications in normative and ethical debates about rights, justice and solidarity (Soysal, 1994; Sassen, 1999). Norms and ideas spread on a global scale due to intensified communicative exchanges across national public and media spheres (Meyer, 2000). Within the European Union, a European communicative space has consolidated not only in the way EU actors and institutions regularly feed the 
media with news content, but also in the way formerly dispersed publics follow the same news stories through their national media, and discover issues of shared concern (Trenz, 2005 and 2015). The Europeanisation of public debates in the media does not necessarily lead to a convergence of views and opinions expressed by journalists and shared by audiences, but is frequently driven by the new politicised dynamics of European integration that enhances the salience of EU issues and debates in the media, and gathers actors from different national backgrounds as protagonists of 'mediatised conflicts' (Michailidou and Trenz, 2010). The making of a European public sphere can, in this sense, be observed with regard to the intensified dynamics of public claims-making that evolve through vertical and horizontal exchanges among actors who engage in controversial debates about issues of focused attention within and across national media spheres (Koopmans and Statham, 2010).

Following scholarly writing, we can thus assume that solidarity contestations do not only evolve within a vertically intersected space of national and European arenas of claims-making, but also within a horizontally interlocked space of diverse national debates. This is why the analysis of this book is put in the context of the broader debate about the various pathways to the formation of a European public sphere. Accordingly, we are interested in evaluating the effects of the refugee crisis on solidarity contestation of Europeans, looking more specifically at the effects of how the main organised actors and news readers intervene across the public and policy spheres, as well as across the national and the transnational level, to raise their voices and thus contribute to the formation or erosion of solidarity among Europeans with incoming refugees.

\section{The contentiousness of solidarity towards refugees in the news}

Solidarity towards refugees as 'distant others in need' remains contested in the news media. On the one hand, national media organisations and journalism will often give preference to a nationalist-exclusive framing of solidarity that distinguishes between insiders and outsiders (Williams and Toula, 2017). Especially in the case of the refugee crisis, we can expect a contentious politics in defence of a nationally exclusive understanding of solidarity against European or global humanitarian commitments (Della Porta, 2018). On the other hand, the media and journalism have the potential to defend an ethos of transnational and global solidarity (Brunkhorst, 2007; Calhoun, 2005). In our case, the news coverage of the 'refugee crisis' facilitated not only almost instant global dissemination, but also turned information about distant events into news that raised questions of solidarity and moral responsibilities. Sharing news about the European 'refugee crisis' is, in this sense, also a way of sharing concern and commitment.

In tracing these contentious dynamics of solidarity discourse in the news media, we build on a specific research design of claims-making that links actors' positions to public justifications. Solidarity contestation in the public domain manifests itself in public claims-making within the media. Media claims are 
partly related to social actors' (individuals, political representatives or institutions) strategies of agenda-setting. As such, they relate to power positions of moral entrepreneurs, who compete for attention in the public arena (Koopmans and Statham, 1999, 2010). Media claims are, however, also given selective salience by media actors who filter and frame public discourse in such a way as to draw audience attention. As such, media claims follow a particular media logic of publicity (Altheide, 2004; Couldry, 2012). This is important to stress, because there is always an infinite number of potential targets of solidarity, which are only brought selectively to the attention of the public. Calls for solidarity or its rejection are, therefore, dependent on successful strategies of agenda-setting that relate to the power positions of the respective public claims-makers, who in turn compete for attention in the public arena. Selective attention of the media institutions further narrows the horizon of pity and compassion, and what passes through the media as a solidarity filter encounters an audience that is not necessarily interested and/or willing to engage.

A focus on refugees and asylum seekers as a particular target group of solidarity contestation is particularly interesting because the case of solidarity with refugees and asylum seekers has divided public opinion all over Europe. News media report about advocates of human rights and open borders opposing supporters of exclusive, nationalist welfare (Della Porta, 2018). But also online commenting joins these debates as a form of bottom-up mobilisation, by voicing opinions that take shape either as a politics of fear or a politics of pity (Boltanski, 1999; Wodak, 2015). We expect that public claims-makers and the social media community of news readers is divided on these issues, and that top-down and bottom-up contestation of refugee solidarity are triggered by particular events and their interpretation in the media, such as the humanitarian disasters at Europe's external borders (Triandafyllidou, 2018). The dramatic events brought into focus by the so-called 'refugee crisis' of 2015 and 2016, are particularly interesting because they were staged in many countries as direct confrontations between citizens and refugees (Thomas et al., 2018). It is therefore all the more interesting to zoom in on solidarity contestation at the peak of a heated debate, when media claims-making was most intensive.

The focus on the so-called refugee crisis allows us to investigate the contentiousness of public debates. It is to be expected that the dramatic growth of migration flows, which were associated with humanitarian tragedies, uncontrolled border crossings and unresolved problems of asylum and integration, provoked substantial conflicts between contending parties. Accordingly, we will be able to unveil potential normative biases that dramatise the conflict between contrasting interests at stake during the crisis. In particular, the element of crisis enables us to provide more evidence regarding the major changes that have (allegedly) been produced, the way issues are debated in the public domain, the position of different actors, and the forms these public interventions take. Our data allow us to pay special attention to social actors such as charities and NGOs, social movements, group organisations of different types (including refugees themselves), traditional political actors along the right/left spectrums, public 
institutions and policy elites. And it also opens insights into the importance of both national and transnational politics in terms of structures, actors, and strategic interventions.

The case of the 'refugee crisis' also enables us to dig deeper into contestations among Europeans, as the crisis has reinforced old geographical cleavages in Europe (the south vs. the north; the east vs. the west) with new reasons for division. The main point is social - whether the increase in humanitarian emergency has indeed loosened social bonding across the European countries but also political, since the increasing clash between the winners and the losers of the crisis, the strengthening of populist and extreme-right wing parties, and in particular, the retreat of expansive citizenship regimes, may have struck a final blow to European solidarity, whose effects will be more visible over time.

\section{The refugee crisis: a media event}

How can we account for this constitutive role of the news media in solidarity contestation? The functions of the media in the promotion of debates can be summed up as follows. First, the media portray the world for us. News journalism creates publicity: It brings possible subjects of solidarity to our attention by representing their (often distant) suffering and their need for assistance and help; for instance, the image of a drowned boy on the beach in Turkey. Secondly, the media interpret the world for us. Journalists provide interpretations of the causes and effects of human suffering; for instance, they divide the world into victims and perpetrators. Yet, media coverage is not simply objective and classificatory. A third function which journalism often fulfils is to engage us in normative debates and critique: they turn us into witnesses of human suffering and discuss the deservingness of victims or the responsibility of perpetrators. Finally, the media tell us what to do, for instance by helping us to understand the possible option of expanding and/or restricting our solidarity engagement. They confront us with the urgency 'to do something about it' and to take action against perceived injustices. Such calls for action can address us as citizens and thus trigger our personal engagement in solidarity action, but more regularly, they address our political representatives, nationally and transnationally (Michailidou and Trenz, 2019; Mortensen and Trenz, 2016; Trenz, 2020).

To understand how relationships of solidarity towards non-present others are extended and/or restricted, it is of crucial importance to unveil whether all these issues are debated consensually or controversially in the media. Do various media outlets portray the same events and help us to focus our attention on the same instances of human suffering? Do they converge in their interpretations of the causes and effects of these instances of injustice, and do they address political representatives in the same way? As mentioned above, the political space wherein solidarity relationships are expressed and agreement can be reached about our normative commitments towards others is commonly held to be identical with the nation state. This does not foreclose the possibility that 
the confines of solidarity are constantly contested between different social groups and political actors, and possibly also extended beyond the nation state. In this context, it is important to remember that public debates within the national public spheres are exposed to controversies about a complex set of legal entitlements and obligations. Nation-states have established institutional and procedural prerequisites - in particular, social rights tied to citizenship - that commit both citizens and political representatives to solidarity, e.g., through social assistance and redistribution (Miller, 2007). This commitment to citizenship, however, comes with a commitment to human rights that is equally constitutionally enshrined and drives journalistic orientations and working practices (Hannerz, 2004). From the latter perspective, contestations of solidarity always extend beyond, or even question, the boundaries of the national community.

The mass media exhibit a Janus face, because they are a transmission belt for universal notions of justice (they represent the world), and a filter for the consolidation of thickened and contextualised relationships of solidarity (they speak on behalf of a national community of equals). This double nature offers opportunities for transnational solidarity mobilisation. There is, in other words, a transnationalising mechanism built into the mass media, because they provide an arena to constantly challenge politically confined solidarity relationships and voice criticism by reference to the justificatory requirement of global justice (Habermas, 1996). In light of this criticism, the political space within which solidarity relationships are established can always be considered to be transitory and amenable to be opened up to external linkages. According to this expansive logic of the public sphere, solidarity engagement might become transnational in the sense that it establishes discursive links that define moral commitments among distant groups of people. Such a widening of our horizon relies on the availability of a mediating infrastructure to bring distant events to our attention and make them relevant for us. The mass media fulfil this mediating role, as indicated above, because they are not just a neutral transmitter of information about what is happening at a distance, but also a forum of critique and of normative debate about the interpretation of these events and their relevance for our moral self-understanding.

In this volume, we will focus on this often-overlooked role played by the media in establishing solidarity relationships among individuals across established borders of national communities. We will empirically investigate and compare mediated solidarity discourses within national public spheres in which mutual obligations between states and the equal rights of individuals across borders are discussed controversially. Given that special interest in solidarity contestations within the public sphere, we will focus our attention on the specific opinions and positions that become relevant within these debates. In this regard, we will be interested in a number of elements or variables that may help to operationalise the notion of solidarity contestations within the public sphere. First of all, we will take a closer look at the entrepreneurs who call for the extension of solidarity relationships or their rejection. There are those, for instance, who provide the basic information about distant events and the needs 


\section{Debating solidarity across borders}

of others, or those who emphasise the primacy of locals over people in distant places. This typically comes along with different moral values and justifications, for instance, in how claimants express a behaviour of benevolence towards these others, or perceive them as threats to their national community. There are, secondly, the targets of solidarity, usually particular categories of social actors in need of assistance. These targets are mainly treated as objects, whose needs are defined by others and represented in public discourse; yet they can themselves take a more active role as subjects with the power to self-define their needs and negotiate the conditions under which they receive assistance. There are, thirdly, media organisations and mediating institutions, such as newspapers and journalists, that facilitate flows of information, create the conditions for the selective visibility of the suffering and the needs of others, and thus selectively amplify the calls for solidarity. Finally, there are the passive and not so passive audiences of those who listen to or are addressed by solidarity discourse. Particular attention will be granted to those members of the audience who decide to post comments on published news articles and thus raise their voice through social media in response to media discourse.

For the analysis of solidarity contestations, it is important to stress that the thematic scope of these debates is highly selective and focused. In the first instance, there is an infinite number of potential targets of solidarity, who are only brought selectively to the attention of the public. Calls for solidarity, or its rejection, are further dependent on successful strategies of agenda-setting that relate to the specific interests, agendas and power positions of the various entrepreneurs competing for attention in the public arena. The selective attention of the media institutions further narrows down our horizon of pity and compassion, and what is transmitted through the media filter encounters an audience that has its own sensitivities, preferences and opinions. In sum, it is highly plausible to assume that 'focusing events' play a pivotal role in the arousal of transnational solidarity debates in the media that are able to draw the attention of national as well as transnational/global audiences.

Media engagement in transnational solidarity debates is usually linked to the salience of particular events like war actions or earthquakes that bring the needs and suffering of distant others to our attention. The exceptional character of news coverage about selected instances of distant suffering follows the rules of the media attention market. As such, transnational solidarity contestation is typically linked to forms of humanitarian campaigning through old and new media, which can be very efficient, for instance, in mobilising humanitarian aid in cases of disaster or famine (Baringhorst, 1998). The reliance on the drama of external events is characteristic in the way the mass media trigger transnational solidarity contestations, and this approach is distinct from the more routinised reciprocal solidarity among citizens. This might be the reason why these eventspecific forms of transnational solidarity mobilisation often find expression in public charity campaigns that are conditional on the selective attention paid to distant events and instances of distant suffering (Andersen and de Silva, 2017; Pallotta, 2012). Through media campaigns, ad-hoc assistance in emergency 
situations can be mobilised quickly, without necessarily evoking more longlasting reciprocal commitments. This form of selective aid remains bound to particular circumstances, and as such, needs to be distinguished from the solidarity of mutual obligations and commitments.

Online and social media communications have enhanced the potential of solidarity contestation around events of distant suffering. What these platforms have in common is that they engage users with media content that conveys information or messages about the needs of other people. Through the confrontation with such content, social media users become witnesses of instances of distant suffering by others. Such witnessing creates a situation of moral spectatorship (Boltanski, 1999; Silverstone, 2006). This spectatorship can build more immediate relationships between online users/citizens and the objects of suffering, while at the same time it can activate their critical capacities (Mortensen and Trenz, 2016). The witnessing of human suffering through the media can be, on the one hand, paired with the expression of strong emotions such as pity, indignation or hatred. On the other hand, it can arouse moral commitments that can motivate and encourage media users to commit and group around a cause. In contrast to the more passive reception of political news through legacy media, social media exposure to controversial, shocking or concerning news content can easily arouse more personal reactions and commitments (Chouliaraki, 2013; Mortensen and Trenz, 2016). Forms of moral spectatorship can, for instance, create new opportunities for global solidarity mobilisation through visuals that are shared through social media and translated into political speech that claims solidarity with victims in other parts of the world, while ascribing responsibility (Chouliaraki, 2013; Chouliaraki and Stolic, 2017). In contrast, it can also fuel perceptions of stigmatisation, threat or hatred towards minority groups - particularly when combined with the circulation of inauthentic material (Georgiou and Zaborowski, 2017). In both respects, they mobilise emotional debates. By expressing this commitment through posting or liking, for example, the expression of emotions is translated into forms of political speech. Instead of an emotion or sentiment analysis of political debates, we propose paying attention to these translations of sentiment into political speech. Such political expressions of emotion in response to media encounters with refugees indicate clear preferences about whether or not the concerned person or group deserves solidarity, and in expressing them in such a controversial way they ascribe political responsibility and thus urge for political action.

In this volume, we wish to argue that the so-called 'refugee crisis' of 2015 is to be treated first and foremost as a phenomenon that was constructed within the public sphere by and through the mass media. The 'refugee crisis' is a 'media event', which means that its salience and its political repercussions need to be discussed in relation to the debates triggered within the mass media and the way media audiences were addressed by politicians and public intermediaries, such as journalists. To emphasise the event-like and exceptional character of the 'refugee crisis' might seem controversial as one might argue 
that the 'refugee crisis' is not a new and recent phenomenon. Besides the fact that Europe's eastern border has always been porous to the inflow of undocumented migrants, large numbers of refugees have made their way to Europe by boat through the Mediterranean since the early 1990s and throughout the 2000s, with increasing inflows following the Arab Springs in the 2010s. Why, then, were European politicians so alarmed at the rise of asylum seekers in 2015? (Lucassen, 2018).

The reference to real events provides possible answers, and our analytical focus on the 'refugee crisis' as a media event is not meant to invalidate an interpretation that refers to facts and causal effects such as the civil war in Syria, the political unrest in the Middle East and the flight of many citizens these events prompted. However, real events matter only partially for the unfolding of the 'refugee crisis', because they do not determine the way they are debated and interpreted within the public sphere and by the media (Triandafyllidou, 2018). The focus of this volume is therefore not on the causality of flight, but on the patterns of perception and commitment: online and mass media grant organised actors and individual readers with opportunities to voice their opinions, but they also contribute to public opinion formation through the way they inform, highlight and interpret events and developments. The 'refugee crisis' was thus highly mediated. This observation can be corroborated by the patterns of reception, given that refugees were welcomed, rejected or simply met with indifference. The arrival of refugees thus triggered quite different responses, which were not just context bound, but in addition also heavily contested. For these reasons, we will thus focus the analyses of the following chapters on how the media created the contextual conditions for the public perceptions of refugees as 'deserving' 'our' attention (making 'them' 'relevant' for us). Additionally, we will be interested in unveiling the role of the mass media as the principal arena of public contestations, where different attitudes towards 'them' are shaped, given expression and translated into policy alternatives that define 'our' collective responses towards 'others'.

To talk of the 'refugee crisis' as a media event might seem cynical or even unethical for some. In fact, media images are not necessarily 'fake', but often reflect the real suffering of the people behind them. Refugees are not only objects of media coverage, but real persons who became victims of violence, terror and war. Moreover, what needs to be taken into account is the possibility that the enhanced visibility of the 2015 'refugee crisis' is also to be explained by real life encounters between the European population and incoming refugees. Many Europeans drew on lived experiences of encounters with refugees and their needs in the streets, at train stations, in schools or at work and not just on televised images, when they made up their mind on whether they deserve our help or not.

Our interpretation of the refugee crisis as a 'media event' does not devalue the relevance of real encounters. On the contrary, we assume that encounters with human suffering do have a significant impact on shaping individual and collective responses. Higher numbers of incoming refugees increase the likelihood 
of real-life encounters, but by doing so they also shape media images, even though this transferal comprises an element of translation and transformation. The misery of refugees and their basic needs become a frequent topic of media stories, both in the form of visuals with often strong content (such as mutilated or dead bodies), and of textual narratives that translate our experiences as witnesses into collective feelings and reactions. In the same way, our daily encounters with the arrival of refugees are turned into media stories, for instance, the photographs or videos taken at ports and train stations in Greece, Italy, Hungary and Germany.

The 'reality' behind the refugee crisis is also evidenced by the impact of mass media coverage on civic engagement. Many have argued that the 'refugee crisis' of 2015 was distinct in the way it triggered at least a momentary civil society bottom-up mobilisation in support of solidarity with refugees (Della Porta, 2018). The 'real events' that accompanied the so-called refugee crisis of the summer and autumn of 2015 personally engaged many people in European countries like Greece, Italy, Austria, Germany or Sweden in humanitarian action. The 'real' was made visible in the elementary needs of the refugees, and in the personal confrontation with their 'real' suffering. A 'welcoming culture' was made possible in some parts of Europe through the direct and/or mediated confrontation with human suffering, and in the end, it mattered little whether public perceptions were shaped by live encounters of the local population with refugees on the streets, or through televised live broadcasting. The emotions and the engagement of thousands of ordinary citizens engaged in humanitarian action created their own media images and stories, which played a crucial role in the collective mobilisation of solidarity.

The events of summer 2015 stand out in the way they enhanced the visibility of human suffering for western viewers. However, international and humanitarian organisations had attempted to mobilise practices of public mourning during previous instances of shipwrecks in the Mediterranean (Albahari, 2015). These attempts had a limited impact and remained confined to the periphery of Europe's southern borders, where municipalities, civil society groups or journalists appealed to politicians in the capitals of their countries and to larger audiences to pay attention to the events on their remote islands. These cases unveil that the shift of attention from the local to the national and transnational requires a massive intervention of mass media organisations. This shift of attention is all the more difficult if national politicians resist the humanitarian agenda of structural injustice by emphasising uniquely such aspects as the socalled war on human smuggling, and by depicting refugees not as 'victims', but as non-deserving economic migrants to be swiftly processed and deported.

If we wish to specify the conditions for the refugee crisis to become a wakeup call for the moral consciousness of a transnational, European public, we therefore need to turn our attention to the public mobilisation for humanitarian concerns through mainstream media channels. In this regard, the 'crisis' frame is crucial to understand how media events are staged and how the media help to focus the attention of audiences. This 'crisis' frame, however, is ambivalent. On 
the one side, the 'crisis' frame can evoke feelings of compassion and pity with victims, which offers opportunities for humanitarian mobilisation out of an emergency situation. On the other side, it is used by those who express concern with mass arrivals of refugees as a security threat, or as a threat to national culture, identity and material resources. In this volume, we are interested in the way media events around the refugee crisis were constructed, and how they were communicated in such a way as to facilitate such a turn from humanity to security, or from security back to humanity. Along these lines, we will be interested in unveiling how the media events aroused solidarity commitments and how long they were able to last.

The analyses of this book are thus committed to better understanding the refugee crisis as a media event that drew its specific dramatic effects precisely from the symbiosis of the 'real' and 'palpable' human suffering and the moral framing tied to the media stories. Media and cultural studies have insisted on the importance of these media stories, because they emphasise that real events need expression in terms of cultural frames and narratives. In particular, they insist on the dramaturgical elements of 'staging' or 'orchestrating' media events (Dayan and Katz, 1992). This insight is helpful to better understand the relevance of non-media actors, who interact with and for the media as protagonists in the public performance. These performers are professionals, for instance, celebrities, royals or sportspersons, who do not work for the mass media, but are strongly familiar with them and know how to perform in front of them. Dayan and Katz especially stress the ritual character of such performances. These events are usually announced at a fixed date in such a way as to arouse expectations, and they are carefully staged and marketised. Audiences as well develop their rituals of celebrating the events by holding the time of broadcasting off, inviting family and friends or organising public viewing. As rituals, media events have, first and foremost, an integrative function. In television, such media events have the potential to gather the whole nation, or even a worldwide viewing public (Dayan and Katz, 1992).

This conceptualisation of media events requires prudent reflection (Couldry et al., 2010), because media communication in a globalised media environment does not seem to emphasise the ritual, but rather the exceptional character of these events. The latter are not necessarily routinely staged. The attention is drawn instead to the extraordinary character of occurrences, in the sense that media events are something that are not expected and/or that are particularly dramatic, potentially affecting large parts of the audience. Couldry et al. (2010, p. 12) criticise the media ritual approach for disregarding other phenomena like moral panics, conflicts, scandals or crisis, which are regularly staged by the media. In all these cases, events are no longer routine, but disruptive. This brings to the attention the contentiousness of media events, because the media are a stage for the performance of rivalries among actors, who have an interest in pushing their competing interpretations about the event, about its relevance and about its lasting consequences. Media events can serve the purpose of drawing the public's attention to potential harm for the community, or harm 
for others, from which follows the urgency to take action. Accordingly, news coverage around such 'focusing events' can open 'windows of opportunity' for diverse actors to push for policy change (Kingdon, 1984). An adequate analysis has thus to consider not only the media event's agenda-setting function (Birkland, 1998), but also needs to examine the drama of the actors who compete for attention and the heightened attention of audiences. From this perspective, media-staged conflicts are often staged as a media-morality play about the interpretation of the events and its political consequences (Wagner-Pacifici, 1986). This does not necessarily lead to the confirmation of norms, because these norms can be contested during these debates, thus affecting the self-understanding and identity of the political community.

The solidarity contestations under analysis in this book provide a particularly interesting case, because the media events reach beyond national borders and achieve a broader cultural significance. On the one side, they resonate with global values and cosmopolitan narratives, and provide evidence for the need to engage in solidarity with refugees. In this sense, they provide opportunities for the manifestation of shared visions of brother- and sisterhood in reaction to humanitarian disasters. On the other side, they are often interpreted as essential threats to the local community at stake. The way such disasters or threats are defined is itself part of the media spectacle, where it is often not the single event, but a sequence of events over time that is used to build drama. Previous studies examining migration related debates have shown that mediated events are typically organised around competing normative discourses that guarantee the consistency of the debate over time (Fiske, 1994) and allow audiences or electorates to identify with the different positions at stake. News events do in this sense not necessarily trigger new debates but rather keep the narrative going. In fact, established narratives require constant renewal in terms of normative arguments and justifications in order to reassert their general validity. This applies to the case of immigration, because nationally exclusive and transnationally inclusive narratives constantly refer to and reinterpret events from their own perspective, portraying them as an opportunity for the arousal of global solidarity, or a threat to national communities (Helbling, 2014).

Beyond the commonly held assumption of media events as 'routines', we thus arrive at an interpretation of 'crisis' as media staged and media constituted (Michailidou and Trenz, 2015). 'Crisis' is an attribute of media discourse, not a core feature of the natural course of events. The notion of crisis is so central to a media event because it provides the opportunity to focus public attention and to stage public or collective reactions in response to a particular grievance targeted by public and media discourse. Media are in this sense seen as constitutive to the 'refugee crisis', both in terms of offering core mediating capacities and providing the public stage for the crisis conflicts. Crises unfold through the available media spheres and infrastructures in Europe - new and old media, offline and online and news. Delving into the media perspective of the crisis is paramount for understanding how the refugee crisis is interpreted either as a major threat to security, or as a humanitarian disaster. Mediating capacities 
are needed to arbitrate between the security threat and the humanitarian dimensions of the crisis and to sustain vital information and communication flows between and across the different space dimensions of the crisis, namely, the subnational, the national, the European and the global. The media play a fundamental role in this process, not only in shaping the perceptions and development of the crisis itself, but also in driving political and social (re)actions to the crisis, and any measures taken at the elite level to counter it. They function as agenda setters (e.g. highlighting particular aspects of crisis and actors who are dealing with the crisis); as crisis actors themselves (e.g., exacerbating a critical situation or creating moral (panics'); and, perhaps above all, as the general 'interpreter of public voice' (e.g., amplifying popular perceptions of blame for the crisis, and often reinforcing collective identity stereotypes). These 'blaming dynamics' are of crucial importance within the 'refugee crisis' debate, because they amplify popular perceptions and stereotypes about the deservingness of refugees, on the one hand, and of countries as recipients of solidarity on the other, and thus have a direct impact on the reaffirmation or erosion of transnational and/or European solidarity.

\section{The unfolding of the media-refugee crisis: how the media contribute to the 'reality' of a European media event}

The analysis of this book starts from the assumption that the 'refugee crisis' is a media event and should thus also be investigated in these terms to better understand its patterns and dynamics. For such an examination, we need to lay down what the distinct characteristics of this media event were, and what allowed European audiences to identify the refugee crisis as a rupture to how immigration debates unfolded in previous times. Staging the refugee crisis as a distinct media event is a complex phenomenon that involves participating actors, different legacy and social media, as well as wider audiences. The fact that this crisis was perceived and enacted as a common European emergency situation even underlines the complexity of the phenomenon under study, evidencing that the crisis unfolded as a synchronised, interlocked or transnationally integrated media event. In order to prepare the empirical analysis of the following chapters, it is thus advisable to highlight those factors that seem to have contributed to the distinctiveness of the media events of summer 2016. Four points must be highlighted:

1 The disruptive event: The definition of immigration events as incidents of a larger crisis was facilitated by the disruptions created by the civil war in Syria. The commotion was extraordinary, because 13.5 million Syrians were mentioned by the UN as requiring humanitarian assistance, thus more than half of the pre-war population (22 million in 2015). ${ }^{1}$ While the majority of these people were hosted inside Syria or in its neighbouring countries, an unprecedented number of people left the war-torn region during the summer of 2015 to make their way to Europe. Many of these people opted for the new Balkan route, which - compared to the barrier of 
the Mediterranean Sea - provided a less dangerous route to Europe. The disruption allows us to delimit the 'crisis' in time and space and to trace the movement from its point of departure to the expected places of arrival within Europe. The unprecedented and exceptional character of these events was constantly emphasised by all actors involved, which contributes to a crisis rhetoric as an important element of the media drama.

2 The live coverage: The mere size of the phenomenon matters when explaining how the 'crisis' came to the attention of western publics, but the arrival of the refugees brought the war victims much closer to the television cameras. Large numbers of journalists were deployed to cover the journey of the refugees and to deliver live images from the Turkish shores, the Greek islands, the Macedonian border and the train stations in Hungary (Feinstein and Storm, 2017). The dramatic moment was amplified by televised images of 'sudden' departure, 'mass exodus', 'coming closer' and a general sense of 'losing control'. The crisis unfolded as a real-time event, so to speak, on the screens in front of our eyes. This was made possible by a flow of journalists who accompanied the flow of refugees, thus delivering live coverage en route. Media-staged closeness also allowed for a combination of eye-witnessing and media witnessing. Once the war refugees crossed 'our' own borders, their presence was no longer virtual and media stories could be authenticated and enriched through personal encounters.

3 The activation of audiences: Through the representation of human needs and suffering, a mediated public sphere can turn into a humanitarian space of personal involvement, where passive members of the audience take active responsibilities as citizens (Andersen and de Silva, 2017). Media stories do not simply activate the moral consciousness of western viewers directly, as this requires exemplary or illustrative action. Media stories do this by addressing witnesses of human suffering as protagonists of human aid. The 'welcoming culture' is part of a 'politics of pity' (Boltanski, 1999) with role models of 'ordinary citizen heroes' - as conveyed by the media providing their spontaneous assistance to the needy. Pity, which is to be defined as an emotional reaction to the witnessing of human suffering, can be considered as an important element in the mobilisation of solidarity, because it allows for rapid changes of opinion from indifference, or even antipathy towards the object of solidarity, to attention and personal emotional engagement that might be followed by individual or collective support action. Especially in Germany, the so-called 'welcoming culture' became a story of national pride that expressed the collective will of the local people to assist the needs of the refugees. Hospitality and empathy towards refugees were encouraged by mediated images of human suffering, such as the image of the drowned boy, Alan Kurdi, on the Turkish beach. They contributed to rapid shifts in opinion in the receiving countries and to considerable levels of political mobilisation (Mortensen and Trenz, 2016). A 'politics of pity' is the reversal of the 'politics of fear', a strong emotional involvement of the audience that was directed against the incoming refugees, stimulated western 
publics to assign for themselves the role of victim, and seemingly legitimated them to mobilise resistance and fight against expected short-term or longterm negative consequences (Wodak, 2015). A 'politics of fear' can be distinguished as a proper style of political mobilisation because it portrays refugees in the media as threats to be excluded from the solidarity community. In line with such a discourse, media coverage often builds on fearappealing metaphors such as flood, swarms or marauders, or on attributes such as unwanted, irregular or illegal.

4 The internalisation of negative consequences: Approaches to crisis differ, depending on whether negative consequences are externalised or internalised. As long as the refugee crisis remained confined to Syria, aid remained optional. Care-taking assumes a different meaning, when people in need are among us. Rules of care-taking apply at first reception as they are not only codified as responsibilities of states, but also bound to moral obligations of hospitality (Benhabib, 2004). Such moral codes of hospitality regulate, in particular, our relationship towards people we encounter at the borders of our community. Once they are among us, hospitality cannot be escaped, care-taking can no longer be delegated, but becomes our responsibility. From the European perspective, the refugee crisis was marked and staged as a series of events of border crossings. First, the symbolic act of crossing the border between Asia and Europe in the Aegean Sea and, secondly, the crossing of the border between Hungary and Austria and Germany marked the refugees' final entry from the periphery right to the core of what defines the Europeans' 'own world'. The predictable arrival of the refugees made it inevitable for Europeans to discuss their own attitudes towards hospitality. The internalisation of negative consequences implied acceptance of a collective responsibility for the fate of the refugees, which again justified the mobilisation of political capacities and resources to take control of the process.

These different elements and processes contributed to the formation of the refugee crisis as a distinct media event that was perceived as a common experience across the various European member states. This distinctiveness is of particular relevance, because it contributed to the salience of solidarity as a core topic of public debates about the crisis. It needs to be added, however, that the mediated experience with the 'refugee crisis' was perceived as a shared and split experience. Differences between countries prevailed, given the specific transit routes and destinations of most refugees, but also given the different ways this reality was arbitrated by national media systems, policy debates and citizens' mobilisations. The experience of a shared crisis often triggered these national differences, because it raised awareness within European countries of different national sensitivities and priorities, thus encouraging the various governments to either look for European solutions or insulate their country from European developments. The analysis of the refugee crisis thus requires a nuanced empirical investigation that is able to disentangle solidarity contestations as a complex 
phenomenon that is segmented in national public spheres, interlocked transnationally and embedded into the shared experience of a European crisis of humanitarian aid. In this sense, we require an analysis that is able to simultaneously unravel and interrelate the national and European dimension of solidarity contestations.

\section{Note}

1 https://www.unocha.org/syrian-arab-republic/about-ocha-syria 


\section{Claims-making analysis and its applications in media and communication studies}

Solidarity contestations in the public sphere are based on public interventions by a variety of actors, and can thus be examined by retrieving and analysing claims made during these occasions. For this reason, we have made use of claimsmaking as a methodology of standardised content analysis to dissect public debates on solidarity, thus adopting an approach that has been widely used in media and communication studies. Claims-making analysis is predominantly used to analyse mediated (political) discourse. This does not preclude other applications, for instance, the analysis of political speeches (Kinski, 2018; Severs, 2012), of documents or web site publications (McCright and Dunlap, 2000), or of protest events (Rucht et al., 1999). But the analysis of public claims seems particularly promising for the examination of public contestations about solidarity with refugees.

The specific methodology applied in single claims-making projects is generally well-documented and granting open access to codebooks is considered good scientific practice. Among the frequently referenced codebooks is the Handbook for the Analysis of Representative Claims created in the framework of the RECONNECT project (Gora and de Wilde, 2019). Other examples include the 'Codebook for the analysis of political mobilisation and communication in European public spheres' (Koopmans, 2002) and the 'Codebook for the analysis of political opportunities' (Castelli Gattinara et al., 2015) documenting the claims analysis conducted in the EUROPUB and LOCALMULTIDEM projects respectively. The ambition of this chapter is similar to these, i.e., to make transparent how the TransSOL solidarity claims-making analysis was conducted. Yet, we also aim to provide general guidelines for researchers who are considering applying the method of claims-making, provide them with a toolkit for its application and to share lessons learned regarding sampling, coding and data analysis.

In the following, we start by discussing the definitions of a claim and the underlying assumptions regarding the process of public opinion formation processes and contestation in an increasingly mediatised world. After this, we discuss several strategies for its application and typical problems of its implementation. This includes a consideration of the tedious process of building intercoder reliability within a team of researchers, who typically run the coding in a 
claims-making project. We will express some words of warning about the risks of errors in the codebooks and the organisation of coding processes, but also give advice on how to manage them. After this follows a description of how we captured social media debates through claims-making analyses and how we adapted the method for these purposes. We conclude with a brief summary of what to expect and not expect from a claims-making analysis.

\section{What is a claim and why do we analyse it?}

\section{From political protest to public discourse}

Claims-making analysis originates from the field of contentious politics and social movements research as a response to the then dominant focus on institutionalised politics. Its aim was to expand the focus and include the perspective of public contestation and civil society (Cinalli and Giugni, 2013b, 2016b; Koopmans and Statham, 1999; Kriesi et al., 1995; Rucht et al., 1999). With the digitalisation of media, politics and society, with the growing mediatisation of political conflicts (Hepp, 2014; Hjarvard et al., 2015) and with the turn from 'collective' to 'connective action' (Bennett and Segerberg, 2013), the investigation of public contestation requires further adaption. One limitation of the original approach is that claims-making analysis was often too protest-centric. It focused on 'organised publics', thereby privileging actors such as state institutions, political parties, main NGOs and social movements, which have the resources to effectively place their statements in the public sphere. In so doing, claims-making analysis disregarded the role mass and social media increasingly started to play when expressing contestation (see Koopmans and Statham, 1999). Yet, mass and social media have enabled strong public contestation beyond organisations or visible forms of collective actions, such as street-protests and demonstrations, by opening space for the direct intervention of digital users in the public sphere.

In order to adapt to the changing face of contestation and its diversifying locations, claims-making methods were expanded beyond physical sites into mediated public spaces where public contestation gains visibility and finds resonance, e.g., through take-up in news coverage or, more recently, social media debates. Social movement and protest researchers coalesced with media and communication researchers to develop a whole array of instruments to measure forms of mediated actions as indicators of political contestation, including simple speech acts in the forms of statements in public debates (Koopmans and Statham, 1999). Scholars also emphasised the need to deal with the relational aspects of public interventions, by retrieving the way claims react to each other in terms of shared or contested arguments, values, and so forth (Cinalli and O'Flynn, 2014). These methodological expansions have at least two advantages. First, claims-making can now be applied to all kinds of media sources - most often those which cover a broad range of issues and reach broad audiences, e.g. broadsheet newspapers and the online debates they often feature. Second, 
it enables us to investigate the claims raised by both institutional and noninstitutional actors (e.g., civil society), as well as by individual citizens themselves. This inclusion of claims beyond the sphere of institutionalised politics can help us to gain a more detailed picture about contestation, the roles and positions of diverse actors in the public sphere, as well as the ways in which these actors relate to each other and compete for media visibility.

Claims can be conceptualised in at least two ways. First, claims can be defined as 'strategic communications in the public sphere' (Bentele and Nothhaft, 2010) or as a 'unit of strategic action' (Koopmans et al., 2005: 25). This definition views claimants as interest- or power-driven actors who strategically aim to place their claim in the public sphere in order to achieve a certain interest (through persuasion), or make their performance visible (e.g., in the news). In this way, claims-making is considered to follow an instrumental logic. Secondly, claims can be understood as basic speech acts, and thus as units of analysis of a broader discourse through which meaning is generated, communicated and validated not by single actors driven by their interests, but through the binding forces of shared public discourse. Claims-making can therefore be seen as norm- and culture-driven. Such a relational model emphasises that the public discourses generate intersubjective meaning, as formulated by Jürgen Habermas in his theory of communicative action (Habermas, 1985). Claims are not simply considered as 'strategic acts', but as communicative acts, or in the words of Habermas, as 'validity claims' (ibid.) through which actors provide arguments to endorse the truthfulness and moral rightfulness of an assertion in a public discourse. In this case, the main focus of claims-making analysis lies in the reconstruction of argumentative exchanges between actors in normative debates that are of constitutive importance for democratic politics (Vetters et al., 2009). A similar approach, yet with a less explicitly normative intention, has been deployed by cultural studies, where claims are used to identify cultural repertoires of meanings and interpretations distinctive of the field of politics, as they are employed in the process of defining and constructing social problems (Best, 2001; Gusfield, 1984; Loseke, 2017).

These two understandings of a claim do not necessarily have to be mutually exclusive. We can, for example, frequently observe how claimants raise issues, such as abortion or healthcare in the US, or immigration and the EU in Europe, which then become the subject of heated normative debates before elections. How claims are conceptualised, then, is the task of the researcher who needs to decide which type conforms to the research purpose most appropriately. Focusing on claims as strategic communication might, for example, help to scrutinise dynamics of power and socio-political hierarchies regarding access, visibility and agenda-setting in news-making. The choice of claims as communicative acts might be more appropriate if the research objective is to better understand how the meaning and relevance of issues for society are constructed and interpreted by different actors across social groups, thus looking at processes of public opinion formation. The first focus will become relevant later on, when we discuss how media and political logics relate to each other; the second one will be 
highlighted when we consider questions about legitimation and public opinion in the next section.

In sum, communicative and strategic understandings of the role of a claim in contentious politics are linked to each other, and the researcher might want to decide which one to prioritise without completely excluding the other. In TransSOL, we have focused more on the construction of meaning and different interpretations of solidarity in the public sphere. Our analysis therefore highlights how different actors take sides, define and justify solidarity or its rejection. In our case, this concerns the hospitality towards refugees and asylum seekers, but also contested notions of deservingness/undeservingness towards these groups as 'objects of solidarity'. A solidarity contestation often takes its starting point in citizen protests, e.g. in protests against the allocation of refugees or in manifestations of solidarity with them (della Porta, 2018). Claims-making analysis does not only enable us to map these public interventions. It allows highlighting the inclusive and exclusive dynamics of media discourse within the public sphere, for instance, when showing how proponents and opponents of solidarity selectively appear in the news and relate to each other. Additionally, it can be adapted to wider societal contexts by digging into the way citizens or users react and challenge social media.

Before this conceptual backdrop, we define a solidarity contestation in the media as a mediated relationship between an opponent and a proponent of solidarity (towards an 'object' of solidarity, in our case refugees). As we know from existing research, such debates in the media are shaped by the intervention of organised publics, which in most cases can be expected to be elite and not civil society driven (Koopmans, 2010; Statham and Trenz, 2013; Vetters et al., 2009). Applied to our case, it is thus essential to explore who dominates mass media debates on solidarity, and to what extent they open a window of opportunity for the mobilisation of civil society. Alternatively, we can ask whether refugees and asylum seekers are a target or object of public contestations that arouse a more bottom-up mobilisation of solidarity through the media.

\section{Analysing the 'making of public opinion: The theoretical foundations of legitimation and political representation}

Another motivation for researchers to develop the methods of claims-making analysis was the dissatisfaction with public opinion research (Koopmans and Statham, 1999). Public opinion surveys typically aggregate individual attitudes and usually aim for a representative cross section of a population's attitude at certain points in time. Claims-making analysis instead reconstructs the dynamic aspects of public opinion formation by focusing on the role of established actors, which are not abstract aggregates of individuals, but a concrete part of (organised) publics. How such public opinion processes take shape, depends on the particular media outlet, the quantity and quality of news and its salience, and on the form of participation, i.e. the dynamic aspects of public debates (Cottle, 2003). The advantage of claims-making is that it allows us to study 
public opinion formation processes in the making. The focus shifts from the study of populations as passive and aggregate 'containers' of opinions to the study of public opinion formation within organised publics as they articulate and convey their claims in the public sphere. The 'making of' public opinion, so to speak, is centre stage.

This focus on the opinion formation process is relevant to building democratic legitimacy. Frequently, however, degrees of legitimacy are measured through attitudinal or behavioural indicators such as the passive support for political institutions, or levels of trust in government, while neglecting the communicative dimension in the 'making of' democratic legitimacy (Schneider et al., 2007). Text-analytical approaches can help by emphasising that legitimation is also a product of political communication and debates, which unfold over time and which allow political representatives to contest political choices, provide good arguments and justification and (ideally) include citizens in the process of political opinion and will formation (Gaus, 2011). Claims-making analysis allows researchers to open up the spectrum of public debates expressed and the justifications delivered in the public sphere through the media. Such mediated opinions are considered to be a horizon for interpreting politics and thus become decisive for public opinion formation and for perceptions of political legitimacy (Schneider et al., 2007). Public debates unfold as an exchange of claims through which organised publics and audiences formulate their views on contested issues, and through which they are also exposed to opposing views and arguments (Michailidou et al., 2014, p. 43). One important function of news media is therefore to stage contestations among claimants in the form of debates in the public sphere. Claims-making is the form that keeps such public debates going whenever actors bring in new arguments, shift their positions or apply different justificatory logics to contest a political issue (ibid.).

More recently, scholars of claims-making analysis have engaged with theories of political representation (De Wilde, 2013; Guasti and Geissel, 2019; Saward, 2006, 2010). Political representation is understood in this case as not necessarily in its institutionalised forms, i.e., established through, for example, elections, but more fundamentally as a 'claim to represent someone else'. The actual legitimacy of such attempts of political representation is not necessarily settled; it is yet to be decided and therefore contested. In many cases, decisions to allow representatives to speak for somebody might be formally legitimised, but in terms of substance, such a legitimacy is never accomplished, or remains settled only temporarily, highlighting again the dynamic element of contestation that is so crucial for claims-making analysis. For this reason, representation materialises in discourse. The importance here lies not in the characteristics or virtues of political representatives, but in the arena of contestation within which claimsmaking takes place and the way this contestation manifests itself. Since its legitimacy is always up for discussion, claims for political representation become contestable and contested: 'there is no claim to be representative of a certain group that does not leave space for its contestation or rejection by the would-be audience or constituency, or by other political actors' (Saward, 2006, p. 302). The 
world of political representation is therefore to be understood as a world of political contestation of 'would-be' representatives who always need to renew their claim to represent someone, make it credible through their arguments and appearances in the struggle over public attention. This also concerns the claims of elected representatives, given that their legitimacy is subject for debate when based on majorities (e.g., 'Should $52 \%$ count as the proclaimed will of the people?') and electoral processes (e.g., 'Is the first-past-the-post system fair?').

Methodologically speaking, claims-making analysis is built on indicators that allow us to systematically reconstruct the triangular configuration of political representation: as claims-makers, an object actor (the constituent) and an addressee (the audience) (De Wilde, 2013; Saward, 2006). Object actors and audiences in claims-making are often identical, e.g., when a head of government addresses the nation in a speech to explain how well she serves the interests of the country. They can, however, also be distinct, for instance, in the case of an NGO that addresses donors (their targeted audience) to contribute to their struggle for the defence of refugees' rights (their targeted constituent). This latter case is of particular relevance to understand the role of non-elected representatives, who may use the media to present themselves in the public sphere as the legitimate representatives of a certain cause and/or constituency. While Parliament is typically the arena for the contestation of elected representatives, both claims by elected and non-elected representatives gain visibility in the public sphere through the news media. Claims-making analysis is a way to shed light on the contributions of such non-elected representatives in democratic politics, for instance, when looking at the way civil society organisations or social movements intervene within the public sphere via the mass media (della Porta, 2009; Gleeson, 2009), alongside with the claims of elected representatives. We argue that claims for solidarity, as we analyse them in this volume, are tightly related to questions of (legitimate) representation, because they frequently build on moral causes or the common good that grant their 'representatives' legitimacy that is as valid as the one granted by formal procedures and political majorities through an electoral system.

\section{Making actors and their contestation measurable and comparable}

Researchers who are interested in understanding opinion formation processes often have similar intentions when adopting claims-making analysis. First, researchers share an interest in the role of actors and their positions in political events or public debates. Claims-making analysis tries to reconstruct the public appearance of actors, their public performance and their public relationships, meaning that this method enables us to reconstruct the mediated expression of (collective) action. However, the method is poorly equipped to analyse mobilisation strategies behind such actions. It does not, for instance, allow us to dig into the participating actors' political interests, their broader political strategies, whom they hope to reach, how and why. Unlike other methods, such as interviews or surveys, claims-making analysis does not talk to individuals or draw 
on direct observations of their actions. Instead, it analyses actors' stances and actions that are visible through mediation in the public sphere. In so doing, it categorises their political or social affiliation or public persona by relying on information related to the claim and the direct circumstances of that claim. This may include an analysis of other arenas where political struggles are carried out, such as Parliaments or rallies of a political party, as filtered through the (news) media. Claims-making analysis is thus a study of politics in its encompassing expressions, as viewed from the perspective of broader audiences that do not directly witness the session of Parliament or participate in a political party rally.

Secondly, claims-making analysis is used by researchers with a genuine interest in the conflict dimension of collective action, that is, how actors relate to each other. It also allows for studying the field of political conflicts within a public arena that creates most visibility for political actors: the mass media. Claims-making analysis provides a whole set of variables to reconstruct the dimensions of political conflict. It enables us to determine, for instance, the relationship between claims-makers and addressees, to distinguish between various forms of actions and/or to explore the driving forces of conflict, which can be interests, norms and identities. Claims-making analysis thus allows counting (e.g., the frequency of the appearance of certain actors) and categorising (e.g., the position or tone of actors about a certain issue in the public sphere).

Thirdly, scholars who engage in claims-making analysis often share an interest in comparison. Given the expression of public discourse as numerical data, claimsmaking analysis allows us to design different strategies for comparison. We can think of cross-sectoral comparisons among different news products, temporal analyses that compare how debates unfolded in different periods and over time, issue-specific inquiries that evaluate how collective action is mobilised with regard to different topical debates, and most commonly, cross-country comparisons that contrast how debates with regard to specific topics unfold in different national public spheres.

Ideally, claims-making analysis is a way to turn text into numbers and, on the premise that reliability of data can be established (see later), to describe trends in public debates and test hypotheses by means of statistical methods. Claims-making analysis therefore seeks to reconcile the continuous struggle between positivist and constructivist paradigms, because it wishes to provide a refined and solid method to measure and analyse processes of meaning production and opinion formation within the public sphere. It can rely on elaborate codebooks that have been tested over time, that are available as templates for future researchers. These codebooks contain variables that allow us to reconstruct strategic elements of communication, such as 'identification of actors', 'attribution of intention' or 'forms of action', but also variables that focus on intersubjective meaning, such as 'exchange of arguments and justifications', or the complex reconstruction of actors' relationships as represented by public and media discourse. 


\section{Shifting between political logics and media logics in the expression of democratic politics}

Claims-making analysis has been developed as a method of standardised media content analysis that oscillates between quantitative and qualitative methods. Most proponents of the method would emphasise their efforts of standardisation of variables as a tool to reconstruct the reality of public contestation in an objective and verifiable way. Numbers as retrieved from claims-making analysis are meant to represent the world of politics, and stand for actors and their relative power in the political struggle. The underlying assumption is that the news media constitute the principal arena of political contestation, where actors compete between each other and try to influence public opinion. Expressing claims-making in numbers is also a way of quantifying the salience and influence of different actors in their attempt to impact on the public sphere, and thus gain communicative power.

This analytic and methodological aim, however, requires critical reflection, because standardised measurements and quantifications make implicit assumptions about the ontological status of the news media, which have unleashed a controversy among proponents of the claims-making approach: the ones defending the neutrality of journalism in mirroring social reality and balancing political opinions (Statham, 2008); the others insisting on the active role of journalists and media organisations in giving selective salience to political actors and shaping public opinion (Trenz et al., 2009). This results in two competing explanations of media agenda-setting: one side explaining it with reference to a political logic, according to which visibility in the news is a result of successful agenda-setting strategies of political actors, their relative power and their visibility in the game of politics (Birkland, 1998; Kingdon, 1984); the other side explaining media agenda-setting with reference to the constructed character of political news and the inherent media logic driving mass-mediated public contestations. Such a media logic is not only held accountable for the selective and framing bias of political news; it also penetrates the political system, because political conflicts are increasingly staged for the media and thus mediatised in a double sense, i.e., by both the political actors and the mass media (Cottle, 2006; Hjarvard et al., 2015). This scholarly controversy is ongoing, as it reflects two traditions of research social movement studies, media and communication analysis - that have informed the claims-making approach since its inception, the former focusing on political opportunity structures and actors' strategic mobilisation (Kitschelt, 1986), the latter focusing on gate-keeping by journalism and information filtering through the application of news selection criteria (Cappella and Jamieson, 1997; Hamilton, 2004).

Claims-making analysis cannot make any direct inference about which of these two logics applies because it neither investigates political actors' mobilisation strategies directly, nor analyses the working practices of news journalism. As such, the paradigm struggle remains inconclusive, and we do not intend to take sides in this book. It is useful, however, to remind students and scholars 
who wish to develop a project based on claims-making analysis that both political and media logics might be at work in news agenda-setting. Claims raised by political actors are filtered through, and framed for, the media; they cannot simply be explained as causal effects of agenda-setting (Entman, 2007; McCombs and Shaw, 1972). The fact that an actor's claim is reported in the news is not a sufficient indicator of a successful strategy of agenda-setting, nor is it sufficient proof for the application of news criteria. We always need to take into consideration the possibility that actors' statements are de-contextualised or misinterpreted by journalists, but we cannot measure the accuracy of political news through the method of claims-making.

If claims-making fails to inform us directly about either political actors' mobilisation strategies or journalistic working practices, the strength of the method lies in the reconstruction of the public expression of politics through the struggles and debates that are made publicly visible for larger audiences, i.e. the process of contestation on which political opinion formation builds. Claims-making's first and major task is the description of contestations about a publicly relevant issue, which gains its importance from the above discussed aspects of legitimacy. The method further offers an accountability tool for researchers and others to document the claimants' speech acts. The claimsmaking approach should therefore always be considered as part of public sphere and political legitimation research (Statham and Trenz, 2013).

This method is also relevant for our investigation of media and solidarity, because solidarity contestations in the public sphere always touch on issues of political legitimacy. Claims-making enables us to analyse, in the first instance, the contested nature of public debates about solidarity, because it provides instruments to measure and map controversies between political actors related to the question of whether and to what extent others require private support or public assistance. Additionally, it highlights the implicit conflict about political legitimation that permeates these controversies. Solidarity contestations also contribute to the construction and definition of social problems - in the case of our study the so-called refugee crisis - that await solutions or remedial actions. They are eminently political because they mobilise and engage actors in struggling against public policies and measures to be taken or to be refuted. Claimants do so by making claims on behalf of refugees' rights or needs, or by refuting such demands in the name of the alleged rights and needs of a national community or public opinion. They thus claim to legitimately speak on behalf of - and thus represent - a larger group or population. The claims-making approach assists us in highlighting that all these opinions about refugees and our relations to them - as expressed in the news media - do not represent public opinion. They guide, however, public opinion formation processes through emotional expressions of pity and compassion, competing interpretations about duties and responsibilities, and various arguments and justifications about required actions and remedies (Boltanski, 1999; Chouliaraki, 2006). Claims-making allows us to take a glimpse at the role of public contestations within the media in constructing the deservingness of refugees and the 
responsibilities of (sub-)national and international politics (Silverstone, 2006; Wagner-Pacifici, 1986). We therefore consider claims-making as a window providing essential insights into public opinion formation processes during a period of heated debate about the high numbers of refugees and asylum seekers arriving in Europe during 2015 and 2016.

\section{How to conduct claims analysis?}

\section{Counting, interpreting, or both?}

Claims-making analysis was established in the early 2000s as a merger between protest event and political discourse analysis (Koopmans and Statham, 1999), and combines the qualitative and quantitative aspects of both (Kluknavská et al., 2019, p. 7). As such, it reflects a more general trend in the development of social science methods to overcome the quantitative-qualitative divide in the struggle over paradigms (Punch, 2014), and in textual analysis more specifically the struggle over the validity of standardised-quantitative content analysis and inductive-qualitative discourse analysis (Franzosi, 2004). More broadly, one lesson to be drawn for content analysis is that the question of either quantitative or qualitative analysis should be considered as a question of weighing and balancing the different elements in the research process. The choice between quantitative or qualitative methods is never an either-or question. Ultimately, there is no quantitative analysis without qualitative elements, and any qualitative analysis always relies to some degree on generalisations and standardisations.

The strength and popularity of claims-making analysis can be explained by its capacity to bridge paradigms, among them most notably political science and institutional studies, media and communication studies and political sociology. This allows for the integration of relatively heterogeneous research communities. Scholars who previously investigated, for instance, political party competition or journalism with separate research agendas and objectives could now meet, engage in common debates and exchange their views and findings. As a unified methodological framework, it even allowed for scholars from different backgrounds to commit to a single transdisciplinary project - a requirement that became increasingly important in the competition for research funding, for instance, in response to funding criteria set by the European Research Programmes of the European Union.

Claims-making analysis requires some degree of standardisation, achieved through the development of commonly accepted definitions of a claim as units of analysis, and of coding instructions delimiting a set of variables to define the different empirical components of a claim. This general agreement on standard definitions and practices has greatly benefitted from the debates among research teams and their readiness to share experiences, coding instructions and code books (e.g., in regard to early analyses in the RECONNECT and EUROPUB projects), which gave guidance to subsequent projects. This praxis can be translated into a first recommendation for future researchers, who plan to develop a 
claims-making project: Coding practices and codebooks should be transparent and made publicly available to the whole research community.

Standardisation of coding practices is a central requirement for coding in a team that often involves diverse researchers dealing with different texts and languages. At the same time, however, standardisation in claims-making analysis has its limits and should not be conceived of as just a mechanical process of assigning numbers to words. This might be a common misconception of the method, according to which claims-making (and content analysis in general) is a purely quantitative method that counts the number of times a specific descriptive variable has been detected in a text. On the contrary, claims-making analysis requires active interpretative efforts from researchers who read text and bring in their own understanding. This starts with the identification of a claim in text - a topic of fierce controversy among researchers - and continues with the use of every single variable that is defined in the codebook. Claims-making research is ultimately quantitative in the way data is processed and analysed, but it includes important interpretative elements when generating data through a process of coding. Claims-making might be built on coding, but this practice is more than counting evidence in a text, because counting assumes prior interpretation. This 'interpretative moment' might be less evident in some variables, because we can relatively safely agree on the date a claim was raised. However, the element is very visible in many other variables, for instance, when researchers have to decide how a specific issue is 'framed'. The same is true even in regard to the position of a claim. In our case, we were interested in coding the position of a claimant towards refugees, which implied quite an interesting process of translating a coders' interpretations into numerical data - in this case, a measurement assigning an opinion to a position on a scale of -1 to +1 . We believe that this hybridity between quantitative and qualitative approaches is one of the strengths of claims-making analysis. We thus formulate a second recommendation for future researchers, by highlighting the necessity of careful design of claims-making projects. In particular, researchers should invest considerable efforts in reaching a common understanding among coders, who are always reading (and thus interpreting) text.

\section{Identifying a claim}

A claim was defined as 'the actual, strategic actions of the claims makers in the public sphere' (Koopmans and Statham, 1999, p. 216). This definition was later expanded to include communicative acts, i.e., contributions to public speech in the form of statements promoted by actors in the media, among others (Koopmans and Statham, 2010, p. 55). This latter definition links claims-making analysis to other discursive approaches in political legitimation research. These studies define their unit of analysis either as a 'legitimation statement' to understand the public evaluation of specific actors or institutions such as the European Union (Hurrelmann, 2007; Hurrelmann et al., 2009), or they describe it as an 'attribution of responsibility in the public 
sphere', as in the case of 'Discursive Actor Attribution Analysis' (DAAA) (Roose et al., 2014). What follows from here is that the unit of analysis of any claims-making project is the single claim, which can be a verbal or nonverbal intervention made in the public domain by any actor (including organisations, groups or individuals). In its most basic form, a claim translates into an intervention of a subject (claimant) over an object (which can, but does not need to be an addressee). At the same time, a claim performs an action by demanding, criticising, blaming or protesting (Lindekilde, 2013).

The identification of a claim as a unit of analysis starts therefore with a search for potential actors in relation to a certain 'purpose'. The 'purpose' of a claim can be defined in general terms with reference to the intention of a claimant to represent someone or something (representative claims analysis (RCA); e.g., De Wilde, 2011; Kinski and Crum, 2020). It can be assigned also to the issue field within which claims are raised, e.g. when focusing on all claims related to the broader topic of migration and refugees (Kluknavská et al., 2019; Van der Brug et al., 2015). The 'purpose' of a claim can finally be defined in relation to object actors at whom political demands, calls to action, proposals or criticism are targeted, e.g., when analysing all claims that have a potential bearing on refugees. In our TransSOL project, we opted for the second strategy by including all public interventions which bear relation to the interests, needs or rights of refugees. In their quality as objects of a claim, these can include refugees as individuals or collective groups.

The findings presented in this book reflect these conceptual decisions, because the unit of analysis is the single solidarity related claim. The latter is an intervention, verbal or nonverbal, made in the public space by any actor (including individuals who engage in acts of solidarity), which bears on the interests, needs or rights of refugees. Claims either express opinions that strengthen/affirm/ support the interests, needs or rights of refugees, or disapprove of/reject/weaken them. As objects of the solidarity claims, we define refugees either as individuals or as a collective/group. In other words, a solidarity claim is a statement of support or opposition towards others (in our case: refugees) in the public space. If it is verbal, a claim usually consists of a statement, an opinion, a demand, a criticism, a policy suggestion, etc. addressed to the public in general or to a specific actor. If it is nonverbal, a claim is usually tied to an activity, an event, a behaviour, a decision or a document reported in the media.

It is important to highlight that claims-making focuses on the single claim as a unit of analysis, and not on the article or the single statement. This strict focus has two implications. First, an article can report several claims. The whole article must therefore be read in a way to include all the claims reported when doing the coding. Secondly, a claim can comprise several statements or actions. Statements or actions by different actors are considered to be part of a single claim if they take place at the same time (on the same day), place (the same locality), and if the actors can be assumed to act 'in concert' (they can be considered as strategic allies). In sum, claims must have a unity of time and place. 
To allow for the identification of solidarity claims in a text, our coding instructions defined four main forms of action:

Political decisions (law, governmental guideline, implementation measure, etc.) Verbal statements (public speech, press conference, parliamentary intervention, etc.) Protest actions (demonstration, occupation, violent action, etc.)

Solidarity action (a direct act of providing help/assistance to others in need of support)

More specifically, all articles were coded which report political decisions, verbal statements, direct solidarity action or protest actions on themes that refer explicitly or obviously to the 'refugee crisis'.

As in comparative claims-making projects comprising several teams of coders in different countries, it was necessary to formulate specific rules for the identification of claims in the text selected for coding. The following guidelines summarise some of the TransSOL coding instructions followed by our team of coders:

- Claims are coded only to the extent that they refer explicitly to the current refugee crisis or contain information allowing that this is the case.

- Only solidarity claims in news articles selected for the study are coded.

- The claimant must be an actor, who is usually based in a country of the EU and Switzerland, or a foreign actor who addresses actors in the EU and Switzerland. This includes claims by international actors (EU, UNHCR) that take place in the EU and Switzerland, or that address actors in the EU and Switzerland. Claims by actors which are usually based in a country of the EU but are made abroad, must also be included. For example, claims raised in Greece, but reported in the Danish press should be coded by the Danish team. Claims must also be included if they are made by or addressed at a supranational actor of which the country of coding is a member (e.g., the UN, the EU, the UNHCR), on the condition that the claim is substantively relevant for any country of the EU and Switzerland. Example: The claim raised by the UNHCR that the German government should open the borders towards Syrian refugees has to be included. The claim raised by the UNHCR that Syrian refugees should be sent back from Turkey to Syria should not be included.

- In case of repeated statements or announcements, each one is coded as a separate claim. Example: An actor announces several times that it will hold a protest against the arrivals of new migrants.

- Claims must have a unity of time and place. Two substantively identical statements by the same actor on two different days, or on one day in two different locales, are two separate claims. Similarly, statements by different speakers during a parliamentary debate or a conference are considered part of the same claim only if they are substantively and strategically compatible. 
This implies that different actors should be coded together under the same claim if they all express a similar point of view. However, if the actors take positions that are substantially different enough to reject the assumption that they are acting in concert, the statements must be coded as separate claims. Another example: If an identifiable part of a peaceful demonstration breaks away from a march and turns violent, the assumption of acting in concert is no longer warranted and a separate claim should be coded.

- Information found in another article or newspaper issue on a given claim that has been coded previously should be corrected. Thus, claims that were coded but are found in a further issue of the newspaper not to have occurred must be withdrawn from the sample. Similarly, additional information found in another article (even in a different issue of the newspaper) regarding a claim previously coded, has to be used to complete the coding of that claim.

- There is NO minimal length of a claim to be coded. 'Open the borders', for example, is a claim.

\section{Basic claims grammar}

Each claim by any actor is characterised by a grammatical structure which can be broken down into a number of elements or variables that aim to capture specific characteristics of a claim (cf. TransSOL WP5 Codebook ${ }^{1}$ ). Numerous variables of this type have been coded in our study, but the cross-national analysis of print media presented in this book only deals with six main variable groups, which refer to the 'actor' (who makes the claim), the 'addressee' (who is held responsible for the claim), the 'issue' (what the main concern is about), the 'form' (the action through which the claim is inserted in the public domain), the 'position' (whether the claim is unfavourable or favourable to refugees), and the 'value' (how claimants justify their interventions). The specification of these variables enabled us to conduct systematic content analysis of newspapers in each of the countries under study, and thus to develop a composite dataset that allows for systematic comparisons and cross-national analyses.

Each of the six variable groups provides an invaluable basis for crossnational claims-making analysis. Information about actors enables us to depict the number, the type and the relative weight of claimants participating in and impacting on public debates, while the coded forms allow us to dig into the contentiousness of claims-making itself. For actors and forms, additional variables can be coded in order to gather data on their scope (e.g., the territorial location or reach), their types, political orientation and the like. Beside the identification of actors and forms of action, a core element of claims-making analysis is to reconstruct the structure of public debates. This is usually done with the help of two variables that belong to the grammatical structure of a claim: object actors and addressees. The object actor is defined in most inclusive terms, as the specific actor whose interests are affected by the claims. The object, implicitly or explicitly, must always be present for a claim to exist. In 
the case of solidarity claims, the object actor was by definition the refugees, the immigrants or alternative nouns referring to them. The addressee of a claim is defined more narrowly as the main actor who is held explicitly responsible for acting with regard to the claim - or at whom the claim is explicitly addressed as a call to act. Experience shows that often only a minority of claims in newspaper discourse contain an addressee. Sub-variables relating to object actor and addressee can include 'scope' (referring to the territorial dimension, such as local, regional, national, European or global), or other qualifying attributes (such as gender or nationality). Often, claims-making projects also distinguish between primary and secondary actors (objects and addressees) to refer to additional actors to which a claimant can relate.

Finally, claims-making analysis is meant to reconstruct argumentative and justificatory practices of claimants, because they take position in media debates, and the contentiousness of public discourses is a direct reflection of these diverse positions. The analysis of this argumentative dimension of claims-making calls for the specification of further variables. In the first instance, we need information about the issue, i.e., the substantive content to which a claim refers. Lists of issues have to be developed to cover the broad range of topical debates within a specific discursive field. In our case, the broader discursive field relates to solidarity contestations in regard to refugees and asylum seekers, within which a number of issues arise, for instance, those related to questions of security and border management, of integration and assimilation, of humanitarian aid. Furthermore, the position of the claim needs to be established in order to ascertain whether the claimant supports or rejects particular activities, measures, statements or demands that are relevant for the object. In the case of solidarity claims, the position is defined by the claimant's argumentative relation to the object actor of the claim, i.e., the refugees. In simple terms, a position depends on whether the claimant is supportive of the needs, demands or rights of refugees, or mobilises against them. Coding of positions is typically done on a scale of -1 to +1 , with neutral, ambiguous, or ambivalent claims receiving code 0 .

Finally, claims-making analysis is very often interested in coding the argumentative dimension of public contentions. This interest draws on a broad scholarly literature on 'framing', relating to the way actors interpret, define and construct the issues or problems they are discussing (Haunss, 2007; Johnston, 1995). The consideration of frames is crucial for an analysis of public contestations: Public issues and problems are identified and defined within and through public contentions, and claimants struggle about the validity of issue or problem definitions, not least because these interpretations and definitions determine what is considered to be a plausible cause, a legitimate demand for action and an accepted solution. The coding of frames, however, is one of the most demanding aspects of claims-making analysis, because it requires interpretative skills in order to establish what the exact frame of a claim is. Several templates for frame analysis exist. Some rely on broader categorisations by distinguishing between diagnostic, evaluative and prognostic frames (e.g. Cinalli and Giugni, 
2016a) in order to better understand the way actors describe the essence of a problem (for instance, the 'European economic crisis'), its causes and potential solutions. Others distinguish between different logics of justification with reference to interest, rights, values and identities (Cinalli and O'Flynn, 2014; Statham and Trenz, 2013; Vetters et al., 2009). In the TransSOL project, we were interested in justifications as well, but aimed at grasping the argumentative structure more accurately. We thus aimed to identify whether claimants grant or reject solidarity towards refugees - and other groups or countries acting on their behalf in the context of the refugee crisis -, and we were interested in the way they justified their statements. In particular, we distinguish between three dimensions or variables: 1) The underlying value on the basis of which solidarity is granted or rejected (affirmation or rejection of solidarity; directly connected to POSIT); 2) Who is potentially blamed for a certain behaviour in relation to the 'refugee crisis'; and 3) Who is potentially credited for a certain behaviour in relation to the 'refugee crisis'.

These variables help to extract crucial information from newspaper articles. They allow us to synthesise and standardise this information in a concise and systematic manner. To illustrate this process of synthetisation and standardisation, we refer to Table 3.1, which lists two examples of solidarity claims and the way the TransSOL codebook has used the basic grammar of claims-making to assign predefined codes to the claims' main dimensions.

The main variable groups presented so far are of crucial importance to help retrieve information on the main dimensions of the claims, and thus to develop a systematic dataset that describes the public debates under analysis. In the case of solidarity contestations, they help to identify the constellation of participating actors, the main issues related to solidarity with refugees, the type of actions and their degree of contentiousness, and the way solidarity is justified or discredited. However, it is worth mentioning that it is also important to pay attention to the context of the claims and the overall debates they are nurturing. While previous guides for claims-making analysis have introduced and discussed the basic claims grammar and further developed or adapted it to specific research avenues, less has been said about coding data that contextualise the claim and, in so doing, enable a certain degree of explanatory analysis. In this regard, we see the need to make use of meta-variables, which help to retrieve standardised information about the context in which the claim is embedded. Such variables concern:

- the type of newspaper (e.g., broadsheet, tabloid)

- the position of the newspaper on the political spectrum

- the date of the claim/publication date

- the locality/place of the claim

In TransSOL, we have included further meta-variables. In particular, we have gathered data on claims in posted articles on Facebook as well as related user comments. This data expands the range and spectrum of claimants 
Table 3.1 Examples for coding of claims-making

Newspaper Article (text part coded as claim in

Coding of variables italics)

'Europe has lost control of the refugee crisis, admits Merkel', The Daily Telegraph, 12 Jan. 2016

ANGELA MERKEL said last night that the Continent had lost control of the refugee crisis, as she confronts public anger over the New Year's Eve sex attacks in Cologne. "All of a sudden we are facing the challenge that refugees are coming to Europe and we are vulnerable, as we see, because we do not yet have the order, the control that we would like to have', the chancellor told a meeting of business leaders.... The findings of a report by the state government of North Rhine-Westphalia released yesterday are likely to add to the pressure.

'Both witness accounts and police reports indicate that people of an almost exclusively immigrant background were the perpetrators of these crimes', Ralf Jäger, the state interior minister, told the state parliament as he presented the report. 'After they were intoxicated with drugs and alcohol came violence. It culminated in the acting out of fantasies of sexual power. That must be severely punished.'

'British writers and actors urge David Cameron to rescue refugee children',

The Guardian, 18 Feb. 2016

The actor Jude Law has assembled some of Britain's most prominent writers and actors to call on David Cameron to rescue the growing numbers of unaccompanied children living in desperate conditions in Calais and Dunkirk, after visiting the migrant camps and being horrified by what he saw. ... He was 'horrified at the sheer number of people living in the most extreme conditions between Dunkirk and Calais, and the level of squalor'. Law was so disturbed by the suffering he encountered that he assembled 145 well known figures to join him in an appeal to the government, asking for immediate action to belp hundreds of migrant children, traveling without their parents and living in tarpaulin shacks in France.
- Claimant: Ralf Jager

- Addressee: Parliament

- Issue: Policies directed at the integration of refugees

- Evaluation: Negative

- Object: Immigrants

- Justification/Frame: Rule of law/security/protection of citizens (interest-based/utilitarian justification)

- Claimant: Jude Law and other celebrities

- Addressee: David Cameron

- Issue: Inhumane conditions/ emergency (e.g. descriptive accounts of conditions of camps, also along refugee routes)

- Evaluation: Positive

- Object: Child Refugees

- Justification/Frame: Human rights (rights-based justification)

and claims, which enables us to reach beyond claims-making in the mass media and investigate other arenas of contestation. Posted articles and user comments also allowed us to include meta-variables about the social media outlets, which are helpful when contextualising this specific form of public claims-making. However, our research did not exhaust the range of potential meta-variables to 
be retrieved. Other possibilities, which were not implemented here, are the inclusion of frames used by the journalist, claimants' political positions on the issue at stake, even the number of article clicks.

Such variables are helpful for contextualising the claims. In fact, the variables presented above give a descriptive account of the claims' main components: who said what about whom, to whom and how. This descriptive information can be analysed with a more analytic or explanatory ambition, when using the meta-variables, because they allow us to explain descriptive incidents with references to contexts and circumstances. In this regard, they can also be used for hypothesis testing. Depending on the number of claims coded, it is possible to analyse trends over time and across newspaper types or national mass media systems, thus enabling for more nuanced comparisons. Both analyses provide greater explanatory power to the descriptive claim's grammar. The richness of such meta-data can mitigate the potential risk of focusing exclusively on the single claim as unit of analysis, thus separating it from its context. As we mentioned earlier, claims become part of a news story through an interplay between journalistic practices of news-making and political actors' strategies of agenda-setting.

These two logics help explain why political decision-makers are usually the most frequently mentioned claimants and therefore tend to dominate debates (e.g. Brändle et al., 2019; Georgiou and Zaborowski, 2017; Kluknavská et al., 2019). In fact, government actors have the power to make decisions relevant for national audiences, therefore scoring high on news worthiness. They also have considerable resources to strategically place claims in the news. However, their public visibility also depends on the logic of journalistic news-making, the types of news outlets and the structures of (national) mass media systems. This contextual information is highly relevant when trying to explain potential differences in the visibility of decision-makers in different news outlets (e.g., quality papers versus tabloids), or when elaborating on the diverging dominance of these actors in some countries when compared to others. Additionally, trends in public debates can be related to contexts and circumstances, when checking the effect of critical junctures (significant events or conflicts), longer socioeconomic, political or cultural developments, or changing news media landscapes on public contestations.

With regard to all these variables, we need to remember that codebooks for claims-making analysis are rarely developed from scratch. They rather build on best practices with variables and coding instructions developed by previous research teams. Using earlier experiences and knowledge is essential to guarantee that one's own codebook is a reliable and valid instrument of data-retrieval. Good codebooks have been developed, tested and implemented by groups of researchers, who very often document and reflect their field-work. The use of these codes and coding instructions is highly recommended, but it does not save time, given that these codebooks need to be adapted to the discursive field under investigation. In most cases, the codebooks need to be 'reinvented', because the main variable groups - in 
particular actors, addressees, issues, positions, frames or values - need to be rewritten significantly in order to match the new field of inquiry. In the TransSOL project, for instance, it was necessary to fill the 'main actors as claimants' with new life. Variables with long lists of categories referring to governmental institutions, political parties or civil society actors had to be developed anew.

The questions to be decided in the planning phase of individual claimsmaking projects relate to the topical specifics and depth of analysis. Designing codebooks typically implies the task to adapt available variables and lists of categories to the specific countries (e.g. adapting the names of political parties), as well as including categories for civil society actors or experts that regularly raise their voice in relevant debates according to the specific issue field. This requires considerable work, very often preliminary and inductive content analysis of news coverage, further testing and progressive refinement of coding instructions.

Additionally, the design of codebooks typically implies choices about the depth of analysis. Researchers need to decide, for instance, whether they are mainly interested in broad categories of data, like the distinction between governmental or civil society actors, or whether they wish to introduce further nuances, for instance, in terms of political party affiliation or scope of activity (e.g., a global, European, national, regional and local reach). As a general rule, we can indicate that depth of analysis comes at the cost of reliability of coding. The more elaborate the codebooks, the more time consuming the coding process will be; at the same time, this increases the risk of diminishing the reliability of the coding process. Researchers who wish to engage in claims-making analyses must therefore carefully consider which depth of analysis is feasible and necessary for their project. This is usually established through pilot studies and reliability tests, which we will discuss in further detail later on.

\section{Sampling strategies}

The selection of news sources in claims-analysis projects typically follows criteria of representativeness of the selected sources for debates shaping the national public sphere. Usually, text sources from printed or online news outlets are given preference, but the inclusion of audio and visual material from radio, television or the Internet is also possible. Traditionally, sampling is done from news archives that allow for keyword searches over extended time periods (such as LexisNexis, Factiva or Europress). The whole population of articles for a given period of time is typically sampled through automated text search from all newspaper sections through predefined keywords that are applicable to all newspaper archives, and, in the case of country comparisons translated into the respective languages. In our case, the key words 'refugee' and 'asylum' were used to select relevant articles. More recently, samples have also been drawn from online news sources (Galpin and Trenz, 
2018) allowing us to combine the analysis of news articles with an analysis of user comments (see Chapter 5). The disadvantage of online sampling is, however, that archives are often incomplete or contain only selected articles for online publication. Moreover, search functions through keywords are often more limited. The question of what constitutes a representative sample needs to be established in a case specific way, but generally, such samples include a mixture of broadsheet newspapers and tabloids with nation-wide distribution and sometimes also regional newspapers. Tabloids tend to report less political news, which is then a valuable expansion to capture public debates beyond political news toward human interest framing of socially relevant stories (Örnebring and Jönsson, 2004). In the case of the TransSOL project, we opted for a selection of three newspapers per country (one more left- and one more right-leaning broadsheet newspaper and a tabloid). Switzerland has regional specificities; accordingly, for Swiss sources we have included five newspapers (two written in German + two written in French + one written in Italian).

Claims-making analysis is usually conducted over longer periods of time to allow for the reconstruction of the chronology of debates. Longer time periods also require larger samples. For the TransSOL project, we decided to restrict our sample to the peaks of the so-called 'refugee crisis', spanning from 1st August 2015 to 30th April 2016. The size of the sample further needs to be established in relation to the number of variables and sub-values that are investigated. The smaller the sample, the higher the risk that the data will be below the level of statistical significance with regard to single variables contained in the codebook (e.g., so-called rare phenomena - rarely coded variables). Considerations of statistical significance are of particular relevance for comparative claims-making projects. As it is difficult to predict results, pragmatic solutions can be found by aggregating values in the statistical analysis if statistical significance is not reached for single variables. Other, however costly solutions, exist in the increase of sample size through additional rounds of coding.

Researchers who plan to engage in a claims-making project are advised to apply some flexibility to their planning and to factor in sufficient time for coding. If the number of articles needs to be reduced to keep the workload manageable, claims should be selected by drawing a (systematic) random sample of articles from the whole population of news articles retrieved for a specific period. Such random sampling procedures can be adapted flexibly if additional coding becomes necessary or when original coding schedules turn out to be too ambitious. In our case, we coded around 700 claims in articles randomly sampled from three newspapers in each country, published between 1st August 2015 and 30th April 2016. We started with 100 articles to detect the average number of claims coded per article; we then used this average to sample the predicted number of articles needed for coding. National teams could extend their coding up to 750 claims so as to have even numbers across the three newspapers ( 250 claims for each newspaper) (see Table 3.2). 
52 Claims-making analysis and applications

Table 3.2 Claims sample size across countries and newspapers

\begin{tabular}{|c|c|}
\hline Countries & Claims coded \\
\hline France & 783 \\
\hline Le Monde & 264 \\
\hline Le Figaro & 265 \\
\hline Le Parisien & 254 \\
\hline Germany & 740 \\
\hline Süddeutsche Zeitung & 247 \\
\hline Frankfurter Allgemeine Zeitung & 244 \\
\hline Bild & 249 \\
\hline Greece & 711 \\
\hline Proto Thema & 238 \\
\hline $\mathrm{Ta} \mathrm{Nea}$ & 236 \\
\hline Kathimerini & 237 \\
\hline Italy & 701 \\
\hline La Repubblica & 235 \\
\hline Corriere della Sera & 235 \\
\hline Libero Quotidiano & 231 \\
\hline Poland & 699 \\
\hline Gazeta Wyborcza & 248 \\
\hline Rzeczpospolita & 249 \\
\hline Fakt & 202 \\
\hline Denmark & 707 \\
\hline Politiken & 235 \\
\hline Jyllands-Posten & 236 \\
\hline$B T$ & 236 \\
\hline Switzerland & 755 \\
\hline Le Temps & 150 \\
\hline Le Matin & 151 \\
\hline Neue Züricher Zeitung & 154 \\
\hline Tages Anzeiger & 150 \\
\hline La Regione Ticino & 150 \\
\hline UK & 750 \\
\hline The Guardian & 248 \\
\hline The Telegraph & 252 \\
\hline The Express & 250 \\
\hline Grand Total & 5846 \\
\hline
\end{tabular}




\section{Challenges and opportunities}

\section{General considerations regarding claims analysis in a comparative, multilingual project}

The method of claims-making is unsuitable for a single researcher's project. Text coding should, by default, be teamwork and requires principal investigators to engage in team building and strategy development for coder training. Claims-making could be $\mathrm{PhD}$ research, but young researchers can only ensure reliability by including other researchers (e.g. students) in the coding process. Team-building is further necessary to cope with large amounts of text required for longitudinal studies, or to deal with the challenge of multilingualism in a comparative project. Ideally, claims-making analysis should be conducted by native speakers with a good background knowledge of political culture, law and politics and, at least a general understanding of the topics under investigation. For our analysis, eight countries' news coverage was analysed by eight individual country teams which consisted of two to three coders. The coding process was supervised by a core team of four researchers who were responsible for developing and pretesting the codebooks, for training and for giving feedback to individual researchers before, during and after the coding. We started the coding process with a one-week training of coders for which we all met at one partners' venue to facilitate face-to-face discussions.

As regards the validity and reliability of coding, it is essential to remember that coding in claims-making projects can build on the strength of teamwork for interpretative text analysis. In that sense, comparative claims-making analysis has to recur to measures of 'inter-team reliability' which is, in a multilingual setting, a highly artificial exercise, given that most coders do not code in their native language. Thus, such tests, and also the coding instructions, need to resort to a common language - usually English. The results of tests are thus dependent on the degree of English fluency of the teams and their coders, but of course also an intimate, near native-speaker familiarity with the cultural and linguistic specificities of the respective English-speaking country. Since instructions are in English, too, such tests nonetheless help not only in creating a common basis, but also when testing how well instructions have been understood. It is to be assumed, then, that coders will be more accurate in their native language because of higher intuitive knowledge of the language and how it is used in the respective social and political context.

Thus, on the one hand, it is important to establish a common understanding of claims-making across teams, even though it is necessarily compromised by the fact that the common language will not be the native language of most coders. It is, on the other hand, also important to establish the reliability and validity of coding in the respective native language. Against this backdrop, tests should ideally be conducted at both levels. We therefore decided to test reliability across teams in English, as well as decentralised within teams in their native language. We provide a more detailed technical report of the results of our reliability tests 
on the online pages of TransSOL. ${ }^{2}$ In the following, we provide more information on the rationale of reliability and validity testing in TransSOL.

\section{Intercoder-reliability}

Generally, questions of validity and reliability of claims-making have not been paid sufficient attention in the literature, and only a few templates for tests are available. As we have discussed, claims-making analysis consists of translating textual data into numbers. Research therefore is, by default, an interpretative process. For a comparative analysis, a shared cultural understanding among all coders is required, but this congruence cannot be taken for granted, meaning that a standardised codebook is not a sufficient guarantee for standardised coding practices. At the same time, however, text interpretations by coders should not deviate from the way regular news readers interpret the news. Data that is generated by claims-making analysis is only valid if text messages are interpreted by the coders in the same (or in approximately the same) way as they would be interpreted by members of the general public. We know from the literature that texts are not read in the same way by different audiences: The de-coding of texts varies between individuals or with regard to different audience segments. At the same time, we can, according to cultural studies, detect a structured variation in the interpretation of text, e.g., people with similar degrees of education, men in a similar structural position, are likely to converge in the interpretation of text (Hall, 1973). Claims-making analysis aims at convergence of text interpretation among coders. It implicitly assumes (but de facto is never fully able to prove) that such convergence is the best indicator for a shared cultural understanding of text, which, in turn, can account for public opinion formation processes.

Claims-making analysis assumes that numerical data can be treated as an indicator of the contestation dynamics of public opinion formation, but this assumption needs to be proven. An essential element of such a proof is the reliability of the coding process. The standard measure in standardised quantitative content analysis is Krippendorff's Alpha, which has also been used in claims-making analysis (e.g., Kluknavská et al., 2019). However, due to the hybridity of the claims-making approach (i.e., the combination of qualitative and quantitative elements), such measures seem slightly problematic. One problem is that such tests are particularly inadequate for variables with long list of values or subcategories because of the low probability that every single subcategory will be coded. Reliability for such 'rare phenomena' has generally proven to be difficult to establish: Krippendorff's Alpha is particularly sensitive in such instances, thereby providing very low scores of reliability even if the number of mistakes is extremely small (see De Swert, 2012 for a more detailed discussion). In most claims-making projects, standard tests - such as Krippendorff's Alpha - can therefore be run meaningfully only at an aggregate level, i.e., with regard to broader categories with higher numbers of cases. In the TransSOL project, for instance, we can establish reliability of the category of 'national 
political actors', but not of subcategories that were used in coding, such as 'government/executive/state actor', 'parliament/legislative', 'courts/judiciary', 'police and other security/military forces', simply because no sample of claims would have covered all these subcategories. In addition, the practice of claimsmaking analysis implies that different values are often not categorically exclusive, because the interpretation of the text would allow for different responses. Such responses would be valid in the sense that experts could agree on the margins of interpretation. They would also be valid in the sense of 'decoding practices' by particular audience segments, even though coding would become unreliable according to standard tests.

To avoid these pitfalls of rigid statistical tests of reliability, existing claimsmaking projects mainly used percentage agreement tests to verify reliability of coding (e.g. the EUROPUB project). For the TransSOL project, we opted for mixed tests. On the one hand, percentage agreement was applied to test reliability of claims-selection against the background that any claims reliability sample is highly likely to be biased towards only relevant claims: irrelevant claims are not coded and, accordingly, would only appear in the sample if included by at least one coder. Hence, agreement on non-relevance would be heavily underestimated. Measures such as Krippendorff's Alpha consider chance agreement (based on the amount of values coded in the sample; i.e., in a dummy variable, chance agreement is 50\%). However, in terms of claims identification, it is unlikely that a claim was identified by chance. Therefore, chance agreement may be assumed to be very low. Strict measures also accounting for chance agreement, therefore, do not seem adequate. On the other hand, we applied Krippendorff's Alpha test for variable coding, acknowledging that satisfactory results can only be achieved at aggregate level and not for each single value of a variable in the codebook. This implies that throughout this book, only aggregate level data will be used for the analysis of solidarity claims that passed the reliability test.

Nevertheless, we insist that detailed codebooks and practices of sub-category coding remain important and should be maintained in future claims-making projects. Even if reliability scores cannot be met for all variables, sub-category coding practices sharpen the eye of the researcher for details in debates and thus promote a general understanding of the complexity of the issue under discussion. Sub-category coding further keeps the possibility of surprise findings open, for instance, when specific sub-categories appear with unexpected frequencies.

To assess the validity of claims coding, we compared reliability scores of national teams with scores from the team of instructors. This allowed for a systematic validity check of results through the template of instructors' team coding. In fact, experts' templates can be used to identify 'valid responses' among the variety of responses delivered by national teams and thus to adjust the results of the test coding beyond the simple statistical variation of coders' coding choices. However, ensuring the validity and reliability of coding practices is not limited to standard tests, but requires continuous efforts that stretch over the whole coding process. Small-scale reliability pre-tests can be 
useful at the stage of training the coders. We conducted such a pre-test for screening purposes during our one-week training session, with the purpose of identifying teams and individual coders in need of further training. The results of such pre-tests are only relevant for internal project-coordination and do not need to be reported. Reliability tests should only be conducted after completion of the teams' training and after each coder has accumulated various hours of coding practice. In our case, material for the tests was selected by the coordination team and sent out to the national teams for individual coding. Reliability results were then discussed at another face-to-face meeting among team leaders only. The purpose was to identify possible systematic errors, which were re-checked afterwards by the teams individually. Reliability of coding could further be ensured through team supervision and systematic cross-checking of coding practices and results. In our case, all teams had regular meetings for discussion of the coding, also involving work package leaders via Skype. In that way, continuous training was ensured. Due to the low number of claims coded in total $(n=700-750$ claims per national team), re-checking and the correction of coding was possible without major resource losses.

\section{Expanding claims-making: Social media as sites of contestation}

A new opportunity for the expansion of claims-making analysis has opened up with the possibility of using social media sites as an access point for political news. Moreover, it permits us to include user comments and reactions to political news as part of the research strategy. This allows relating the results of claims-making research in mainstream media discourse to forms of reception analysis of selected news readers and their engagement with political news. The assumption supporting this methodological expansion is that political news consumption shifts online and thus social media become increasingly relevant for the distribution of political news (Rackaway, 2014; Siapera and Veglis, 2012). Our own research on solidarity contestation in the media pioneered a methodological template for assessing this linkage between news-reading on social media and forms of user engagement.

For that purpose, we combined the analysis of news coverage through legacy media with an analysis of Facebook news readers' comments on political news. As a specific feature of comment sections on Facebook, users can comment freely on published articles and are not bound to commit to journalistic standards or political deliberation formats. Instead, comments can be understood as more spontaneous and are often uninformed reactions to what is written 'above' (see Reagle, 2015). Consequently, we understand user comments as part of informal and uncoordinated political debates in social media. In particular, they provide us with a window on the process of political opinion formation through contestation by social media users who respond to political news. The user comments analysis is thus a useful supplement to the claims-making analysis because it allows for adding a bottom-up perspective when analysing solidarity contestation (Trenz et al., 2020). 
As with every research project, the sampling strategy depends on the research purpose. Social media commenting is a moving target in the sense that it is still up for debate how to conceptualise it. Moreover, we still need to better understand the role it plays with regard to public opinion formation, the type of public it constitutes (Citizens? Readers? Users?) or the impact it has on the framing of political issues by journalists and political claims-makers. What we know is that the share of commenters among news readers is considerably lower than the share of online news readers, and varies across countries (Newman et al., 2016). There seems to be some agreement that online commenters cannot be held as representative of the whole population nor of public opinion as measured by surveys. Instead, commenters tend to be characterised by lower rates of trust in established news media; they report higher levels of political interest and align themselves to stronger ideological convictions (Kalogeropoulos et al., 2017).

Given less formal space for political debate and contestation in the Facebook commenting sections, a coherent sampling strategy is crucial. To allow for correspondence with our claims-making analysis, we opted for sampling articles from Facebook pages run by the same newspapers that also informed our sample of offline news. Our sampling strategy was purposive, targeted to collect material on instances with high degrees of contestation. Through our claimsmaking analysis, we found September 2015 to be the month with the most intense debates in all countries analysed. In order to gain a detailed look at bottom-up solidarity contestation, we chose to focus on that month. Consequently, only posts and comments with a publication date from the 1st to the 30th of September 2015 were included in our sample.

To increase the relevance of our purposive sample, we ranked posted news articles in order of popularity according to the number of Facebook comments they achieved. For each team, we then selected the five most commented on Facebook posts from each newspaper (thus 15 news articles). Additionally, Facebook's algorithms sort comments, thus making some more visible than others, e.g., those from friends, verified accounts, accounts with more engagement (Facebook, 2020). This allowed us to collect the comments with high degrees of engagement (e.g. likes and responses to comments), because we assume that the latter indicates either contestation or at least support of the position of a 'contester'. For each of the 15 posts, the 20 top comments were coded; replies to these comments were excluded. Our sample thus consists of an absolute number of 300 comments per country, divided into comments on three newspapers (expect for Switzerland) (see Table 3.3).

As mentioned earlier, comments on social media need to be interpreted and treated differently to claims. A comment can take the form of a claim by a news-reader, but often its grammatical structure is truncated. This has implications for the claims-making approach, because with regard to social media, we can consider the single, entire user comment to be the unit of analysis. ${ }^{3}$ Accordingly, the analysis of users' comments conducted during the TransSOL project was a pilot study. Our experiences allowed us to delimit a method of 
58 Claims-making analysis and applications

Table 3.3 Comment sample size across countries and Facebook pages of newspapers

\begin{tabular}{|c|c|}
\hline Countries & Comments coded \\
\hline France & 300 \\
\hline Le Monde & 100 \\
\hline Le Figaro & 100 \\
\hline Le Parisien & 100 \\
\hline Germany & 300 \\
\hline Süddeutsche Zeitung & 100 \\
\hline Frankfurter Allgemeine Zeitung & 100 \\
\hline Spiegel* & 100 \\
\hline Greece & 300 \\
\hline Proto Thema & 129 \\
\hline Ta Nea & 64 \\
\hline Kathimerini & 107 \\
\hline Italy & 300 \\
\hline La Repubblica & 100 \\
\hline Corriere della Sera & 100 \\
\hline Libero Quotidiano & 100 \\
\hline Poland & 300 \\
\hline Gazeta Wyborcza & 100 \\
\hline Rzeczpospolita & 100 \\
\hline Fakt & 100 \\
\hline Denmark & 300 \\
\hline Politiken & 100 \\
\hline Jyllands-Posten & 100 \\
\hline$B T$ & 100 \\
\hline Switzerland & 300 \\
\hline Le Temps & 60 \\
\hline Le Matin & 60 \\
\hline Neue Züricher Zeitung & 60 \\
\hline Tages Anzeiger & 60 \\
\hline Blick* & 60 \\
\hline UK & 300 \\
\hline The Guardian & 100 \\
\hline The Telegraph & 100 \\
\hline The Express & 100 \\
\hline Grand Total & 2400 \\
\hline
\end{tabular}

Note: For Germany and Switzerland, the sample used for comments coding slightly differs from the sample used for claims coding (newspapers marked with an asterisk); in Greece, the share of comments coded per article was organised slightly differently due to the fact that there were not enough comments for $\mathrm{Ta} \mathrm{Nea}$. 
social media commenting analysis that can be used by others, but requires further development and refinement by future research. We firmly believe that this expansion of claims-making analysis towards news commenting analysis of social media is a highly relevant venture, because bottom-up contestation is increasingly channelled through social media sites and because 'alternative' news agenda gain visibility. More than that, a systematic combination of 'traditional' claims-making analysis and the additional approach of news commenting analysis is a promising mission, given that it enables researchers to link top-down claims-making to bottom-up contestation.

\section{Conclusion}

In this chapter we introduced the claims-making method. We discussed the different definitions of claims as strategic acts of communication and as broader forms of political discourse, arguing that such definitions are complementary and lend themselves to an empirical investigation of public contestation. We have further described the role of claims-making as a method not for understanding representative public opinions and attitudes but for analysing the process of political opinion formation across different social groups and political actors. Claims-making is in this sense particularly helpful in an increasingly mediatised political landscape where mass and social media have become the main arenas for contestation and political opinion formation processes.

Claims-making, however, also harbours methodological challenges, as we experienced during the implementation of our TransSOL project. Hence, we have discussed the various tasks that applied research on claims-making involves. These tasks include the development of codebooks and coding instructions, the delimitation of a total population of articles and the extraction of a sample of claims, as well as the training of coders and the application of intercoder reliability tests suited for a multi-site and multi-language project. We also introduced the TransSOL codebook and discussed best practices. Finally, we introduced our adaptation of claims-making analysis to the context of social media, in our case Facebook. Combined with the analysis of claims from posted news articles, we could show how claims-making enables researchers to link elite contestation to bottom-up contestation visible in Facebook's comment sections.

Against this background, it becomes clear that the claims-making method is not the holy grail to understanding political contestation as it unfolds in mediatised politics. However, it offers a valuable and pragmatic entrance into a systematic analysis thereof. Claims-making is not only transferable to different contexts, media platforms and types of communication, but it also enables researchers to link different actors across disciplines. It is further suitable for single case studies, as well as comparative research questions and projects, as long as researchers are aware of the methodological risks and challenges to be encountered during the research process. 
60 Claims-making analysis and applications

\section{Notes}

1 See https://transsol.eu/outputs/data/.

2 The technical annex is provided on https://transsol.eu/outputs/data/

3 Each comment was coded only once, irrespective of whether it contained zero, one or multiple claims. For a more detailed sampling strategy, including the rules for discarding off-topic comments, see Trenz et al., 2020, pp. 155-156. 


\section{Solidarity under siege \\ The 'refugee crisis' in the news media}

\section{Introduction}

When the number of refugees and asylum seekers from war zones in Syria increased in the summer of 2015, the response of EU member states varied widely with regard to the question of transnational solidarity and the degree of hospitality that should be granted to the incoming refugees. Our book provides a snapshot of the variation of public reactions and debates and thus illustrates, first and foremost, the national specificities of media debates on solidarity. On the surface, such differences can be explained by reference to geo-political location, position of the government and short-term interests of a country in confronting the 'refugee crisis'. Greece, together with Italy, as the first entry point to the European Union for most refugees, insisted on fair burden sharing with the rest of Europe. Germany was the first country to listen to these demands for solidarity and, after a series of dramatic events at Europe's external borders and on the transit routes through the Balkans, decided to suspend the Dublin Regulation at the end of August 2015 so as to accept asylum applications from refugees travelling from Greece. In turn, this open-door policy triggered intergovernmental conflicts within the European Union. It was supported by France, which was, however, less affected by the immediate effects of the inflow of refugees; yet it was heavily criticised by Denmark and Poland. It was also fundamentally questioned by other countries, such as Hungary, which are not part of our sample. The British government took an outsider position: It strengthened its stance against France over the responsibility of refugee camps in Calais and accepted a minor number of war refugees from Syria as a symbolic gesture of solidarity. Finally, Switzerland, as a non-EU country, but nonetheless a part of Schengen, also received increasing numbers of refugees from Syria, mainly entering through its southern borders with Italy.

These differences of country approaches towards refugee solidarity resulted in differences in news coverage across countries, as evidenced in the first available research (Berry et al., 2015). . We will contribute to this mapping of cross-country variation in contesting refugee solidarity in Part II of this volume with more detailed evidence from the specific country contexts (Chapters 6-13). In this chapter, the focus is not so much on country specificities and the development of 
national debates. We rather wish to test out some explanatory variables to make sense of the variation in news coverage within the public sphere across countries. Variation in news coverage of migration can be a consequence of deep rooted conflicts among EU member states, but also of systemic differences of media, culture and society. It is well known that countries diverge in regard to the way the news frames migration, depending on prevailing cultural patterns of stereotyping different groups of foreigners, like Turks in Germany and people from the Maghreb in France (see Eberl et al., 2018 for an overview). The public sphere of claims-making is thus selective and constructed. Yet, not only does news media affect logics of selection and framing; it also provides the essential space for the unfolding of the public sphere through 'organised' claims-making as a form of public contestation. From this viewpoint, the arena of public claims-making that is intrinsic in the news media overlaps to some extent with the public sphere of political interventions by organised actors such as politicians, stakeholders or major NGOs.

From this perspective, our analyses map a European field of solidarity contestation in the context of the 'refugee crisis', which is culturally divided. The news media bring these divisions to the fore, because such cultural clashes among organised actors take place within this public sphere, dividing countries, but also segments of the public within a country. Broadly speaking, we can distinguish between different positions in the debate, which we call 'cultural' as they involve specific perceptions, evaluations and justifications based on beliefs and values as much as on political interests and strategic choices. To the extent to which these positions dominated public debates at a certain time in specific countries, we can speak of 'shared cultures of solidarity'. We can discern a 'welcoming culture' that unfolded during the first weeks of 'crisis' in Germany, but was heavily contested in other parts of Europe, a 'culture of denial' of shared European responsibility that characterised public debates in Denmark and the UK, and a 'culture of categorical rejection' of international humanitarian obligations and solidarity that we found frequently expressed in Poland. These positions are however not simply national-specific and exclusive but cross-cutting: They define the main axes of solidarity contestation domestically and cross-nationally, opening thus a European field of solidarity contestation. An inclusive, pro-solidarity attitude towards refugees was, for instance, temporarily mobilised across the European spectrum, especially during the first weeks of mobilisation when the 'welcoming culture' that found first expression in Germany resonated in other countries. In turn, anti-immigration voices in the news media increased across European countries as the debate unfolded over time (Damstra et al., 2019; Eberl et al., 2018). Solidarity debates were further characterised by frequent discursive shifts in the way refugees were either framed as 'persons in need' or as 'threats' (e.g. Kluknavská et al., 2019), often failing to pay attention to refugees' own voices and experiences (Chouliaraki and Stolic, 2017; Georgiou and Zaborowski, 2017). These shifts in media discourse and framing can be triggered by a multitude of factors, such as external events, a change of government, or mobilisation efforts of particular actors (e.g. Greussing and 
Boomgaarden, 2017). If public perceptions of the 'deservingness' of refugees are shaped by media debates, this also means that solidarity is dependent on the attention cycle of news media and the differences in the success of media agenda-setting strategies of particular groups of actors over time.

In light of these differences, this chapter analyses how the 'refugee crisis' was made salient and selectively amplified in the news media through claims of organised actors in the public sphere. In particular, drawing on claims-making, we identify the extent to which acts of solidarity towards refugees were granted public awareness and what claims on behalf of or against hospitality towards refugees were made, and by whom. We also examine the discursive construction of European solidarity in terms of its positions and justifications, and how such differences are used in contestations between various allegiances (e.g. proponents and opponents of humanitarian transnational solidarity vs. traditional national solidarities). In addition, we look into the fault lines that opened up across Europe; in particular, we assess the extent to which national debates followed similar patterns of division among governments, political parties and civil society actors in the public sphere, for example, in terms of both the positioning vis-à-vis refugees, and the way these same actors justified (or disqualified) solidarity with refugees.

\section{Mapping solidarity claims cross-nationally}

The solidarity contestations under analysis in this chapter are representative of a particular momentum of time in which solidarity was granted high salience in the media and contributed to focus the whole of Europe's public attention on the fate of refugees. These contestations can be mapped and analysed empirically when looking at public claims-making in the mass media. As spelled out in further detail in our methods chapter (Chapter 3), propositions of and opposition to different solidarity projects are taken as 'claims' that compete for salience in the public sphere as delimited and mediated by the media. As actors of these 'claims', claimants intervene within national public spheres, but their interventions are not limited to national borders. Solidarity contestations are carried out across Europe since the decision of one country to open its borders towards refugees potentially affects all the others. This broadens the scope of solidarity contestations considerably, because the question of whether a government or citizenry in a given country should care for refugees is directly linked to the question of whether national governments and populations should support each other in their attempts to address the needs of refugees. What is at stake in public debates about solidarity with refugees is the fact that solidarity relationships are not containable within one single country, but need to be renegotiated between all Europeans across different countries.

Through the template of claims-making analysis, we can approach our general object of research as forms and practices of solidarity contestation in the news media. The different indicators used in claims-making analysis allow us to raise a number of research questions, and through our aggregated data, we are 
able to provide responses that are based on cross-national and cross media comparisons. First, we gain insights into the intensity and temporality of solidarity debates in a moment that is generally interpreted as crisis by looking into the salience of debates across countries: How did national debates about refugee solidarity emerge and develop over time? When and with regard to what external events did debates peak? Secondly, we learn about the drivers of conflict when focusing on the involved claimants: Who are the proponents and the opponents of refugee solidarity in national public spheres? Protagonists of solidarity contestations in international conflicts can often be governments or civil society organisations across public and policy spheres, but their role can also be challenged domestically by various oppositional actors, political parties, and other populist or xenophobic forces. As the voice of these actors in our claimsmaking analysis is mediated, i.e., selectively made salient in the news media, we learn, thirdly, about the filtering processes of news and the possible biases of political journalism: How are actors selectively made salient and what forms of actions are typically reported by different news outlets (e.g. by comparing quality newspapers and tabloids)? Fourthly, we gain information about the main concerns that are given expression in solidarity debates. Around what issues do solidarity debates unfold, and how are these issues debated controversially in the news media? This relates to the second level of the news selection process: In addition to rewarding particular actors with media salience, news media also selectively grant specific issues a news value over others. The 'refugee crisis' as a 'focusing event' allows claimants in the news to focus public attention on issues they consider to be of particular relevance. Such selective issue attention is highly relevant as an aspect of interpretation and understanding of the 'refugee crisis', because it determines the way the problem is defined and which actions should be taken to address it. For our purpose, it matters, above all, whether the refugee crisis is discussed primarily as an issue of public security, or as an issue of humanitarian intervention. Fifthly, our comparative analysis of solidarity contestation turns to the question of how the deservingness of refugees is debated controversially in the news media. To what extent is solidarity towards refugees granted or rejected, and how are these different proposals towards refugee solidarity justified? We thus conclude with an analysis of the tonality of debates, and the framing of claims over time and across countries. In relation to this, we also present information about the spatial dimension of debates and the degrees to which solidarity is debated cross-nationally. We will give attention to foreign actors and events in the media to highlight contestations that stretch beyond national borders, for instance, in terms of coalitions and conflicts between EU member states and governments. What are the degrees of Europeanisation/transnationalisation of solidarity debates?

Taken together, this set of questions is of key relevance for understanding the 'refugee crisis' as an event that is constructed in the public sphere through the intervention of various actors and the news reporting practices of news media. As we argued in Chapter 3, the interplay between these two sets of actors is 
crucial to adequately understand the situation. In fact, the salience of the 'refugee crisis', its collective interpretations, and also its political repercussions need to be discussed in relation to the media debates it triggered and the way media audiences were exposed to the spectacle of mediated solidarity contestations. While the mass media play a key role in public debates, it is also necessary to focus on the drivers of solidarity contestation, its majority organised claims-makers such as politicians, humanitarian organisations and various stakeholders. We thus argue that the 'refugee crisis' was constructed not only by the media, but through the media. The news media are considered to be the main arena of collective interpretation of external events, which are also selectively brought to the attention of the audience in the way they call for or deny solidarity with refugees. Understanding the relationship between the public sphere and the news media, as well as the latter's agenda-setting and framing processes, is of high practical relevance as it helps us to discuss the media's role in triggering public responses of solidarity, such as the 'welcoming culture' in Germany, but also in spreading anti-immigrant sentiments, amplifying claims of exclusion, or even xenophobia. ${ }^{1}$ The comparative analysis of claims-making in the news media thus results in a snapshot of the state of solidarity in Europe.

Turning now to our comparative findings, we will first present an overview of how the debate unfolded chronologically across countries and peaked at different moments in time. We will ask whether there are country-specific dynamics in solidarity contestations salient in the news, and will also look at potential differences between newspaper types to investigate expected differences between tabloid and broadsheet newspapers. After that, we turn to the organised contestants who drove these debates in the media, keen to know which voices became dominant, with which issues, and their positions regarding solidarity with refugees. Finally, we will take a look at how actors justify their positions about solidarity.

\section{Salience of solidarity debate}

By looking at the overall distribution of solidarity claims over time and across countries, peaks occur in correspondence with critical events, such as political decisions or negotiations at EU level, but also increased salience due to humanitarian crisis. Both article and claim frequency suggest that especially the increasing number of people dying in the East Mediterranean Sea and the failure of EU migration management to handle an unfolding humanitarian crisis created a European momentum of solidarity contestation in September 2015 (see Figures 4.1 and 4.2). This is tragically illustrated in the ways in which the photo of the dead body of Alan Kurdi, on a Turkish beach, was rapidly circulated on social media and picked up by mass media across Europe from early September onwards. It is interesting to note that many newspapers were actually overwhelmed by the social media diffusion of this picture, as journalists' ethical standards would commonly prohibit reproduction of images of dead people, especially under-age children in print media (Mortensen and Trenz, 
2016). Independently of whether newspapers decided to reproduce the picture or not, they nonetheless replicated the moral indignation that was expressed by the 'distant witnesses' of suffering.

Another instance of a European moment of solidarity contestation was the German chancellor Angela Merkel's call for solidarity: 'Wir schaffen das' ('We can do this'), which was widely quoted and which was part of the government's decision to grant accommodation to high numbers of civil war refugees from Syria. As this decision de-facto meant a suspension of the Dublin Regulation, which stipulates responsibility for asylum applications in countries of firstarrival, it was debated very controversially between member states, some of them accusing Germany of breaching European solidarity. September 2015 was also the month of political controversy and negotiations at EU level, given that the EU ministers voted on - and rejected - the EU Commission's plan to redistribute 160,000 refugees between EU member states.

The November 2015 Paris attacks or the New Year's Eve 2015 sexual assaults at Cologne's train station in Germany, instead, were experienced as trauma and, as such, possibly linked to the spread of anti-refugee sentiments across countries and newspapers, to some extent reversing the pro-refugee solidarity moment of September 2015. Peaks in news coverage of these events were, however, consistently lower than the solidarity momentum of September 2015, indicating not only a change in mood, but also of agendas in public debates turning their attention away from specific groups of refugees to generalised anti-immigration and anti-foreigner sentiments.

After September, salience decreased in all countries, and debates more closely followed national dynamics focusing around events that did not gain European momentum (see Figures 4.1 and 4.2). Some examples of heated solidarity debates, with high peaks of attention that nonetheless remained nationally

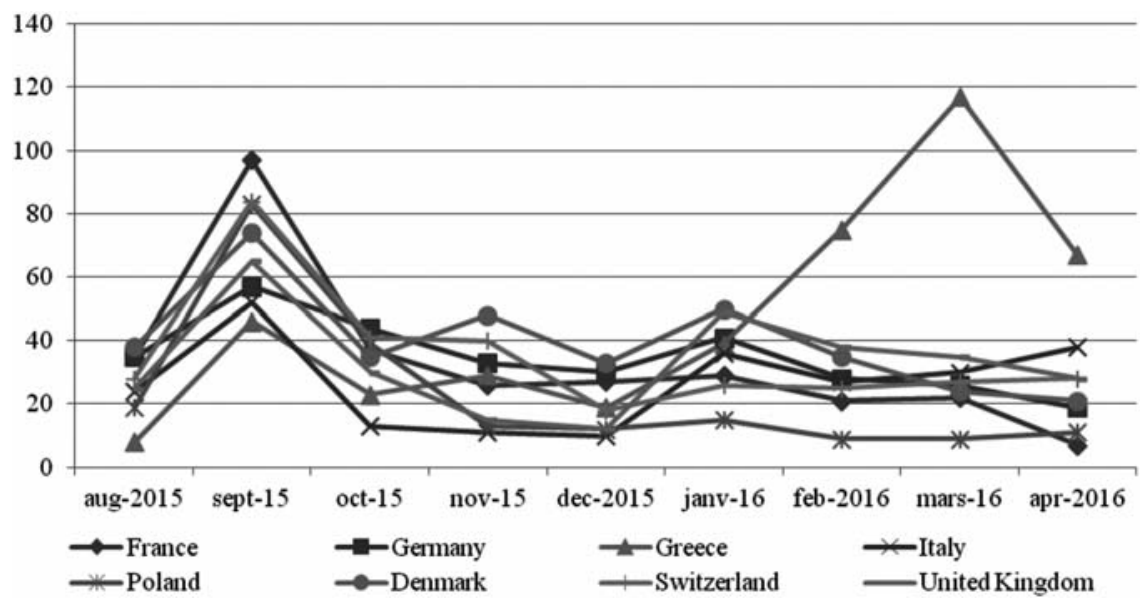

Figure 4.1 Total number of articles over sample time period 


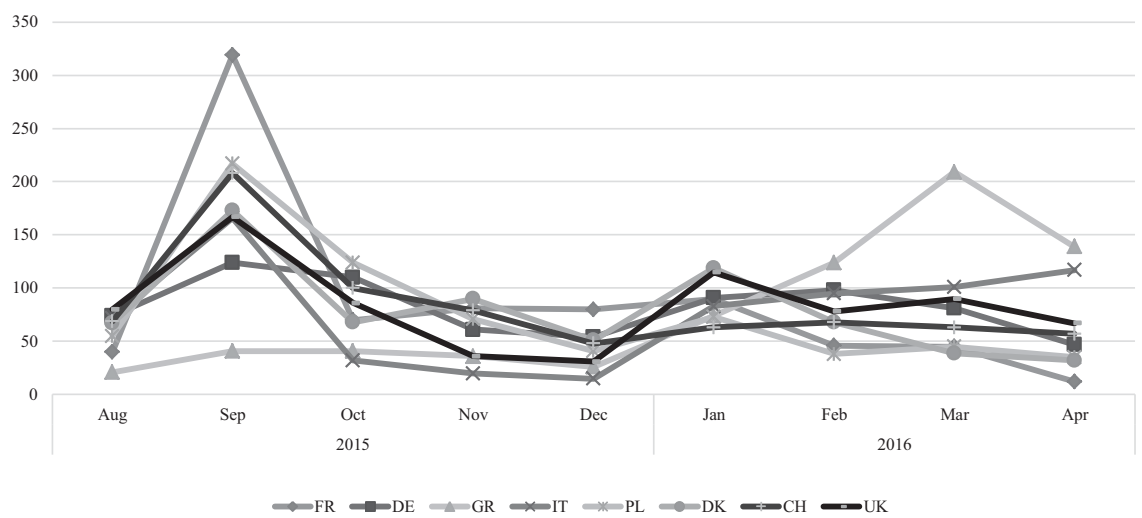

Figure 4.2 Total number of claims over sample time period

confined, were Denmark's infamous 'jewellery law', which allowed authorities to take valuables and cash from refugees, and the EU-Turkey agreement, which peaked in Greek newspapers in March 2016.

These specificities show that despite the similar patterns of news coverage (Figure 4.1) that broadly followed European events, we cannot speak of a convergence of contestations across countries (Figure 4.2). After the 'European momentum' of September 2015, a national re-appropriation of the transnational 'refugee crisis' took place. Public debates took different routes in different countries from late autumn 2015, as they responded to domestic events and policies and the diverging dynamics of contestation they unleashed. The two converging peaks of September 2015 and January 2016 were thus profoundly different. The first reflected a common supranational momentum, which was lost in the renationalisation of the public sphere in the following months, thereby triggering national claims-making, which increased in early 2019 due to follow-up events or policy decisions taken by national governments.

Our findings support research in media and communication studies that mass mediated debates react to 'real life events', but develop dynamics of their own via which such events are constructed, selectively amplified and framed in specific ways in the interplay between public claims-makers and journalists (Couldry et al., 2010; Dayan and Katz, 1992). Increased numbers of incoming refugees do therefore not determine but rather act as a trigger of public debates. Mass mediated public debates follow their own rules, selective logics, and framing devices, which all contribute to the construction of the so-called 'refugee crisis' as a 'media event'. In order to further validate this assumption, we can simply contrast the diachronic trend of public debates in terms of articles and claims with the development of the number of incoming refugees, measured in terms of asylum applications. If public contestations mirrored objective reality, then the higher numbers of asylum applications would also increase the likelihood of coverage in proportional terms; their media salience should reflect 
'real world' events and trends, thus triggering media contestation and news coverage in general. By contrast, lower numbers of asylum seekers would translate into lower levels of claims-making and media coverage in general.

Figure 4.3 shows numbers of first time asylum applicants. It confirms very similar patterns of asylum-seeking across the eight countries, and this seems to nourish the expectation that a similar diachronic pattern of debates should be found in the news media. While the European momentum of solidarity contestation of September 2015 corresponds indeed with a rise of asylum applications in all countries, the news coverage during the following months, however, hardly follows the same pace as asylum requests (see Figure 4.3). In particular, the second peak of asylum requests in February 2016 with even higher absolute numbers than in autumn 2015, did not lead to a second European momentum of solidarity contestation. In other words, discursive dynamics in the public sphere follow, at least partly, a logic of public-claims-making that is only loosely coupled with (but also not decoupled from) real time events. Specifically, the acuteness of the suddenly 'exploding' numbers of refugees in September 2015 and the connected 'surprise' effect may here be seen as prime expressions of a media logic of news values with 'new', sudden, surprising events being deemed more newsworthy than 'old news' (O'Neill and Harcup, 2009). The 'refugee crisis' of September 2015, thus can be singled out as a 'media event' in all countries, and this event of shared attention has not only to do with objective grievances, but also with the selective biases of news media and the strategic posture and claims-making capacity of actors in the media sphere.

\section{Protagonists of solidarity contestations in the news}

The construction of media events is largely determined by the protagonists involved in solidarity contestation. For this reason, it is essential to have a closer look at 'claimants'. Our analysis shows that organised claims-makers can

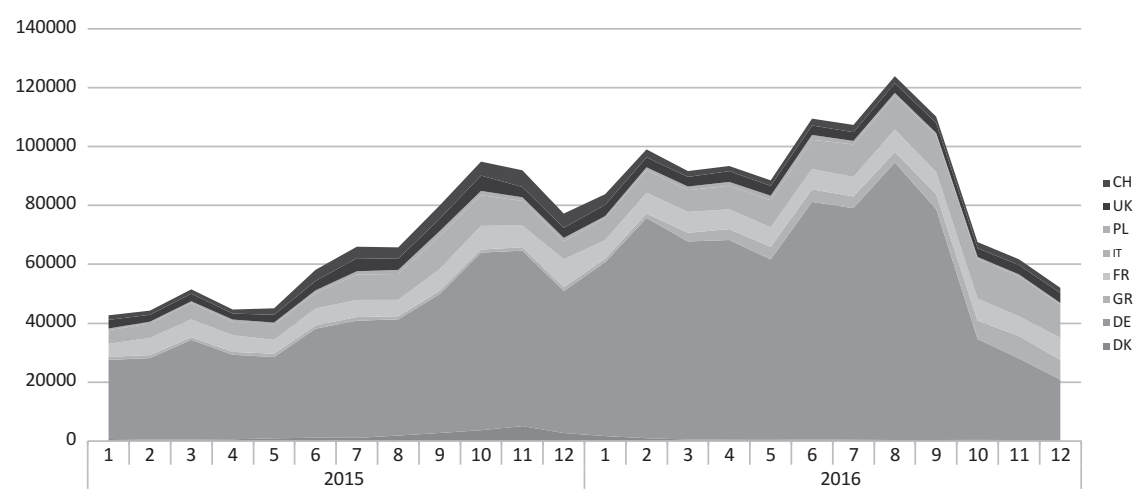

Figure 4.3 Number of first time asylum applicants during the 'refugee crisis' Source: Eurostat 2018 
be considered as the primary definers of the 'refugee crisis' in the mass mediated public sphere. For reasons of comparison, we focus here on the relative salience of three main groups of organised actors: domestic state actors (government, political parties and courts), civil society actors (solidarity organisations, including NGOs, trade unions, churches, but also anti-solidarity groups or movements), and supranational actors (mainly EU institutions and the UN). A fourth group is included in the analysis, as it represents individual citizens whose claims are indicative of broader collective mobilisations (for instance, with regard to acts of solidarity) but which sometimes also embrace the voices of refugees themselves.

The question of the relative salience of particular groups of organised actors in the public sphere relates to the question about the selective bias that news media apply when highlighting some claimants over others. While for obvious reasons we cannot measure 'real-time' and 'non-mediated claims' raised by actors in the public sphere directly, we can still plausibly assume that the news media are more inclined to report about the claims of organised actors. This means that we can delimit the selective bias of the news media by comparing the relative salience of particular actor groups of claimants across time, countries and different media formats.

Among the organised actors that dominated media debates on solidarity, it comes as no surprise that state actors were the main protagonists of solidarity contestation across all countries analysed. We can report very little variation between countries with the highest (Italy) and the lowest (Denmark) percentages, respectively (see Table 4.1). This is in line with other studies devoted to the EU and foreign news coverage, which show that journalists mainly rely on official state sources in framing international conflicts (Evans, 2010; Koopmans, 2010). This might be due to the fact that state authorities were also those mainly responsible for taking action in a situation defined as an 'emergency'.

Table 4.1 Actors of claims by country

\begin{tabular}{lllllll}
\hline & $\begin{array}{l}\text { State } \\
\text { actors and } \\
\text { political } \\
\text { parties }\end{array}$ & $\begin{array}{l}\text { Civil } \\
\text { society } \\
\text { groups/ } \\
\text { collectives }\end{array}$ & $\begin{array}{l}\text { Individual } \\
\text { citizens) } \\
\text { activists }\end{array}$ & $\begin{array}{l}\text { Supranational } \\
\text { actors }\end{array}$ & Unknown & $\begin{array}{l}\text { Total } \\
\text { (absolute } \\
\text { numbers) }\end{array}$ \\
\hline FR & $64 \%$ & $23.2 \%$ & $6.4 \%$ & $6.4 \%$ & $0 \%$ & $100 \%(764)$ \\
DE & $63.5 \%$ & $15.8 \%$ & $13.5 \%$ & $7.2 \%$ & $0 \%$ & $100 \%(740)$ \\
GR & $63.1 \%$ & $20.6 \%$ & $5.6 \%$ & $10.5 \%$ & $0.2 \%$ & $100 \%(753)$ \\
IT & $64.5 \%$ & $21.4 \%$ & $6 \%$ & $8 \%$ & $0.1 \%$ & $100 \%(701)$ \\
PL & $58.8 \%$ & $26.9 \%$ & $7.9 \%$ & $6 \%$ & $0.4 \%$ & $100 \%(699)$ \\
DK & $57.7 \%$ & $22.9 \%$ & $9.8 \%$ & $9.6 \%$ & $0 \%$ & $100 \%(707)$ \\
CH & $62.7 \%$ & $20.4 \%$ & $5.4 \%$ & $10.8 \%$ & $0.7 \%$ & $100 \%(796)$ \\
UK & $62.3 \%$ & $20.9 \%$ & $5.1 \%$ & $11.7 \%$ & $0 \%$ & $100 \%(788)$ \\
Total & $62.1 \%$ & $21.5 \%$ & $7.4 \%$ & $8.8 \%$ & $0.2 \%$ & $100 \%(5948)$ \\
\hline
\end{tabular}


The low cross-national variation in the salience of different actors is confirmed when dealing with civil society groups. With the exception of Germany, where the government took the solidarity initiative of pushing civil society into a secondary role (only $15.8 \%$ of all claimants), the percentages in all other countries vary between $20.4 \%$ for Switzerland and $26.9 \%$ for Poland. The salience of civil society is notably higher during the so-called refugee crisis, when compared, for instance, with the general coverage of immigration related news. According to EUROPUB comparative data from seven European countries for the period of 1994-2002, domestic civil society actors account for an average of $18 \%$ of all claims (Koopmans, 2007). This score of civil society claims-makers is considerably lower, as the same study elicits, when focusing on debates about EUlevel policies, where only $5 \%$ of claimants can be attributed to civil society actors (Koopmans, 2007). While EU debates tend thus to be state and government driven - with only low visibility of EU-level civil society and NGOs - the refugee solidarity debate provides an exceptional case, given the strong plurality and relatively high visibility of civil society actors, such as trade unions, advocacy groups and human rights organisations.

The overall shares of individual citizens and activists is low in comparison to state actors and civil society, and this is true for all countries, except Germany, where news coverage reported on an almost equal share of claimants from civil society and individual citizens. The 'welcoming culture' that involved many individual acts of solidarity, especially during the first month of debate, was thus widely covered in the news media. The share of supranational actors (such as the EU) is instead low in all countries. This is astonishing because the 'refugee crisis' was also a crisis of the European Union itself. It involved EU institutions, EU and international NGOs at all stages, and activated important processes of EU-level decision-making and problem-solving, such as the suspension of the Dublin Regulation or the efforts to find agreement on EU burden-sharing. This European dimension of the conflict was not made sufficiently visible in the public spheres of the various countries under analysis, which highlights how complex the relationship between politics and the (construction of) a European public sphere is. Above all, it evidences that national news media privilege a national focus of attention in their practices of news coverage.

\section{Issues of concern in refugee solidarity debates}

To investigate variation of issues that were considered to be of major concern for debate across countries, we rely on the following broad and aggregated issue categories, namely, migration management, integration, the background of refugees, consequences of the 'refugee crisis', and public/civic initiatives. Overall, data show that the debate in Europe was highly focused on migration management, which covered approximately two thirds of all claims in all countries (except for Germany) (see Table 4.2). Obviously, the refugee crisis raised major concerns about security and national border controls. This is 
Table 4.2 Issues of claims about the 'refugee crisis' by country (percentages)

\begin{tabular}{lllllll}
\hline & $\begin{array}{l}\text { Migration } \\
\text { management }\end{array}$ & $\begin{array}{l}\text { Integra- } \\
\text { tion }\end{array}$ & $\begin{array}{l}\text { Back- } \\
\text { ground of } \\
\text { refugees }\end{array}$ & $\begin{array}{l}\text { Con- } \\
\text { sequences } \\
\text { of refugee } \\
\text { crisis }\end{array}$ & $\begin{array}{l}\text { Publicl } \\
\text { civic } \\
\text { initiatives }\end{array}$ & $\begin{array}{l}\text { Total (abso- } \\
\text { lute numbers) }\end{array}$ \\
\hline FR & $64.9 \%$ & $5.2 \%$ & $10.9 \%$ & $11.9 \%$ & $7.1 \%$ & $100.0 \%(764)$ \\
DE & $49.9 \%$ & $8 \%$ & $12.3 \%$ & $16.2 \%$ & $13.6 \%$ & $100.0 \%(740)$ \\
GR & $66.1 \%$ & $2.9 \%$ & $11.6 \%$ & $11 \%$ & $8.4 \%$ & $100.0 \%(753)$ \\
IT & $65.5 \%$ & $2.6 \%$ & $15.4 \%$ & $7.1 \%$ & $9.4 \%$ & $100.0 \%(701)$ \\
PL & $62.4 \%$ & $4 \%$ & $10.6 \%$ & $9.9 \%$ & $13.1 \%$ & $100 \%(699)$ \\
DK & $66.5 \%$ & $8.9 \%$ & $7.6 \%$ & $7.8 \%$ & $9.2 \%$ & $100 \%(707)$ \\
CH & $66.1 \%$ & $4.2 \%$ & $8.4 \%$ & $6 \%$ & $15.3 \%$ & $100 \%(796)$ \\
UK & $68.1 \%$ & $3.2 \%$ & $15.9 \%$ & $8.6 \%$ & $4.2 \%$ & $100.0 \%(788)$ \\
Total & $63.7 \%$ & $4.9 \%$ & $11.6 \%$ & $9.8 \%$ & $10 \%$ & $100.0 \%(5948)$ \\
\hline
\end{tabular}

consistent with the high salience of state and institutional claims-makers, who typically raise such concerns and are expected to act as crisis managers who provide solutions (e.g., Boin et al., 2009; Heath, 2010). In turn, this means that public concerns that are more genuinely related to social inclusion and solidarity with refugees were less addressed. It is here where we observe the greatest variance in national debates, with Danish actors in news coverage focusing more on integration (and thus long-term effects of the inflow of refugees), the UK's concern lying more with the background of refugees (e.g., the situation in Syria), thus treating the 'refugee crisis' more as an external event, while Germany's focus was fixed on the short- and long-term consequences of the crisis.

We can contextualise these numbers by considering the dominance of political decision-makers in national news coverage in every country of our sample. The absence of integration related issues in national debates (with the absence of Denmark) could be explained by a rather constrained and narrow perspective on refugees as 'temporary visitors' and 'undesired others' among the main claimants. What appears as wide-spread disregard of long-term challenges might then, however, be due to the fact that political decision-makers dominate the pool of claimants and are, by profession, more concerned with migration management (and generally more negative towards refugee solidarity as we will show later) than with the aspect of integration and individual backgrounds. In this sense, news values favour claims-makers of the political executive as the relevant decision-makers, and therefore the most powerful protagonists of 'crisis'. This also leads to the increased salience of 'security' and 'crisis management' and, at the same time, marginalises voices from civil society. This lack of focus on individual circumstances and life stories supports a rationalisation of refugees presented as an anonymous 'group'; by disallowing the public to bear witness to refugee suffering, a sense of empathy and compassion is forestalled. 


\section{The 'refugee crisis' in the news media}

\section{Solidarity divides across countries}

A first look at the contested field of solidarity within national public spheres seems to reveal a constellation of countries, newspapers and/or actors that conforms to the cleavage between proponents and opponents of transnational solidarity. For instance, public contestations seem to pit Germany against Greece, state actors against civil society, left-wing against right-wing partisan actors, or citizens against foreigners and refugees. The picture, however, is infinitely more complex.

In order to better understand these constellations of contestation in the national debates, we first turn to the distribution of negative, neutral/ambivalent and positive claims regarding refugee solidarity in each country (Table 4.3). High levels of contestation refer to debates where most actors voice a clear position and where positive and negative claims are equally distributed. We find this to be the case in all countries, except for Germany, where most claimants were reluctant to express negative positions towards refugees and rather preferred neutral positions. Generally, positive claims prevailed $(40.2 \%$ on European average), yet this pattern is reversed in the case of the UK. At the time of the crisis, the UK was still an EU member state, yet not part of the Schengen area and geographically difficult to reach for refugees, meaning that it was less affected by the 'crisis'. Nevertheless, Britain was the country where claims-making was most negative. As we shall see in the discussion of country findings in Part II of this book (Chapters 6-13), the slight positive bias is mainly an effect of the solidarity campaigns during the first weeks of the crisis, but the claims became here, and in all other countries - more negative as the debate unfolded. In our comparative overview of user commenting to news (see Chapter 5), we will see that the predominantly positive voice of claims-makers did not resonate in readers' responses, which were overwhelmingly negative with regard to the question of whether solidarity should be provided for refugees.

The UK's position as the outlier in the European debate about solidarity becomes even more evident when analysing the variance of positions across

Table 4.3 Position across countries (distribution in \% and average -1 to 1 )

\begin{tabular}{|c|c|c|c|c|c|}
\hline & Negative & Neutrallambivalent & Positive & Total & $\begin{array}{l}\text { Average position } \\
(-1 \text { to } 1)\end{array}$ \\
\hline FR & $31.42 \%$ & $29.89 \%$ & $38.70 \%$ & $100 \%$ & 0.072796935 \\
\hline $\mathrm{DE}$ & $29.59 \%$ & $31.76 \%$ & $38.65 \%$ & $100 \%$ & 0.090540541 \\
\hline GR & $36.29 \%$ & $15.47 \%$ & $48.24 \%$ & $100 \%$ & 0.11954993 \\
\hline IT & $30.24 \%$ & $29.39 \%$ & $40.37 \%$ & $100 \%$ & 0.10128388 \\
\hline PL & $34.33 \%$ & $30.19 \%$ & $35.48 \%$ & $100 \%$ & 0.011444921 \\
\hline DK & $40.03 \%$ & $19.94 \%$ & $40.03 \%$ & $100 \%$ & 0 \\
\hline $\mathrm{CH}$ & $34.04 \%$ & $18.41 \%$ & $47.55 \%$ & $100 \%$ & 0.135099338 \\
\hline UK & $44.53 \%$ & $22.80 \%$ & $32.67 \%$ & $100 \%$ & -0.118666667 \\
\hline Grand Total & $35.05 \%$ & $24.75 \%$ & $40.20 \%$ & $100 \%$ & 0.051488197 \\
\hline
\end{tabular}


countries. The overall differences between countries regarding positions were examined by the Kruskal-Wallis test. Results indicate that samples differ significantly (chi-squared $=48.77$, df $=7, \mathrm{p}=0$ ); yet looking more closely at pairwise comparisons between individual countries reveals that this result is driven by the claims coded for the UK sample. Positions of UK claimants differ significantly from almost all other countries, with the exception of Poland and Denmark, which, on average, are closest to the UK's position (see Table 4.4).

Solidarity towards refugees does result in high levels of domestic contestation, as the shares of positional statements with supportive or hostile claims in Table 4.3 have shown. This raises questions about the constellation of actors responsible for the contentiousness of solidarity debates. Such an analysis of actors' positions, however, is faced with limits, as the sample size does not allow for systematic testing of ideological divisions along specific subcategories of actors, for instance, between government and opposition, or between representatives of competing political parties. However, a comparison of the main categories of actors is possible. At this aggregate level, we find two actor groups that are on average supportive of solidarity with refugees: civil society and supranational actors, among them mainly EU-related organisations, but partially also representatives of the UN (Figure 4.4). State actors and political parties tend to be negative on average, but what is more surprising is that this posture is not prevalent everywhere. Despite their insistence on issues of crisis management and border control, state actors position themselves mainly in solidarity with refugees in some countries (notably Greece and France), or remain on average neutral (e.g., in the case of Germany). The expected divide between state and civil society is thus limited to some countries only. It is most pronounced in Denmark and the UK, where governments took harsh lines to exclude the arrival of refugees, whereas in the case of Greece, the position of the left government and of civil society organisations rather complement each other. This reaction is asymmetric to the number of asylum seekers in these countries, again showing that actual numbers of asylum seekers as such are only a weak predictor of news attention. This furthermore means that the 'refugee crisis' triggered divisions in some countries, while it temporarily united others around the call for solidarity with refugees.

These findings corroborate that the constellation of actors imprints strongly on solidarity contestations in the public sphere. Everywhere, we can identify opponents and proponents of solidarity with refugees. While some non-institutional actors tend to defend the needs and demands of refugees consistently across countries and times (in particular, civil society organisations), there are other institutional actors that have a fluctuating position, with a tendency toward negativity. This is true particularly for state actors, whose shifting role has decisive consequences for public contestations about solidarity.

For a better overview of these different constellations, we list the frequency of the five most raised claims in each country, based on actor-issue-position combinations (Table 4.5). The four most quoted issues all relate to the field of migration management. As mentioned earlier, they deal with the question of 
74 The 'refugee crisis' in the news media

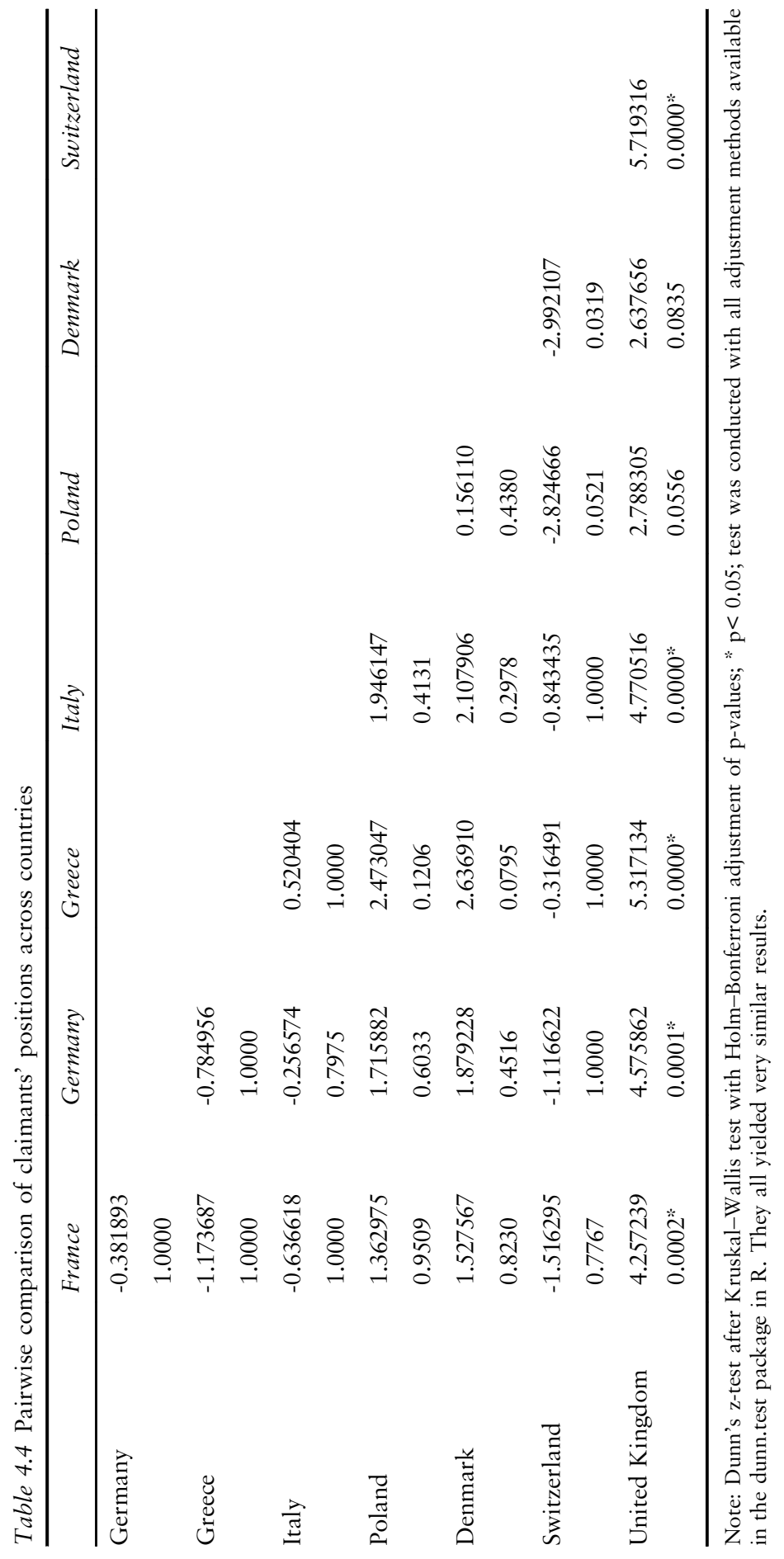


爱

Civil society groups/collectives

Individual citizens/activists

Supranational actors

State and political party actors

띰

Civil society groups/collectives

Individual citizens/activists

Supranational actors

State and political party actors

원

Civil society groups/collectives

Individual citizens/activists

Supranational actors

State and political party actors

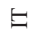

Civil society groups/collectives

Individual citizens/activists

Supranational actors

State and political party actors

$\ddot{2}$

Civil society groups/collectives

Individual citizens/activists

Supranational actors

State and political party actors

光

Civil society groups/collectives

Individual citizens/activists

Supranational actors

State and political party actors

己̈

Civil society groups/collectives

Individual citizens/activists

Supranational actors

State and political party actors

光

Civil society groups/collectives

Individual citizens/activists

Supranational actors

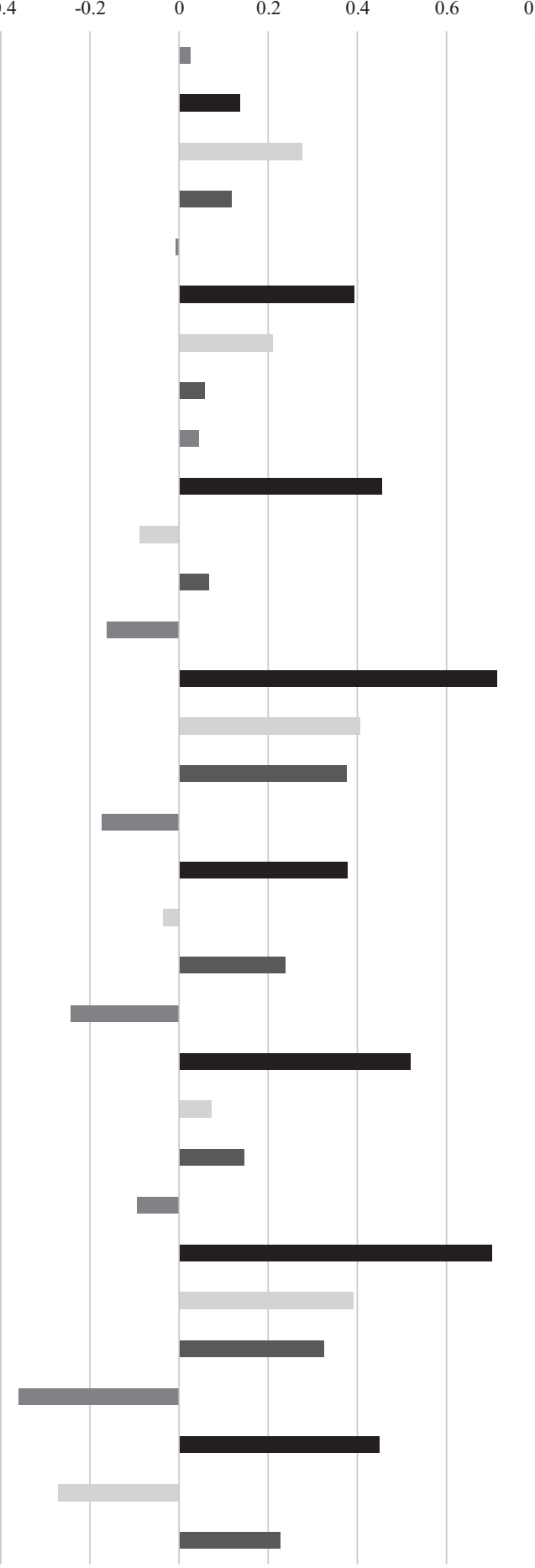

Figure 4.4 Average positions (-1 negative to 1 positive) across countries and actor types Note: The actor category 'unknown/unspecified' is excluded for reasons of readability, making in total 12 (out of 5,846) claims with unspecified actors (Greece: 2 counts, avg -1; Italy: 1 count, avg -1; Poland: 3 counts, avg 0; Switzerland 6 counts, avg 0.166666667). 'Average positions' does not take into account frequency of claims and should not be understood as frequency measures for the different actor categories. 
76 The 'refugee crisis' in the news media

Table 4.5 Five most frequent claims based on actor-issue-position combinations

\begin{tabular}{lrrrrrrrrr}
\hline & $F R$ & $D E$ & GR & \multicolumn{1}{c}{$I T$} & PL & DK & CH & UK & Total \\
\hline State-MigrMa-neg & 133 & 111 & 132 & 151 & 131 & 178 & 185 & 209 & 1230 \\
State-MigrMa-neutr & 104 & 125 & 54 & 134 & 118 & 72 & 74 & 94 & 775 \\
State-MigrMa-pos & 145 & 65 & 167 & 64 & 71 & 75 & 119 & 61 & 767 \\
CS-MigrMa-pos & 26 & 17 & 34 & 38 & 31 & 45 & 31 & 36 & 258 \\
CS-PubIni-pos & 17 & 27 & 20 & 27 & 41 & 28 & 53 & 14 & 227 \\
Total & 425 & 345 & 407 & 414 & 392 & 398 & 462 & 414 & 3257 \\
\hline
\end{tabular}

Note: $C S=$ civil society; PubIni = Public/civic initiatives; numbers are absolute numbers of claims raised showing the respective combination of values; combinations are ranked by the total number of claims (i.e., across all countries) per combination.

managing the inflow of refugees (e.g. by providing accommodation and reallocating them across the territory) while securing borders and coordinating migration policies at domestic, European and international levels. In relation to these four topics, state actors' claims are by far the most dominant and account for the greatest share of both positive and negative claims in all countries. The tonality of public debates is thus particularly dependent on the role of the state, and the way state actors position themselves in solidarity contestations. Only the fifth topic relates to typical solidarity related activities, such as volunteering and political activism, an issue that is not put on the agenda by state actors but by civil society.

Interesting differences appear in country comparisons of the most dominant claims in national debates. There seems to be a divide between two groups of countries. In Italy, Poland, Denmark, the UK and Switzerland, claims by state actors raising the issue of migration management and rejecting solidarity with refugees are most salient. This is not the case in the other three countries: in France, and especially in Greece, the most frequent claims are made by state actors about migration management who are positive toward refugees: in Germany, neutral. The so-called 'welcoming culture' is thus mainly reflected in public attitudes expressed in Greece as the country of first arrival of refugees and less in Germany, with which it is commonly associated. A 'welcoming attitude' also dominates debates by French political executives, while in all other countries, it is openly rejected by the majority of claims-makers representing government.

Our findings show that the main logic for selecting a claim and covering it in the news is its authorship (state actors) and not the negativity of its content. In turn, this indicates an overlap between news media and the public sphere when prominent organised actors are concerned: the news value of the prominence of state actors beats the prominence of the negativity of content. Accordingly, positively framed content has a good chance of making it into the public sphere as long as it is promoted by state actors. We find country differences with regard to the share of positive and negative attitudes expressed by state actors, less in the frequency of claims made by state versus civil society actors. These differences can be explained by the government's official position in the 
respective countries, which was highly negative in the case of the UK, Denmark, Italy and Poland, but more balanced or even positive in the case of Switzerland, France, Germany and Greece. This confirms the idea of governments as prime agenda definers in the refugee crisis, while the voice of civil society has comparatively little impact.

In addition to issues, actors, and their positions, we also looked into the justifications that claimants gave for their positions (see Figure 4.5). We categorised these into interest-based, rights-based, and identity-based justifications: Interest-based justifications were coded when the claims were concerned with efficiency, instrumentality and pragmatic notions of the issue of immigration (Eriksen and Fossum, 2004, p. 438). Such justifications are based on a more instrumental conception of solidarity. An example would be that solidarity is rejected due to institutions, strategies and procedures being overburdened with the task of managing a heavy inflow of refugees. A rights-based justification referred to more abstract, universal principles of justice and fairness. Such principles can be expressed in a justification based on human rights, democracy, civil and social rights. Actors justify or reject solidarity for refugees, for example, with humanitarian arguments, moral responsibilities, or explanations of what is fair and for whom. Identity-based claims justify the support or rejection of solidarity based on a community to which certain characteristics are attributed (Eriksen and Fossum 2004, p. 441). It focuses on a bounded, exclusive understanding of the 'we', while at the same time describing and demarcating an 'other'. Solidarity for refugees is rejected, for instance, because national citizens' privileges or their basic needs are perceived to be neglected. Actors give a pro-solidarity identity-based justification when claiming that in their country, support for the vulnerable is part of the national culture.

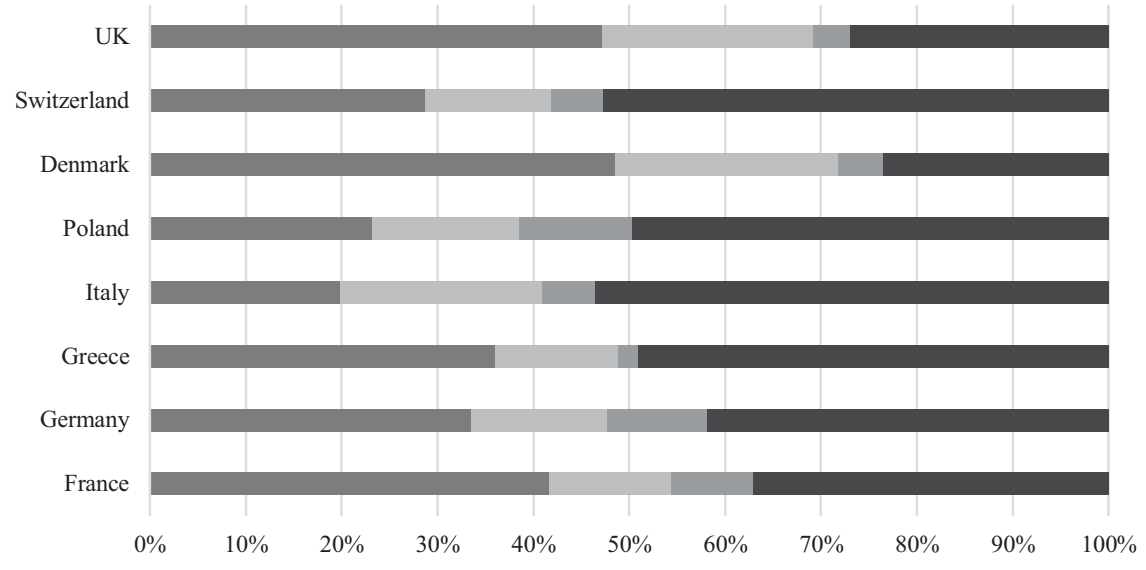

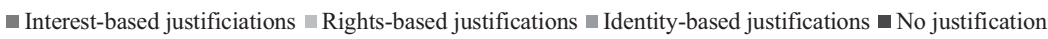

Figure 4.5 Justifications in claims by country 


\section{The 'refugee crisis' in the news media}

Overall, the debate over the 'refugee crisis' was mainly about values and the morally defensible limits of humanitarian assistance (Bauböck, 2018, p. 141). With regard to our analysis, the question then is whether and how claimants justified their respective stances on the question of solidarity with refugees. Country differences in this respect are less pronounced (see Figure 4.5). Claims with no justification represent by far the largest share, followed by interest-based justifications.

Connecting justifications to the respective position (see Table 4.6), claims without justifications were more positive, while interest-based justifications tended to be connected to a more negative stance towards refugee solidarity. When focusing on specific actors, we find that interest-based justifications seem to be reserved for political actors and their negative positions, rather than the other claimant groups that are, as already stated, more positive overall and use rights-based arguments to justify their opinions.

To sum up, solidarity contestations are patterned strongly by the constellation of actors, in particular by the specific position state actors take in regard to the needs and demands of refugees. The centrality of state actors seems to be augmented by the mass media, given that their news reporting practices tend to privilege politically powerful actors, thus providing them with more space and weight. This observation raises the question of whether different types of newspapers shape solidarity debates differently.

\section{Contextualising the debates: Differences across newspaper types?}

To approach this question of different patterns of solidarity contestation across types of newspapers, we compare positionality of claims across newspapers. It

Table 4.6 Percentages of justifications $(\mathrm{n}=5948)$ in all claims by position and claimant

\begin{tabular}{lrrllc}
\hline & $\begin{array}{l}\text { Interest- } \\
\text { based }\end{array}$ & $\begin{array}{l}\text { Rights- } \\
\text { based }\end{array}$ & $\begin{array}{l}\text { Identity- } \\
\text { based }\end{array}$ & $\begin{array}{l}\text { No } \\
\text { justification }\end{array}$ & $\begin{array}{l}\text { Grand } \\
\text { Total }\end{array}$ \\
\hline Political actors & & & & & \\
Negative & $13.8 \%$ & $1.7 \%$ & $1.8 \%$ & $10.8 \%$ & $28.0 \%$ \\
Neutrallambivalent & $9.4 \%$ & $1.4 \%$ & $0.7 \%$ & $9.0 \%$ & $20.4 \%$ \\
$\begin{array}{l}\text { Positive } \\
\text { Civil society actors }\end{array}$ & $6.4 \%$ & $6.0 \%$ & $1.0 \%$ & $9.1 \%$ & $22.5 \%$ \\
Negative & $2.2 \%$ & $0.4 \%$ & $1.5 \%$ & $3.4 \%$ & $7.5 \%$ \\
Neutrallambivalent & $1.3 \%$ & $0.3 \%$ & $0.3 \%$ & $2.4 \%$ & $4.2 \%$ \\
Positive & $2.0 \%$ & $6.8 \%$ & $1.2 \%$ & $7.1 \%$ & $17.1 \%$ \\
Unknown/unspecified & & & & & \\
Negative & $0.0 \%$ & $0.0 \%$ & $0.0 \%$ & $0.1 \%$ & $0.1 \%$ \\
Neutrallambivalent & $0.0 \%$ & $0.0 \%$ & $0.0 \%$ & $0.0 \%$ & $0.0 \%$ \\
Positive & $0.0 \%$ & $0.0 \%$ & $0.0 \%$ & $0.1 \%$ & $0.1 \%$ \\
Grand Total & $34.9 \%$ & $16.7 \%$ & $6.5 \%$ & $41.9 \%$ & $100.0 \%$ \\
\hline
\end{tabular}


might be possible that different newspapers lean more towards a specific opinion about solidarity with refugees, and that they thus might tend to grant more space and weight to actors that profess these positions themselves. This would lead to a more polarised public sphere, where different media outlets are associated with diverging political opinions or solidarity claims. Our data, however, do not support this proposition. Newspapers do not seem to polarise domestic debates and group audiences or readerships against each other. Even though tabloids are on average more negative (in interest-based and identitybased justifications) and less positive in rights-based justifications in their position towards refugees compared with broadsheets, the distribution of negative and positive claims in relation to justifications still remains the same: interestbased justifications and identity-based justifications are typically combined with a negative evaluation of the deservingness of refugees, while humanitarian justifications expectedly correlate with a strongly positive correlation across all newspapers (see Figure 4.6). In terms of news outlets, the public sphere of domestic solidarity contestation is integrated and thus not fragmented in different and diametrically opposed news readerships, who adhere to different values or are confronted with different ideological positions.

The lack of significant differences in tonality and justifications across media outlets seems to indicate that public debates about solidarity with refugees are highly integrated and contentious at the same time. Most probably, both aspects are tightly interrelated. Claimants are able to make their voices heard in various media outlets, thus participating in what we could call an integrated arena of contestation. At the same time, the high level of integration is responsible for the contentiousness of public debates, given that diverging positions are heard, addressed, opposed or refuted. The constellations of actors we have been able to unveil for each country are thus a factor that transcends various media outlets and imposes itself on national solidarity debates. This has consequences for the dominant position of state actors, as they can reaffirm their centrality across the spectrum of media outlets, and thus within the public sphere at large.

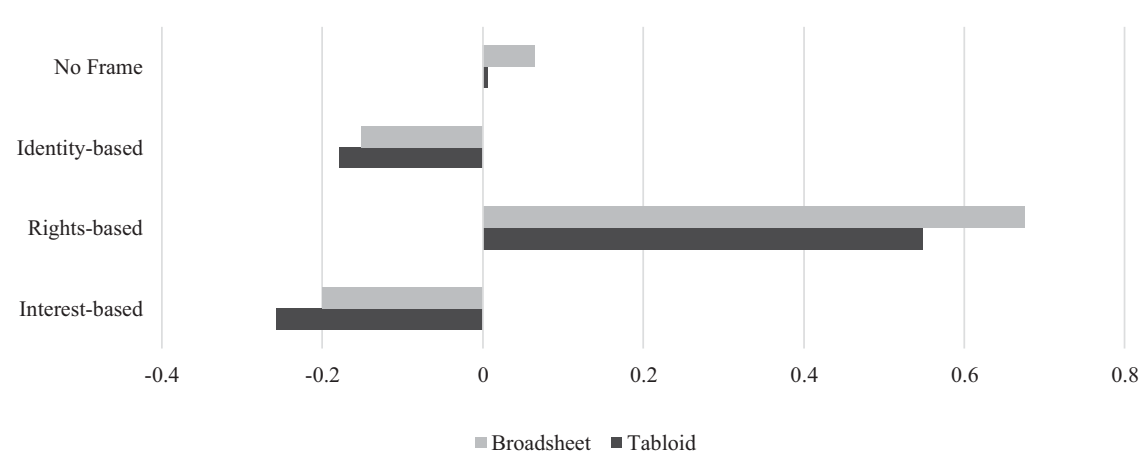

Figure 4.6 Average tone of claims and solidarity justifications across broadsheet/tabloid newspapers 
The high level of integration of the public sphere in terms of actors and media outlets might have consequences for the closure of national debates towards the outside. If public debates are dominated by a delimited number of actors, and if media outlets basically converge in terms of news values and claims-making privileges, then it might be harder for claimants from other countries and/or supranational governance levels to make their voices heard. This might limit the chances of promoting solidarity with refugees, particularly if this decreases the opportunities for international organisations, more supportive of refugees, to raise their voice within the national media. This question touches the issue of Europeanisation, and thus the degree to which national debates are permeated by actors and issues coming from other European member states, or EU institutions themselves. The contentiousness of solidarity debates might thus depend on the degree to which national arenas are closed or opened towards the outside.

\section{Europeanisation and transnationalisation of debates or re-nationalisation?}

For these purposes, we turn now to our last research question regarding the scope of claimants. This general proposition can be validated when looking at the territorial scope of actors involved in national solidarity contestations, asking whether actors located at the local, national or European levels profess different solidarity positions. To answer this question, we pooled the information about the actors' scopes across countries. Figure 4.7 shows quite clearly that actors are, on average, the most negative when they have a national scope, whereas claimants with a scope beyond or below the national context are substantially more positive over time. This seems to match the divisive nature of electoral politics at the national level, which has led to the upsurge of extreme right-wing parties in many European countries. By contrast, sub-national and EU politics follow quite different dynamics, as they are often inspired by the common search for bipartisan solutions to specific issues (the subnational level), or by the formation of consensus among different national perspectives. More broadly, our findings corroborate a

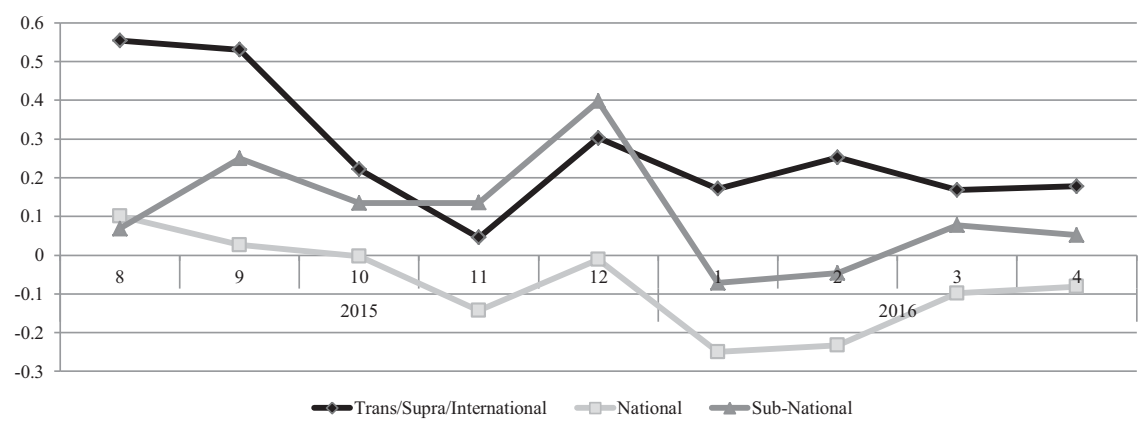

Figure 4.7 Average position of actors by scope across all countries over time 
structural contraposition of national and European scopes. There is a division between national governments looking for electoral support on the one hand, and the EU on the other, as the latter favours European solutions that are based on universal human rights. The EU finds itself in opposition to national governments, which refuse to comply with EU resettlement schemes. However, this contraposition has to be qualified in longitudinal terms. The average position of actors at all scope-levels seems to follow similar diachronic trends, and this particularly affects the average position of international or EUrelated actors, as they tend to become less supportive. This suggests that events like the Paris attacks in November 2015 and the sexual assaults in Cologne over New Year in 2016 influenced the discourse about solidarity with refugees towards the negative at all levels of political debate, even though transnational actors tend to stick to a more supportive attitudes towards refugees, even in more difficult times.

Looking into the average positioning of organised actors at different scopes by country reveals some remarkable differences. Figure 4.8 shows that Germany and Greece, for example, are the two countries in the sample where national actors have, on average, more positive claims about refugees, whereas in all other countries, national scope equals negative tonality. Germany stands out as having the smallest gap in positioning between the domestic and the European level, not surprisingly so, given its leadership in Europe and the relatively minor role the supranational cleavage plays in its electoral politics. A small gap can also be observed in Greece, standing out in particular when looking at the position of actors with a larger than national scope. Greece is the country in the sample with the most negative claims put forward by trans-, supra- or international actors. Possibly, this is due to the usual way the media portray European actors for their problem-bringing, rather than problem-solving capacity since the beginning of the debt crisis in 2008. Overall, solidarity claims in Greece seem to follow the opposite dynamic in terms of positions and scopes, when compared to most of the other countries in our sample.

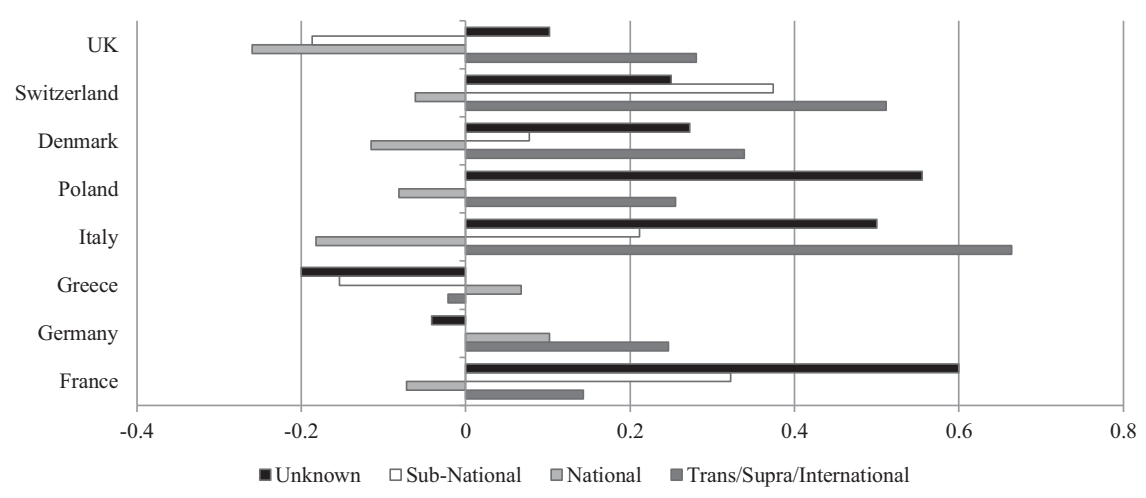

Figure 4.8 Average positioning of claimants by country/scope 


\section{Conclusions}

In this chapter, we have shown that public debate and contestation in the news media over the 'refugee crisis' emerged as a dynamic process of cultural exchange between European governments, oppositional parties, transnational civil society and segments of the public. The way solidarity is contested in the EU cannot be explained by looking at nationally confined debates only, nor can we reduce it to international conflicts in the form of cultural clashes between states. Instead, we can speak of a European field of solidarity contestation where attention was focused on the same events, common lines of arguments were developed, and positions were shared by different segments of the public.

By looking at media contestation over the refugee crisis, this chapter has uncovered the ambivalence of European solidarity between the needs to provide humanitarian assistance and the protection of national welfare and democracy. While one may disagree with the idea that the 'refugee crisis' was Europe's September 11 (Krastev, 2017b), it is nonetheless clear that the 'refugee crisis' has not only been about refugees, but has also been, and still is, about Europe itself. Our findings thus support the idea of a new dynamics of transnational solidarity contestations that is driven by a new ideational divide that replaces traditional ideological cleavages and that juxtaposes so-called communitarians with cosmopolitans (de Wilde et al., 2019; de Wilde and Zürn, 2013; Kriesi et al., 2012).

This dynamic exchange started with a genuine European momentum of solidarity, which dwindled quickly through the re-appropriation of the 'refugee crisis' by national actors, who were mainly driven by concerns and positions of national politics. We showed that solidarity contestation depends on particular moments. Such a moment for European solidarity was triggered by the dramatic events that unfolded throughout the summer of 2015. Yet, such a European momentum of what was emphatically referred to as 'welcoming culture' was neither embraced equally in all countries, nor did it last. National specificities re-emerged over the following months across public spheres based on a culture of denial and rejection of refugee solidarity and the closure of national and European borders. At the same time, our findings have suggested that the 'refugee crisis' has not yet become a genuinely European field of contentious politics. In fact, we observed the presence of heterogeneous forms of action, whereby protest does not dominate the large variety of country-specific repertoires.

Looking into the average positioning of public claims-makers, we showed that the public sphere is not the arena that can be held solely responsible for promoting anti-solidarity and anti-refugee attitudes, justifications, and positions. The overall position of claims was often favourable rather than unfavourable vis-à-vis refugees, while some emphasis was regularly put on humanitarian issues and not just on security concerns. In addition, civil society was particularly active, and most often with a positive stance. In particular, we showed consistently positive attitudes among civil society actors across countries. By contrast, we found that variation is stronger when looking at intra-national differences between organised actors: state and political actors stand out for 
their stronger involvement in negative claims, whereas civil society groups and collective actors engage more extensively in pro-refugee claims. However, state actors diverged considerably between countries in regard to their average position towards solidarity with refugees, thus having an important impact on the overall tonality of public debates within their country.

Claimants with a trans-, inter-, or supranational scope were overwhelmingly positive regarding solidarity with refugees, in contrast to national scope claimants. Our data reveal a considerable gap between the more cosmopolitan standing of the EU, on the one hand, against the national revival across member states, on the other. However, the gap tends to be diminishing, given the less supportive role of international and European institutions within national debates. Furthermore, we have identified relevant patterns of justifications, which claimants appeal to when justifying their claims. In particular, rights-based justifications are often used when claiming solidarity with refugees, while the opposite is true for interest- and identity-based justifications. This finding corroborates the opposition between supranationalism and renationalisation processes: National governments often refused to comply with EU resettlement schemes so as to defend their interests and identities, while EU actors favoured a solution based on universal human rights.

Ultimately, our findings show that there was potential in news media to mobilise solidarity beyond the borders of national publics. However, the promise of more solidarity with the refugees was especially linked to the European momentum of September 2015, after which solidarity simultaneously declined and re-nationalised. This momentum of solidarity is not an unusual experience, given that European integration has always been promoted as an expansive solidarity project. The EU is widely seen, for instance, as a humanitarian power that guarantees the free flows of labour, capital and people, propagates inclusive notions of citizenship or a European social model (Trenz, 2016). Yet, European solidarity can also turn into a more exclusive and protective project, where national interests become focal points of orientation. In this new constellation, European cooperation would be limited to the coordination of the fight against irregular immigration and of external border controls, with the sole objective of protecting national welfare regimes.

\section{Note}

1 We will deal with such public responses selectively in our analysis of social media user comments to political news in Chapter 5. 


\title{
5 Bottom-up solidarity contestation through social media
}

\author{
How Facebook users respond to \\ political news
}

\section{Introduction}

Our analysis of public claims-making in the previous chapter was built on the premise that news media constitute a representative arena for generalised public opinion formation processes. The way solidarity is contested in the news media would thus also reflect country differences of attitudes towards refugees. Contestants in the news would speak for particular segments of the public and the salience of either positive or negative attitudes in the news could even indicate trends in the development of public opinion turning more open or more hostile towards refugees. From existing studies, we know that media negativity in the coverage of immigration-related issues is also paired with negative attitudes expressed in public opinion (Boomgaarden and Vliegenthart, 2009).

The claims-making method is insufficient to understand this empirical link between media negativity and public opinion. However, by expanding claimsmaking to social media and the analysis of user reactions, we are able to grasp the opinions and claims of media consumers and thus understand better how this group of people receive and contest solidarity regarding refugees. By doing so, our analysis reaches beyond the discourse of organised actors as claims-making in news media, thereby shedding light on people who feel the need to engage in public discourse. In our study, we therefore make - to our knowledge - the first systematic attempt to include selected responses of single individuals to media claims of organised actors into the analysis of public debates. This goes significantly beyond existing analyses which have studied political contestation in the media arena in isolation from the responses of individual readers themselves. We build here on new opportunities offered by the spread of political news through social media, where selected user responses exist as an attachment to shared online news articles. One caveat is that these responses are highly selective and therefore not representative of the opinions of the general public. This observation is true insofar as only a minority of news readers make use of these commenting opportunities and that a self-selection bias of 'angry citizens' who raise their voice online might apply (Chen, 2017; Gonçalves, 2018). However, it also needs to be taken into consideration that these selective online debates increase their potential impact by creating broader visibility: comments are published on news sites that reach out to 
rather broad audiences and thus they are also read by others. Their effects on public opinion formation remains, of course, difficult to assess, but given the fact that an increasing number of people, especially young adults, mainly read political news online and through social media, such possible effects should not be disregarded.

In light of the news media's influence on opinion formation processes it thus seems overdue to take this arena of political contestation more seriously. For this purpose, we now turn to Facebook commenting in reaction to news, which has been shown to facilitate expressions of xenophobia and racism, especially with regard to debates on foreigners and immigration (Chaudhry and Gruzd, 2020; Graham, 2019). Such expressions might be even more prevalent in the context of the 'refugee crisis', which has presented a springboard for right-wing populist parties to reinforce xenophobic sentiment and nationalistic tendencies, openly criticising the trustworthiness of established news media themselves.

We will focus our analysis of user-driven bottom-up contestation on the case of the 'refugee crisis', and here in particular on public debates during the month of September 2015. That month was marked by a series of dramatic events that brought the 'refugee crisis' to the attention of a wide European audience, especially when images of Alan Kurdi, the boy from Syria who drowned on a beach in Turkey, were widely shared through social media, triggering a wave of solidarity mobilisation (Thomas et al., 2018). The visual images of distant human suffering allowed for the emergence of what has been called 'impromptu publics of moral spectatorship' (Mortensen and Trenz, 2016).

Given the complementary nature of this chapter to the claims-making analysis of mainstream media coverage (Chapter 4), we selected Facebook user comments that were posted in response to news articles on mainstream newspapers' Facebook pages. This suited our aim to collect data on the more hidden side of the public sphere: While our claims-making analysis allowed us to map the official voices and public interventions of organised actors, the online commenting analysis in this chapter collects the informal ways individual news readers of social media seize the chance to express their views and emotions and translate them into political speech from the bottom up. In this way, the following analysis adds to an understanding of solidarity contestation from below, considering users' Facebook comments as arenas for direct involvement in political discourse.

\section{Online news commenting: Theoretical considerations}

New and social media are increasingly used by readers to engage and debate the boundaries of what they perceive to be their political community and the desirability of solidarity among each other. The group of social media commenters might still constitute a niche, yet it is growing and becoming more active on mainstream newspaper sites on social media, thus arousing the attention of large audiences. What online commenters think about the deservingness of refugees, and how these commenters express themselves in response to political representatives is therefore of relevance to understanding how solidarity is negotiated 
within the public sphere. The existing literature does not provide clear indications about the effects of social media commenting on civic attitudes and democracy, because scholars are divided in their assessments. On the one hand, they emphasise the destabilisation effects of social media. In particular, social media and news commenting sites are often held responsible for the spread of hate speech and uncivic culture towards fellow citizens (Gerhards and Schafer, 2010; Michailidou et al., 2014; Rasmussen, 2014). On the other hand, media scholars have highlighted new opportunities, because the social media stimulate agenda-setting, more inclusive deliberations, identity building, and therefore also solidarity. Political debates are more civic, global, inclusive and accessible, empower disadvantaged groups and pluralise the public sphere in various ways (Dahlgren, 2013; Rauchfleisch and Kovic, 2016). This optimistic assessment stands in contrast to the former one, as this position assumes that social media stimulate an uncivic online sphere that is a potential threat to established solidarity relationships.

The analysis of user comments will not only provide new insights into public contestations, but also into the mobilisation of citizens' solidarity. Bottom-up mobilisation of solidarity is commonly analysed in terms of individual practices and attitudes (Gerhards et al., 2019; Lahusen and Grasso, 2018) and/or initiatives by civil society activists and grassroots movements providing support to vulnerable groups of the population (Kousis et al., 2018; Kousis et al., 2020). An investigation of bottom-up solidarity contestations in the social media allows new light to be shed on an important arena where citizens form their opinions and commit to social and political norms or values. Such an inquiry is interested in the ways in which reader-users express their opinions and emotions on Facebook. These expressions are of particular relevance, because they are placed in a public medium that is more visible than established news sites. ${ }^{1}$ The analysis of users' comments thus enables us to better understand how solidarity is contested within the public sphere in reaction to broadsheet and yellow press news on their respective Facebook pages.

The following analyses of Facebook comments will be driven by two overarching questions. On the one hand, we are interested in understanding whether users' comments can be treated as contributions to a meaningful debate between proponents and opponents of solidarity. The analysis will help to assess whether online commenting is a manifestation of a civic or uncivic public sphere. On the other hand, our investigation will attempt to map and analyse solidarity contestations by showing the extent to which solidarity emerges in reaction to news articles and the claims reported therein, and by indicating how strong opposition to solidarity with refugees is among readers of such news.

Individual users might decide to add a comment when confronted with the news coverage about the 'refugee crisis'. By doing so, they enter into some sort of collective, interpretative work through social media. They produce text in the form of comments, and these texts relate to the news content in very specific ways: They interpret the evidence presented in the newspaper articles, they support or reject claims raised by politicians and other organised actors in the news media, they ascribe political responsibility and they reflect on political 
consequences. User debates on social media are therefore not cut off from mainstream political debates as covered by the news media, neither do they develop in self-chosen isolation within closed communities. The meaning structures of user debates on open Facebook pages remain embedded and are influenced by the frames of interpretation used by actors in the mainstream media (Galpin and Trenz, 2019). User debates are to be considered, first and foremost, as a valuable contribution that adds to the plurality of public opinion formation in the democratic public sphere. In addition to journalists, intellectuals and political actors, who are dominant claimants in the news media, users can also exploit public channels in order to contribute to public discourse. To do this interpretative work, individual users cannot only relate back to claims-making of organised actors reported in the news media and support or reject their arguments. They can also relate to each other, engage in an exchange of arguments and come up with their own justifications as to why solidarity towards refugees is accepted or rejected.

The manners in which such an exchange of viewpoints is organised varies, however, in important ways. In line with our theoretical argument developed in Chapter 2, we wish to distinguish conceptually between two alternative scenarios: An online civic sphere of solidarity contestation and an online uncivic sphere of solidarity contestation. According to the first scenario, news readers' commenting practices on social media are part of an online civic sphere that enriches the traditional top-down ways of political communication by facilitating horizontal exchanges among citizens, making the media voice more plural and participatory, and thus building a more inclusive sphere for the formation of public opinion (Dahlgren, 2013). In this way, Facebook news sites offer platforms for people who feel the need to engage in the bigger debates, to respond to the claims in the posts curated by the newspapers, and subsequently to participate in democratic discourse.

This hypothetical scenario of an online civic sphere could be validated if commenting practices meet the following three criteria. First, we would expect online users to be responsive to news contents and to claims raised in the news media. Secondly, we would expect them to relate directly to refugees as 'objects' of solidarity (as coded) and to critically judge whether or not solidarity should be granted to them. And thirdly, we would expect users to seek political influence, i.e., to translate an informal and individual opinion into formal and collective political action. Taking voice through individual commenting should be paired with demands for collective action: 'we shall', 'let's do'. Such calls for actions could try to oppose or subvert solidarity with refugees, but they could also aim to expand bonds of solidarity towards refugees, either by reference to emotions such as pity, or by references to universal principles supporting a notion of transnational solidarity. In all these cases, individual users would motivate and encourage each other to swing to collective commitment and to support a cause for or against solidarity with refugees. As such, they would become secondary definers of the 'refugee crisis', because they would not simply accept or reject claims raised by organised actors in the media, but also bear 
witness, engage in their own collective practice of interpretation of the situation and take sides on the question of refugee solidarity.

At the same time, online participatory news formats and, in particular, user commenting on social media and online news sites have become the object of a harsh normative critique (Gerbaudo, 2014; Krämer, 2017). According to our second scenario - the uncivic sphere - online publics are defined as nonresponsive and marginal, as they lack public visibility. The online media would engage selected citizens, but these debates would remain detached from political deliberations and formal decision-making contexts, and they would have minimal impact on public opinion and/or political outcomes (Givskov and Trenz, 2014). Considering the general relationship between news content and commenting on Facebook, the online publics would be fragmented into different opinion bubbles, closed communities where users mainly exchange opinions among the like-minded (Sunstein, 2009). Online fragmentation would further affect users' capacities to talk beyond their individual stand, to express informed opinions and to defend values of social justice and solidarity. Closed within their bubbles, online users would position themselves in increasingly polarised ways. Such a polarised constellation of online discourse would be paired with increasing distrust and enmity between the opposing camps, who would engage primarily in an exclusive and non-solidary rhetoric against their political opponent or against migrants as undeserving outsiders. There would, in other words, be a general tendency among online users to adopt what, in line with Benjamin Moffitt (Moffitt, 2016), can be called a populist style that challenges the performance of democratic (representative) politics and displays or amplifies primarily the positions taken by populist parties in the electoral contest. The online uncivic sphere would unfold through a populist style of user debates that is exclusive and anti-solidary either against the political opponent or against people in need. In terms of solidarity contestation, we argue that this scenario can be validated by ascertaining the extent to which online publics voice their discontent with established representative politics, restrict rather than expand solidarity relationships and target political enemies or refugees in an exclusive way, i.e. as undeserving of solidarity.

\section{Engagement in social media debates: The civicness of citizens' commentary on Facebook news sites}

Before diving into the analysis of how solidarity contestation among news readers unfolded, we show in which ways users engaged in the news debates during the month of September 2015 (see Chapter 3 for the sampling strategy). The analysis of user comments is restricted to this one month because our overview of claims-making evidenced that public interventions peaked at this moment of time in all countries under investigation (see Figure 4.2 in Chapter 4). Other studies have shown that sympathy with refugees peaked for a relatively short period and only in some countries (Thomas et al., 2018). Additionally, news and social media did not become a unified space 
of solidarity mobilisation, because this space continued to be fragmented along national lines (Triandafyllidou, 2018).

Our own analysis does not allow us to portray developments across time and national fragmentations in the intensity of bottom-up contestations. However, our data provide evidence that news readers in all countries under study were heavily engaged in commenting on news articles on the refugee crisis. Even though solidarity remained contested within and between countries, the coverage of the Syrian war and of the human histories of war refugees created a European momentum of public sensitivity. This focused attention on the 'refugee crisis' and was clearly visible not only in the contentious dynamics of public claims-making in the news media (see Chapter 4), but also correspondingly in the practice of user engagement on social media during September 2015. It is therefore all the more important to establish a linkage between public claims-making of organised actors in the news and readers' responsiveness at the individual level in the social media.

In this part we will provide more substance to these general observations. First, we need to clarify how commenters engaged with the posted articles, that is, whether they engaged directly with the respective claims or topic of the news articles, or whether they expressed their opinions independently of the post. After that, we focus on those comments that are directly related to refugees as potential recipients of solidarity. We will look into the tone of commenters as they expressed opinions and emotions regarding solidarity with refugees, and we identify the justifications they use to back their views.

In order to understand user comments, we first need to know their stance regarding solidarity toward refugees in the claims of the articles posted on Facebook, in other words, the posts to which commenters reacted. We are interested in the responsiveness of user comments on Facebook; we need to have knowledge about how solidarity was contested in the articles posted on Facebook. Figure 5.1 suggests a positive trend in the news in the sense that most claims were supportive of solidarity with refugees during the month of September in this sub-sample. This applies independently of the positioning of the respective government in these countries. In Denmark and Poland, whose governments were officially rejecting European solidarity with refugees, the average tone in the news posted on Facebook was even more positive than in countries like Greece and Germany, where the governments welcomed refugees from Syria.

By giving information on the tone in the sampled Facebook articles, as well as the sampled Facebook comments, we can show that both texts were interrelated in terms of content and message. Our data does not substantiate the assumption that social media users are part of an uncivic public sphere that is detached from public deliberations and secludes itself in egocentric bubbles of like-minded people. On the contrary, as we will show, we found that commenting is generally responsive to news coverage and often motivated by a proactive engagement in public debate. We distinguish three forms of motivation: 1) to make a general contribution to the debate raised by the article, 2) to 


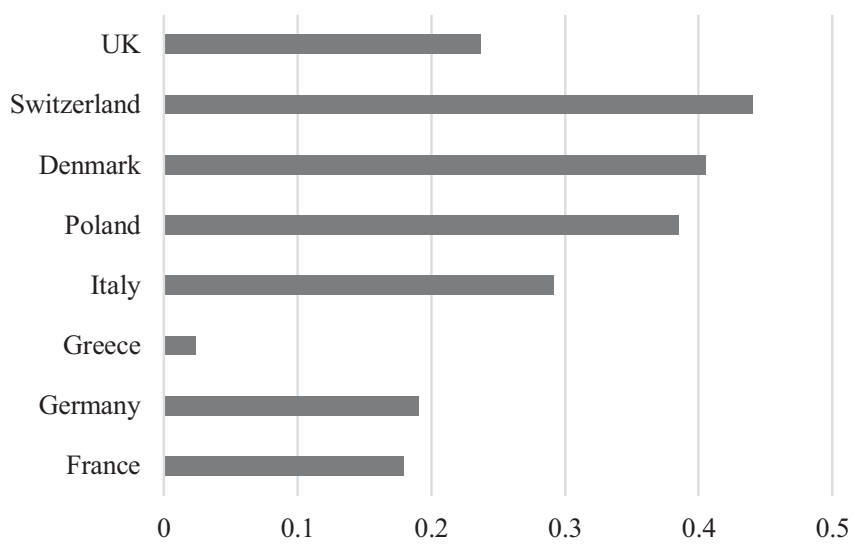

Figure 5.1 Average tone of claims regarding solidarity with refugees in articles posted on Facebook

respond to a claim by an organised actor, and, 3) to make an independent contribution to the debate outside the thematic context of the article. The second form is obviously the most inter-discursive, but also the first and the third can be considered to be - from a deliberative point of view - valid contributions to a political debate.

The responsiveness of commenters on Facebook and the degree to which they enter into an exchange of opinion was very high: $74.4 \%$ of all commenters responded to news content on the refugee crisis and only $25.6 \%$ of the users posted unrelated independent statements. Most of them, however, were still within the thematic context of the refugee crisis. Among those comments related directly to news content, the majority $(39.2 \%)$ responded to the general issue raised in the main article, but every third comment $(35.2 \%)$ also responded to a claim raised by an organised claimant in the main article (Trenz et al., 2020, p. 158). Regarding national specificities, interesting differences can be shown (see Figure 5.2). Italy, Germany and Greece appear as the countries with the highest level of bottom-up contestation during the refugee debate, i.e. those countries where claims in the news, most of them raised by elites and political representatives, are most challenged on social media. Low levels of bottom-up politicisation, as in the case of Poland or the UK, point instead to a congruence of opinion expressed by political elites in those countries (most of them representing the national government) and online news readers. There is, in other words, less motivation for online users to be emotionally engaged in the debate as, overall, they feel represented by the claims raised in the news media.

The engagement of Facebook users with news articles becomes even more palpable when looking at the way commenters react to the posted articles. Table 5.1 sheds light on the response patterns to journalistic outputs. We find that the great majority of commenters $(80.1 \%)$ took sides in the sense of either affirming or opposing claims or issues in the posted news article, $19.9 \%$ 


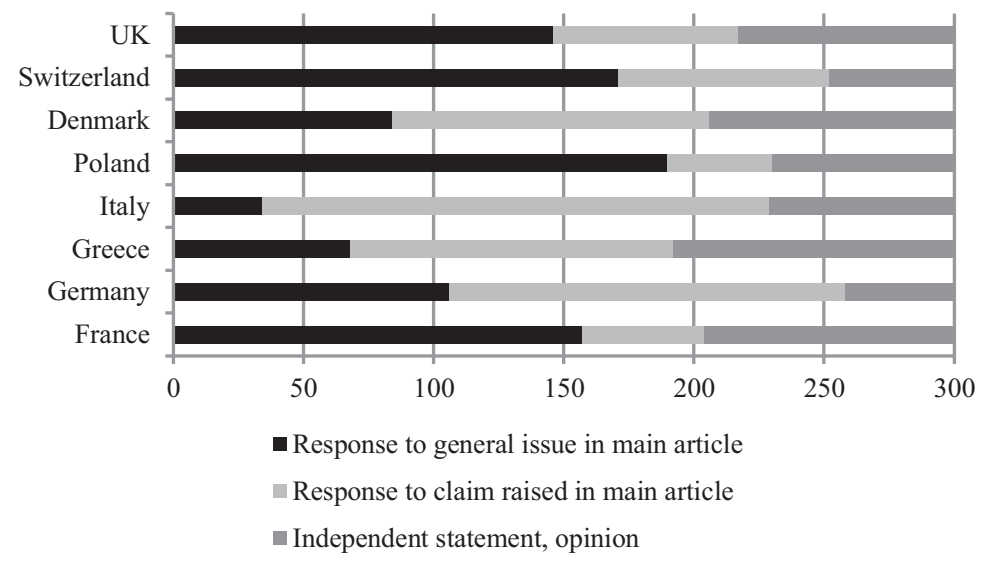

Figure 5.2 Overview of user engagement across countries and reactions (types of comments in frequencies)

Table 5.1 The type of comment by position of commenter towards the issue/claim in the posted article (frequencies in brackets) ${ }^{2}$

\begin{tabular}{lllll}
\hline & $\begin{array}{l}\text { Negativel } \\
\text { opposing }\end{array}$ & $\begin{array}{l}\text { Neutrall } \\
\text { ambivalent }\end{array}$ & $\begin{array}{l}\text { Affirmativel } \\
\text { supportive }\end{array}$ & Total \\
\hline $\begin{array}{l}\text { Response to general issue in } \\
\text { main article }\end{array}$ & $29.6 \%(463)$ & $10.1 \%(158)$ & $14.3 \%(224)$ & $54.0 \%(845)$ \\
$\begin{array}{l}\text { Response to claim raised in } \\
\text { main article }\end{array}$ & $17.4 \%(272)$ & $9.8 \%(154)$ & $18.8 \%(294)$ & $46.0 \%(720)$ \\
\begin{tabular}{l} 
Total \\
\hline
\end{tabular} & $47.0 \%(960)$ & $19.9 \%(428)$ & $33.1 \%(626)$ & $100 \%(1565)$ \\
\hline
\end{tabular}

remained neutral or ambivalent. Among those, $47 \%$ were in opposition to the general issues or claims in the main article, and only $33.1 \%$ expressed support. User commenting was, in this sense, found to be more critical than affirmative.

To understand what is at stake in commenters' contestation regarding solidarity towards refugees, we looked at the issues (or concerns) raised in debates. The numbers in Table 5.1 indicate that there is a tight linkage between journalism debates and online commenting: Commenters tend to have similar topics in mind, because the distribution of issues among their comments largely mirrors the distribution of issues addressed by organised actors in news articles (see Figure 5.3). Basically, users stick to the topics raised by journalists and the organised actors quoted in their articles.

This general finding has to be broken down according to countries in order to assess the extent to which commenters focused on the same issues. We would expect that attention should be distributed unequally with different issues brought into focus by commenters in different countries, because national newsmaking is focused on country-specific topics and national audiences (Pfetsch, 


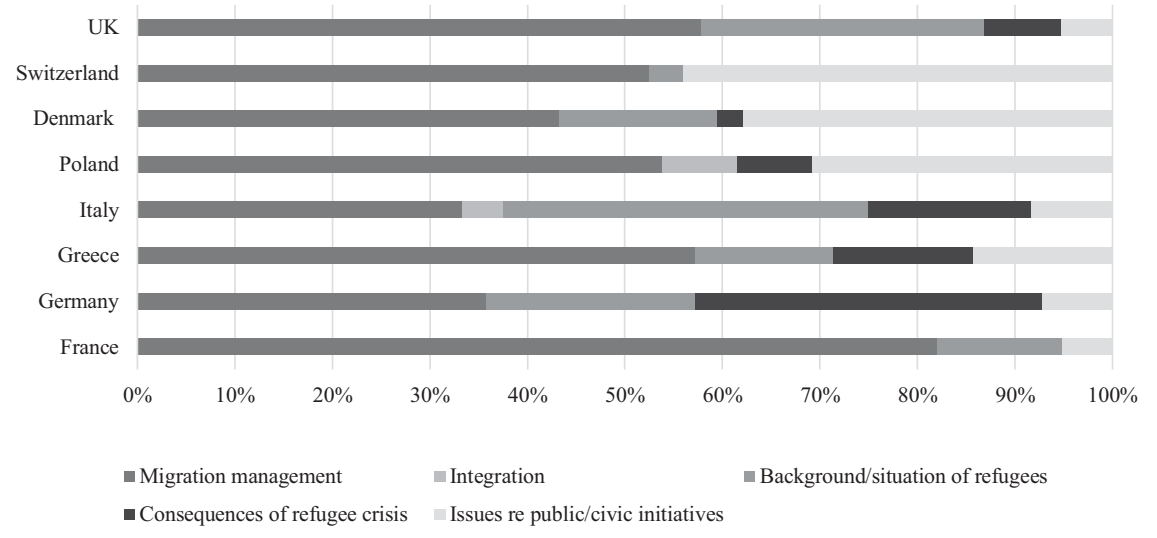

Figure 5.3 Overview of issues discussed in articles posted on Facebook

2007). However, as shown in Table 5.2, we did not find a clear pattern in the cross-country distribution of issue attention. Rather, we can see a partial congruence of agendas, because social media users tend to raise similar issues of concerns in all countries under investigation, when articles reporting on refugees are at stake. Commenters in all countries focused on the 'refugee crisis' as a management problem that required the state to regain control and adopt adequate policies. Additionally, they voice concerns regarding the general consequences of the crisis and the problems created by refugees. Non-state civic activities also figured prominently, especially in Denmark and Switzerland. The background situation and the fate of refugees were also discussed to some

Table 5.2 Cross-country distribution of issues in comments

\begin{tabular}{llllllll}
\hline & $\begin{array}{l}\text { Migra- } \\
\text { tion } \\
\text { manage- } \\
\text { ment }\end{array}$ & $\begin{array}{l}\text { Inte- } \\
\text { gration }\end{array}$ & $\begin{array}{l}\text { Back- } \\
\text { ground/ } \\
\text { situation } \\
\text { of } \\
\text { refugees }\end{array}$ & $\begin{array}{l}\text { Con- } \\
\text { sequences } \\
\text { of refugee } \\
\text { inflowl } \\
\text { crisis }\end{array}$ & $\begin{array}{l}\text { Issues } \\
\text { regarding } \\
\text { publicl } \\
\text { civic } \\
\text { initiatives }\end{array}$ & $\begin{array}{l}\text { Unkn- } \\
\text { own }\end{array}$ & Total \\
\hline France & $49.3 \%$ & $3.0 \%$ & $7.3 \%$ & $21 \%$ & $17.7 \%$ & $1.7 \%$ & $100 \%$ \\
Germany & $16.3 \%$ & $0.3 \%$ & $17.3 \%$ & $40.7 \%$ & $22 \%$ & $3.3 \%$ & $100 \%$ \\
Greece & $54 \%$ & $0 \%$ & $18 \%$ & $10.3 \%$ & $17.7 \%$ & $0 \%$ & $100 \%$ \\
Italy & $33.3 \%$ & $1 \%$ & $21.3 \%$ & $5 \%$ & $21.3 \%$ & $18 \%$ & $100 \%$ \\
Poland & $25.3 \%$ & $9 \%$ & $15 \%$ & $30.7 \%$ & $18 \%$ & $2 \%$ & $100 \%$ \\
Denmark & $44.3 \%$ & $0.3 \%$ & $13.7 \%$ & $7.7 \%$ & $31 \%$ & $3 \%$ & $100 \%$ \\
Switzerland & $29.3 \%$ & $4.3 \%$ & $20 \%$ & $14.3 \%$ & $31 \%$ & $1 \%$ & $100 \%$ \\
UK & $49.3 \%$ & $0.7 \%$ & $30.7 \%$ & $8.7 \%$ & $10.7 \%$ & $0 \%$ & $100 \%$ \\
Total & $37.7 \%$ & $2.3 \%$ & $17.9 \%$ & $17.3 \%$ & $21.2 \%$ & $3.6 \%$ & $100 \%$ \\
\hline
\end{tabular}


degree, especially around the case of the drowned Syrian boy, Alan Kurdi. In other words, in the heat of the 'refugee crisis' of September 2015, Europeans largely talked about the same issues of concern, in spite of divisions between national media and public spheres.

Overall, these findings point to a solid linkage between claims-making inputs about refugee solidarity and online user responsiveness. They thus confirm the first scenario of an online civic culture. For the great majority of news readers, online commenting is an opportunity to actively intervene and take sides in a controversial political debate. This is why issue agendas of online commenting and mainstream news coverage largely overlap. We find little evidence for fragmented user debates among individual citizens that are decoupled from mainstream public debates of organised actors in the news media. These findings lend some support to other research on social media commenting (Hille and Bakker, 2014). Instead of understanding comment sections on mainstream news Facebook pages as an outlet for blatant political outrage and disillusionment that ignore discourse in the public sphere, it is important to distinguish between different contexts and platforms where commenting takes place, linking mainstream or niche news outlets with different segments of audiences.

\section{Engagement with refugee solidarity: Reactions to the witnessing of human suffering}

In this section, we turn from a general discussion of the civicness of online debates at the individual level and their linkage to claims-making of organised actors to the more specific question of how refugee solidarity is contested in Facebook news commenting forums during the 'refugee crisis'.

Turning now to our sample of Facebook comments in response to the above articles, it is important to establish how many of these comments engaged in solidarity debates with refugees. Facebook news readers are of course free to comment on any related or unrelated issues they consider to be of relevance. Commenters who express a position about solidarity can do this either by maintaining high levels of interdiscursivity, i.e. a reaction to posted content in the news, or a response to a solidarity claim, or out of context of the posted article, but related to the broader context of the refugee crisis. In the same vein, commenters who do not express themselves on the issue of refugee solidarity can also still engage with the posted material in meaningful ways and engage in political debates, yet without relating to refugees as objects of solidarity (for instance, they may contest the position of a political representative on an issue unrelated to the case of refugees).

To establish how important the issue of solidarity with refugees was for them, we distinguish between comments where commenters refer to the issue of refugee solidarity (object=yes: all comments where refugees as objects of solidarity were recognisable), and comments on any other, not further specified issue $($ object $=$ no). These represent $83.9 \%$ of all comments found on Facebook news sites with the object filter on 'Yes' (see Table 5.3). Table 5.3 shows 
Table 5.3 Subsampling comments with position regarding refugee solidarity $($ Object $=$ Yes $)$

\begin{tabular}{lcll}
\hline & Object: No & Object: Yes & Total \\
\hline France & $8.7 \%$ & $91.3 \%$ & $100 \%$ \\
Germany & $33.0 \%$ & $67.0 \%$ & $100 \%$ \\
Greece & $8.0 \%$ & $92.0 \%$ & $100 \%$ \\
Italy & $20.3 \%$ & $79.7 \%$ & $100 \%$ \\
Poland & $20.3 \%$ & $79.7 \%$ & $100 \%$ \\
Denmark & $22.7 \%$ & $77.3 \%$ & $100 \%$ \\
Switzerland & $2.3 \%$ & $97.7 \%$ & $100 \%$ \\
UK & $13.3 \%$ & $86.7 \%$ & $100 \%$ \\
Total & $16.1 \%$ & $83.9 \%$ & $100 \%$ \\
\hline
\end{tabular}

further that the Facebook commenting function was used for an intense and focused debate on the issue of refugee solidarity. Commenters used the Facebook news sites in order to voice their views in regard to issues pertaining to refugees directly, and only a minority shifted the focus of debate to other unrelated issues (such as the legitimacy of domestic actors during the 'refugee crisis'). In other words, online news readers all over Europe used the opportunity for bottom-up mobilisation at the individual level to express their opinion in support of or in opposition to the question of whether refugees should be welcomed during the crisis peak, September 2015.

Our comment analysis builds on the notion of a politics of pity. In particular, we wish to investigate the way emotions, such as fear or pity, are given political expression. We do not analyse emotions directly, but the way emotions translate into a public statement of side-taking solidarity. Consequently, we are focused on moral debates in which citizens are engaged in discussing whether solidarity should be granted or not (Mortensen and Trenz, 2016). Through our combination of claims-making and reader commenting analysis, we argue that fear or pity as emotional expressions in media discourse are used as an element of political claims-making to distinguish positions in the solidarity debate, ascribe responsibility and call politicians to act. The question thus is what contributes to the salience of pity or fear at any particular moment of the debate, and who defines and interprets pity and fear and translates them into calls for or rejections of solidarity.

\section{Taking sides in the solidarity question}

By looking at commenters' tonality regarding refugees, we can measure degrees of polarisation of the solidarity debates. We speak of a polarisation of solidarity contestation when user comments at the individual level clash with statements by organised actors in the media and/or express diametrically opposed opinions, or when their opinions were, on average, more extreme on the tonality scale. 
We first analyse how far users are supportive or critical of refugees. Generally, and across all countries, we can see that even though the largest share of user comments $(47.7 \%)$ rejected solidarity with refugees, there was a substantial minority of supportive users $(31.1 \%)$, while $21.3 \%$ remained neutral or ambivalent (see Table 5.4). These numbers suggest plurality of opinion and disagreement among the commenters in the solidarity question. At the same time, they disprove that media users are a homogenous group sharing anger and/or rejection. Nevertheless, users who reject solidarity are the dominant group, a finding that contrasts with the position of claims-makers in the news articles, because the latter are dominantly positive towards refugees $(47 \%)$. As a matter of fact, the share of negative and positive comments among individual Facebook users is reversed when looking at claims-making of organised actors in the news articles (news claims: $30.7 \%$ negative, $22.3 \%$ neutral, $47 \%$ positive; comments: $47.7 \%$ negative, $21.3 \%$ neutral, $31.1 \%$ positive). Even though Facebook commenting on the pages of mainstream newspapers is often not associated with the spread of hate speech and xenophobia (due to moderation practices), the opportunities for bottom-up mobilisation are nevertheless used to take sides against solidarity with refugees, and, in addition, to raise a voice to criticise the discourse in the public sphere.

Figure 5.4 reports similar findings by comparing the average tonality across countries. Except for Poland, degrees of negativity in user commenting are relatively low, or even balanced. In two countries (Greece and Italy), the average tone in Facebook commenting regarding the question of refugee solidarity is even positive. This might be the result of a politics of pity from below (i.e., the expression of care for the suffering and needs of refugees) that is nurtured by the immediate experience of hardships of the incoming refugees in countries with external borders, and the intense mobilisation of civic solidarity at the grass-roots level (see Kousis et al., 2020). Northern European countries might

Table 5.4 Percentage of positive, neutral, and negative claims and comments across countries

\begin{tabular}{lllllll}
\hline \multicolumn{5}{c}{$\begin{array}{l}\text { Claims on newspaper } \\
\text { Facebook sites }\end{array}$} & \multicolumn{5}{l}{ Comments } \\
\cline { 2 - 7 } & Anti & Neutral & Pro & Anti & Neutral & Pro \\
\hline France & $28.5 \%$ & $24.5 \%$ & $47 \%$ & $53.3 \%$ & $26.3 \%$ & $20.4 \%$ \\
Germany & $22.6 \%$ & $28.2 \%$ & $49.2 \%$ & $55.2 \%$ & $21.4 \%$ & $23.4 \%$ \\
Greece & $41.5 \%$ & $17 \%$ & $41.5 \%$ & $24.6 \%$ & $42 \%$ & $33.3 \%$ \\
Italy & $31.9 \%$ & $22.3 \%$ & $45.8 \%$ & $27.6 \%$ & $23 \%$ & $49.4 \%$ \\
Poland & $27.2 \%$ & $29 \%$ & $43.8 \%$ & $75.3 \%$ & $15.9 \%$ & $8.8 \%$ \\
Denmark & $39.3 \%$ & 14.5 & $46.2 \%$ & $47.4 \%$ & $12.9 \%$ & $39.7 \%$ \\
Switzerland & $24 \%$ & $14.4 \%$ & $61.6 \%$ & $48.8 \%$ & $16.4 \%$ & $34.8 \%$ \\
UK & $40.7 \%$ & $24.6 \%$ & $34.7 \%$ & $52.3 \%$ & $10 \%$ & $37.7 \%$ \\
Total & $30.7 \%$ & $22.3 \%$ & $47 \%$ & $47.7 \%$ & $21.3 \%$ & $31.1 \%$ \\
\hline
\end{tabular}




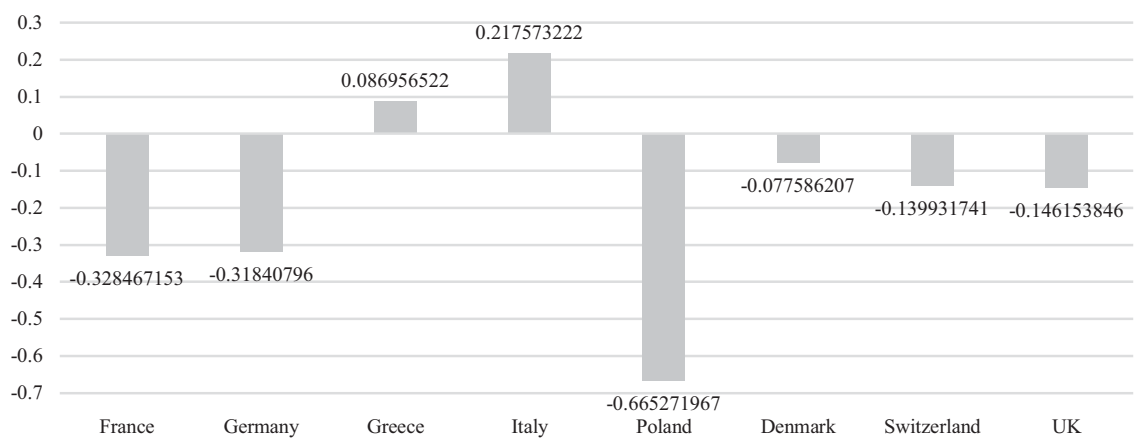

Figure 5.4 Average stance towards refugees in comments

be less exposed to these immediate needs. Moreover, and in spite of the 'welcoming culture' that turned into a popular movement in countries like Germany and France (see again Kousis et al., 2020), the selective group of Facebook commenters were more critical of this wave of support in their countries. Poland, with the lowest number of asylum applications (9,490 from August 2015 to April 2016 according to Eurostat, 2018), was the most negative country. All this seems to confirm our interpretation that the refugee crisis is a 'mediated event' that is not fully explained by facts and numbers.

It is noteworthy that negative and supportive commenters raised different issue agendas (Tables 5.5 and 5.6). In line with a politics of fear, the most salient issue (i.e., migration management) was more recurrently referred to by negative commenters (Table 5.5: 42.0\%), ${ }^{3}$ followed by issues relating to the consequences of an increased migration influx to their countries $(29.5 \%)$. As Table 5.6 shows, positive commenters highlighted instead the refugees' personal backgrounds and situations $(38.0 \%$, compared to $11.6 \%$ in negative comments in Table 5.5), positions that are more in line with a politics of pity. Positive comments were also associated with civic initiatives $(30.2 \%)$. Hence, whenever the background situation or fate of the refugees was referred to (politics of pity), the likelihood of a positive positioning towards refugees increased. If instead an emphasis was put on moments of crisis (politics of fear), this was mostly done in the context of a negative statement towards the refugees. If government and state policies were mentioned, this was mainly associated with negative attitudes towards refugees, while civic activities were related to positive statements.

Our findings thus show in sum that Facebook commenting on newspaper sites became a site of user engagement and of moral commitment with questions of refugee solidarity. In this moment of heightened attention, a politics of fear was countervailed by a politics of pity that placed its focus on the need to provide humanitarian assistance to the needy in an emergency situation. User commenting fora were not found to be, as is often assumed, the place for a radicalisation of political opinion through the expression of xenophobia or hatred. 
Table 5.5 Issues in comments with negative stance towards refugees

\begin{tabular}{llclllll}
\hline & $\begin{array}{l}\text { Migra- } \\
\text { tion } \\
\text { Manage- } \\
\text { ment }\end{array}$ & $\begin{array}{l}\text { Inte- } \\
\text { gra- } \\
\text { tion }\end{array}$ & $\begin{array}{l}\text { Back- } \\
\text { ground/ } \\
\text { situa- } \\
\text { tion: } \\
\text { refugees }\end{array}$ & $\begin{array}{l}\text { Conse- } \\
\text { quences } \\
\text { of refu- } \\
\text { geecrisis }\end{array}$ & $\begin{array}{l}\text { Issues } \\
\text { regarding } \\
\text { publicl } \\
\text { civic } \\
\text { initiatives }\end{array}$ & $\begin{array}{l}\text { Unkn- } \\
\text { own }\end{array}$ & Total \\
\hline France & $61.6 \%$ & $1.4 \%$ & $2.7 \%$ & $22.6 \%$ & $11.6 \%$ & $0.0 \%$ & $100 \%$ \\
Germany & $20.7 \%$ & $0.0 \%$ & $4.5 \%$ & $64.9 \%$ & $9.9 \%$ & $0.0 \%$ & $100 \%$ \\
Greece & $57.4 \%$ & $0.0 \%$ & $4.4 \%$ & $25.0 \%$ & $13.2 \%$ & $0.0 \%$ & $100 \%$ \\
Italy & $43.9 \%$ & $1.5 \%$ & $9.1 \%$ & $13.6 \%$ & $21.2 \%$ & $10.6 \%$ & $100 \%$ \\
Poland & $19.4 \%$ & $11.7 \%$ & $16.7 \%$ & $43.3 \%$ & $7.8 \%$ & $1.1 \%$ & $100 \%$ \\
Denmark & $42.7 \%$ & $0.9 \%$ & $25.5 \%$ & $17.3 \%$ & $13.6 \%$ & $0.0 \%$ & $100 \%$ \\
Switzerland & $35.7 \%$ & $5.6 \%$ & $12.6 \%$ & $22.4 \%$ & $23.8 \%$ & $0.0 \%$ & $100 \%$ \\
UK & $65.4 \%$ & $0.7 \%$ & $12.5 \%$ & $16.9 \%$ & $4.4 \%$ & $0.0 \%$ & $100 \%$ \\
Total & $42.0 \%$ & $3.5 \%$ & $11.6 \%$ & $29.5 \%$ & $12.5 \%$ & $0.9 \%$ & $100 \%$ \\
\hline
\end{tabular}

Table 5.6 Issues in comments with positive stance towards refugees

\begin{tabular}{lccccccc}
\hline & $\begin{array}{l}\text { Migra- } \\
\text { tion } \\
\text { Manage- } \\
\text { ment }\end{array}$ & $\begin{array}{l}\text { Inte- } \\
\text { gration }\end{array}$ & $\begin{array}{l}\text { Back- } \\
\text { ground/ } \\
\text { situa- } \\
\text { tion: } \\
\text { refugees }\end{array}$ & $\begin{array}{l}\text { Con- } \\
\text { sequences } \\
\text { of refu- } \\
\text { geecrisis }\end{array}$ & $\begin{array}{l}\text { Issues } \\
\text { regarding } \\
\text { publicl } \\
\text { civic } \\
\text { initiatives }\end{array}$ & $\begin{array}{l}\text { Unkn- } \\
\text { own }\end{array}$ & Total \\
\hline +France & $41.1 \%$ & $3.6 \%$ & $8.9 \%$ & $19.6 \%$ & $26.8 \%$ & $0.0 \%$ & $100 \%$ \\
Germany & $6.4 \%$ & $2.1 \%$ & $53.2 \%$ & $8.5 \%$ & $29.8 \%$ & $0.0 \%$ & $100 \%$ \\
Greece & $16.3 \%$ & $0.0 \%$ & $52.2 \%$ & $5.4 \%$ & $26.1 \%$ & $0.0 \%$ & $100 \%$ \\
Italy & $17.8 \%$ & $0.8 \%$ & $47.5 \%$ & $4.2 \%$ & $29.7 \%$ & $0.0 \%$ & $100 \%$ \\
Poland & $23.8 \%$ & $4.8 \%$ & $23.8 \%$ & $9.5 \%$ & $38.1 \%$ & $0.0 \%$ & $100 \%$ \\
Denmark & $37.0 \%$ & $0.0 \%$ & $12.0 \%$ & $1.1 \%$ & $48.9 \%$ & $1.1 \%$ & $100 \%$ \\
Switzerland & $26.5 \%$ & $2.0 \%$ & $27.5 \%$ & $6.9 \%$ & $35.3 \%$ & $2.0 \%$ & $100 \%$ \\
UK & $25.5 \%$ & $1.0 \%$ & $61.2 \%$ & $0.0 \%$ & $12.2 \%$ & $0.0 \%$ & $100 \%$ \\
Total & $24.4 \%$ & $1.3 \%$ & $38.0 \%$ & $5.6 \%$ & $30.2 \%$ & $0.5 \%$ & $100 \%$ \\
\hline
\end{tabular}

These radical opinions may have been downgraded by other users and thus would not have been included in our sample as popular comments; additionally, they may have been filtered out by the moderators of the Facebook pages, in case they breached netiquette. But concentrating here on the most commented on posts and the most popular comments - ranked highest on Facebook and moderated by the newspapers' web administrators - refugee solidarity was debated in a mostly balanced way, with supportive users still outweighing commenters rejecting refugee solidarity. However, this anti-solidarity voice did not dominate the debate and did also not systematically turn disrespectful towards the opinions of others, or towards refugees as our objects of solidarity. 


\section{Justifications}

Our initial assumption has been that a politics of pity and a politics of fear require individual users to translate their first emotional reactions into public speech. This translation requires justification, because users have to provide good reasons for why they opted to express support or rejection of refugee solidarity in their online comments. The only caveat to keep in mind here is that online commenting forums are not structured in a way that facilitates an exchange of arguments among users. Commenters rarely enter a dialogue with each other (Barnes, 2018; Galpin and Trenz, 2019). Providing justifications by expressing one's opinions is therefore in no way self-evident, as opinions are often expressed in an abbreviated way by making use of more emotional language and marginalising rational argumentation. Especially with regard to the events associated with the 'refugee crisis', debates around solidarity were rather driven by emotions and not by a rational exchange of arguments (Chouliaraki and Stolic, 2017).

Despite these restrictions, we found that a slight majority of commenters ('pro', 'neutral', and 'anti' together: 57.2\%) justified their stances regarding solidarity towards refugees (Figure 5.5). This indicates that news commenting is a form of discursive contestation and engagement, and not plain opinion-stating. By making solidarity statements, user-commenters took sides, meaning that they had to decide whether to treat refugees as worthy objects of solidarity. Anti-solidarity commenters notably engaged to a higher degree in justificatory practices $(33.0 \%)$ than pro-solidarity commenters did $(15.4 \%)$ (see Figure 5.5 ). This is a surprising but revealing finding: While the rejection of solidarity is largely backed by arguments, solidarity with people in need is often spontaneous and is not justified.

Commenters relied on a wide spectrum of arguments to justify their choices when backing or rejecting solidarity with refugees. ${ }^{4}$ Among the comments opposing solidarity with refugees and providing justifications, the most frequent argument used was that national citizens should be regarded first (welfare chauvinism, $16.1 \%$ ) (see Figure 5.6). This was followed by references to the inappropriateness of migrants' behaviour $(11.9 \%)$. Religious reasons ranked third on average with

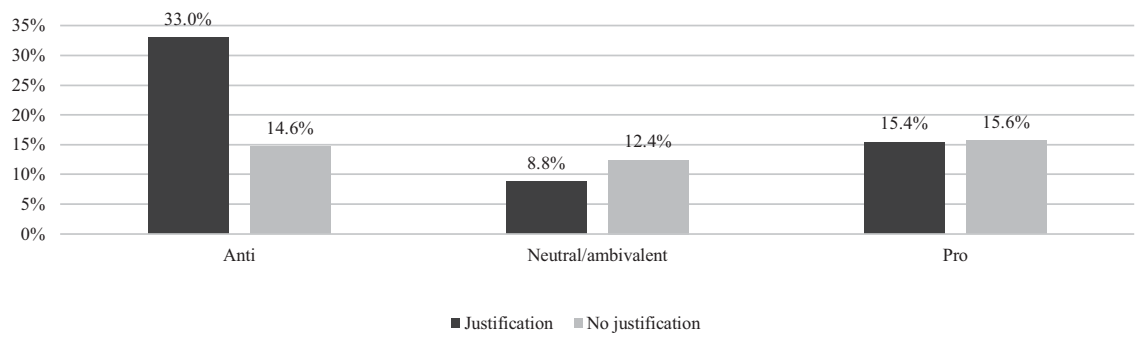

Figure 5.5 Justification versus no justification in comments with tonality toward refugees (in \%) 


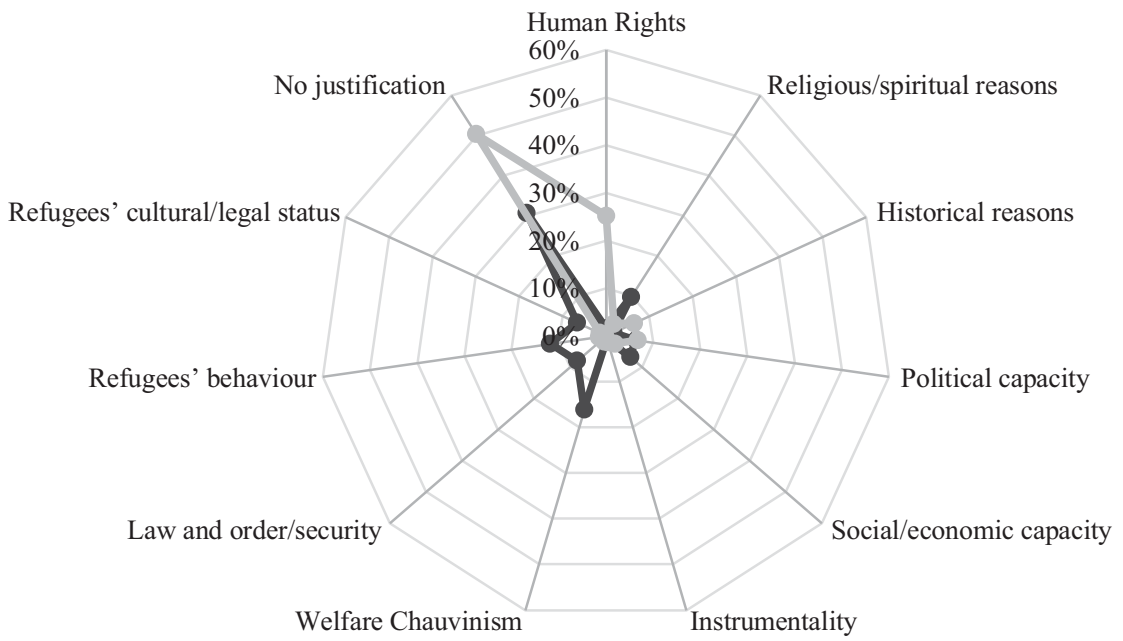

$\longrightarrow$ Anti-refugee $\longrightarrow$ Pro-refugee

Figure 5.6 Justifications of solidarity of negative and positive comments compared

9.7\% as a justification for negative stances. Among the pro-solidarity justifications, we can list human rights and broader humanitarian aspects as the most diffused arguments $(25.2 \%$ of positive comments as compared to only $1.6 \%$ of negative comments).

Figure 5.7 indicates that tabloid readers use the same patterns of interpretation that structure the debate about the refugee crisis across newspapers and countries, even though they tend to make more use of exclusionary and less supportive frames. Debates in both types of newspapers are plural, defending both pro- and anti-solidarity positions. The range of arguments used in userdriven debates is broad, but they overlap between newspaper formats. There is, in other words, no evidence in these data for separate online communities on Facebook. This means that, by and large, national news audiences are still addressed by the same agenda of news. They are involved in shared debates about the same issues of concern which, according to political theorists, is a key condition for a well-functioning democracy (Habermas, 1996, Ch. 8.3).

In sum, findings allow us to paint a nuanced picture of bottom-up solidarity contestation within social media news commenting forums. First of all, our data show that user debates allow for the expression of plural opinions and arguments. It is true that the number of Facebook commenters rejecting refugee solidarity outnumbers the share of supporters in almost all countries (except in Italy and Greece). Additionally, one out of five users abstains from taking sides in this debate. However, a sizable group of online commenters speaks out in support of refugee solidarity on the social media sites we analysed. Secondly, 


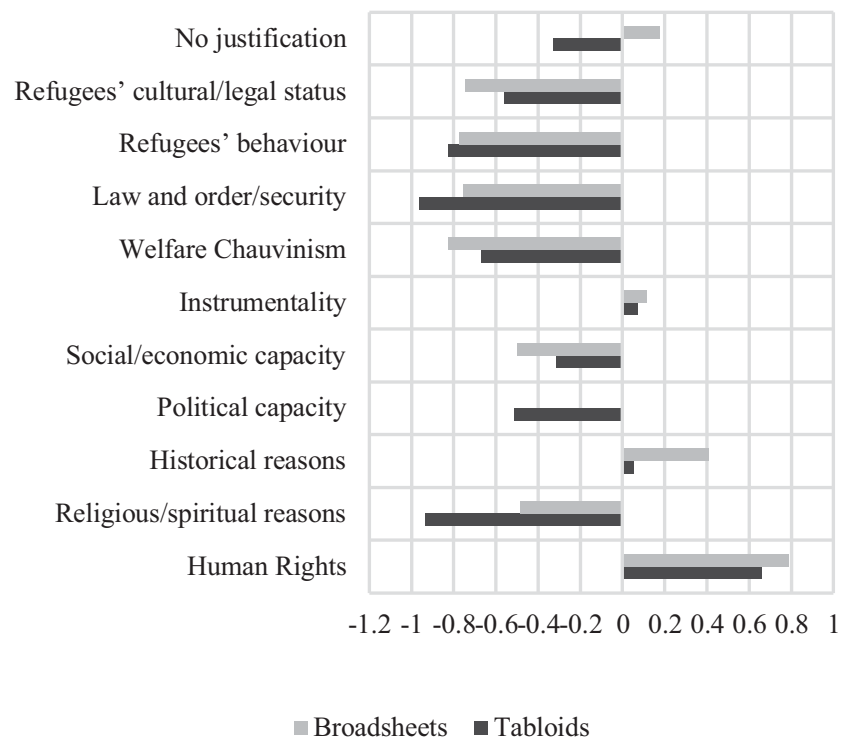

Figure 5.7 Average position in broadsheets and tabloids in relation to justifications

taking sides on the question of refugee solidarity via user comments creates a justification requirement, even though proponents and opponents are engaged in argumentative exchanges to different degrees. In fact, solidarity seems to be a widely accepted norm, and this seems to be evident to most Facebook users, irrespective of whether they are supportive or critical of refugees. Solidarity is a socially desirable norm, and this means that showing solidarity towards people in need is a reasonable and expected response within the Facebook community of news readers. As such, it does not need to be further justified and might be backed only by the expression of emotions (e.g., 'I feel so sorry for the poor children'). The choice to reject solidarity towards those people in need seems to put the commenter on social media under pressure to engage in an explicit justification (Chouliaraki, 2013). The quite substantial presence of commenters with positive views about refugees and their attitude as 'do-gooders' (a pejorative term often used by the group of negative commenters) further urges the opponents of solidarity to back their opinions with arguments, i.e. explain why they are against refugees.

\section{Conclusion: A European sphere of online solidarity contestation}

One key question addressed by analysts and commentators of political communication within the social media is whether more participatory forms of online news consumption and commenting can meaningfully contribute to democratic politics, and whether social media may help to engage users in political debates and facilitate a more pluralistic process of public opinion formation (Dahlgren, 
2013). This question is also highly relevant for our study of public debates about the 'refugee crisis'. During our analyses, we thus asked whether 'taking sides' and 'witnessing human suffering' through the social media translates into more open forms of user engagement and participation. These findings would help to validate the emergence of an online civic sphere that contributes to public debates about refugee solidarity through a pluralistic exchange of arguments.

The analysis of social media commenters, however, must proceed with care. In fact, even if news reading through social media has become a widespread practice, we need to remember that people who make a more active use of online media channels by engaging in participatory forms of journalism are not to be regarded as representative of the whole population (Bruns, 2010). From existing studies, we know that users who regularly engage in political debates on social media are younger and better educated. As such, they may be more likely to be politically active (e.g., Mellon and Prosser, 2017; Vissers and Stolle, 2014) and more critical of how solidarity politics are practiced in the EU (Brändle and Eisele, 2019). To do justice to this debate about the status of social media commenting, we decided to put a particular focus on how Facebook online news sites are confined to particular online communities of like-minded news readers.

Our findings do not support the assumption that Facebook news sites facilitate the formation of a separate arena of segregated user groups. Our comparative analysis of bottom-up solidarity contestations at the height of the so called 'refugee crisis' shows how citizen-users on Facebook took the opportunity all over Europe to make their voice heard on an issue of shared concern. These voices were raised in the commenting sections of mainstream newspapers' public Facebook sites. They were informed and motivated by witnesses of a humanitarian disaster and human suffering of refugees coming to Europe. But they were also fuelled by diffuse feelings of fear in light of a seemingly uncontrolled influx of refugees. We found elements of a politics of fear (Wodak, 2015) and a politics of pity (Boltanski, 1999) - two concepts that express how emotions were translated into public speech by Facebook commenters in order to express a political opinion and take sides in regard to the question of whether solidarity with refugees should be granted or not.

The Facebook comment sections of mainstream newspaper sites offered citizens an opportunity for focused debates about the 'refugee crisis' through the exchange of a plurality of positions and arguments. Our analysis highlights, however, that social media commenting is not an entirely autonomous space of debate, because commenters remain tied back to the context of debate provided by organised claimants in the political news posted on Facebook. Social media commenting did in this sense not unfold within a bubble, but rather contributed to the broader public sphere within which solidarity is debated at national and European levels.

Bottom-up solidarity contestations at the individual level are thus found to be closely related to the broader public and political discourses in the various countries under analysis. The newspaper sites on Facebook, which we selected for analysis, are not just niches found in some hidden angle of the Internet. 
They reach out to mass audiences that are in part even larger than the readership of offline newspapers. In this sense, they expand the reach of news coverage and claims-making of organised actors, and provide additional arenas of user-driven discussion and contestation. The analysis of solidarity contestations via user comments further shows that social media provide spaces for an exchange of opinions that does not conform to the picture of an undifferentiated, angry user community, as is often assumed (Fletcher and Nielsen, 2017). Looking at public Facebook sites of mainstream newspapers, we found a strong link between organised contestation in online news and individual contestation in online commenting. This points to an integrated public sphere of solidarity contestation, where primary definers (organised claims-makers such as politicians, stakeholders or main NGOs) in the news media set the agenda and the main frames for social media users, which in turn become active on their own as secondary definers of the debate. In social media responses to political debates, a plurality of issues, concerns and justifications are expressed, contributing to the bottom-up formation of public opinion.

Looking more closely at the dynamics of user-driven solidarity contestations, we find that these contestations are most often verbally fought out. This means that social media are not used for targeted political mobilisation in the sense of direct calls for protests or acts of solidarity. We learned that user-driven contestations largely follow the public agendas set by the posted articles and the claims made by organised actors therein. This is obvious when looking at the issues Facebook commenters addressed in their own posts, given that they followed the ranking of most or less important topics, ranging from migration management and security concerns, to issues of social integration, welfare benefits, civil society initiatives, living conditions and personal stories of refugees. News articles and user comments diverge more strongly when looking at the tonality of the claims and statements made. Opinions expressed by commenters were overall more negative than the views voiced by claims-makers in the news media. In the two border countries (Italy and Greece), a positive view prevailed over hostility among social media users. The comment sections of news sites on Facebook were, however, not used for the expression of political extremism, of xenophobia or of hate towards foreigners. Again, we are aware that it is likely that news sites moderate their Facebook pages. Moreover, they will take preventive measures by selecting less controversial news content posted on Facebook. The lack of radical opinions, however, does not exclude contentions and conflicts. On the contrary, we find in our data that the online voice of users is particularly critical of claims stated in the posted articles. Commenters in all countries systematically referred to claims-making of organised actors in the news media, and if they did, they tended to be critical towards them, not affirmative. In this sense, we see that citizens use the social media to interact critically with the mass media, and to engage in contentions with public claims-makers, many of them considered their political representatives.

Solidarity contestations among media users, however, were not marked by strong polarisations, even though commenters tend to disagree when solidarity 
with refugees is at stake. They did not take fundamentally opposed views. Additionally, our analyses showed that Facebook users tended to acknowledge similar moral exigencies, to which they had to react while making public claims. In fact, taking sides on the question of refugee solidarity generated a requirement to justify one's position in public debates. This justification requirement was spelled out differently, depending on whether commenters rallied for or against solidarity with refugees. While pro-solidarity commenters often relied on an unconditional form of justification, such as the higher morality of human rights, anti-solidarity commenters most commonly defended a notion of conditional solidarity. This required them to spell out the conditions under which solidarity should apply or be withdrawn. The anti-solidarity voice in all countries generated, therefore, a higher amount of justifications than those comments that called for solidarity with refugees. Denying solidarity thus requires more argumentative work, while granting solidarity was communicated as an implicitly reasonable and desirable attitude.

These findings, however, need to be taken with care, given that our analysis is centred on a very specific time, September 2015, which was marked by a situation of humanitarian emergency and controversies about the decisions of the German government to open its borders to refugees. Our purposive sample might thus mirror a very specific part of opinions from hostile to more supportive attitudes towards refugees (Ditlmann et al., 2016). This specific context surrounding our sample, however, does not seem to have had a strong impact on political opinions expressed by users on Facebook news sites. In fact, the so called 'welcoming culture' made itself heard, particularly in the news media's coverage and the claims-making of organised actors. As a consequence, the opinions expressed by these actors peaked in every country in its support for refugees during the month of September. Individual social media users, however, did not necessarily join in on this unconditional support. Facebook news sites, during this critical period, remained an arena of political contestations, where solidarity was contested more controversially than in the news. This became especially visible in Germany, where commenters remained more distanced and critical of the decision to open the borders to refugees and of the so-called 'welcoming culture' by civil society organisations. They thus displayed an attitude of critical scepticism (Brändle and Eisele, 2019), indicating that the solidarity momentum of September 2015 would remain short-lived and exceptional.

Our findings paint a much more complex picture of solidarity contestation than expected. User-driven debates are partly dissociated from claims-making in the news media, as they seem to provide a vehicle for the expression of scepticism or criticism of established politics and media-driven debates. At the same time, however, online user debates largely follow the patterns of the broader discussions within the mass-mediated public sphere. We are not dealing with a segmented arena driven by its own logic and detached from the political mainstream. Social media users contribute to public debates and complement public deliberation dominated by organised actors. In this sense, they also contribute to a more balanced picture of solidarity contestations, because they show that 
solidarity with refugees was a much more fragile phenomenon than views on the news coverage of the mass media might have conveyed. In this sense, our data corroborate the main argument of this volume about the fragility of solidarity contestation across Europe. The investigation of the social media has powerfully confirmed this assumption, because even at this exceptional moment of heightened attention for the humanitarian needs of refugees, prevailing in September 2015, citizens displayed quite different attitudes across arenas and countries and on the whole remained critical with regard to claims-making in the mainstream media. The solidarity momentum woke feelings of compassion with refugees, thus making a politics of pity into a widely diffused approach. However, the quick shifts of opinion in the subsequent months evidenced the difficulties translating the momentum into an enduring and collective support of solidarity (Vollmer and Karakayali, 2017). Social media therefore remain fragile and contested arenas of solidarity.

\section{Notes}

1 We noted during data collection that many newspapers closed their own website commenting functions below the news articles, shifting toward user engagement on their Facebook pages where a separate unit was likely responsible for content monitoring.

2 Independent statements are subtracted from the total number of comments because they do not relate to the article as such, or the claims raised in the article.

3 Similar for neutral or ambivalent commenters.

4 As country differences in the use of justifications were neither significant nor did they show the expected correlations (e.g. the emphasis on religion in Poland), we only compare the argumentative patterns of pro- with anti-refugee commenters. 
Part II 



\section{Solidarity contestation in Switzerland - fragmented news, fragmented solidarity?}

\section{Refugee solidarity in the Swiss context ${ }^{1}$}

Switzerland as the only non-EU country in the sample is an attractive country for migrants, mirrored in a share of permanent non-Swiss residents of around $25 \%$ and a share of over $30 \%$ belonging to ethnic minorities, or having an immigrant background (Bonfadelli, 2017). Switzerland is characterised by political, cultural and linguistic diversity: Manifested also in the strong federalism implemented in the unique Swiss political system, Swiss cantons have their own more or less far-reaching political systems. Moreover, there are three major linguistic regions (German, French, Italian) in the country. Overall, this leads to a high degree of internal heterogeneity and fragmentation in political, linguistic and cultural respects (Kriesi and Trechsel, 2008; see Fernández 2018a for an assessment of fragmentation in terms of solidarity practices in particular). More importantly, however, Switzerland represents the country with the strongest features of direct democratic participation in our sample. Political, cultural and linguistic diversity together with a strong, direct influence of citizens in political decision-making indicates a particularly high degree of contestation given the overall fragmentation of the country.

Regarding Switzerland's relationship with the EU, 'almost everything ... points towards Switzerland being part of the European Union' (Sarrasin et al., 2018, p. 203). Indeed, the strong economic ties with the EU are secured through a range of bilateral agreements. Being situated among EU member states, Switzerland also entered the Schengen area, abolishing border controls and guaranteeing rights of free movement to EU citizens and citizens of member states of the European Economic Area (EEA) (Hanke et al., 2019). However, Switzerland never formally became a member of the European Union, due to the majority of Swiss citizens' opposition to membership. The referendum of EU-membership in 1992 officially marked the end of accession plans and mirrored the aforementioned regional fragmentation, with the French Swiss being overwhelmingly pro-European versus the German and Italian Swiss rejecting membership (Trechsel, 2007). Reservations towards formal membership are nurtured by Euroscepticism (Wagschal, 2007), which has grown since 1992 and is often related to European immigration policies. Euroscepticism is mainly endorsed by 
the radical right, most prominently the Swiss People's Party (Schweizerische Volkspartei - SVP), which is today the strongest party in the Swiss Federal Assembly (Sarrasin et al., 2018, p. 206).

The prominence of the far right in Switzerland has also increased public salience of the issue of migration: "The rise of the SVP ... can be at least partly attributed to the party's ability to persuade voters to agree with them on matters associated with immigration' (Fitzgerald and Jorde, 2018, p. 199). In line with the literature, this comes with preferences for less social spending in terms of welfare policies (e.g., Alesina and Glaeser, 2004), a disposition most likely influenced by the anti-immigrant rhetoric of the radical right which underlines that immigrants might profit most from it (e.g., Bonfadelli, 2017). During the 'migration crisis' of 2015/2016, the number of asylum applications went up from 23,500 in 2014 to 39,400 in 2015 according to Eurostat, but decreased again the year after to 27,100 applicants (Eurostat, 2018). From a comparative perspective, Switzerland thus managed to keep the number of incoming refugees relatively low. Nevertheless, incoming refugees fuelled the quite hostile antiimmigration climate. Migration became the most controversial topic in public discourse and a source of polarisation, also nurturing the grand success of the SVP in the general elections in October 2015 (e.g., Bochsler et al., 2015).

Overall, there seems to be a fundamental ambivalence embedded in the Swiss case, since Switzerland is emphasising internal ethnic and linguistic heterogeneity and tolerance on the one hand, but has enforced one of the most restrictive immigration and naturalisation regimes in Europe on the other hand' (Bonfadelli, 2017, p. 300). These restrictive policies are, on the one side, often directly informed by popular initiatives or referenda, as citizens are involved in legislative decision-making via direct democratic tools. On the other side, attitudes towards refugee solidarity are, according to our own TransSOL survey (Grasso, 2017), on average more positive than the average of our sample countries (i.e., Denmark, France, Germany, Greece, Italy, Poland, the UK): more than half of the population $(52.2 \%)$ agreed with a moral responsibility of Switzerland to accept refugees (14.5\% 'strongly agree', $37.7 \%$ 'agree') against $22.6 \%$ answering 'neither', $14.4 \%$ 'disagree' and $11.1 \%$ 'strongly disagree'. Furthermore, $16.4 \%$ agreed to admitting higher numbers of Syrian war refugees in 2017 (TransSOL survey average 12.4\%), while 12.1\% opposed their admittance (against 19.5\% TransSOL survey average). All of these issues taken together make Switzerland an interesting case study for how solidarity contestation during the 'migration crisis' unfolded across different publics.

\section{The Swiss public sphere}

In line with the fragmentation of the political system in Switzerland, the media system in the country is also divided along linguistic borders and regions. This is mirrored by the dominance of regional newspapers and TV channels, and the lack of a news outlet at the federal level, which would allow citizens from the whole country to follow public debates. Given this fragmented 
nature of the Swiss media landscape, Kriesi (1992) concluded that a Swiss public sphere does not exist, even though established coordination mechanisms between regional media organisations meet the requirements of a functional democracy (see also Mono, 2009).

It is not surprising, therefore, that the regional media principally address regional and linguistically divided audiences with different issue agendas. The lack of a federal newspaper fosters the weight of subnational media, which are tied back to each linguistic-area and strengthen their role as pseudo-national media. In addition, the external impact of Swiss German-, French-, and Italianlanguage newspapers in the Swiss media needs to be taken into consideration, as well. Neighbouring countries' media have influenced Swiss newspapers, and Swiss readers are well-informed about political and cultural events from the adjacent country of linguistic reference, and might also follow solidarity discourses towards refugees in their media (see Studer et al., 2014, pp. 7-10).

To account for the specifics of the Swiss case, the analysis here was based on five newspapers that represent the three major linguistic regions of the country. No tabloid press was coded; instead, we decided to increase regional representation by coding a Swiss-Italian newspaper. For each newspaper, we coded a minimum of 150 claims. For the Swiss-German region, we used the Neue Zürcher Zeitung (NZZ) and Tages Anzeiger; Le Matin and Le Temps for the French-speaking region; and La Regione for the Swiss-Italian region. Since the Italian newspaper was not available on Facebook, we had to substitute it with the German-language tabloid, Blick, for the social media commenting analysis.

Given the high involvement of Swiss citizens in politics via direct democratic procedures (e.g., popular initiatives and referenda), the media play a crucial role as a source of information and an arena of public opinion formation processes. Accordingly, over $65 \%$ of Swiss journalists believe that it is extremely or very important to share information in their coverage to enable people to make up their minds about political issues. This value is higher in comparison with their German or Austrian colleagues $(69 \%$; in contrast to Austria: 63\%; Germany: $56 \%$; see Hanitzsch and Lauerer, 2019, p. 147). Regarding the function of the media in society in general, the 'refugee crisis' has generally fuelled a heated discussion in Switzerland about the responsibility of journalists: Should journalists provide moral guidance and opinion while risking to patronise their audience? Or should they remain a neutral and distant observer, conveying reality in an unpartisan and objective way, but risk being mere bystanders where universal human rights and freedoms are being disregarded (Hanitzsch and Lauerer, 2019, p. 136; more generally also Hanitzsch and Vos, 2018)?

Research on how migration is debated in the Swiss media before the refugee crisis found that foreigners and migrants usually had very low media visibility: 'When it comes to immigrant minorities, neither media regulation nor media performance reflect Switzerland's tradition as a multicultural and multilingual country' (Signer et al., 2011, p. 419). Low salience in the media did not prevent journalists from using recurring frames when reporting about immigrants from different parts of the world: Turkish or North-African immigrants, for 
example, were usually connected to Islam, religious fundamentalism and gender inequality. And more generally, immigration bore rather a negative than a positive connotation, while immigrants themselves were usually talked about and only rarely granted an active role (Trebbe and Schönhagen, 2011). This reflects, to some degree, the strong anti-immigrant rhetoric of the right-wing-populist Swiss People's Party (SVP), which has gained strength over the last 20 years.

\section{Patterns of political claims-making: Fragmentation into regional public spheres?}

Against the more general background just discussed, we would expect that, also in terms of solidarity contestation, Switzerland's public sphere is fragmented. Yet it seems that the Swiss debate does not conform to these expectations, but follows very similar patterns, when comparing different regional newspapers within Switzerland and the Swiss case with the other countries in the sample: The debates about refugees in the media of all linguistic regions, like in the other TransSOL countries as well, were dominated by domestic/national state actors and political parties (overall $60 \%$ of claims). They raised most of the claims and were also most often directly addressed in claims.

In terms of pro- and anti-solidarity positioning, the share of positive claims was higher than those conveying an anti-solidarity stance. However, unfavourable demands could count on the support of core political actors: political parties were the most negative with respect to solidarity with refugees $(52 \%)$, directly followed by state actors $(42.4 \%)$. Civil society organisations and supranational actors like the EU or the UN, in contrast, were overall supportive of solidarity with refugees. Even though they were less visible in terms of claims frequency, they counterbalanced the strong negative bias of parties and state actors as responsible decision-makers to a certain extent. Differences between newspapers or languages are less pronounced for this central variable. With regard to newspapers, only Le Matin sticks out, being the most positive $(52.7 \%)$ in comparison to the other four newspapers. But also when clustering results by the language of the newspaper, the patterns are very similar, suggesting that there are no systematic differences between linguistic spheres in terms of position.

Swiss media contestation also follows the main European pattern with regard to issues. Public claims makers focus their debate mainly around the issue of migration management (over $60 \%$ of all claims), thus searching for political solutions to the assumed challenges and practical problems associated with the accommodation of the increased number of incoming refugees. The debate thus centred on state policy reactions and not, for instance, on refugees' life stories and living conditions. A much lower share of claims dealt with public activities and civic initiatives not involving political institutions (around $15 \%)$. This low visibility of such activities and initiatives is noteworthy in light of the high degree of political participation that traditionally characterises Swiss politics, but also in light of the strong role played by Swiss civil society 
associations and volunteers, which form an essential supporting infrastructure assisting a relatively weak welfare state (see Helmig et al., 2017).

The patterns of justification used to support or reject solidarity with refugees in the Swiss debate follow the main patterns of the other EU countries in our sample, as well. Justifications communicated in claims were most often rooted in interest-based considerations, putting emphasis on rational cost and benefit calculations (over 60\%). A much smaller share (around 25\%) was based on rights-related arguments maintaining, for example, that solidarity with refugees derives from the universality of human rights. Claims referring to identityrelated arguments, in contrast, were rather rare (just over 10\%). State actors, political parties and supranational actors tended to justify their mostly negative claims by interests, whereas civil society actors, in contrast, tended to focus their more positive claims on rights-related justifications. Almost half of the claims covered in Swiss newspapers, however, were not connected to arguments at all, but were mere opinions about refugees that did not explicate a rationale or frame. When looking into different linguistic areas, patterns of justifications connected with positions were very similar, with one exception - claims referring to identity-related justifications: Claims using identity-based justifications were on average more negative in German language newspapers (-0.05) than in French $(0.4)$ or Italian (0.6) language newspapers. This is mainly due to the fact that more extreme right-wing actors were covered by German language news for this category of claims. Regarding the argument of a fragmentation of solidarity contestation in the Swiss public sphere, however, these differences do provide only very weak support given the very small share of identity-based claims.

\section{A month of contestation on Facebook: Commenters' responses to the solidarity debate}

The analysis of Facebook comments allows us to check whether news readers responded differently in the linguistic communities. As explained above, the Italian newspaper was not available on Facebook, which is why we focus only on French- and German-speaking Facebook commenters. These two groups of commenters were leaning towards a neutral or anti-solidarity stance, with the French-speaking Le Matin's commenters sticking out with $90 \%$ negative comments (in contrast to German speakers, ranging between $31-38 \%$ and Le Temps with $42 \%$ ). Again, we do not find any systematic evidence that would support the hypothesis that Swiss social media commenters differed across language areas and/or newspapers.

Forty-three per cent of all Swiss comments failed to indicate any justification for their position. If they did, they were mostly related to a negative position. Only the humanitarian crisis frame ( $84 \%$ of comments) and human rights frame (69\% of comments) were overwhelmingly connected to a pro-solidarity stance. However, we need to consider that comments with no justification conveyed more positive positions towards refugees. While newspapers seem to differ slightly in 


\section{Solidarity contestation in Switzerland}

their coverage of specific frames, the numbers of comments coded were sometimes very small and thus do not allow any more generalised conclusions. Commenters also seemed to mostly follow the tone of the article discussing refugee solidarity. Thus, Swiss solidarity commenting does not backlash claims-making by organised actors in the media, and this observation is specific for the Swiss case, given that the backlash pattern was observed for the other countries in the TransSOL sample.

\section{Discussion}

Switzerland has been characterised as a democracy that functions without an overarching public sphere (Kriesi, 1992). In fact, the country is marked by political, cultural and linguistic diversity, as this applies also to the media landscape, which caters to the different target audiences respectively. However, these differentiations do not seem to impede cross-regional policy debates and deliberations that complement, control or fuel institutionalised politics. Our own data corroborate this general proposition, because linguistic differences are much less pronounced than expected when taking a closer look at solidarity contestations within the public sphere. This might be explained by cleavages along liberal-multicultural and nationalist-communitarian lines that characterise all three language communities, and structure public debates about migration and border control in a similar way. Switzerland is therefore not fundamentally different from the other countries in our sample. Everywhere, we detected a strong solidarity divide between institutional/political and non-institutional or civil society actors: the former defending security interests and debating questions of 'crisis management', the latter emphasising the personal needs of refugees, questions of care and the defence of rights.

In the case of user commenting on Facebook, the divisions between linguistic communities were more pronounced than among claims-makers in the news, but do not evidence a strong fragmentation of the debate. Overall, the debate about refugee solidarity in Switzerland does not exhibit strong traits of fragmentation, and even seems to suggest homogeneity when it comes to questions of migration. Contestation seems to follow similar patterns across the different linguistic communities within the country. Additionally, similarities are also pronounced when comparing Switzerland with the other countries included in our sample. Switzerland might stick out as the only country in the TransSOL sample that is not a formal member of the EU. However, it is not very different from other countries in terms of how immigration is debated and how the country positions itself with regard to the contested notion of European solidarity. Here, as everywhere, political actors and citizen-commenters tend to express a rather sceptical view with regard to solidarity with refugees.

\section{Note}

1 We would like to thank Eva Fernández Guzman Grassi for valuable research contributions. A detailed discussion of the findings of the Swiss case can be found in Fernández (2018b). 


\section{Solidarity contestation in Germany - 'Can we really do it?' Refugee solidarity in the German context ${ }^{1}$}

With its decision to open borders for incoming war refugees from Syria in late August 2015, within days Germany became the epicentre of the so-called refugee crisis of 2015 and 2016. The new open border policies had far-reaching effects for Germany and for the whole of Europe. Domestically, the country had to handle a staggering 477,000 asylum applications in 2015 and 745,000 in 2016. According to Eurostat, this amounts to more than one third of the total number of asylum applications within the EU in 2015, and more than half of all EU applications in 2016. At the EU level, the decision by the German government was fiercely opposed by some member states and only half-heartedly embraced by others. By unilaterally suspending the Dublin regulation, Germany was pushing for an EU-wide distribution of refugees, yet the EU remained deeply divided on the question of burden-sharing.

Solidarity was thus contested: both on the German and on the European Union front. Domestically, Angela Merkel spearheaded public debates about an open policy towards refugees by reassuring public authorities and citizens in their ability to rise to the current challenge by arguing: 'We can do it'. Additionally, the oft-cited 'Willkommenskultur' ('Welcoming Culture'), with people welcoming refugees at the train stations of Munich and elsewhere, prominently illustrates the positive German response towards refugees (e.g., Hamann and Karakayali, 2017). The early enthusiasm, however, provoked a substantial counter-mobilisation that was nurtured by public worries about Germany's absorptive capacities, but also by several events in the ensuing months. First of all, the attacks in Paris on 13 November 2015 played on security narratives of refugees as potential security and terror threats. The feeling of immediate emergency was best summarised by the comment of the Bavarian finance minister, Markus Söder, who in the aftermath stated: 'Paris changes everything' (Holmes and Castañeda, 2016, p. 18). Another event that aroused similar concerns was New Year's Eve 2015/2016 in Cologne, which impacted even more on public opinion than the Paris attacks, as it became 'a touchstone in debates about refugees in Germany' (Weber, 2016a, p. 80; also Weber, 2016b).

Immigration is an important topic, given that Germany has increasingly turned into an immigration-friendly country over the last decades, with a $25.5 \%$ share of the population having a migratory background (Bundeszentrale für 


\section{Solidarity contestation in Germany}

politische Bildung, 2019). Public policies partially mirror this immigrationfriendly orientation: Political and public debates have shifted towards the issue of integration of immigrants into the labour market, while the right of residence and the immigration of spouses and family reunion have become more restrictive over the years, thus contributing to stagnating numbers of immigrants (Müller-Hofstede and Butterwegge, 2007). This ambivalence is also true when looking at public opinion, as conveyed by opinion polls. Germans are divided over the question of how Germany should have handled the refugee crisis. According to our TransSOL survey (Grasso, 2017), a slight majority of Germans claimed in retrospect that the country should have accepted lower numbers of Syrian refugees $(37 \%)$, or should not have let anybody in $(12.8 \%)$. On the other hand, $9.3 \%$ would have accepted higher numbers, and $35.7 \%$ think that the number should be kept about the same. The German population, thus, remains internally somewhat divided on the question of refugee solidarity.

A second line of confrontation was fought at the EU level. Germany, traditionally one of the political heavyweights in the EU, tried to act as a leader in response to the crisis, emphasising that the EU's failure in light of the refugee situation would destroy its intimate relationship with universal civil rights (Harding et al., 2015). However, the welcoming approach did not remain undisputed. Merkel and her government were 'not able to get the rest of Europe to follow ... [their] lead' (Matthijs, 2016, p. 150). Merkel grew to be an increasingly contested public figure among European neighbours, nurturing very mixed and polarised reactions. Those ranged from the celebration of Germany as a bulwark of human rights, to reproaches that Merkel's open borders policy was responsible for fuelling further refugee surges. These criticisms often related Germany's response to the country's fascist history and its desire to clear its conscience (e.g., Conrad and Aðalsteinsdóttir, 2017). Merkel's policies, it was argued, set incentives for economic refugees to come and, in doing so, played into the hands of populist right-wing parties, capitalising on an overwhelmed administration struggling to accommodate the huge arrivals of people in need. With increasing worries about Germany's absorptive capacities, Merkel's critics in Europe and Germany started characterising her decision not to close the border as 'naïve and foolish' (Matthijs, 2016, p. 149). Merkel's position also grew more and more contested within her own party (Holmes and Castañeda, 2016, p. 14).

\section{The German public sphere}

Despite the fragmentation of media systems and the decline of traditional media in general (e.g., Mancini, 2012), newspapers still play an important role in Germany. This is mirrored in the comparatively high circulation numbers, and also in the broad range of newspapers from which readers can choose (Thomaß and Horz, n.d.). There are a few national newspapers and many regional ones, the latter documenting the strong political tradition of federalism in Germany (Kleinsteuber, 2004). The country's media market is not only the largest in 
Europe, but also the most dynamic and stable. Against the backdrop of the massive instrumentalisation of the press for propagandist purposes under the Nazi regime, political parallelism is low in the sense that newspapers are not linked to specific parties. Yet, opinion-leading quality newspapers can still be clustered along the political cleavages embedded in the party system (e.g., Eilders, 2000, pp. 184-185).

The selection of newspapers for the claims-making analysis was guided by the TransSOL sampling strategy. We included three newspapers that have country-wide circulation and contribute to covering the political spectrum. We thus selected Bild Zeitung as the biggest (politically right wing) tabloid, the Frankfurter Allgemeine Zeitung (FAZ) (centre-right broadsheet) and the Süddeutsche Zeitung (SZ) (centre-left broadsheet). Overall, our coders coded a total number of 740 claims in 264 articles (see Table 3.2 in Chapter 3), giving us an average number of 2.8 claims per article. For the analysis of articles and comments on newspapers' Facebook accounts, we used Spiegel instead of Bild, meaning that we used a slightly different sample for the analysis of bottom-up contestations. This was due to the fact that a preliminary search for our key terms (refugee and asylum) returned no results for articles posted on the Bild Zeitung's Facebook page.

Previous research on the media representation of migration before the crisis found that migrants and refugees were not very visible in the public sphere. They were often framed as passive objects or pure numbers, and not as subjects or agents with their own voice in the media. News coverage was consistently biased towards the alleged negative traits of migrants, who were often portrayed as criminals or a threat and a burden to the German welfare system. This negativity bias was particularly accentuated in the tabloid newspaper Bild Zeitung (Weber-Menges, 2008). Furthermore, asylum seekers were the most prominent group of migrants in the news and also the most negatively framed (see Eberl et al., 2018 for an overview). Regarding the migration crisis, existing studies show that external events have influenced the German discourse on immigration, which explained the strong degree of volatility in public debates (e.g., Triandafyllidou, 2018; Vollmer and Karakayali, 2017; Wallaschek, 2017).

Immigration is thus a news topic that is prone to contestation. The latter seems to be fuelled by broader socio-cultural questions of nationhood that tend to arouse considerable concern. This is evidenced by recurrent debates about whether or not Germany is an 'immigration country' ('Einwanderungsland') and whether multiculturalism is an enrichment or risk for German culture, particularly when discussions are related to the Muslim population. Specific events have made the latent nationalist fundament more manifest. An example is the intense debate following the massive number of sexual abuse and harassment cases during New Year's Eve in Cologne, dominated by perpetrators with a migratory background. This event induced a massive public contestation regarding the country's capacities to host refugees from non-Christian countries. Conrad and Aðalsteinsdóttir (2017), for example, analysed the framing of refugees in three German broadsheet newspapers. The media seized the 
opportunity to frame the refugees as a burden or risk over the course of the second half of 2015 until March 2016.

\section{The German debate about refugee solidarity in the print media}

For Germany, our analysis sketches the picture of a welcoming climate that was interrupted by external shocks, thus creating room for anti-refugee concerns to be voiced. Our analyses corroborate that the events of New Year's Eve in Cologne 2015/16 are a clear turning point, because the average tone of the claims regarding solidarity with refugees became more negative, especially among claimants with national scope (see Figure 4.7 in Chapter 4). Other research confirms this tendency of an increasing negativity of news coverage towards refugees, too (e.g., Conrad and Aðalsteinsdóttir, 2017; Weber, 2016a, 2016b).

As is the case with claims in other countries in our sample, public contestations are dominated by state actors in Germany as well. Additionally, debates tend to focus primarily on migration management. Civil society organisations, especially during the first weeks of September, did not act in opposition, but rather played an auxiliary role supporting the federal government and local administrations in order to accommodate the incoming refugees. Our data deviate slightly from this, because the tone of claims by political actors in the news media was on average balanced. This also means that oppositional and governmental, critical state actors had their say in the news. This partly contradicts other research findings, which accused the German media of a onesided coverage that leaned towards an elitist, pro-immigrant voice and was not representative of the German political landscape, thus contributing to deepening the ideological rift between liberals and nationalists (Haller, 2019). Our own study did not spot this bias, even though our data stems from a random sample of claims made in the news during the heat of the refugee crisis. On the contrary, our analyses show that different voices in the media had a say: The political spectrum was rather evenly represented in the news coverage of the newspapers under study, to the point where different positions balanced each other out. A majority of positive claims in support of refugee solidarity is only expressed by representatives of civil society and not by state actors. Nevertheless, when merging claims by political actors, civil society and other groups, the general tone of public claims in the German media was clearly supportive of refugee solidarity without fully reflecting, however, a German 'welcoming culture'. Instead, the data unveil a pattern of news journalism that is more or less similar to what we find for the other countries (see Figure 4.4 in Chapter 4).

In line with the dominant focus of media claims-making on crisis management, interest-based arguments were most commonly used to justify claims. This suggests that public claims-makers behaved in a rather rational-pragmatic way and were not reacting emotionally, as suggested by other studies (Haller, 2019). Also in Germany, we find that more positive claims tend to come without a justification, while claims expressing negative attitudes towards refugees 
are more regularly justified. One reason for this lower level of justificatory argumentation in pro-solidarity claims is that many positive claims were linked to direct acts of solidarity such as, for instance, examples of citizens or celebrities helping refugees. In such cases, solidarity actions were a spontaneous reaction to the witnessing of the suffering of people in need, as we have argued in Chapter 2. Such claims can do without justifications because they build on the underlying assumption of a strong consensus on the validity of humanitarian values. A similar logic may be at play in the case of justifications related to a rights-based frame. In fact, actors with positive stances towards refugee solidarity most often referred to universal principles, such as the defence of human rights, to argue in favour of the unconditional right of war refugees to seek asylum. Less supportive claims make use of different frames and justifications. In this regard, we can highlight the interest frame which is used by claimants concerned about the economic capacities of Germany (see also Chapter 4). They remain more ambivalent and neutral regarding the issue of refugee solidarity. Overall, positions in German claims appeared quite balanced with a slight tendency towards negativity. Our evidence thus contradicts the findings of other studies that speak about a biased and dominantly positive news coverage during the refugee crisis (Haller, 2019).

\section{The German debate about refugee solidarity in social media commentary}

Before the backdrop of claims-making analysis, we now turn to German news readers on Facebook and the way they responded to media claims-making during the refugee crisis. In general, we were able to identify complementary findings. On the one hand, we detected considerable synchronicity between public claims in the news media and readers' responses in terms of topics covered and main frames of interpretation used. On the other hand, we spotted slight differences in terms of audiences when comparing different newspapers and their readers' readiness to support refugee solidarity.

The issues raised in comments were largely identical to those discussed in the news. News readers on Facebook as well were mostly concerned with the political management of migration and short- and long-term consequences of the refugee crisis, such as economic costs. Facebook news readers, however, also picked up on so-called alternative agendas and discussed, for instance, the role of civil society, the involvement of ordinary Germans in solidarity action or the background of refugees. They thus positioned themselves in relation to the 'welcoming culture', either by embracing aspects of volunteering or by critically discussing the refugees' deservingness of solidarity, for instance, through the distinction of 'real' and bogus refugees. These overlapping issue agendas between newspaper claims-making and commenting are partly explained by the fact that comments were most often expressed in direct response to issues and claims raised in articles. Media claimsmakers are thus clearly distinguishable as 'primary definers' of the debate, as they set the agenda for the debate on social media. The public sphere constituted by Facebook is, in this sense, rather secondary and not 'alternative' to the news 
media. Thus, Facebook commenters often mirror public claims-making directly, confirming the interactive feature of the online debate.

Significant differences can be found, however, with regard to the overall tone of the debate. Facebook users are not only more critical with regard to the content of the article; they are also much more negative in regard to refugee solidarity than media claims-makers. Important differences in the tone of the debate are also found between different audience segments across the three newspapers under study. While keeping in mind the limitations of our rather small sample, we find that $S Z$ commenters express the most positive stance towards refugees (0.43, in contrast to FAZ: -0.75; Spiegel: -0.23 ), whereas the FAZ commenters, while commenting the least, are the most negative (see Eisele and Perfler, 2018, p. 82). Additionally, the distance in positions between the FAZ newspaper claims and comments' responses is also the greatest among the three newspapers (difference in mean position: 1.19 ; in contrast to SZ: 0.5; Spiegel: 0.57). In this respect, Spiegel readers are more in line with the more balanced claims reported in Spiegel.

The findings suggest a nuanced relationship between public claims-makers as covered in the news media and Facebook users' comments. While users in their comments largely follow the issue agendas defined by the news articles they have read, they tend to use the opportunity to disagree with the public claimants' positions. In fact, while the top-down communication by organised actors covered in newspapers conjures up the image of the overall positive, welcoming approach of German politics and society, we see that social media users engage in bottom-up communication that takes a more negative stance. This result can be related to more general discussions about the assumed hostility within online discussions, which are perceived to be 'undermining the deliberative potential of online interaction' (Ksiazek et al., 2015, p. 850). While it needs to be acknowledged that user commenting on Facebook is not an appropriate format for the unfolding of argumentative debates (in fact, $25 \%$ of all comments did not provide any justification), we need to highlight that Facebook users are nevertheless committed partly to engaging in argumentative reasoning. In fact, there is a recurrent pattern among Facebook users to provide dominantly moralising arguments in order to justify their claims. They do, for instance, refer to the appropriateness of the behaviour of migrants (as individuals or as groups) and provide religious or spiritual reasons when expressing their opinions in opposition to claims raised in the news. In this sense, we can speak of a negative trend among Facebook commenters that is not restricted to Germany, but is to be found also in the main patterns of user responsiveness in all other countries, except maybe for Italy and Greece (see Figure 5.4 in Chapter 5).

\section{Discussion and conclusion}

Public debates about solidarity with refugees as covered by German newspapers exhibit a clear pattern: they are dominated by contestations among the political elite; they focus primarily on the management of refugees and the possible 
problems and consequences of the large numbers of arriving immigrants. The dominance of state actors and the focus on crisis management fostered a perception of refugees as a 'problem that awaits solutions'. However, the discourse among the dominant political elites that was covered in newspapers was not biased in the sense of either embracing solidarity or rejecting it. Debates developed in cycles, depending on external events, and thus shifted from an overwhelmingly positive stance in the months of September to a decidedly negative one in response to the Cologne events on New Year's Eve 2015. Some weeks later, however, some balance is restored when discourse indicates that neither pity with refugees in need, nor fears about criminal refugees had a lasting impact on opinions expressed in public claims-making.

Our analysis thus sketches a rather balanced picture of the German political discourse on solidarity with refugees during the crisis. This is true in regard to participating actors. While political actors had a strong say, other actors could make their more positive opinions heard, as well. Angela Merkel is the most prominent figure in the debate, yet the government did not monopolise claimsmaking and other political leaders from the opposition and from the regional level were regularly given voice in the news. Thus, we find supportive evidence for the expectation that power and influence are important for explaining the media's interest in political leaderships. Moreover, conflict plays a significant role as well when it comes to what journalists regard as worthy of being covered in the news. This observation, however, conforms to the fact that claimsmaking analysis is a tool to map contestation, and thus a way to analyse dynamics of conflict - thus inherently linked to the media logic of newsworthiness (e.g., O’Neill and Harcup, 2009).

While the welcoming culture is strongly echoed in an overall positive tone of claims reported in news articles during September 2015, the discussion unfolding on Facebook's comments draws a more negative picture. Relating this to the findings that issues are mirrored in comments and comments often relate to claims in articles directly, it seems that commenters interactively engaged with political claims communicated top-down in the news media. However, Facebook comments are driven by some sort of backlash, even though these statements cannot be reduced to mere opposition. Commenters also formulated claims of their own, including justifications for their positions.

Our findings paint, on a more general level, a partial picture of solidarity contestations in Germany. We need to remember that previous analyses of Facebook data have shown that Facebook users are not representative of the whole population. For a study like ours, engaging in 'sampling only politically vocal social media users, is likely to have even fewer representative samples' (Mellon and Prosser, 2017, p. 6) is particularly relevant when evaluating our findings. We need to stress that the case study of September 2015 is but a glimpse into the public discussions about solidarity with refugees, as they are unfolding offline and online, and should therefore not 'tarnish' the radiant image of volunteers welcoming refugees at Munich's main station that month. Still, it provides important insights into the perceptions of commenters and 


\section{Solidarity contestation in Germany}

their otherwise probably unheard views on solidarity and migration. In addition, it deepens our understanding of the forces that influence public opinions about one of the most challenging and salient issues of our times - not only for the European Union, but for today's democratic societies at large.

\section{Note}

1 We would like to thank Jana Bernhard and Filip Perfler for valuable research contributions. A detailed discussion of the findings of the German case can be found in Eisele and Perfler (2018). 


\section{Solidarity contestation in Denmark \\ A national escape from transnational crisis ${ }^{1}$}

\section{Refugee solidarity in context}

At the peak of the so-called 'refugee crisis' in autumn 2015, Denmark was among the most inhospitable countries in the European Union. The welcoming culture that was sparked in neighbouring Sweden and Germany in the initial weeks of August and September 2015, mobilising substantial parts of the population in solidarity actions towards Syrian refugees in particular, did not extend to Denmark. Rather, the Danish government insisted on the strict application of the Dublin Regulation, rejecting the asylum applications of refugees who entered via its southern borders with Germany (Olsen, 2015). This unreceptive approach conforms with the orientation of the Danish asylum system, which openly privileges immigration policies which aim at deterrence of possible migrants, such as cutting social benefits for refugees by $50 \%$ and introducing further restrictions on family reunification (Gammeltoft-Hansen, 2017). By early September 2015, the Danish government had even placed advertisements in Lebanese newspapers, warning refugees that they would encounter these harsh measures, including detention and deportation, if they decided to come to Denmark (Gormsen, 2015). At the same time, the Danish government, for some time, allowed refugees to transit to Sweden providing only minimal assistance during their journey through Denmark, and considering their stay only temporary. Nevertheless, Denmark experienced a considerable increase in asylum applications in 2015, accepting a total of 21,000 refugees, which ranks it number 10 among the EU countries with the highest intake of refugees per capita of the population (though seven times less than neighbouring Sweden and two to three times less than Germany; Connor, 2016).

In contrast to its neighbouring country, Sweden, immigration debates in Denmark have been always fought in a highly controversial way, categorically rejecting multiculturalism as a model for Danish society and expressing a clear preference for a restrictive control of incoming migrants and refugees (Green-Pedersen and Krogstrup, 2008; Hedetoft, 2010). The Danish government's harsh approach to the European crisis fuelled an intense debate within the country, as well as critical voices across the EU demanding more solidarity. And domestic debates insisted that the Danish government had to conform to its responsibilities. In fact, the 
Danish population was not found to be particularly hostile in terms of solidarity towards refugees, when compared to other European countries. On the contrary, the harsh policies by the Danish government resulted in $18.1 \%$ of the population believing that Denmark should admit higher numbers of refugees from Syria. ${ }^{2}$ A substantial number of citizens also expressed embarrassment over their government's lack of solidarity towards refugees. During September and October 2015, tens of thousands of people took part in pro-refugee rallies in all the major cities of Denmark, and civil society all over the country organised private action in support of incoming refugees (Sand, 2015).

Public opinion on the issue of solidarity with refugees is characterised by an increasing polarisation of Danish society on questions regarding immigration, multiculturalism and international human rights obligations (Trenz and Grasso, 2018). Solidarity becomes increasingly contested between two opposite ends alongside a right-communitarian and left-cosmopolitan scale (Brändle et al., 2019; de Wilde et al., 2019). The right-communitarian pole is formed by the Danish People's Party (Dansk Folkeparti, DF) that defends an exclusive notion of nationalistic solidarity based on strong ethnic ties. At that time, DF was Denmark's second largest party, having gained $21.1 \%$ of the votes in the 2015 general elections and (together with the Liberal Alliance party and Det Konservative Folkeparti) subsequently provided parliamentary support for the rightliberal minority government formed by the Venstre party. The mobilisation power of the DF was particularly influential during the 'refugee crisis', as it was able to reach the whole population and influence public debates successfully. The left-cosmopolitan pole was represented by the Red-Green Alliance (Enhedslisten), garnering 7.8\% of the vote in the 2015 elections, and sees itself in proximity to many civil society initiatives, who rallied in support of the refugee cause and the moral obligations of inclusive, humanitarian solidarity. The largest opposition party, the Social Democrats (Socialdemokratiet, SD) were not explicitly opposed to the government's restrictive policies towards refugees and did not propose a more inclusive solidarity agenda.

\section{The Danish public sphere and solidarity}

Governmental EU positions are hardly challenged in the media, and journalists typically present a unified vision of Danish interests (De Vreese, 2003; Trenz et al., 2009). Over time from 1970 to 2016, Danish newspapers have increasingly become harsher in their reporting on immigration, portraying immigration as a threat, unlike in Sweden where victim-frames were more frequent and in Norway where coverage is less harsh than in Denmark (Hovden and Mjelde, 2019).

Denmark's media landscape is characterised by a wide distribution of newspapers which reach a broad readership and thus play an influential role in public debates. The three nationally distributed newspapers, namely JyllandsPosten, Politiken and Berlingske, uphold standards of quality journalism and guarantee wide-ranging coverage of political events both nationally and internationally. We included Jyllands-Posten and Politiken in our sample, because 
these two Danish newspapers have the widest circulation (Slots- og Kulturstyrelsen, 2017, p. 5). Jyllands-Posten is considered to be more government friendly, representing conservative readership (Hjarvard, 2007), while Politiken is considered to be more critical of government, representing a liberal-left leaning readership. The two national tabloids, Ekstrabladet and BT, play a minor, though not insignificant role. We included BT in our sample, because it has the larger readership of the two tabloids and was expected to be supportive of the governmental restrictive policies towards refugees.

\section{Patterns of political claims-making: The denial of transnational solidarity}

By looking at the chronology of the debate in the Danish media, the peaks shown in the articles and claims frequency (see Figures 4.1 and 4.2 in Chapter 4) correspond to a few decisive political decisions and developments regarding the influx of asylumseekers to Denmark and its neighbouring countries, Germany and Sweden. Generally, the hard-line approach to refugees was upheld by the government during the entire time period. In early September, the Danish Integration Ministry published announcements in Lebanese newspapers warning potential migrants against coming to Denmark. In the same month, the southern borders to Germany caught the public's eye as refugees and asylum-seekers made their way on foot along highways towards Denmark, most of them aiming to reach Sweden (Gormsen, 2015). With the Swedish government deciding to introduce border controls in November 2015, Denmark was no longer a 'transit country' for refugees. Responding to its neighbouring country, in the first week of January 2016, the Danish government implemented border controls itself. Later that month, the government announced its highly provocative 'jewellery law', which allowed for the seizure of assets from refugees upon arrival in Denmark. These harsh measures caused an international outcry, but were also discussed as controversial within Denmark. Our data reveal that newspapers report the same events and aspects in an almost parallel way. This indicates a relatively unified public sphere with clearly delimited debates. The patterns of claims-making regarding solidarity towards refugees point to an overall emphasis on migration management and political control. The increasing numbers of refugees are discussed as a problem of the national government that requires domestic measures of security and border control, and not externally coordinated actions at the European level embedded in a humanitarian framework. This general observation can be broken down into four main findings.

First, the Danish debate is centred around domestic state actors. We can therefore speak of a focus in Danish newspapers on debating refugee-related issues mainly from a state-centred, top-down perspective. Emphasis is put on control instead of solidarity. Public support of solidarity is mainly mobilised by civil society organisations, and most often these claims stand in opposition to statements by state actors (Figure 4.4 in Chapter 4). Among the political party actors (Brändle et al., 2018), the Danish People's Party (the DF), strictly opposed to refugee solidarity, was responsible for the representation of most 


\section{Solidarity contestation in Denmark}

claims. The main opposition party, and Denmark's largest political party, the Social Democrats (Socialdemokratiet, SD) ranks second among the claimants, though not in major opposition to the government's negative stance: Venstre, the governing party on the centre-right, is the third most frequent claimant in the media. The centrality of these three parties is noteworthy, because it shows their ability to dominate the public debate. Indeed, other parties who defended a solidarity agenda with refugees, such as Enhedslisten, were hardly ever given voice in the debate. It was the $D F$, in particular, which gained visibility in the media via provocative statements that expressed hostile attitudes toward refugees (Brändle et al., 2018).

The dominance of these actors suggests that public debates about the 'refugee crisis' were mainly domestic and excluded foreign or European voices to a large extent. This points to a low level of Europeanisation of the refugee debate in the Danish media. The latter put less emphasis, for instance, on the discussion of the causes and effects of flight, the wider European repercussions of the crisis, and the European-international context of cooperation within which possible solutions to the 'crisis' were debated. Almost two thirds of the main claimants have a national scope $(63.9 \%)$. Regional $(18.2 \%)$, and in particular, supranational actors (16.3\%) are clearly underrepresented (Brändle et al., 2018), and crucially national actors on average took negative stances toward refugees (see Figure 4.8 in Chapter 4).

Secondly, and in line with the high visibility of domestic state actors, issues relating to refugee solidarity were given generally low salience in the Danish media. Debates centred dominantly on policies of 'Migration Management', that is, on issues touching upon asylum policies, border controls and other ways to control, secure or administer the influx of refugees and asylum-seekers. At $66.5 \%$, such security and control issues take most space in the debate, leaving minimal room for claims raising alternative agendas in support of refugee solidarity. In fact, only every $11^{\text {th }}$ statement raises a solidarity issue regarding the integration of refugees $(8.9 \%)$, and only every $13^{\text {th }}$ claim thematises refugees' experiences of flight or their personal stories (7.6\%) (see Table 4.2 in Chapter 4). This pattern suggests an overemphasis on the domestic perspective of the 'refugee crisis', privileging questions of security, control and border management, and downplaying humanitarian issues, which are externalised and relegated to the European Union. Of all the issues raised in the debate, $71.3 \%$ are of a purely national or subnational scope, i.e., do not look beyond the borders of Denmark. Less than one third of the claims touch on the European and transnational ramifications of the refugee crisis.

Thirdly, the refugee solidarity debate in Denmark is driven by a focus on political decisions. This points to a top-down perspective that addresses the 'refugee crisis' through the lenses of state actors, and not through civil society or opposition parties. Solidarity contestation is confined to the official arena of state and party politics, and there is little attention paid to solidarity action or protest. The mass-mediated debates thus privilege an official account of how decisions are taken within the political institutions, but leave out protest events 
and direct solidarity actions such as providing resources to refugees directly. In this way, visibility is granted to top-down decision-making, while relegating contestation to the outside: Opposition is expressed by civil society and grassroots organisations or NGOs, and not by political parties, but this means that these voices receive considerably less attention in the news reporting. Ultimately, confrontation takes place between state and civil society, not along ideological lines between political parties.

Fourthly, the overall distribution of pro- and anti-solidarity claims towards refugees reflects a sharp polarisation of the debate dividing the claimants in two equally large groups: Positionality towards solidarity with refugees is divided into shares of $40.0 \%$ negative, $40.0 \%$ positive and $19.4 \%$ neutral claims, with no significant difference in the position of reported claims between the newspapers (see Table 4.3 in Chapter 4). Therefore, contestation is high since $80 \%$ of the claimants take an explicit stance on refugee solidarity. Generally, state and political actors hold the main share in negative positions towards refugee solidarity (see Figure 4.4 in Chapter 4). This stands in contrast with positions taken by civil society and other actors, who are more supportive of refugees. Most frequent were claims by state and political actors who adopted a negative tone toward refugees, focusing on rational solutions and a 'management' approach to 'crisis', dominated by state actors (see, e.g., Table 4.5 in Chapter 4). Additionally, political actors used mostly interest-based justifications (see Brändle et al., 2018). We found rights-based justifications in around a quarter of the claims, but hardly used by political actors and rather used by civil society actors, suggesting more humanitarian forms of solidarity among these claimants. Identity-based justifications were rare, meaning that claimants did not often refer to aspects of identity or ethnicity when justifying their stances regarding solidarity. These patterns are similar to the ones found in the other countries (see Table 4.6 in Chapter 4 ).

\section{A month of contestation on Facebook: Commenters' responses to the solidarity debate}

An important dimension to understand Danish solidarity contestation regarding the 'refugee crisis' is whether commenters in social media supported or opposed the positions expressed by the main claimants in the news media, because this allows us to identify the way they positioned themselves with regard to solidarity with refugees. Our data show that commenters on the Facebook sites of Danish news media strongly engaged with the issues and demands expressed in the posted newspaper articles. This engagement was mainly critical, because the majority of the commenters 'talked back' to claimants in the media by opposing their views. Despite the fact that articles posted by Danish newspapers on Facebook were on average more positive towards refugees, Facebook users' voices were raised mainly to reject solidarity towards refugees: $47.7 \%$ of comments spoke out against refugees directly, in contrast to $39.7 \%$ that were supportive of solidarity toward refugees, while $12.9 \%$ remained neutral or 
ambivalent (see Table 5.4 in Chapter 5). In instances where justifications were used, commenters mostly justified their stances with references to human rights. In these cases, commenters were mostly positive regarding solidarity. In negative comments, we found more commenters justifying their rejection of solidarity by referring to refugees' (supposedly 'bad') behaviour, as well as to the demand that national citizens' needs are more important than the needs of 'outgroups' (justification 'welfare chauvinism') (Brändle et al., 2018).

These findings show that Facebook users engage in commenting on articles in order to express criticism or opposition to the claims reported in the posts. They thus deviate from the picture painted by the previous research in two ways. On the one hand, Facebook users are involved in criticising and arguing with regard to the claims reported in the posted news, which means that Facebook comments are much more than a generalised and vague expression of political discontent and frustration. The level of interdiscursivity is not as low as others have argued (Hille and Bakker, 2013). On the other hand, social media sites are not an arena where commenters form 'counter-publics' and evolve around shared notions of immigration as a threat, as research has suggested (Toepfl and Piwoni, 2015). Even though there is a dominant negativity in Danish user comments, these commenting forums can hardly be described as a counter-public, because we also found pro-refugee engagement and counter mobilisation by users against the anti-solidarity claims of the majority.

\section{Discussion: A national escape from crisis}

The 'refugee crisis' debate of 2015 reflects the increasing polarisation of Danish society along the lines of inclusive humanitarian solidarity orientations towards others and exclusive national-communitarian solidarity. Civil society representatives appear in the media not simply as care-takers or charity actors, but as actors in opposition to the government. The refugee crisis leads in this sense to a politicisation of the civil society sector. This confirms the bipolar patterns of refugee solidarity in Denmark, which we also found in our survey of civil society solidarity action (Duru et al., 2021): While on the one hand, the refugee crisis has mobilised many Danish people in support of refugee solidarity through charity action and political protest, there is, on the other hand, a widespread attitude of welfare chauvinism among Danish citizens paired with anti-immigrant attitudes.

The Danish civil society and its lively support of refugees, however, is not a plot for news stories in the media. Danish citizens' engagement in voluntary work is only marginally dealt with as part of the news coverage of the 'refugee crisis'. Additionally, Danish news media tend to cover the international and European 'refugee crisis' from a rather narrow national perspective. They give ample floor to the position of the government and its supporting parties, which join in on the attempts to define 'refugee crisis' as something that does not affect Denmark and is thus to be treated as something external. Against this majority of claims, there is only a minority of oppositional voices that rally for 
refugee solidarity but cannot gain high media salience. In this sense, there is a polarisation of debates about the 'refugee crisis', but this contestation does not reside in dissent between governmental and oppositional parties The analysis rather suggests that the division is between a dominant group of political actors rejecting solidarity and a small segment of civil society actors in support of solidarity. The Danish media thus leave little space for actors seeking confrontation that challenge the positions taken by the government.

The Danish debate is thus characterised by what can be called a 'national escape from crisis', because it distances itself from the causes of increased migration and insists on keeping developments under control in a situation of national emergency. A more fundamental debate about the foundations of solidarity in Europe does not take place. Only a minority of voices raises inconvenient questions in the media, when they ask why Denmark shows so little solidarity in Europe and why its policies of deterrence should be in line with the Danish self-understanding of universal welfare and human rights.

The country is divided on refugee solidarity, but this division is underplayed by the media. Instead, there is a remarkable salience of Danish political actors discussing the 'refugee crisis' in terms of political management of borders and asylum policies. This is a matter of concern, not only because pro-solidarity voices are misrepresented in media claims-making, but also because the centrality of anti-solidarity measures in news coverage might distract the readers from the actual humanitarian crisis which still forces millions of people to flee to safer areas.

In light of these results, we have found that the Danish media rather uncritically reflect the official position of Denmark in Europe, promoted by the government, and thus carry rejection of solidarity, undisputed, into public debates. The rather negative news coverage of solidarity and immigration in the news in general makes it difficult for bottom-up initiatives to promote their engagement for people in need against more powerful top-down voices of rejection.

\section{Notes}

1 We would like to thank Freja Sørine Adler Berg and Anna Sofie Rosenberg for valuable research contributions. A detailed discussion of the findings of the Danish case can be found in Brändle et al., 2018.

2 The Danish population is, according to our own TransSOL survey, the most favourable with regard to the question of taking in refugees from Syria. The average level of support among the eight countries included in the survey is $12.3 \%$. The survey was fielded at the end of 2016 (Grasso, 2017; Lahusen and Grasso 2018). 


\section{Solidarity contestation in France \\ Bottom-up polarisation and segmentation}

\section{Refugee solidarity in context ${ }^{1}$}

Solidarity is a major pillar of the French constitutional framework, built into the brick of 'brotherhood' (fraternité) and contained in the same Revolutionary tricolour and national anthem. In the migration and refugee field, however, political developments throughout the 2000s and 2010s have signalled an overall process of declining solidarity, combined together with an increasingly restrictive stance of the French state. The traditional generosity of the French system, both in terms of the short-term welcoming of refugees and the long-term integration of migrants into full citizens has been replaced by a series of restrictive twists. Accordingly, new 'reforms' have prevented migrants and refugees from accessing the country by making it more difficult for them to attain citizenship (Cinalli, 2017), while at the same time nurturing anti-migrant discourses which push the idea that migrants and refugees are a burden on society (immigration subie). Perhaps the strongest symbol of the migration crisis has been the 'Calais Jungle', a camp near the northern city of Calais. Many migrants living in this camp have pursued the objective of crossing the Channel and entering Great Britain. The camp gained global attention during the refugee crisis, particularly with respect to mass evictions which French authorities have been carrying out since October 2016 (Baumard, 2016), peaking with the final clearing of the 'Jungle'.

Indeed, restrictive measures have underscored the negative agenda of successive governments, left or right, which have deterred new arrivals, introduced tougher border controls at the time of the 'Arab Spring' and the Syrian war, denied solidarity to the large number of Tunisians and Syrians reaching France, and implemented coercive measures against those who provide solidarity aid to migrants and refugees. All these dynamics have taken place within a highly sensitive context, owing to a series of terrorist attacks such as the Charlie Hebdo shooting on 7 January 2015 and the Paris massacre in November 2015. Since then, the public sphere has been shaped into a deeply emotional debate, impinging on the discussion of the refugee crisis. Thus, at the time of the refugee crisis, France was ravaged by draconian measures of public emergency; it was burdened by the economic and political legacy of the economic crisis and 
wars in Iraq, Syria and Libya; and it underwent intense party competition combined with a growing popular support for the extreme right.

The shifting policy-agendas have had considerable repercussions on debates and activities of solidarity at the time of the refugee crisis, because they have introduced ambivalences and contradictions. In fact, French authorities have also intervened in the field with a favourable position vis-à-vis refugees. Thus, they have transferred to NGOs and social firms the burden of sustaining migrants and refugees through granting specific funding, since NGOs and social enterprises can implement programmes that are broader in scope and deeper in outreach. Accordingly, favourable interventions have targeted the disadvantaged neighbourhoods with the highest percentages of migrants and people of migrant background (Escafré-Dublet et al., 2014). A number of civil society organisations have taken the responsibility for actions that are invaluable to mediate between the state willingness ('in principle') to welcome on the one hand and, on the other, the promise of migrants and refugees' integration into the French Republic. Some civil society organisations, for example, have connected migrants with firms to create job opportunities, maintained databases of potential candidates for employers, offered refugees training courses, set up group workshops, individual coaching, media training with professional communication and human resources. Simply put, there has also been renewed evidence of increasing pro-beneficiary mobilisation on behalf of refugees and migrants (Cinalli, 2004 and 2007; Giugni and Passy, 2001).

\section{The French public sphere and solidarity}

We can now provide a picture of how the French public debate over the refugee crisis has developed between August 2015 and April 2016. Our focus on the refugee crisis enables us to deal with a highly resonant topic in the public sphere which has stood out as a central focus for the state, policy-makers and civil society. Accordingly, our aim is to analyse the main dynamics such as the role that French citizens have had in the definition of the issue, the specific grids by which refugees have been framed (for example, as victims or otherwise as a threat), the degree to which organised publics have engaged with solidarity actions on behalf of refugees, as well as the main level shaping the public sphere (national, transnational, subnational). Our analysis follows an operationalisation of the public sphere that draws on 'claim-making' (Cinalli and Giugni, 2013a, 2016a; Koopmans and Statham, 1999), shedding light on specific national dynamics within the context of broader European comparative analysis, offered in Chapter 4.

The French media landscape is characterised by a wide distribution of newspapers with a high readership and influence in the public sphere. In particular, our analysis draws on Le Figaro and Le Monde (having the widest circulation and standards of high-quality and wide-ranging coverage), as well as Le Parisien (standing out for its more tabloid style that reports sensationalist news). The number of readers for all three newspapers represented almost 
1 million in 2015 (Alliance pour les Chiffres de la Presse et des Médias, 2017). The newspapers chosen ensured the equal representation of opposed opinions and socio-political cleavages in France so as to fit our focus on solidarity contestation in a country where issues of migration and diversity are highly contentious (Cinalli, 2017). Le Figaro is a conservative right-wing media; Le Monde represents left-wing citizens and Le Parisien the centre. Overall, our analysis gathered information on 764 claims, identified through the examination of 301 articles (with an average of ca. 2.5 claims per article).

At the same time, the analysis focuses on user commenting to add another crucial layer of contestation in the migration and refugee field. In so doing, the analysis allows for stretching our study of the public sphere in a way to include the voice of individual French readers who intervene to express their position and (dis)satisfaction vis-à-vis claims of the main organised publics in the media. In this case, our data refer to 300 Facebook comments in response to 13 newspaper articles related to the refugee crisis over the period of September 2015. Data were extracted from Facebook using the online application Netvizz. This tool allowed us to collect all comments responding to media articles for Le Figaro, Le Monde and Le Parisien in September 2015, with numbers of likes, shares and replies. This first step involved the selection of posts (links to newspaper articles) that related to the research object. The final sample included a total of five posts for Le Figaro, five posts for Le Monde and three for Le Parisien, with 20 user comments coded for each. Since certain comments fell short of the sampling criteria, a total of 97 comments were coded for posts published by Le Figaro, 100 for Le Monde, and 103 for Le Parisien.

\section{Patterns of political claims-making}

Our findings show that the highest peak in terms of public coverage of the refugee crisis refers to the strong public impact of the support of the French President, François Hollande, in favour of establishing a refugees' quota system. Claims' distribution shows that this peak occurred in September 2015 (see Figure 4.2 in Chapter 4), at the same time when the President announced that France would welcome 24,000 refugees. The prominence of these events is in line with the general pattern within our data, according to which state actors lead more than half of the whole claims-making. Behind numerical figures, we find that German Chancellor, Angela Merkel, is a prominent actor in the French public debate, even more so than the French President. This corresponds to the decision of the German President to accept the largest number of refugees in Europe in spite of tough internal and external opposition. More broadly, we find a strong presence of German actors, signalling a certain Germanisation of the refugee crisis debate. Beyond this specificity, French debates are structured along a clear distinction between state actors, whose scope is mostly national and sub-national, and categories like 'group-specific organisations', 'civil society and human rights organisations' as well as 'professional organisations groups' which are characterised by both an international and a sub-national scope. 
Looking behind the general figures, it is important to say that claims by state actors include guidelines for the welcoming of refugees (which the national government give to subnational governments), official visits by the Prime Minister in Greece to help the Greek government, as well as declarations maintaining an open dialogue with controversial state leaders such as Viktor Orbán and Recep Erdogan. The prominence of state actors is followed by that of political parties, which include mainly representatives of the Socialist Party, the Republicans and the National Front. Emphasis must be put on the relatively low visibility of civil society in general, as well as 'advocacy and policy-oriented groups'. The diverging presence of state, political and civic actors has consequences for public debates, because these actors advocate for different types of narratives that nurture contentiousness in the overall field. State actors, especially under the Socialists' rhetoric, lead a neutral discourse about the refugee crisis and the role of France as a country of transit for refugees. Against this position, the extreme right stands out for its tough position, calling for an end to any systematic plan for welcoming, while the Republicans take a middle position by calling for tougher controls at the French borders, together with major plans for international aid.

As regards the position vis-à-vis refugees in particular, it is important to note that a substantial share of ca. $40 \%$ of claims by state actors are openly supportive of refugees (with the remaining claims being distributed evenly between a neutral and an anti-refugees stance, respectively), whereas nearly half of claims by political parties are in explicit opposition to refugees. ${ }^{2}$ This is evidence of increasing contentiousness, a result of competition between main political stakeholders in the party system, beyond the more soothing attitude of main institutions and especially civil society. It is instructive to look at the justifications public claimants employ when supporting or opposing solidarity with refugees. In this regard, we see affinities between justifications in support of solidarity and positions towards objects (see Table 4.6 in Chapter 4). Approximately two thirds of the rights-based justifications supporting general or universal principles are linked to favourable claims towards refugees, whereas over $40 \%$ of identity-based justifications rejected solidarity towards refugees. As regards interests-based/utilitarian justifications, they are in a balanced situation between anti-refugee and pro-refugee positions.

Some final findings consist of the extensive variation of claims-making across different newspapers. Table 9.1 shows that Le Monde is the newspaper that most often avoids reporting a solidarity justification, while Le Parisien almost always does so. This finding is somewhat counter-intuitive since one would expect more complete information over claims in higher quality newspapers than in the tabloid-style press. Yet it is in line with the major effort that a tabloid-style newspaper such as Le Parisien has made in France to show that the refugee crisis touched the core of interests, rights, and identities of citizens. Another interesting variation can be found in terms of more identity-based newspapers on the one hand, in line with the conservative vision of Le Figaro, and more rights-based newspapers on the other, in line with the progressive vision of Le Monde. 
Table 9.1 Solidarity frames across newspapers

\begin{tabular}{lllllllll}
\hline & $\begin{array}{l}\text { Le } \\
\text { Figaro }\end{array}$ & $\%$ & $\begin{array}{l}\text { Le } \\
\text { Monde }\end{array}$ & $\%$ & $\begin{array}{l}\text { Le Par- } \\
\text { isien }\end{array}$ & $\%$ & TOTAL & $\%$ \\
\hline $\begin{array}{l}\text { Interest-based/ } \\
\text { utilitarian }\end{array}$ & 106 & 33.44 & 57 & 17.98 & 154 & 48.58 & 317 & 41.49 \\
$\begin{array}{l}\text { justifications } \\
\begin{array}{l}\text { Rights-based } \\
\text { justifications }\end{array}\end{array}$ & 22 & 22.22 & 21 & 21.21 & 56 & 56.57 & 99 & 12.95 \\
$\begin{array}{l}\text { Identity-based } \\
\text { justifications }\end{array}$ & 24 & 36.36 & 13 & 19.70 & 29 & 43.94 & 66 & 8.63 \\
$\begin{array}{l}\text { No } \\
\text { justification }\end{array}$ & 98 & 34.75 & 173 & 61.35 & 11 & 3.90 & 282 & 36.93 \\
\begin{tabular}{l} 
Total \\
\hline
\end{tabular} & 250 & 32.72 & 264 & 34.55 & 250 & 32.72 & 764 & 100 \\
\hline
\end{tabular}

\section{A month of contestation on Facebook: Commenters' responses to the solidarity debate}

To fully understand whether solidarity is collectively supported or contested in the debates, it is important to include bottom-up mobilisation beyond mass mediated discussions. ${ }^{3}$ Our findings show that refugees were the subject of debate for $91.3 \%$ of Facebook comments.

Facebook users' reactions revealed the predominance of negative positions towards refugees. With a mean of -.328 , the study shows that French commenters did not express solidarity with the newcomers. Often, French Facebook users were opposed to welcoming refugees, granting refugee status and asking for border closure. In second position are placed those who expressed neutral attitudes: they questioned politicians, values of French citizens, and/or the way the media presented events (i.e. media manipulation). Only a minor proportion of the French Facebook users expressed solidarity with the refugees in their comments. In this case, they often defended refugees, reminding readers of the human perspective, supporting open asylum policies and stressing that refugees' lives were in danger in their home country.

A majority of the comments justified their stances regarding solidarity, while $22 \%$ did not. When commenters provided a justification against solidarity, they referred firstly to 'welfare chauvinism' (16\%), suggesting putting the needs of French citizens above refugees' needs. This was followed by individuals who questioned the social or economic capacity of France to host refugees $(10.3 \%)$. By contrast, pro-refugee justifications built around philanthropic reasons, i.e. human rights, represented only $10 \%$ of Facebook users. Human rights have certainly emerged as a main justification among pro-refugee commenters: being human, or humanity has thus been used to express solidarity towards the refugees, or to call explicitly for their protection.

Findings show that an overall majority of $3 / 5$ users related to the conservative newspaper do not express solidarity towards refugees. By contrast, readers of the progressive newspaper express a more equal distribution between 
those who show negative, neutral and positive positions vis-à-vis refugees. Users of Le Parisien show equally a proportional distribution between positive, neutral and negative positions, yet they display similar levels of opposition as Le Figaro This suggests that commenters seek out the newspaper that speaks to their personal opinion, thus users' positions vary when comparing the three newspapers. In this sense, solidarity contestations seem to be strongly segmented along different camps sharing similar ideological orientations, while congregating under the roof of ideologically akin newspapers. In this sense, French newspapers tend to contribute to the polarisation and segmentation of public debates about solidarity.

\section{Discussion}

Our data indicate that the refugee crisis has been a highly relevant topic for discussion in the public sphere, raising extensive debates among the state, policymakers of different kinds, as well as organised publics and individual citizens. The most crucial point, however, is the ways in which positive, neutral and negative stances vis-à-vis refugees are distributed across claimant types. In particular, the tonality of the debate is on average slightly supportive of solidarity with refugees; however, we also see a strong contentiousness of public claims-making, given that only about one third of all public interventions raise neutral or ambivalent views, and thus around two thirds of claims endorse or reject solidarity with refugees (see Table 4.3 in Chapter 4). Political actors show on average an anti-refugee stance, while civil society organisations join the voice of those supporting refugees; as regards state actors, they maintain a moderately positive stance, which seems to be influenced by the position of the German government and the binational relations between both countries.

The solidarity contentions are also related to the arguments and justifications used by public claimants when endorsing or refusing solidarity with refugees. In fact, our findings have confirmed that there is a tight relationship between certain types of justifications on the one hand, and the positioning vis-à-vis refugees on the other. In particular, the defence of refugees comes together with a strong emphasis on a humanitarian perspective, supporting open asylum policies and stressing that refugees must be protected in the name of fundamental human rights. In contrast, the opposition against solidarity with refugees is most often defended through identity-based justifications. Solidarity contentions are increasing because the public sphere is fragmented between newspapers according to the specific political orientations which they convey. In fact, claims-making varies across different newspapers to such an extent that their audiences remain divided according to traditional ideological cleavages between the left and the right of the French political spectrum.

Similar patterns can be observed in the comment sections on Facebook, where commenters seem to stick to the newspapers according to political preferences. This leads to differences between comment sections of the three newspapers. It is in this sense difficult to speak of shared solidarity contestation 


\section{Solidarity contestation in France}

when looking at bottom-up mobilisation in the French case. Instead of arguing with each other, news readers tend to search for like-minded arenas and commenters that support their views, thus contributing to a more polarised and segmented bottom-up debate. It thus seems that the political leanings of the traditional media have left their mark on social media debates, as well.

\section{Notes}

1 We would like to thank Rosa María Lechuga Morales, Carlo de Nuzzo and Maria Jímena Sanhueza for valuable research contributions. A detailed discussion of findings of the French case can be found in Cinalli et al. (2018).

2 For detailed numbers and a discussion on the position of French claimants, see Cinalli et al. (2018).

3 For detailed numbers and a discussion on commenters' responses to the solidarity debate, see Cinalli et al. (2018). 


\section{Solidarity contestation in Greece Standing on the verge of emergency ${ }^{1}$}

\section{Refugee solidarity in context}

Since 2009, solidarity in Greece has been seriously put under pressure by a context of multiple crises with considerable political, social and humanitarian repercussions (Mexi, 2018). Besides the economic and financial crisis, migratory pressures have increased and since 2015, Greek authorities have struggled to accommodate the high number of people arriving at its borders, especially on the islands of Lesbos and Samos. Given its geographical location, Greece became the main entry gate for refugees and migrants into the European Union. According to statistics provided by the UNHCR, 856,000 arrivals were recorded in Greece in 2015, most of whom were refugees escaping from the war in Syria (Velentza, 2018). Against this backdrop, the number of first-time asylum applications, according to Eurostat, was somewhat delayed and much lower, with 13,210 applicants recorded in 2015 and 51,105 in 2016. For a great number of incoming refugees, Greece was merely a transit country on their journey towards other destinations in the EU.

The SYRIZA (Coalition of the Radical Left)-ANEL (Independent Greeks) coalition government called at that time for external support, and asked Frontex and the EU for help to control its borders and provide humanitarian assistance for people who were expected to transit through Greece. As a beneficiary of European solidarity itself, the Greek government made clear that its efforts to engage in refugee solidarity could only be minimal and would be reliant on international assistance (Paschou and Loukakis, 2018, p. 95). Unlike the former governments, who implemented a harsh control policy towards immigration and erected a fence at the Greek-Turkish border, the SYRIZA-ANEL government was less restrictive. It allowed refugees to enter the country, but did not comply with its obligations as stipulated by the Dublin Regulation to register asylum seekers in their first country of arrival (Velentza, 2018). While the dysfunctionality of the Dublin Regulation became evident for all (see Zaun, 2018), Greek immigration and asylum policies were characterised by incoherence and conflicting domestic demands. Hostile, anti-immigrant claims were raised, above all by extreme right-wing parties, who had become increasingly popular during the decade of 'crisis', putting social solidarity and cohesion under stress 
(Mexi, 2018, p. 350). In the weeks and months of major influx of refugees (August 2015 until early 2016), the government's 'open border policy' mainly facilitated the transit of refugees from the Greek islands in the Aegean Sea to the Macedonian border, from where they headed towards northern destinations. At the same time, the Greek government emphasised the interlinkage between the financial and humanitarian crisis, and called for solidarity from the EU and from member states. It made use of what was called the 'refugee crisis' as a bargaining chip to handle the Greek debt crisis with more flexibility (Evangelinidis, 2018).

By insisting on Greece being a 'transit country', the Greek government attempted to externalise the problem. Yet the country also had to face a humanitarian disaster domestically, as human lives had to be rescued and first aid assistance had to be provided to the incoming refugees, who arrived on the shores of the Aegean islands often in desperate condition. The televised pictures of the overcrowded refugee camps incited a broad mobilisation of solidarity in the whole of Europe, and were also the background for the accusation of the UNHCR that the Greek government was neglecting its humanitarian duties (Mexi, 2018, p. 348). Refugee reception took place under poor conditions (and continues to do so; see Bell, 2020). A lack of functional state structures forced Greece to rely primarily on the informal sector of civil society volunteering that had already emerged in Greece during the Great Recession in response to economic hardships (Kalogeraki, 2018). Informal and often politicised civil society support networks were reactivated in 2015 to provide spontaneous assistance to refugees in situations of emergency and to raise awareness about the danger of right-wing extremism and xenophobia, such as those linked to the rise of the group Golden Dawn. Such informal and local citizens' initiatives tried to take a substitutive function in the absence or inefficiency of state help and more formalised support action (Kanellopoulos et al., 2020; Kousis et al., 2020). However, their capacities to shelter their beneficiaries from precariousness were limited, and it soon became clear that in the face of a problem of such magnitude, volunteering could not substitute state action and the absence of organised civil society. International aid brought partial relief in the form of transnational solidarity coalitions between NGOs, International Organisations such as UNHCR and IOM (International Organisation of Migration) and volunteering citizens from all over Europe, which collaborated with local support groups on the Greek islands and at the border with the Republic of Macedonia to provide first assistance. Grass-roots level solidarity that is spontaneously organised by local citizens in response to urgent need in their immediate environment was thus interlinked with broader networks of transnational solidarity (Kousis et al., 2018).

Public attitudes of solidarity towards refugees in Greece were not significantly different compared to the rest of Europe. According to our own TransSOL survey on solidarity attitudes and behaviour (Grasso, 2017; Lahusen and Grasso, 2018), the moral obligation to provide help to war refugees from Syria was generally accepted by the majority of the Greek population. Despite the experiences of economic deprivation, $31 \%$ of Greeks agreed with the intake of the high number of 
refugees or would even have supported higher numbers. A substantial majority of the Greek population (51\%) demanded, however, that this number should be lowered and $12.9 \%$ categorically rejected the intake of Syrian refugees. There was thus quite a clear opinion that Greece took in more refugees than it could possibly handle, and that it should be assisted by Europe, but this attitude did not compromise a general support of the principle of refugee solidarity. ${ }^{2}$

\section{The Greek public sphere and solidarity}

The Greek public sphere is traditionally shaped by the strong role of party discourse amplified by journalists who are more party affiliated than independent reporters. The independence of journalism suffers from political patronage and entanglement with politics (Doudaki and Boubouka, 2019). Typically viewed as a polarised pluralistic media system, strongly established in Southern Europe (Hallin and Mancini, 2004), the Greek public sphere is distinguished by ideological cleavages that shape polarisation in public attitudes. Journalists typically propagate a Greek identity based on a strong ethno-cultural notion of nationhood and are committed to defending national interests towards 'an outside', but they are also torn by the fractured solidarity at the inside along the lines of social class and party affiliation (Iosifidis and Boucas, 2015). As a consequence, Greek media and journalism are among the most distrusted in Europe. ${ }^{3}$ During the economic crisis, the established structures of this media system collapsed, when public broadcasting was partly suspended, several of the country's largest media organisations went bankrupt, and newspaper coverage dramatically shrank (Michailidou and Trenz, 2015; Siapera et al., 2015).

Greece's media landscape is characterised by a low distribution of newspapers, a considerable decrease in the number of news readers since 2008 and the closure of several flagship newspapers, with a parallel rise in digital newspapers and news portals. The three newspapers selected for our content analysis, the centre-right, Kathimerini, ${ }^{4}$ the liberal centre, Ta Nea, ${ }^{5}$ and the tabloid/ right-wing newspaper, Proto Thema, ${ }^{6}$ are among the most popular outlets and occupy an influential place in political debate.

As in other countries of our sample, public and media attention at the peak of the so-called refugee crisis was high. It was even enhanced by journalists travelling in from countries worldwide to provide live coverage of dramatic and unfolding events in what they considered to be 'the epicentre of crisis'. A quantitative content analysis of Greek news coverage by Fotopoulos and Kaimaklioti (2016) revealed that for the early months of 2016 there was a dominant focus on the 'inhumane' living conditions in the refugee camps. This observation is confirmed by our own study of claims-making, because Greek newspapers tended to individualise the crisis, giving refugees voice or portraying their individual stories. On average, their coverage of the refugees was favourable, but they were critical of the government and the EU.

This humanitarian agenda seems to be a reflection of political developments in Greece preceding the 'refugee crisis'. In earlier times, migrants were badly 
integrated into Greek society (Triandafyllidou, 2009) and, driven by the rightwing forces, public opinion grew increasingly negative with repeated incidents of racist attacks, especially against migrants from Muslim countries, who were seen as a threat to the ethnic-national homogeneity of the Greek nation (Kadianaki and Andreouli, 2017). While previous governments opposed liberal immigration policies and engaged in securitisation measures (Evangelinidis, 2016), a major shift came with the Tsipras government, which took office in 2015 and engaged in a radical-left discourse on immigration that linked the issue to capitalist globalisation, impoverishment and wars (Nestoras, 2015), and put Greeks and migrants on par as 'victims of crisis'. Even though this left-leaning internationalism had little direct impact on public debates, media attention nevertheless shifted towards a more favourable position towards refugees. Existing research of Greek press coverage during that short period in early 2016 highlights that journalism clearly focused on the living conditions in the refugee camps and on procedural/administrative issues related to migration, e.g., transfer and registration, as the most frequently reported topics (Fotopoulos and Kaimaklioti, 2016). Furthermore, evidence from comparative research suggests that Greece, alongside other frontline countries during the 'refugee crisis', scored significantly higher in humanitarian action as opposed to military securitisation in its media narratives and gives more voice to refugees compared to other western European countries (Georgiou and Zaborowski, 2017, p. 10).

\section{Patterns of political claims-making: The externalisation of crisis}

Our own claims-making analysis confirms this picture of Greece as a transit country in a situation of emergency. In line with the rest of Europe, debates about refugee solidarity in Greece peaked in September 2015 with the mass arrival of refugees, but in contrast to how the debate unfolded in other countries, the issue continued to be high on the agenda and the intensity of debates even increased in early 2016 (Figures 4.1 and 4.2 in Chapter 4). The second peak of highest media attention is located in mid-March 2016 and corresponds with the EU-Turkey deal signed on 19 March 2016, after which numbers of incoming refugees were considerably reduced. This lasting salience of the refugee issue over an extended period of time is related to the decision of the European governments in late 2015 and early 2016 to close their borders to transiting refugees. Other countries were more successful than Greece at taking the 'refugee issue' off the agenda, by taking drastic measures with significant negative side-effects for Greece. Refugees were stranded here, and many of them reached deadlock at the border with the Republic of North Macedonia, where the situation escalated in March 2016 (Paschou and Loukakis, 2018). Public attention for the so-called refugee crisis and controversial discussions were very unequally distributed across the European public sphere. The resistance of European partners to assist Greece in an emergency situation in early 2016 triggered heavy debates and many protests in Greece, but considerably less so in the rest of Europe. 
The intensity of public debates is not the only aspect that distinguishes the Greek situation from the one in the other countries under study. Everywhere else, the refugee crisis was portrayed mainly as a problem to be dealt with by national governments, called to take adequate measures at the domestic level in terms of security measures and border controls. The Greek debate is special because domestic actors pleaded for external help and coordinated action within a European framework dedicated to humanitarian aid. Political claims regarding solidarity towards refugees exhibit two main features that are strongly interrelated: low levels of domestic political contestation on the one hand, and an external dimension that is manifested in the plea for international support and cooperation in the management of the refugee inflow, on the other, that placed particular emphasis on lobbying for European solidarity. The agenda was set by the emergency situation and the necessity to respond to the basic needs of the incoming refugees. That such assistance had to be provided was uncontroversial and did not need to be further contested in the media. The debate was documented and informative; it could evoke emotions, but it was not strongly opinionated. This also explains why claims-making in Greece was less focused on security issues, which the government had few resources to provide anyway. The emphasis was rather on humanitarian concerns and a solidarity response from abroad.

Three salient patterns underline these results. First, as in other countries in our sample, the dominance of state actors is overwhelming in the Greek debate. This can be explained by the external dimension of the crisis, which led to the formulation of a nationally unified position. In a situation defined as 'emergency' and 'crisis', state actors can occupy both security and humanitarian agendas, and thus ensure a monopoly of the debate. Such a convergence of agendas can be considered to be atypical compared to traditional patterns of political culture in Greece: Instead of polarisation, the Greek debate led, at least temporarily, to a unification of the voice of media claimants, mainly represented by state and governmental coalition who entered a short-term coalition with NGOs and civil society groups. State and political party actors in Greece were expressing themselves on average more positively towards the issue of the refugee solidarity $(+0.05)$, distancing themselves quite considerably from the average, mostly negative attitudes that were expressed by groups of state and political party actors in other countries $(-0.12$ as the average of the eight countries analysed) (Figure 4.4 in Chapter 4). The main line of confrontation was between Greece and the rest of Europe (Germany and the EU). This line of disagreement is, however, not only a confrontation, but also a relationship of mutual dependencies, as pleas for solidarity between Europe and Greece were combined with the accusation that Europe was responsible for the crisis.

Secondly, the Greek government's strategies to externalise or Europeanise the 'refugee crisis' became most evident in the high salience of supranational claims-makers and the predominance of addressees with a transnational scope. The latter reflects pleas by Greek actors for international support and cooperation during the crisis period. Such pleas were addressed at the EU level, 
especially during the first peak of claims-making in September 2015, and regarding individual countries, most notably in Germany with $15.6 \%$ of all the claims that contain addressees. ${ }^{7}$ Externalisation thus does not mean a denial of responsibility, as was discussed in the case of Denmark, but 'Europeanisation' in the sense of involving other EU countries in burden sharing. The Greek government also used the UN Plenary, the Bratislava EU Summit and an emergency summit of the Southern European state leaders, all of which took place in September 2015, to call for transnational support (Kaitatzi-Whitlock and Kenterelidou, 2017, p. 134).

Thirdly, as regards the tone of the debate towards refugees, the patterns of claims-making confirm that confrontation was not around the issue of refugee solidarity as such, but about European solidarity. The average tonality in claims-making is positive (0.12); in fact, Greek claims-makers are most supportive of refugee solidarity compared to the average in all eight countries analysed (see Table 4.3 in Chapter 4). This confirms our observation that refugee solidarity did not become a contested issue of party contestation. In contrast to other European countries during this period, the Greek government expressed explicitly favourable positions towards refugee solidarity, and this partially amplified the views of civil society. The fact that state actors were on the same page as advocacy organisations reflects the predominance of a solidarity discourse, which united different fractions of society rather than dividing them. Negative claims were typically raised by New Democracy, the main opposition party advocating primarily for securitisation. However, these positions were marginalised during this period of emergency, or they were confined to the fringes of the political spectrum, where political parties of the extreme right gained some visibility, accusing the government of neglecting its obligations to control external borders. What our data show, however, is an increase in anti-refugee and xenophobic stances over time, reflected often in the increasingly negative reactions of local actors and municipalities who were most exposed to the influx of refugees (Paschou and Loukakis, 2018).

\section{A month of contestation on Facebook: Commenters' responses to the solidarity debate}

Commenters on the Facebook sites of the three Greek newspapers engage in broader political debates in the context of the 'refugee crisis', but do not necessarily express an opinion on the issue of refugee solidarity. As in other countries, the majority of Greek commentators 'talked back' in a way to contest opinions expressed by political actors in the main article or to express their own opinions in the context of the debate, but not directly related to debate inputs by political actors (see Figure 5.2 in Chapter 5). The remaining comments are not 'out of context', but often contributed general information or factual statements to the debate. If we use these comments as a mirror of public opinion of politically engaged social media users in Greece, what draws the eye is the vagueness of Facebook commenting. In the majority of the cases, opinions 
of users often remain ambiguous and are not targeted, with $52 \%$ of comments being neutral with regard to the needs and demands of refugees (Paschou and Loukakis, 2018). Among the comments that allowed us to identify a clear positioning of users towards the issue of refugee solidarity, positive comments outnumbered negative ones in all three newspapers analysed, which further backs our observation that the need to provide assistance to incoming refugees, at least during these initial weeks of the 'refugee crisis', was not contested among engaged news readers. Additionally, political claimants in the news remained the primary definers of debate in terms of content, because they set the issues that also became a matter of concern within the commenting forums, which centred mainly on the management of the inflow of refugees. This issue convergence in claims and comments confirms the absence of clashes between political representatives and news readers. Most notably, social media news readers did not mobilise an alternative agenda - for instance in support of security and restriction - from the bottom-up. The emphasis was rather on local contexts and the practicalities of providing initial support to incoming refugees.

\section{Discussion: Multiple crises unfolding}

As in other countries in our study, the issue of refugee solidarity in the Greek media was primarily defined by political representatives and did not offer an opportunity for bottom-up mobilisation by civil society. Unlike other countries, however, the Greek debate about the reception of Syrian war refugees was not strongly contested domestically. This finding is somewhat surprising when considering the tradition of Greek political culture and the propensity of mass media to sustain rather polarised debates. Despite the fact that Greece was the most vulnerable country in Europe and experienced the highest influx of refugees during the period of analysis, this emergency situation did not trigger substantial degrees of public and political mobilisation. The strategy by the Greek government was to highlight the responsibility of the European Union for a 'crisis' that was not strictly defined as a Greek problem. These attempts were successful in setting the media agenda. In light of the multiple crises that affected Greece, the government was thus able to formulate a unified national position against the rest of Europe. The attempt of the main opposition party to mobilise public support by emphasising securitisation and border control were less effective during this period of European emergency. In addition, attempts by the extreme right to instrumentalise the refugee crisis in order to radicalise public opinion were marginalised by legacy media and more interactive websites like Facebook.

It is noteworthy, however, that the economic crisis contributed to the dismantling of the legacy media analysed in this chapter, thus contributing to a more hybrid media system in which many Greeks turned to alternative and online news. As Siapera argues, important discursive shifts took place on social media because civic groups in solidarity with refugees were circulating alternative counter-discourses online (Siapera, 2019). The mainstream conservative views that were expressed in the legacy media might therefore no longer be 
considered as representative for the discursive field of solidarity in the Greek public sphere.

With this caveat in mind, we found that refugee solidarity in the Greek news was primarily discussed as a case of first aid and humanitarian assistance, and not in terms of a durable solution that encompasses the whole of Europe. As Greece understood itself as a first arrival and transit country, and not as a place of final destination, solidarity became auxiliary and transitory. Greek government actors and other political forces used the 'refugee crisis' mainly as a momentum to call for solidarity with Greece. The Greek media adopted this frame when stressing that the country was an indispensable beneficiary of solidarity action from Europe, but not a provider of solidarity that shares the burden with the rest of Europe. While initial support towards refugees remained uncontroversial, contestation in the media was mainly about the external dimension of solidarity and about burden sharing with the rest of Europe. It needs to be added, however, that a small-scale 'welcoming culture' was established by bottom-up initiatives from local civil society, often in coalition with transnational actors. Their solidarity engagement remained, however, fragmented, episodic and hardly made it into the news.

Our findings thus point to a solidaric Greece, oscillating between calls for solidarity action with the EU, and standing in opposition to the rest of Europe. This discursive constellation was, however, confined to a political moment identified as an 'emergency' by all actors involved. Important discursive shifts towards a re-securitisation of the refugee debate took place in later years and ultimately contributed to the change of government in 2019 (Dinas et al., 2019).

\section{Notes}

1 We would like to thank Maria Paschou and Angelos Loukakis for valuable research contributions. A detailed discussion of the findings of the Greek case can be found in Paschou and Loukakis (2018).

2 Support to take in higher or equal number of refugees from Syria was lower in Greece than the EU average and at a comparable level to Italy, according to our own 2018 TransSOL survey (Grasso, 2017).

3 According to Standard Eurobarometer 88, Autumn 2017, Media Use in the EU, only $22 \%$ of the Greek population tend to trust television and $22 \%$ trust written news compared to an EU average of $51 \%$ and $47 \%$ respectively (https://ec.europa.eu/comm frontoffice/publicopinion/index.cfm/ResultDoc/download/DocumentKy/82786).

4 Kathimerini is the oldest centre-right newspaper with the first issue published in 1919, and the highest in circulation (on average, 14,000 on a daily basis and 61,225 for the Sunday edition in 2016); source: Argos press distribution agency: http://www.argoscom. gr/eng/index.php

$5 \mathrm{Ta}$ Nea has the highest circulation of centre-left newspapers in Greece (13,500 on average for the daily edition in 2016); it started its operation in 1939; source: Argos press distribution agency: http://www.argoscom.gr/eng/index.php

6 Proto Thema is a tabloid newspaper, published every Sunday (printed edition), which is also the newspaper with the highest circulation in Greece (on average 76,500 issues in 2016); source: Argos press distribution agency: http://www.argoscom.gr/eng/index.php

7 For detailed numbers and a discussion on the role of addressees, see Paschou and Loukakis (2018). 


\section{Solidarity contestation in Italy \\ A dual debate between regulatory and confrontational discussions}

\section{Refugee solidarity in context ${ }^{1}$}

Following on from the TransSOL project (Maggini, 2018), we know that the total number of sea arrivals in 2014 reached 170,000, almost a third of whom were rescued by the operations 'Mare Nostrum' and/or 'Frontex'. Almost half claimed to be escaping from Syria and Eritrea. A new record was registered in 2016, when the total number of sea arrivals reached 181,000: an 18\% increase compared with 2015 (154,000). Individuals arriving by sea between January and November 2016 mainly originated from Nigeria (21\%), Eritrea (12\%), Guinea, Côte d'Ivoire and Gambia (both at 7\%). Several thousand people perished at sea. In 2016, the number of people who lost their lives was 5,022. Finally, 2016 data also highlight Italy's record for the number of landings in the Mediterranean: approximately half of ca. 360,000 migrants arriving by sea into Europe landed on the Italian coast, $48 \%$ of the landings occurred in Greece, while the remaining numbers landed in Spain.

As regards the requests for asylum, they were in limited numbers until 2013, at least in comparison with other European countries: this is in line with difficult conditions for application and the prevailing approach in Italy to act since it was predominantly a 'transit' country. Yet, between January and October 2016, over 98,400 persons lodged asylum applications in Italy compared to 83,970 applications in the whole of 2015. As a result, Italian decision-makers adopted crisis-driven measures not always consistent with the principle of solidarity. Solidarity both as a source of legislation and as a constitutional paradigm, has thus been a core point of political equilibrium during the crisis, standing out either as a main stronghold to defend or target for change from different political perspectives.

Given that the Italian courts, and especially the Constitutional Court, have emerged as a second, very relevant actor for the protection and respect of solidarity as a source of legislation, the Italian government reformed the procedure in 2017, restricting the scope for appeals. The crisis-driven legislation and policies have thus generated high levels of contentiousness, with an increasing number of restrictive measures that in turn have been challenged in the courts invoking the respect of solidarity, fundamental human rights, and equality. The 
Home Affairs Minister, however, has operated in a way to make overall restriction the prevailing force, targeting in particular the concession of 'humanitarian' permits, that is to say, the more flexible form of legal protection for refugees in Italy. Accordingly, the Italian government has abolished almost completely this type of permit by enforcing a new highly restrictive 'security decree' in 2018 by Law 113 (Bonizzoni, 2020).

This restrictive policy has run parallel to increased xenophobic sentiments. Initially, extensive discourse on migration in the public sphere was characterised by an increasing politicisation of migration (Colombo, 2017), which has become a central issue of the political agenda in line with many other European countries (Krzyżanowski and Wodak, 2009). In the longer term, actors with anti-migrant stances such as the right-wing populist Northern League, have prevailed owing to the restrictive change in terms of policies and public discourse, thereby reframing the politics of migration under new populist terms (Richardson and Colombo, 2013).

\section{The Italian public sphere and solidarity}

We can now provide a more systematic assessment of how the Italian public debate over the refugee crisis developed between August 2015 and April 2016. As for other national cases in this book, the refugee crisis allows for dealing with a highly resonant topic in the public sphere which has garnered huge attention by the state, policy-makers and civil society alike. Also in this case, our aim is to analyse the main dynamics that shape the public debate (Koopmans and Statham, 1999; Cinalli and Giugni, 2013a), placing the specific national dynamics of the Italian case within the broader European comparative analysis context offered in Chapter 4.

The Italian media landscape is characterised by the presence of newspapers with sizeable readership and influence in the public sphere. In particular, our analysis draws on Il Corriere della Sera and Repubblica, the two main Italian newspapers with the highest circulation (ca. 308,000 and 275,000 copies respectively in 2015); to the analysis of these two main newspapers we have added Il Giornale (ca. 68,000 copies in 2015) and Libero (ca. 52,000 copies in 2015). Following the selection of other newspapers for the study of other national cases in this book, our choice has followed the need to ensure as representative and unbiased a sample as possible, including both quality newspapers and more tabloid-orientated newspapers across the left-right political spectrum. Thus, Il Corriere della Sera traditionally represents the moderate Italian bourgeoisie, while La Repubblica has a progressive, centre-left orientation. Il Giornale is a conservative newspaper, which has been crucial in completing our collection of data for claims-making. Finally, Libero is a right-wing newspaper with a tabloid format that fits our analysis of Facebook comments so as to detect the contribution by individual readers to the overall discourse.

The articles from these newspapers have been retrieved using Factiva archive and the following keywords: rifugiati (refugees) or profughi (refugees) or 
richiedenti asilo (asylum seekers). As regards our analysis of claims-making, the starting number of selected articles was 1,896 for Corriere della Sera, 1,124 for La Repubblica and 1,103 for Il Giornale. Afterwards, we randomly selected 351 articles from each of these three newspapers, before settling on 241 articles for coding. This final step has resulted in an overall figure of 701 claims (235 for Corriere della Sera and La Repubblica and 231 for Il Giornale) (see Table 3.2 in Chapter 3). As already mentioned, Libero has been crucial for extending the analysis of Facebook comments in such a way to include a newspaper with an explicit tabloid style.

\section{Patterns of political claims-making}

The 'European refugee crisis' has particularly affected Italy because this country is positioned at the centre of several migration routes in the Mediterranean Sea and, hence, is one of the key entry points to the EU. The increased inflow of refugees from Syria and other regions affected by war, and the hesitancies of the EU institutions and EU member states in establishing a coordinated system of admission and integration, put solidarity under enormous pressure, increasing press attention on the refugee situation with daily media coverage. In the period under analysis in this book the issues of migration and asylum have thus gained high visibility within the Italian mass media, which in turn have voiced a broader concern for the many challenges and problems this dramatic migratory inflow brings for both the Italian society and the refugees themselves. In particular, by looking at the distribution of claims, we can notice that these reached a peak in September 2015 (see Figure 4.2 in Chapter 4), thereby confirming that selecting this month as a specific case study for the analysis of the European refugee crisis is an empirically rational choice. In fact, the share of claims decreased after September 2015 until the beginning of 2016, when they increased again, reaching a second peak in April, 2016 (16.7\%). This is consistent with new records of sea arrivals registered in 2016.

Moreover, it is noteworthy that the refugee crisis has become a highly controversial issue in Italian politics and the media, questioning many aspects, such as the Italian government's capacity to handle the refugee influx, the fairness of the quota system for distributing refugees among EU countries, EU responsibility in the drowning tragedies and, more generally, the existence of solidarity between EU member states. The contentiousness is marked, for instance, by opposing positions fought out within the public sphere in line with the main political parties: on the one hand, the centre-left Democratic Party (in government during that time) adopting an open position towards refugees regarding rescue boat missions and their ensuing welcome; on the other hand, the antimigrant positions taken by right-wing political parties, such as the Northern League, together with the centre-right Forza Italia and the anti-establishment Five Star Movement.

Our data mirror the specificity of this situation clearly, even while highlighting important differentiations. On the one hand, we see that a substantial 
segment of public debate was devoted to the question of how to manage the emergency with which Italians and refugees were confronted. This is evidenced in the dominance of state actors discussing measures and issues of migration management in more or less neutral terms. In this segment, public discourse within the print media was less polarised and aggressive. National newspapers gave the lion's share of space to subnational issues, such as the subject of accommodating refugees in cities and municipalities, and paid less attention to transnational issues, such as the EU quota system, rescue operations at sea, or the EU-Turkey deal to stop the Balkan migratory route. We might thus speak of a more managerial or technocratic discourse that dominated the core of the public sphere, and relegated a more politicised discourse towards its margins. Here, however, public debates were highly controversial and engaged in overt contestation of solidarity. Within these politicised debates, we can detect two opposing positions: positive attitudes towards refugees led by humanitarian values, and negative attitudes towards refugees fostered by welfare chauvinism. Positive frames prevailed over negative ones.

A closer look at our data confirms these patterns. First, Italian debates about the refugee crisis were dominated by state actors as claimants $(64.5 \%$ ) (see Table 4.1 in Chapter 4) and migration management issues (65.5\%) (see Table 4.2 in Chapter 4), and thus by a debate strictly focusing on administrative, financial and regulatory measures. Civil society organisations $(21.4 \%$ ) (see Table 4.1 in Chapter 4 ) were relegated to second place, as were issues related to the personal background of the incoming refugees $(15.4 \%$ ) (see Table 4.2 in Chapter 4). However, it is noteworthy that this share of refugee-related issues is one of the highest among all countries under analysis, thus illustrating the strong visibility of refugees, their personal stories and hardships and the considerable sensitivity Italian claimants have developed, considering that this country was confronted, almost overnight, by a humanitarian tragedy of epic proportions.

Secondly, the centrality of a state-led debate about migration management has implications for the contentiousness of the debates about solidarity with refugees. This effect can be corroborated when looking at the way solidarity with refugees is granted or rejected and how it is justified, evaluated and interpreted by organised publics. The most noticeable finding for the Italian case is that the majority of claims have no justification, meaning that there is no underlying value as to whether solidarity with refugees should be granted or rejected (Maggini, 2018). More technical, regulatory or managerial issues seemed to be centre stage, a position that does not require or mobilise argumentative justifications. Only a small share of claims addressed core values to be defended, and in this regard more diversity and opposition seemed to emerge. Among claims with a clear justification, interest-based/utilitarian justifications and rights-based justifications represented a similar share $(19.8 \%$ and $21.1 \%$, respectively). Only $5.6 \%$ of claims, conversely, were framed through identity-based justifications (see Figure 4.5 in Chapter 4).

Thirdly, these diverging justifications are crucial for the contentiousness of solidarity debates, because different justifications are endorsed by different 
actors. It is remarkable that $57.1 \%$ of claims were made by civil society and human rights organisations, and $45.8 \%$ of the claims by advocacy groups showed rights-based justifications, whereas $38.6 \%$ of claims by political parties were characterised by utilitarian justifications (Maggini, 2018). As for the most frequent actors (i.e. state actors), after the 'no justification' category, the most frequent values were interest-based justifications $(20.2 \%)$, followed by rightsbased justifications $(12.8 \%)$. The diverging justifications promoted by these actors were highly consequential for the contentiousness of solidarity debates, since values are strongly correlated with the overall position of the actors towards refugees: $87.2 \%$ of rights-based justifications supported general or universal principles in favour of refugees, whereas $61.5 \%$ of identity-based justifications rejected solidarity with refugees. Interests-based/utilitarian justifications showed a less polarised situation, with a prevalence of anti-refugee positions $(41 \%)$ over pro-refugee positions $(25.2 \%)$. Once again, the relationship between justifications and positions is consistent with the polarisation of main political parties on migration-related issues over time. On the one hand, right-wing political actors, such as the Northern League, stand out for their long-term mobilisation against migration and multiculturalism, while on the other, the centre-left and the Catholic parties stand out for their humanitarian positions.

\section{A month of contestation on Facebook: Commenters' responses to the solidarity debate}

By contrast with claims-making (with the prevalence of a more regulatory, managerial or technocratic debate), bottom-up contestations on Facebook showed that solidarity was clearly contested within national borders. Public debates were particularly pronounced during September 2015, because claimsmaking peaked in that month with almost $24 \%$ of all claims in the printed sample under analysis (see Figure 4.2 in Chapter 4). Hence, it is important to have a detailed look at September 2015, not only in relation to the claims of more powerful organised publics that could easily reach the public sphere, but also through the Facebook comments of ordinary citizens. The data evidence an intense and critical engagement by news readers with the public debates reported in the mass media. Around $90 \%$ of the selected Facebook comments were responses either to claims raised in the main article $(71.1 \%)$, or to the general issue of the main article $(17.2 \%)$. This means that commenters were highly 'responsive' to the political debates between organised actors, avoiding independent statements (Maggini, 2018). Furthermore, it is noteworthy that Facebook commenters showed confrontational attitudes towards claimants, with $82.4 \%$ of responses to claims showing a negative position towards the claim in the posted article. Negative stances prevailed for issues raised in the posted articles, though to a lesser extent.

These insights show that news readers engaged in critical reading of media coverage, and raised their voices to make their dissenting views heard. In 
particular, we have found some considerable divergences and oppositions, meaning that Facebook commenters engaged in public contestations subscribing or opposing solidarity with refugees. It is interesting to see that the fragmentation of the Italian media system structures these contentions to a considerable extent, as it provides opposing views with a privileged access point to the public sphere. In fact, Facebook commenters were clustered according to the newspaper they were reading: There was a strong distinction between commenters of La Repubblica's posts $(79.6 \%$ had positive attitudes towards refugees) and commenters of Libero's posts $(62.1 \%$ had negative attitudes towards refugees, while only $3 \%$ had positive attitudes). Commenters of Corriere della Sera's had more mixed views, but with a prevalence of positive attitudes (52.5\%) over neutral and negative ones. This differentiation is perfectly consistent with the political orientation of newspapers, showing that Italy stands out for a segmented public sphere. Ideological preferences still matter in the choice of news source.

The strong polarisation of the public debate on Facebook is confirmed when looking at the way commenters justified their public interventions, and the type of values or justifications they used to defend, qualify or oppose solidarity. Indeed, the three most frequent justifications were 'human rights/ humanitarian crisis', 'political capacities' and 'welfare chauvinism'. The first and the third justification are polar opposites. All human rights-based justifications have a positive position towards refugees, whereas no comment framed under welfare chauvinism is pro-refugees. Compared to these justifications, commenters who shared the 'political capacities' frame had more mixed stances towards refugees (Maggini, 2018), but with a prevalence of positive $(60.9 \%)$ positions over negative ones $(26.1 \%)$. Finally, our Facebook comments were not populated predominantly by commenters supporting populist parties and expressing hostile attitudes towards foreigners. A positive position towards refugees remained predominant $(44.1 \%)$, followed by neutral/ambivalent positions (34.6\%). The Italian case does not convey an overall picture of social media as being a space for overwhelming hate speech and political radicalisation.

\section{Discussion}

Italy has witnessed a parallelism of two types of debates: regulatory and technocratic discussions about the management of the refugee crisis on the one hand, and, on the other, highly confrontational discussions about the extent to which solidarity with refugees should be granted or denied. This parallelism is evident twice within the mass media: We have found it within the field of massmediated claims-making in the contraposition of a state-led debate of migration management and polarised discussions between antagonistic forces, and we have found it when comparing the field of claims-making in the news media with the Facebook comments by news readers, given that the latter are much 
more opinionated and voice their dissenting views in opposition to claimmaking by organised actors in the news.

Both spheres of debate also diverge in relation to the level of solidarity contestation. Commenters on Facebook dealt with issues that have a national scope primarily, while issues addressed by organised actors within the print media were mostly sub-national, with national and transnational issues showing similar shares. This means that public debates within the news media give more space to subnational issues, where the management of migration emerged as an immediate (administrative, regulatory or organisational) challenge, e.g., in terms of cities and municipalities hosting refugees. This is consistent with the Italian model for the accommodation of refugees, with the direct involvement of local governments in migration management. Against this backdrop of attention among claimants in the press, Facebook commenters were more focused on national issues.

In spite of these differences, however, both spheres are interrelated quite considerably, as in most of the other countries under analysis. Commenters on Facebook expressed strong political views about the refugee crisis issue, and were characterised by their engagement in contentious debates. This means that they did not post inconsistent or decontextualised statements, but rather engaged with content and arguments raised previously in the print media by political actors and organised publics. This points to the agenda setting and framing power of news media, as the content of the news articles remains the main reference point of the debate of news readers; however, it shows that Facebook commenters are a secondary definer of public opinion, given that they critically engage with the issues and positions voiced in the news media, advocating for diverging views that either support or oppose the needs and rights of refugees. Moreover, our findings show that the contentious elements of public debate relate to the fragmented structure of the Italian media system and the respective segmentation of audiences.

Overall, public discourse in the print media was less polarised and aggressive, but less favourable towards refugees, when compared to the Facebook debates. It is here, in the more polarised spheres of public contestations, that conflicts in regard to solidarity with refugees stood out most forcefully. We have detected both security discourses supported by extreme-right and populist parties, but also, to some extent, by centre-left parties (Colombo, 2013; Richardson and Colombo, 2013), and utilitarian discourses based on economic interests. As regards the latter, centre-left and centre-right parties have essentially accepted 'the functionalist case for migration (necessary in terms of labour market shortages) - a position also held by key economic actors such as employer associations' (Bigot and Fella, 2008, p. 306). Pro-solidarity discourses tend to centre more strongly on humanitarian pleas and/or universal human rights. These positions were certainly not located at the centre of public debates, which were dominated by state actors and their policy agendas. Yet, it is remarkable that these voices seem to have contributed to a public discourse that 
150 Solidarity contestation in Italy

has shown little propensity for open hostility towards refugees, at least during the period of time under observation.

\section{Note}

1 We would like to thank Nicola Maggini and Valentina Pagnanelli for valuable research contributions. A detailed discussion of the findings of the Italian case can be found in Maggini (2018). 


\section{Solidarity contestation in Poland The categorical denial of responsibility ${ }^{1}$}

\section{Refugee solidarity in context}

Poland had long been considered a country with high rates of migration before opening its borders in 1989 and the country's accession to the EU in 2004 (Kępińska and Kindler, 2014). While immigration had not been as politicised an issue as in other European countries, this political discourse shifted in the second half of 2015 with the 'refugee crisis', fueled predominantly by the antiimmigration stance of the right-wing populist Law and Justice Party (Prawo $i$ Sprawiedliwość, PiS) (Krzyżanowski, 2018). While the previous government was still willing to accept a small number of war refugees into Poland, the newly elected PiS government had campaigned with demanding categorical exclusion of refugees, politicising the issue of refugee solidarity before the national elections in September and October 2015 (Krzyżanowski, 2018). In this position, it was also backed by the newly elected parliament, the Sejm, where centre-left MPs were no longer represented, and all remaining five parties tilted to the right on issues of solidarity.

The harsh position of the newly elected government also explains why Poland stands out in our sample as the country that experienced the lowest intake of refugees, with 12,190 asylum applicants in 2015 and 12,305 in 2016 (Eurostat, 2018). The government claims that there is an unknown higher presence of non-documented migrants from Ukraine, Russia and Tajikistan, but exact numbers of these groups are not confirmed (Petelczyc, 2018a). In regard to refugees, however, it was obvious that the Polish government wanted to keep the country on the margins of the events triggering the major inflow of refugees from Syria in the summer and autumn of 2015. Refugees stayed away from Poland, either because it was unattractive as a host country, or because the government, which insisted on control of entry, managed to keep them out.

This policy orientation is not unusual among Eastern European governments, which have been advocating a fierce defence of national sovereignty against the prerogatives of European integration, thus rallying for anti-liberalism and xenophobia, which have become mainstream within public debates, entering official state rhetoric and practice during the refugee crisis (Szczerbiak, 2012). As argued by Krastev and Holmes, the wave of populist xenophobia stems from 
resentment-fueled reactions within parts of the Eastern-European populations against the post-1989 imperative to become Westernised (Krastev and Holmes, 2019). In the Polish case, this applies to the PiS government, which since 2015 has been propagating the 'refoundation of Poland' through the defence of national identity and traditional values, thus rejecting 'liberal values' such as gender equality, LGBTQ rights or multiculturalism (Szczerbiak, 2019).

Before this backdrop, the very notion of solidarity had been severely contested and reformulated. Solidarity is historically anchored in the trade union movements (Solidarność) and the strong hold of the Catholic church (Brier, 2009). However, as the country of Solidarność, Poland has only reluctantly embraced notions of transnational and global solidarity. During the transition period, solidarity became increasingly narrowed down as applying primarily to co-nationals, and only secondly to other Europeans and foreigners. The PiS government propagated a kind of natural hierarchy of solidarity relationships that puts family and nation first and defines solidarity towards strangers as secondary or 'unnatural' (Petelczyc, 2018b). Immigration, which had been a non-issue in public discourse before 2015 (Sadowski and Sczzaviska, 2019), thus became increasingly framed as a threat to national identity defined in ethnicexclusive terms.

The lack of solidarity with refugees exhibited by the PiS government is largely echoed by public opinion at the present time. In fact, Poland is also the country in our sample with the most negative opinion on the question of whether refugees fleeing from the war in Syria should be granted asylum. Thirty-six per cent of the population, according to our own TransSOL survey, support the most extreme position, demanding that the country should categorically reject the intake of Syrian refugees, an additional $16 \%$ ask for lower numbers, while only $9.6 \%$ wish that Poland would let in more refugees. ${ }^{2}$ One explanation for this hostility towards refugees is provided by the deep religiosity and the widespread anti-Islamism of the Polish population (Petelczyc, 2018b, p. 143). During the 2015 election campaigns, refugees from Muslim countries were discussed as a threat to Polish identity, and the newly elected Prime Minister Beata Szydlo declared that she would categorically reject the further intake of refugees, specifically those from Muslim countries (Petelczyc, 2018a, p. 413). A particularly aggressive language against refugees was also used by the PiS leader Jaroslaw Kaczynski, who warned that refugees from the Middle East could bring diseases and parasites to Poland (Petelczyc, 2018b, p. 142). The same party also categorically rejected the principle of European solidarity that demanded burdensharing and refugee quotas, defining the influx of refugees as a 'German problem', and that Germany did not deserve solidarity with Poland (Petelczyc, 2018a, p. 413). The political climate against refugees also targeted grassroot organisations, which were seen as agents of internationalism and as such, unPolish (Petelczyc, 2018a, p. 414).

Public opinion was thus largely committed to a discourse of national sovereignty and cultural identity. However, solidarity with refugees was not completely absent, even though it went largely unperceived. In fact, the denial of 
solidarity towards foreigners and refugees was met with resistance at grassroots levels, where local support groups mobilised with the aims of building multicultural dialogue and more positive attitudes towards refugees (Piłat and Potkańska, 2017, p. 42). This mobilisation was echoed by our TransSOL survey, because one in four Polish respondents (i.e., 27\%) reported that they had been involved in support activities for refugees or asylum-seekers, a number that is even slightly higher than those in France or Great Britain, and not very distant from the share of engaged Germans or Greeks (34\% and 36\%, respectively).

\section{The Polish public sphere and solidarity}

Poland's media landscape can be described as being in transition. Two main components of this transition merit particular attention: The privatisation of the mass media system and the stronger plurality of media outlets on the one side, and the growing influence of the Polish government on journalism and news coverage, with decreasing degrees of tolerance towards dissent and diversity (Zarycki et al., 2017). This double process is not contradictory, because in several post-communist countries, privatising mass media systems remained under the control of political elites. Since the transition period, the Polish media has been marked by a high degree of politicisation in terms of allegiances between media outlets and political parties. At the same time, it is characterised by low rates of journalistic autonomy and a strong intervention by governments in power. Polish mass media might thus be marketised and plural, but they remain subordinated to elite groups (Sparks, 2008).

The political control and tutelage have proven to survive present times, when considering the ongoing interventions from the PiS government, which has changed broadcasting laws and imposed its own appointees to leading bodies. The public media have been renamed 'the national media' and have been thus transformed into government propaganda mouthpieces (ibid.). The transition from state media to public media, and from public to national media is thus currently leading to a revitalisation of the political elites' mission to 'repolonise' media content (Glowacki, 2015; Klimkiewicz, 2017, pp. 201-202). According to Reporters without Borders' latest report from 2019, Press Freedom in Poland, is in jeopardy. ${ }^{3}$ Little seems able to stop the conservative government in its determination to 're-found Poland' and 'make the media Polish again'. Press freedom is one of its main victims.

Until 2015, immigration discourse in Poland was not particularly present in the media, which changed with the electoral success of PiS (Krzyżanowski, 2020). The influence of the government in the Polish media landscape also shows itself in migration news coverage: Pro-government newspapers follow the anti-immigration stance of the government directly, framing refugees as threats and outsiders (Szylko-Kwas et al., 2017). Our sample, however, is

represented by three country-wide distributed newspapers that cover the whole ideological spectrum: Fakt - a tabloid, the newspaper with the highest circulation in Poland (272,000 readers on average), Gazeta Wyborcza - a centre-left 
newspaper, critical of the government, with 133,000 readers on average and 'Rzeczpospolita' - a centre-right oriented newspaper with a focus on financial and legal issues, which has also distanced itself from the government (ca. 52,000 readers on average). ${ }^{4}$

\section{Patterns of political claims-making: The categorical rejection of solidarity}

Poland is a bystander that follows the Syrian refugee drama as a remote event and as a potential threat to be kept out through preventive measures. This general observation is remarkably clear and consistent along all variables and dimensions of our dataset. First, public debates in Poland deal with the refugee crisis and potential calls for solidarity as a purely external topic that has to be kept at a distance. In fact, the issue cycle runs parallel to other countries with peaks of attention in the month of September, but the intensity of the debates throughout the period is very low. Moreover, the media cover the topic as foreign events, e.g., when reporting about the mass arrival of refugees in Greece and Germany, even though these stories do not simply follow the pattern of foreign news coverage, but show high engagement of domestic claims makers.

Second, public claims-making was strongly dominated by governmental actors $(46 \%)$ and political parties $(11.3 \%)$. Levels of public contestation were low because the government's harsh stance towards refugees was not criticised or qualified domestically. Polish state actors and parties monopolised the public debate to such an extent that they were successful in silencing opposing groups in favour of refugee solidarity. In fact, civil society and human rights organisations, who rallied for this cause, were largely without a voice within the media, as they only account for $1.6 \%$ of all claims. The monopolisation of the public sphere by the state, the marginalisation of pro-solidarity opposition groups and the definition of the refugee crisis as an external threat were thus successful in establishing public consensus and avoiding public contestation or polarisation within the news. Even the low levels of contestation are to be attributed to the activity of the PiS, which during the electoral campaign of 2015 mobilised against the ruling government with a political manifesto that demanded even harsher anti-refugee policies. Once in government, the PiS leaders started to implement these new policies against the demands for inner-European solidarity, voiced by the European Commission and other European member states, such as Germany. Their promise to categorically ban Muslim refugees from Polish territory may have caused irritations and criticisms in the rest of Europe, but the level of domestic contestation after the electoral campaign of 2015 remained very low (Szczupak et al., 2018).

Third, the consensus within the Polish public debates is also true when taking a closer look at the argumentative content of claims. Positions about the deservingness of refugees in need of solidarity might have been equally distributed among claimants in the Polish media. However, positive statements were mainly promoted by foreign actors (like German claimants, represented in 
$18 \%$ of all claims), while the positionality of claims raised by Polish state actors and political parties was on average decidedly more negative. The fact that prorefugee claims were mainly represented by foreign actors points to remarkable polarisation in the debate between Polish and European (foreign) claimants. Domestic actors supporting refugee solidarity could thus easily be blamed as anti-Polish by government actors and political parties, and as illegitimate attempts to prevent the government from defending national interests and a unified Polish position against the rest of Europe. The ability of the PiS government to monopolise the tonality of the public debate was considerable, when taking a closer look at the changes before and after electoral campaigns. While the previous Civic Platform government still tried to argue for the moral and legal obligations of the country to grant asylum to war refugees, the change in government altered the positionality within the larger debate significantly. Since November 2015, when PiS had started to impose its highly exclusive rhetoric towards refugees, the average position of claims raised in the public sphere shifted considerably to veer towards the negative (Szczupak et al., 2018).

\section{A month of contestation on Facebook: Commenters' responses to the solidarity debate}

Organised actors were the primary definers of public debates about solidarity with refugees in Poland. They did not only play a crucial role in setting the agenda of claims-making within the news coverage of Polish newspapers, but basically also defined the agendas and positions of users' comments within the newspapers' Facebook sites. Polish comments distinguish themselves most clearly from the users of our other countries, because they express themselves during September 2015 in an almost unanimously negative way $(75.3 \%$ of all comments), targeting refugees as undeserving and putting their own needs first. In no other country in our sample have so few users spoken out in favour of refugee solidarity $(8.8 \%$ ) (Szczupak et al., 2018). However, negativity towards refugees among the Polish users is not only an echo of organised public claimsmaking, but also a pure appendix of the electoral campaigns and government policies publicised within the news media. As shown in the positionality of comments posted on Facebook in response to news articles, it is true that users partly amplified the negativity of representatives of the Polish government and of political parties, and they rewarded the extremist opinions of some of their leaders with highly supportive comments. Partly, however, Facebook users also ran their own campaigns, criticising Germany or human rights' associations for their pro-refugee stance, when they engage in hate speech, or when they undermine the legitimacy of pro-refugee claims-makers and claims. Furthermore, we find instances of openly racist and extreme speech in the comments, an observation that stands out in comparison to the other national cases. Poland is thus the only country in our sample where extremism in user commenting became manifest, confirming the hypothesis found in the literature about a polarisation and radicalisation effect of social media commenting (Chen 
and Lu, 2017; Hughey and Daniels, 2013; Toepfl and Piwoni, 2015). However, it needs to be added that this negativity in Polish comments is not limited to the social media sites, but rather reflects the general public opinion within the public sphere, as expressed through claims-making within the news media. Negativity is thus defined and promoted by a public discourse dominated clearly by state actors and political parties. Social media do not seem to provide opportunities for a more open and contentious debate, as they tend to be monopolised and stream-lined by users that largely share the views of those actors already populating the public scene.

\section{Discussion: The Polish exceptionalism - virtual debates, but absent refugees}

The Polish case stands out against the rest of our countries when considering the high level of synchronisation of debates and the low level of internal contentiousness. In fact, public debates within the news media are strongly monopolised by state actors and political parties, and the marginalisation of dissenting voices is so strong that organisations and initiatives rallying for solidarity with refugees are largely absent. The same applies for user comments on the newspapers' Facebook sites, where only a very small minority of readers dares to express supportive opinions. The tone within Polish public debates is negative, to some extent even aggressive. Government actors and political parties overtly refuse to grant support to refugees, and users join in by rejecting any kind of solidarity with them, given that both propagate the categorical exclusion of refugees.

There are, however, limits to negativity and hate speech. Polish newspapers try to countervail these tendencies to some extent in the way they cover the news. In fact, Polish debates reported within the newspapers were balanced in so far as foreign actors were given a voice to express solidarity with refugees against the dominant views of domestic actors. The considerable share of these claims highlights that journalists took their responsibilities seriously when covering the 'refugee crisis' from a broader perspective and bringing in plural voices from other countries. The Polish media also struggled against the hate speech of user comments, for instance, when Gazeta Wyborcza shut down the commenting function on articles on the refugee issue on its own news website after experiencing extremism in user comments during late 2016. Commenting on the Facebook news page remained, however, unaffected by these measures. Despite possible moderation effects, $80 \%$ of newsreaders left outspokenly negative comments in response to the largely balanced views expressed in Gazeta Wyborcza news articles.

These attempts to moderate public debates and ensure plurality of views have proven to be negligible. In fact, the Polish data evidences a radicalisation of the Polish public sphere on the issue of refugee solidarity. Part of this radicalisation might be an echo of the electoral campaign of 2015 and the attempts of the PiS party to mobilise its constituency by means of a xenophobic, right-wing 
nationalist rhetoric. This radicalisation is a matter of concern, as it does not seem to mirror objective problems. Poland remains the country in our sample with the lowest inflow of asylum seekers, which means that refugees from Syria were highly visible virtually, but physically absent. Before this backdrop, we might assume that the anti-refugee rhetoric was mainly an instrument to politicise and stream-line public opinion in support of the new government's policy agenda. The Polish mass media seem to have willingly lent themselves to this political manoeuvre. It is true that they have granted room to foreign actors that, however, could easily be discredited as non-Polish. More consequential is the fact that Polish newspapers have contributed to the discursive exclusion of dissenting domestic actors. The political control and tutelage of the Polish mass media, and the politicisation of public debates along the political agendas and interests of leading political elites is thus an obvious, albeit troubling finding of our analyses.

\section{Notes}

1 We would like to thank Klaudyna Szczupak, Janina Petelczyc and Maria Theiss for valuable research contributions. A detailed discussion of the findings of the Polish case can be found in Szczupak et al. (2018).

2 Support to take in higher or equal numbers of refugees from Syria was lowest in Poland compared to all other countries, and support for the extreme position that categorically denies entry to refugees was highest.

3 https://rsf.org/en/poland

4 Numbers are for 2016 and taken from https://www.wirtualnemedia.pl/. 


\section{Solidarity contestation in the UK Reluctance during political uncertainty}

\section{Refugee solidarity in the British context ${ }^{1}$}

The state of solidarity in the UK is weakening on regional, national as well as transnational levels (Montgomery and Baglioni, 2018a, p. 189). Since the economic crisis in 2010, the British welfare state has suffered consequences affecting the most vulnerable groups in society. Beyond traditional class struggles, the cohesion of the country has been shattered by new identity struggles and long-seated conflicts between the English, Scottish, Irish and Welsh nations. Moreover, on the EU level, the UK's latest governments increasingly showed unwillingness to engage in European solidarity and principles of burden-sharing, e.g. with regard to the reallocation of refugees and asylum seekers.

Before the Brexit referendum of 2015, a major driver of anti-EU campaigning was indeed the issue of immigration (Prosser et al., 2016). Public contentions became even more amplified by the many attempts by migrants to cross the Channel from France and the dramatic images of the refugee and migrant encampment in Calais near the tunnel entry during the 'refugee crisis' from $2015 / 16$. What is noteworthy in regard to British solidarity contestations is that the UK received comparably moderate numbers of first-time asylum applications in $2015(39,720)$ and $2016(39,240)$ (Eurostat, 2018). Additionally, survey data evidenced that public opinion was not generally hostile towards refugees when compared with the other countries under study. According to our own TransSOL survey from 2016 (Grasso, 2017; Lahusen and Grasso, 2018), public opinion on the question of whether war refugees from Syria should be accepted was split, with $18.1 \%$ accepting that the country should admit higher numbers than previously, but $20 \%$ supporting that the country should not allow more refugees to come to the country. Just over $58 \%$ of the population took a moderate position. The UK government's anti-immigration stance is therefore not sufficiently explained by public opinion. Rather, it might be that a few but highly influential actors who successfully played off notions of popular and national sovereignty against principles of European solidarity and humanitarian commitments during the 'refugee crisis', could place their messages on the political agenda (see Gifford and Wellings, 2017). The populist right-wing antiimmigration party UKIP, for example, instrumentalised the 'refugee crisis' to 
the benefits of the Leave campaign, linking the traditionally strong notions of sovereignty in the country's political culture to the generally strong Eurosceptic tendencies.

Due to its geo-political situation, the UK has always been an outsider in EU cooperation in Justice and Home Affairs and has opted out of most of EU regulation in the field of immigration and asylum policies (see Geddes, 2005). In fact, the UK is not a member of the Schengen area, thus maintaining control of its national borders within the EU, even though it participates in EU border policies to some extent (see Costello and Hancox, 2014). Regarding asylum policies, the UK opted in to the first phase of the Common European Asylum System which sets minimum standards for asylum. Moreover, it also signed the Dublin Regulation, steering the allocation of EU member states responsible for processing asylum applications. However, it did not join the second phase, which brought common standards in regard to asylum granting procedures for EU member states.

In spite of its partial integration into the European immigration and asylum policies, the British approach is dominated by the issue of border control over humanitarianism and solidarity. When the Conservative Party was elected into government in 2015 in the wake of the 'refugee crisis', it made clear that it would further curb migration (Geddes and Scholten, 2016, p. 39). Over the summer of 2015, David Cameron's administration took a very restrictive stance with regard to the intake of refugees arriving via the Mediterranean Sea, which was justified by highlighting their financial support efforts in the region (Montgomery and Baglioni, 2018b, pp. 472-473). The government further pushed for the eviction of the Calais refugee camps in cooperation with the French government, which eventually took place in October 2016.

\section{The UK public sphere}

While the BBC as public service broadcaster remains strong, the British newspaper industry has come under high commercial pressure with the gradual shift towards online media. Nevertheless, legacy media have been able to maintain considerable influence in the political system with exclusive access to politicians and civil servants in Westminster (Chadwick 2013, p. 48). Degrees of political parallelism are medium to low (Brüggemann et al., 2014; Hallin and Mancini, 2004). The news press, however, is strongly divided between tabloids and broadsheet papers and is typically less consensus-oriented than the Scandinavian press systems, for example. Indeed, at least since 2012, some astute observers warned of an unhealthily close relationship between politicians and the press (The Right Honourable Lord Justice Leveson, 2012, p. 24). The British press has moved its traditionally Eurosceptical orientation, which was especially strong among the tabloid segment, towards an explicit anti-EU position - a development that started in the 1980s but has accentuated until today (Anderson and Weymouth, 1999; Galpin and Trenz, 2017). The interdependencies between the press and politics have made proEuropean stances among politicians more difficult and less accepted among the population (Daddow, 2012). 
In this sense, the UK public sphere is characterised by a high degree of contestation of European issues, one of the most dominant of which is immigration. Greenslade $(2005$, p. 13 ) shows how the tone of the tabloids about asylum seekers runs parallel to the degree of negativity about European integration. News coverage has portrayed immigration as a contested, sometimes threatening phenomenon, at least since the early 2000s. In part, this is connected to the EU's eastern enlargement in 2004 and 2007, which provoked debates about intra-EU migration, particularly from the new member states to the UK. Public worries reached the level of moral panic about 'welfare tourism' (Fitzgerald and Smoczynski, 2015), a perception fuelled most fervently by the strong tabloid outlets. After the 2010 general election, which resulted in a conservative-liberal coalition government headed by David Cameron, negative news coverage towards immigrants, and especially towards EU working migrants from Central and Eastern Europe, further increased (Blinder and Allen, 2016).

Although pro-immigration Civil Society Organisations (CSOs) have exerted some influence over national policy-making (Freeman, 2002), empirical evidence from news content analysis points to the dominance of political elites not only in news discourse, but also in Great Britain's restrictive immigration policies (Statham and Geddes, 2006). Leading up to the 'refugee crisis' the term 'mass migration' was a dominant term used across newspapers (Allen, 2016). Research further documents the rise and increasing visibility of the anti-immigration UKIP in news coverage of the British press around that time, especially among right-leaning newspapers (Berry et al., 2015, p. 34). Moreover, experts widely contend that British newspapers have contributed to rationalising human suffering before, during and after the 'refugee crisis' (Fotopoulos and Kaimaklioti, 2016; Georgiou and Zaborowski, 2017).

The three newspapers selected for our analysis represent this tendency towards conflict-oriented public debates. The Guardian and The Telegraph are broadsheet/quality newspapers, with The Guardian being the leading centre-left newspaper and The Telegraph, the equivalent on the right. The Daily Express represents the typical tabloid style of newspapers with a combined anti-EU and anti-immigrant stance. The average print circulation for The Guardian in April 2016 (i.e. at the end of our sampling period) amounted to 169,424 readers (-3.82\% to April 2015), for The Telegraph 498,474 (+2.56\% to April 2015), and for the Express 419,328 (-4.17\% to April 2015) (Ponsford, 2016, reporting ABC $\left.\operatorname{data}^{2}\right)$.

\section{The UK debate about refugee solidarity in the press media}

Our claims-analysis confirms the long-term trends of the British press in expressing a 'destructive dissent' with Europe in combination with the mobilisation of antiimmigration attitudes (see Daddow, 2012): public-claims making in the British news was found to be mostly negative on the issue of refugee solidarity compared to all other countries that were covered by our analysis. The negativity towards refugee solidarity is complemented by a strong externalisation of the issue, as 
corroborated by the development of the debate. As is the case with the other country samples, British press coverage peaks in September 2015 both in terms of articles and claims within articles (see Figures 4.1 and 4.2 in Chapter 4). After this period, salience decreases again, yet a second momentum ensues in January 2016. It is noteworthy that both peaks are explained by external events to which the UK was an outsider and hesitant to become involved in: The humanitarian disaster in the Mediterranean in September 2015 and other events on the continent, such as the conditions in the Calais refugee camp, the Swedish government's tightening of refugee intake, or the sexual assault by migrants on 31 December 2015 in Cologne, Germany. The UK press were keen to cover the very events they were eager to sidestep. It is a coverage of a 'crisis' of others that gains news value through some dramatic events but is not bound to longer spans of public attention. The UK's geographical location makes such a detached framing of 'crisis' as 'not belonging to us' somehow credible. However, it needs to be added that the tonality of claims reported in the news towards refugees remains highly negative, in fact, the most negative in our sample of eight countries (see Table 4.3 in Chapter 4).

As in the other TransSOL countries, coverage is further dominated by voices of elite actors, above all state and political actors (see Table 4.1 in Chapter 4): Three out of five claims were pronounced by these actors $(62.3 \%)$, as opposed to one out of five by civil society actors $(20.9 \%)$. The comparatively high share of public interventions of supranational actors $(11.7 \%)$ is indicative of the strong externalisation of British debates. Expressions of solidarity towards refugees are strongly divided across newspaper outlets, with The Daily Express - and The Telegraph to some extent - taking particularly negative positions (Montgomery et al., 2018). These observations support earlier research that finds key differences between right-wing and left-wing UK newspapers when it comes to the more general 'presence (or absence) of humanitarian themes' (Berry et al., 2015, p. 42.). Overall, however, there is a rather negative tone in the claims across the three selected British newspapers, which is not a new development restricted to the 'refugee crisis', but reflects a more persistent tendency in UK newspapers to highlight problematic issues and concerns regarding migration (e.g., Allen, 2016; Philo et al., 2013).

The UK coverage of the 'refugee crisis' is mainly focused on political conflicts and problematises domestic capacities to accommodate people in need, as is true for the other countries in our sample. However, there are some specificities that merit attention (see Table 4.2 in Chapter 4). The public agenda is centred more strongly than in other countries on debates about migration management $(68.1 \%)$, even though claims addressing the personal background of refugees $(15.9 \%)$ are also slightly more prominent than in other countries. This runs counter to issues related to civic initiatives $(4.2 \%)$ and integration $(3.2 \%)$, which are below average when compared to other national debates. Priorities are thus clearly stated, given that debates spotlighted the need for an adequate (and restrictive) management of migration rather than on welcoming or integrating refugees. 
The British approach dominating public debates thus pairs a strong focus on internal policy issues with a significant externalisation of the 'refugee crisis'. This specificity is mirrored by the justifications provided by claimants for their views or demands (see Figure 4.5 in Chapter 4). The strongest focus is on interest-based justifications $(47.1 \%)$ which underline the importance of domestic costs or benefits as basis of these claimants' often more negative stances toward refugees. Rights-based justifications $(22.0 \%)$, which are generally paired with supportive dispositions towards refugee solidarity, are second in importance, but mostly attributed to civil society actors, while state actors clearly lean towards a negative stance towards refugees. In this regard, we once again find differences between newspapers. The Guardian hosted more supportive claims, because from the $29.0 \%$ of total justifications, $25.4 \%$ made positive statements. This is opposed to the $18.3 \%$ positive, rights-based claims (out of a total of $23.0 \%$ ) in The Telegraph, and $10.8 \%$ positive claims contributing to only $14.0 \%$ of rights-based claims in The Express (Montgomery et al, 2018).

\section{Facebook users' comments: Segmented contentions}

Social media users on British newspapers' Facebook commenting pages express themselves in a predominantly negative way with regard to the question of refugee solidarity. However, the issue remains contested by a substantial minority of users who express opinions in support of solidarity engagement with refugees (see Table 5.4 in Chapter 5): $52.3 \%$ of all comments are negative, $10 \%$ neutral and $37.7 \%$ positive. The way these opinions are distributed across newspapers suggests a polarisation of different readership communities, which means that we cannot speak of contestation in the form of an exchange of opinions among users within the same forum. The group of supportive commenters is constituted mainly of readers of The Guardian, whereas readers of The Daily Express raise an almost exclusively anti-solidarity voice (Montgomery et al., 2018). However, it must be highlighted that social media commenting in the UK is not more negative than the average of social media comments in other countries in our sample (see Figure 5.4 in Chapter 5). The stronger diversity of opinions among Facebook users might stand in contrast to the stark negativity of the UK government towards refugees, and also to the dominant negativity expressed by political representatives in the media. While the UK press is by far the most negative among the selected newspapers and countries in our sample, the tonality of user commenting approaches European standards. British claims-makers in the news are thus much more hostile than the European average, but not the people commenting on Facebook.

Furthermore, our findings point to a relatively high level of responsiveness and active engagement of users in Facebook commenting (see Figure 5.2 in Chapter 5). By placing a Facebook comment, a majority of news readers engage with the content of the main article, fewer even respond directly to claims in the posted articles. Around a third of all comments are posted by news readers to express their opinion, and do not relate directly to the content of the news 
article. However, also in these cases, comments do not necessarily need to be out of context. Also here, patterns differ between Facebook pages, with Guardian readers showing the highest degree of responsiveness and engagement with the news.

Our analysis of Facebook comments indicates that solidarity contestations are strongly patterned by the British media landscape. In the UK, differences in ideological stances between newspapers translate from print to the online sphere. As the high degree of responsiveness and user engagement indicates, social media commenting pages are indeed becoming a forum for public debates, yet these debates unfold among secluded publics of like-minded users. Echo chambers are maybe not so much a new phenomenon in the UK, but result from the ideological segmentation of the news media market and their audiences. These differences enable pro-solidarity voices to find their own platforms to be heard, most notably on The Guardian's Facebook pages, where more balanced discussions and a stronger engagement with news content seem to take place.

\section{Discussion}

Our claims-making and social media analysis is in line with previous studies in the UK, because it confirms that public debates within this country express very negative attitudes toward immigration. As is the case with other countries in our sample, domestic political actors dominate the news discourse during the 'refugee crisis' and impose an agenda that centres mainly on issues of migration management and border control. Unlike other countries in our sample, however, British claims-makers predominantly reject a notion of transnational (European) solidarity with refugees and asylum seekers. The percentage of claimants who defend solidarity with refugees is, in fact, the lowest when comparing the British press with other countries investigated $(32.7 \%$ as compared to a $40.2 \%$ across all countries in the sample; see Table 4.3 in Chapter 4 ). This significant negativity of claims-makers in the news is also mirrored in our social media analysis with over $50 \%$ of commenters rejecting solidarity with refugees.

It should be noted, however, that this anti-solidarity stance towards refugees is not expressed in a unanimous way across newspapers. The UK stands for an ideologically divided news coverage more than any other country in our sample. And this also implies that the readership is divided into two polarised camps, depending on whether it supports or rejects solidarity with refugees. This dividing line seems to correspond to the well-known cleavage between a liberalpro-European and a nationalistic-Eurosceptic camp that also dominated the debates about Brexit (Brändle et al., 2019). Tabloid coverage, in particular, seems to be an important driver of these cleavages. In fact, they were influential agenda-setters during the 'refugee crisis', because they aroused moral panic in a country whose refugee intake is lower than many of the other countries in our sample, notably Greece, Italy and Germany. The interdependency between 
politics and the press seems to contribute to the polarisation of debates, given that the media granted special attention to anti-immigrant and anti-European sentiment in their coverage. The British tabloid press may have contributed to a hostile anti-EU and anti-immigrant debate that marginalised moral claims in favour of European solidarity (see also Daddow, 2012). Unsurprisingly then, and in the absence of significant domestic opposition, the UK government insisted on its restrictive stance in handling the 'refugee crisis' and was not ready to engage in European solidarity with its partners.

We find similar tendencies of polarisation on Facebook comment debates, where users tend to be largely negative toward refugees, but split into two ideological camps. On the one side, users on The Guardian's Facebook page engage more directly with news content and express themselves in favour of solidarity, while on the other side, readers of tabloid newspapers are the least engaged with and most negative towards refugees. In this sense, we find that two factors associated with the British media system - the newspapers' political positions and the difference between broadsheet and tabloid papers - clearly help to predict how debates about solidarity with refugees unfold.

These findings are particularly interesting against the background of comparatively low numbers of first-time asylum applicants in the UK during this period. This highlights the particular importance of news coverage in interpreting the facts and constructing the events, which largely were located outside of the country. The 'refugee crisis' is externalised in a similar way to the Danish and Polish debates. The decisive difference in the British case, however, is that the UK government was effective in shielding the country from the 'crisis', due to its geographical position. It is a sad irony that despite the effectiveness of these policies in keeping refugees out, the external threat narrative became nevertheless most salient in the UK. It was propagated by the 'Leave' campaign in their endeavour 'to brexit' the EU, thus not only rejecting solidarity with other EU member states, but most importantly, also with the people most in need.

\section{Notes}

1 We would like to thank Tom Montgomery and Francesca Calò for valuable research contributions. A detailed discussion of the findings of the British case can be found in Montgomery et al. (2018).

2 Audit Bureau of Circulations, https://www.abc.org.uk/ 


\section{Conclusion}

\section{The divided Europe of solidarity contestation}

\section{European solidarity in the media}

This book started out with the assumption that (the mass) media and the public sphere through public claims-making play a constitutive role in the construction or erosion of solidarity in modern society. Solidarity can never be taken for granted, but remains a contested notion. It thus requires continuous effort to reaffirm its value, mobilise commitments and ensure broad consensus in its defence. The public sphere and the media are thus needed to reach out beyond the intimate relationships of the private, and provide spaces for the arousal of a collective sense of solidarity. This is particularly true with regard to the target group under analysis in this book: refugees and asylum-seekers. Compassion with the needy, the persecuted and displaced people is an immediate human expression, but collective solidarity with strangers is a more politically contested demand that needs to be morally grounded, with related commitments and mutual interests in need of justification and negotiation, respectively. The public sphere is thus of crucial importance for the relevance of solidarity as a societal force, given that it is a privileged realm of conflict among stakeholders with opposing views regarding whether and how to share our common resources in a way that is both just and solidary.

While solidarity relationships within nationally confined communities of cocitizens can rely on 'strong ties' of ethnic and cultural belonging, the ties that bind diverse and globalised societies are commonly held to be weaker and less committed (Banting and Kymlicka, 2017). This study contributes important insights into the potentials of transnational and global solidarity, in that it shows that the public sphere and the mass media are not exclusively bound to specific communities. They open a window onto the world, but to fulfil this function, need to be understood as the horizon for the dynamic unfolding of global solidarity among strangers (Trenz, 2020). The mediapolis embraces the polis as constituted by the modern nation-state, but also reaches beyond it (Silverstone, 2006). This is best reflected in the professional self-understanding of journalism to make the world relevant to us, but at the same time to remain open to diversity and the perspectives of others (McQuail, 2013). In this sense, the media are the motor of a political morality of solidarity in the form of 
public debates that allow for the confinement of forms of civic friendship in light of global commitment (Brunkhorst, 2005).

As we have argued in this book, the mass media do not necessarily conform to this ambition, as their contribution to the formation of (transnational) solidarity is rather ambivalent. The Janus face of the media and the public sphere is related to their double role, as they are a transmission belt for universal notions of justice (representing the world) and a filter for the consolidation of thickened and contextualised relationships of solidarity within a community of equals (representing the nations). This ambivalence, however, offers an opportunity for arousing transnational solidarity and for making solidarity mobilisation visible. Media representations of human suffering in distant parts of the world are regularly used by charity organizations to mobilise humanitarian support (Chouliaraki, 2013). Additionally, the mass media help to give these initiatives and organisations visibility, thus contributing to the wave of solidarity mobilisations that have swept through many European countries since the 2010s (Lahusen et al., 2021). Within the EU, however, such humanitarian commitments and mobilisations went beyond charity, and placed the political dimension of solidarity at centre stage by underlining the importance of human needs and rights. This observation conforms in particular to the European experience, where solidarity is an eminently political notion. This has to do with the EU's role as an actor in international relations, the EU's external borders and the internal regime of EU citizenship, which have all created a political space in which economic, social or humanitarian challenges need to be faced collectively, and in which solidarity thus becomes an important principle and reference point for problem-solving (Eriksen, 2017).

It is thus no coincidence that European integration implies a commitment to global justice, and that one of the fundamental values underpinning European unification is the principle of solidarity (Eriksen, 2017). Before this backdrop, solidarity has become an important reference point and a recurrent topic of public debates across Europe. This salience underlines the importance of taking a closer look at solidarity contestations within the public sphere. What makes our focus on the public sphere even more cogent is that the term solidarity is not only recurrent throughout the official EU documents and solidarity jurisprudence (De Bùrca, 2005). It is especially fundamental for the public assessment and political solution of a large number of crucial issues at stake for Europeans, including the European Social Model, the recent economic crisis, the potential dissolving of the Union with Grexit and Brexit, and of course, the refugee crisis.

Our analysis of the public sphere can thus be seen as contributing to existing knowledge about the state of union or disunion between Europeans and their outside. It helps to better understand whether policy actors and European citizens, throughout these intense debates, see themselves as being bound to one other by solidarity, capable of playing a bonding role between national states and the broader international order of human rights and global justice, or whether they lean towards closed conceptions of solidarity that are restricted to 
national communities and introduce strong differentiations between duties visà-vis their own compatriots, other EU citizens, and even refugees coming from the rest of the world.

The refugee crisis of 2015 and 2016 provides an emblematic case of analysis, because it allows us to focus on the contentiousness of solidarity and the ambivalent role of the mass media in mediating and patterning related debates. On the one hand, it is well known that in facing collective challenges that require solidarity among Europeans, the European public sphere remains fragmented along national lines and is served mainly (or almost exclusively) by the national media as the transmission belt of solidarity discourse. Solidarity contestation within the European Union therefore follows mainly intergovernmental logics through conflicts that are primarily carried out within each member state with regard to the country's readiness to help, and among governments debating about their readiness to engage in burden-sharing activities. This segmentation is responsible for a strong compartmentalisation of solidarity debates, and distracts from shared problems and responsibilities. In fact, while EU member states could agree that the humanitarian crisis triggered by the war in Syria posed a European challenge to solidarity that had to be dealt with collectively, the responses to the unfolding emergency were still largely shaped by national executives.

On the other hand, however, national segmentations do not exclude European-wide debates about solidarity, as our analysis has shown. The dramatic events related to the refugee crisis opened a public sphere of solidarity contestation in all European countries under study, with a significant mobilisation of citizens and civil society, and a broad participation of diverse groups of actors (Lahusen et al., 2021), thus generating considerable attention by the mass media and the general public. While these debates triggered by the crisis were clearly interlinked, the principal arena for selectively amplifying and framing them was constituted by the national media. In this sense, solidarity contestation is marked by the apparent dilemma that public debates revolve around the issue of European solidarity as a shared challenge, mechanism and value, but that European solidarity is propagated and/or opposed to the perspective of very diverse national spheres of contestation with their own agendas, concerns and beliefs. This dilemma is the reason why we have opted in this book to analyse European solidarity contestations on the basis of national newspaper discourses as representative of national public spheres. On these grounds, we are able to assess what effect the fragmented nature of the EU public spheres has had on public contestations about European solidarity. Let us summarise the main findings.

\section{Contesting European solidarity}

In our cross-country comparison of public claims-making in the news media, the dramatic events that accompanied the refugee crisis of late summer 2015 could clearly be distinguished as a 'humanitarian moment' of peak attention. In 
our claims-making analysis of news covering the crisis in eight countries (Denmark, Germany, France, Greece, Italy, Poland, the UK and Switzerland) we found converging patterns of debate. The most apparent findings refer to the way refugee solidarity was contested, with tonality turning more positive towards refugees during the month of September but then quickly changing towards a more negative stance. These shifts are closely related to incidents and developments in singular European countries. The early endorsement of solidarity has to do with the wave of solidarity mobilisation in various countries, in particular the incipient welcoming culture in Germany that partly resonated in other countries. During the months of September 2015, emotional reactions to the media witnessing of human suffering were collectively expressed as a 'politics of pity' (Boltanski, 1999). This allowed for rapid changes of opinion from indifference or even 'antipathy' towards refugees to attention and personal engagement that was followed by possible forms of individual or collective support action. The media also played a fundamental role in placing justice high on the public agenda, which pushed public debates to go beyond concerns about charity in terms of humanitarian assistance, and allowed political contestants and audiences to get involved in discussions about collective responsibilities and the joint duty to take action. The solidarity agenda addressed by public debates thus transcended questions about the immediate engagement with refugees in need of assistance and expanded into a discourse about common challenges, shared obligations and joint affairs among all Europeans and their humanitarian commitment in the world.

In this way, the solidarity agenda helped to revive the contestation between those who see Europe as an intergovernmental organisation (though endowed with a relevant supranational dimension) on the one hand, and on the other, those who see it as a transnational body that accounts for multiple and overlapping constituencies that may cut across territorial distinctions (Nicolaïdis and Howse, 2001). This latter view, in its more inclusivist ambition, opens up space for discussing the potential transformation of borders into 'seams' (Cinalli and Jacobson, 2020), driving cross-national networks and discourses within Europe and beyond, as well as establishing the middle-ground position of the EU between the national state and wide-spread transnational forces. European solidarity, under this viewpoint, is a major element for sustaining cross-cultural relationships, exchanges and discourses in the public sphere, as a way to defuse a dystopic normative ideal which views the EU as a simple instrument for realising the self-interest of each, separately taken, constituent part (Bellamy, 2017). In fact, Europe may be taken as the privileged locus of solidarity, where a Euro-wide demos could take the best of existent democratic institutions at the EU level (Mertens, 1996).

It would, nevertheless, be an exaggeration to talk of late summer 2015 as a wholly European momentum of solidarity. While attention peaked visibly across Europe, the reception contexts remained sharply different. The European landscape of (domestic and cross-national) conflicts prompted by the 'refugee crisis' was complex. Solidarity contestation was triggered, firstly, cross-nationally by the 
positioning of each country as transit or final destination, as welcoming or unwelcoming. Such cleavages were partly determined by ideological left-right divides (e.g. the welcoming attitude of the Syriza government in Greece and the hostile attitudes of Hungary and/or Denmark), partly resulted from more proEuropean and Eurosceptic attitudes of the respective countries, and partly reflected long-term historical and cultural divides towards migration politics in general. With regard to this last point, it has been argued that the refugee crisis has brought to light internal frictions within the EU and re-opened the old cultural and political cleavage between Eastern Europe and the West (Krastev, 2017b). The categorical rejection of the welcoming rhetoric by countries such as Hungary, Slovakia and Poland is in this sense also to be understood as an implicit denial of Western lifestyles and values. The contestation about European solidarity does not involve the incoming refugees alone, but is about redistribution and recognition within the EU, about EU power politics, about quotas and burden-sharing and about the defence of national sovereignty against a perceived European (or German) hegemony.

Secondly, it should not be overlooked that solidarity towards refugees was also heavily contested internally. Our country briefs give clear evidence of the increase in domestic conflicts and the sharpening of cleavages in the aftermath of the events of late summer of 2015. Research has repeatedly pointed at the volatility of discourses and the instability of emotions that were triggered by mediated images of pain (Chouliaraki and Stolic, 2017). In Germany, the solidarity moment at the first refugee reception in September did not impose itself on public opinion permanently, because opposition voices, silenced by the 'welcoming culture', soon gained ground again (Vollmer and Karakayali, 2017). The 'welcoming culture' did not, as it was sometimes claimed by the right-wing opposition, establish a hegemony of discourse. Established, stereotypical frames of security, threat, and economisation proved more powerful in the long run, not least because political actors, as well as journalists, could routinely refer to them in political contestations (Greussing and Boomgaarden, 2017).

Domestic solidarity contestations were largely determined by the position of state-actors, in particular public authorities and parties in government. This comes as no surprise, because news coverage privileges these actors systematically, and this means that they had the ability to set the agenda and define problems and solutions in regard to the 'refugee crisis', as well. The centrality of state-actors does not only explain the prominence of migration management issues within public debates in all countries under study, to the detriment of topics closer to the accounts, needs and rights of the refugees themselves. It also explains why the public sphere was dominated everywhere by business-like, technocratic or regulatory claims that did not need any kind of justification or reasoning. The hegemonic position of state-actors, however, also helps to better understand the differences between our countries in terms of solidarity with refugees, given that the divergent position of national governments largely determined the tonality of the public debates at large. In the case of Greece, Germany and to a degree, France, state actors appeared to be more sensitive 
towards the humanitarian tragedies and personal hardships of incoming refugees, thus providing debates about solidarity with refugees with more space and visibility. On the contrary, public administrations in Great Britain, Denmark, Poland, Italy and Switzerland were considerably more hostile, thus imprinting the whole debate with a negative tonality. While right-wing parties strongly contributed to a belligerent discourse, it was mainly civil society organisations and civic initiatives that upheld the voice of solidarity with refugees and engaged in justifications that placed rights and values at centre stage. The refugees themselves were largely excluded from public debates, which meant that their fate largely depended on the visibility of domestic actors propagating their cause, and from the receptivity of policy-makers conforming to some of their demands.

In these internal debates, as well, European solidarity assumed multiple meanings. On the one hand, the humanitarian commitment towards refugees was grounded in a principle of solidarity that is propagated as a European value and defended by the forerunners of European integration against nationalist backlashes. This has to do with the principle of free movement, which is taken as the most crucial element in the building of the European Union. In fact, opening borders to people is comparably more important in regard to the unification of Europe than opening borders to goods, capitals or services, because free movement is the basis on which European citizens genuinely commit to each other in a fully egalitarian way (Favell, 2014). At the same time, the fourth freedom was primarily meant as an invitation for Europeans to build a solidarity community, which came at the price of erecting an external border towards the outside world (Bigo et al., 2013). It might be true that the Dublin regulations were installed as a complement to the Schengen treaty, thus ensuring that free movement is restricted to European citizens, to the detriment of non-Europeans. However, the contraposition of internal freedom and external closure is an open wound of the European integration project, and thus a constant thorn in the side of political, legal and ethical debates about the basic values and constitutional rights of the European Union. It has caused the EU to commit its members to refugee protection and asylum policies, and even though the Common European Asylum System is one of the most contentious European policy fields, it signals that open borders continue to be a fundamental element of European values, among which lies the principle of European solidarity.

The call for solidarity articulated in the public debates under study thus included two demands, the support of refugees in need of protection and shelter, and the mutual support of Europeans to share the burden of welcoming and sheltering the incoming refugees. Against this vision, numerous claimants raised their voice in the mass media to propagate, on the other hand, a more exclusive notion of solidarity, playing off exclusive, mono-ethnic traditions against inclusive multicultural notions of community. These debates did not call for a 'politics of pity' but were driven by a 'politics of fear', because refugees were defined as a threat to the national community in economic, political and/or cultural terms. Refugees were not treated as victims but as predators that take 
away jobs, cheat on social benefits, transgress social order, engage in criminal offences and subvert domestic values. This position not only denies support to refugees, but it rebuffs mutual assistance between Europeans; in part, it subverts the very idea of solidarity in the name of 'omnis homo sibi' - every woman for herself, every man for himself. In its nationalistic and xenophobic essence, the denial of solidarity with refugees was very often linked to the most Eurosceptic position, which marks the EU as on the wrong path, with its institutions doomed to failure and destruction (Malcolm, 1995).

These two opposite visions of (European) solidarity correspond partly to different political projects of the left and the right, even though the left has developed its own Eurosceptic positions (Streeck, 2014; Tuck, 2016). In part, these opposite visions are also used to visualise a new domestic cleavage between cosmopolitans and communitarians (Zürn and de Wilde, 2016). While evidence for these new domestic cleavages along inclusive and exclusive notions of solidarity were found in all countries analysed, our study challenges the assumption of new geographical cleavages within the EU among winners and losers of European integration (Teney et al., 2014) or among the south and north of Europe (Grande et al., 2019; Hooghe and Marks, 2018; Hutter et al., 2016). Dividing lines of solidarity towards refugees run between Denmark and Germany, while countries of first arrival in the south of Europe did not develop particularly hostile attitudes towards refugees. Domestic partisan cleavages therefore matter more than country cleavages to explain solidarity attitudes towards refugees. What would need to be further analysed in this context is how the crisis of 2015 and 2016 triggered debates about the project of European integration, about European responsibilities in the world, and about future trajectories of integration. We find that meta-frames were used in all countries to discuss, for instance, Germany's role in the European Union, the power relationship among European member states and the broader role of Europe in external relations and its position in the world. Our study does, however, not allow us to trace such a meta-discourse over time. Extrapolating from our findings, we would assume that such debates would not necessarily divide member states, but rather allow for the construction of coalitions and allegiances across countries.

We further contest the idea that the refugee crisis of 2015 and 2016 has contributed to a radicalisation of immigration debates, or has triggered a newly politicised dynamic of European integration that is mainly driven by ethnonationalist or populist political forces (van Prooijen et al., 2017). Public debates about solidarity were highly contentious, even though a considerable share of interventions, issues and statements were moderate, regulatory, and in part even technocratic in tone and argumentation. This mainly has to do with the type of public debates under analysis here, given that newspapers grant prominence to organisational actors, among them political parties, public authorities, agencies, experts and commentators. This limits the focus, because public debates as reported within the newspapers do only cover part of what we must consider to be the public sphere. To provide a broader vision of solidarity contestations 


\section{Conclusion}

within the public sphere, we thus expanded the focus of analysis in order to give news readers and newspaper users a proper voice. In particular, the Facebook comments section of mainstream newspaper sites offered an excellent opportunity to take a closer look at focused debates about the 'refugee crisis' from the media usage perspective. Our comparative examination of bottom-up solidarity contestations at the height of the so-called 'refugee crisis' during the month of September 2015 shows that citizen-users all over Europe actively seized the opportunity provided by the Facebook sites. Most commenters strictly engaged with the news content - the topics, claims and justifications publicised in the posted articles, thus disproving the assumption that news commenting sections are a space of diffuse, uncivilised or irrelevant communication. Commenters wish to actively participate in public debates, and thus aim to have an impact on public opinion formation. The voices and views articulated in these sections are as diverse as the positions detected in the news articles themselves. Public Facebook sites were used by some to give testimonies of the humanitarian disaster and the human suffering of refugees, while others expressed their diffuse feelings of fear in light of a seemingly uncontrolled influx of refugees. This contentiousness largely replicated the one found within the news articles of the newspapers under analysis. More than that, the comparative analyses highlighted that news readers actively engaged with the issues and claims raised in the news articles, thus showing that bottom-up contestations within the online media were strictly interrelated with the public debates reported by the print media's news coverage.

Our findings thus confirm the centrality of the media public sphere (both onand offline) for public debates about solidarity. Moreover, they point to a fairly integrated public sphere of solidarity contestation, because online news and online commenting remained strongly coupled. This observation, however, needs to be complemented by two further findings that relate to the internal structure of this public sphere. On the one hand, it is necessary to differentiate the uneven impact of news coverage and online commenting on public opinion formation. In regard to solidarity contestations, we identified primary definers (claims-makers such as politicians, stakeholders or intellectuals), whose interventions were covered in the news media and were thus able to set the agenda and define the main frames and messages of the news. Facebook sites provided spaces for secondary definers (the news readers and commenters), who made use of the online media to express their (dissenting) opinions. These linkages between primary and secondary definers are significant, and help to explain the divergence of public debates between the various countries under analysis. In fact, we saw that the tonality of news coverage was largely replicated on the level of Facebook comments, as news readers joined in a negative, in part hostile rhetoric against refugees (Denmark, Poland and the UK), or amplified the more positive or balanced discussions (Greece and Italy). In the other countries, news readers used the opportunity to oppose the dominant debates, most often by defending a hostile posture against a seemingly overly friendly stance among policy actors (Switzerland, Germany and France). 
On the other hand, evidence suggests that the politicisation and parallelism of the newspaper system has an effect on public contentions about solidarity, as well. Facebook comments on the sites of tabloids were the most negative in regard to refugees, followed at some distance by the conservative broadsheets, while the more liberal or leftist newspapers tended to host comments that more often expressed support for refugees and sympathy for their cause. This speaks to the ability of newspapers - and the political parties and forces close to them - to mobilise an ideologically akin segment of the audience, not only in terms of passive readership, but also in regard to active grass-roots opinionformers. This observation indicates an ideological segmentation of the public sphere, which limits the discursive potential of solidarity contestations. In fact, public debates may allow engagement in argumentative reasoning - even in the case of heated discussion - as long as contenders are involved in mutual disputes and exchanges of views and arguments. The segmentation of solidarity contestations in separate spaces of opinion-formation, however, does imply the risk of fragmentation and radicalisation.

\section{Conclusion: The contested future of European solidarity}

The 'refugee crisis' was linked to real events of war, plight and violence, but it was only through mediated images of human suffering that a 'politics of pity' could be triggered. It mobilised not only civil society and humanitarian organisations, but also large parts of Western publics in solidarity with refugees. The interpretation of the 'refugee crisis' as a media event is useful to understand how public perceptions of refugees are formed (how refugees are made relevant to us), and how policy agendas are set by the expression of opposing positions (how collective responses are defined). The media can thus be seen as constitutive to 'crisis' in two regards. First and at the most elementary level, media discourse is decisive with regard to the definition of refugees as either victims or threats, as people deserving solidarity or being unworthy of help. We have seen how the media in different member states shifted across time between these two perspectives. They made more salient the personal or humanitarian needs of the refugees in the initial stage of the 'crisis', and turned to the alleged negative consequences for the community in the later stage of the debate. Secondly, media stories about the 'refugee crisis' form public opinions in terms of cognitions, evaluations and emotions (Chouliaraki, 2013), because they nurture feelings of sympathy or antipathy towards refugees, highlight or downplay their rights and our obligations, and they propose potential causes and adequate solutions. Our data has evidenced that news coverage fuels solidarity contentions significantly because it grants visibility to different actors advocating for diverging, very often opposing perceptions and interpretations of what the 'refugee crisis' means in terms of problems, causes and solutions.

The mass media has thus played a crucial role in defining, interpreting and constructing the events during the summer of migration in 2015 as a 'refugee crisis'. In this regard, the most outstanding finding of our analysis is the strong 


\section{Conclusion}

volatility of public perceptions and opinions. The mass-mediated 'refugee crisis' aroused a strong momentum of European solidarity, but this momentum was fragile and did not last for long. This has to do with the structure of public debates within the European Union. The common political space continues to be fragmented, and public opinion formation and contestation took place in nationally confined media spheres. The refugee crisis remained, first of all, heavily politicised internally, and this was particularly true in regard to the contentiousness of solidarity with refugees. In countries like Germany, public discourse of hospitality had a short-term impact on public opinion, but the 'crisis media event' was not prone to being restricted to a single or 'hegemonic' frame of interpretation. After the so-called Cologne attacks of New Year's Eve 2015, a series of contrasting images was delivered, portraying dark-skinned young men from North Africa, who formed gangs to go after defenceless German women. As some of the German media were initially rather timid to build a causal connection between the Cologne sexual assaults and the influx of refugees, journalists who defended the refugee cause were increasingly met with mistrust and charged with being biased, or even lying. In the long run, public debates started to revolve around issues of threat and security, and it proved impossible to shift the attention back from security and threat to hospitality against the powerful political mobilisation by right-wing and populist actors who undermined trust in journalism and immigration friendly politicians and civil society groups (Greussing and Boomgaarden, 2017).

Secondly, the inability to build and maintain a lasting sense of solidarity with refugees in the public sphere is linked to European contentions about the 'refugee crisis'. In fact, while the initial moment of domestic solidarity in welcoming countries was linked to the hope of finding a joint European solution, disillusionment soon prevailed within the public sphere, due to governments that coupled a strong hand domestically with an uncooperative posture at the EU level. The 'refugee crisis' thus became a crisis of European integration in the way it made salient irreconcilable frictions and fundamental conflicts of values among EU member states. When looking at media contestation, it thus became clear that there is a wider connotation of the term 'refugee crisis', which is quintessentially not about refugees, but about 'us' as Europeans. Ivan Krastev encapsulated the idea in his essay 'After Europe', calling the 'refugee crisis' Europe's September 11 (Krastev, 2017a).

The humanitarian disasters at Europe's external borders in the Mediterranean and in the Balkans do indeed challenge the foundations of Europe and the values on which our liberal and inclusive democracies are based. European integration has always been advanced as an expansive solidarity project: The European social model, the EU as a humanitarian power, free flows of labour, capital and people, or inclusive notions of citizenship are all committed to this overarching goal (Trenz, 2016). However, even if the European Union was set up as a community of solidarity, the related relationships among the European partners have remained undefined and have assumed multiple and contested meanings for a long time (Delanty, 2008; Jones, 2012; Silveira et al., 2013). This 
is particularly true in regard to the field of immigration, refugee protection and asylum, which has been marked by contestations since its beginnings. Various attempts to coordinate the politics of immigration have been made (Menéndez, 2016; Thielemann, 2004), especially in terms of harmonised measures to share the responsibility of welcoming refugees. But repeated failures in negotiating joint goals, quotas and allocation mechanisms provoked a shift in the definition of European solidarity. While it initially demarcated a relationship among equals, it has now become a principle of differentiation (Michailidou and Trenz, 2019). In a European Union of differentiated integration, differentiated solidarity redefines the relationship among European partners: It is no longer reciprocal and equal, but shaped by power relations among non-equals. Today, flexible arrangements among EU members are linked to discretionary redistributive mechanisms that need to be constantly renegotiated. Solidarity remains, therefore, more open depending on the constellations of power and national interests at particular points in time. In this political space of power and domination, there is an incentive for EU member states to give further restrictive twists to their policies so as to pass on to other EU states the burden of processing an increasing number of asylum applications. Jurisdictions in the form of establishing legal or constitutional guarantees are unwanted. Solidarity shall only be exceptionally granted, such as in the case of Angela Merkel's decision to temporarily open the borders. It is thus redefined as a voluntary act of benevolence towards thirds, in other words, as charity. At the same time, egalitarian solidarity becomes exclusively defined as belonging to the national and not the European realm. This implies that European partners have taken on an increasingly defensive position at the European level in their constant renegotiation of the costs and benefits of European integration.

The political debate about the refugee quotas was one of the issues where such flexible European solidarity arrangements were discussed among the European partners. What is interesting to observe in these debates is that flexible solidarity is strongly promoted by weaker European partners against the perceived hegemony of the Commission or other members, especially Germany. At the Bratislava EU summit meeting of September 2016, a joint statement was issued by the four Visegrad countries introducing the new principle of flexible solidarity to the EU's refugee relocation scheme. Their intention was to invalidate the idea of solidarity as mandatory and imposed by supranational authority. Flexible solidarity should enable weaker member states, in particular, to decide on specific forms of contribution, taking into account their cultural specificities and potentials. The declaration further stressed that any refugee distribution mechanism should be voluntary. This would imply that 'solidarity' and 'responsibility sharing' would need to be negotiated case by case, e.g., through side payments. Member states would ultimately have veto power to decide about the degree of involvement in humanitarian assistance. Particularly in this case, solidarity is reduced to an act of charity that depends entirely on the good will of the donor. 


\section{Conclusion}

Ultimately, the European refugee crisis converts into a crisis of solidarity (Grimmel and Giang, 2017). If solidarity is reduced to questions of first help in a situation of emergency, then the debates that are unfolding within and across national media spheres are deprived of their central element, namely that solidarity is, first and foremost, a reminder of our duties to correct structural injustice (Eriksen, 2017). It is thus necessary to recombine claims for European solidarity with claims for justice, and to grant more attention to those voices that try to keep these principles alive in adverse times. Genuine solidarity might have lost its vigour in political debates, but those who carried the strong momentum of European solidarity during the dramatic events of 2015 and 2016 have just been pushed out of public visibility and will find their time to reinvigorate the debate about what solidarity means to Europe. 


\section{References}

Aalberg, T., Papathanassopoulos, S., Soroka, S., Curran, J., Hayashi, K., Iyengar, S., Jones, P.K., Mazzoleni, G., Rojas, H., Rowe, D. and Tiffen, R. (2013) 'International TV News, Foreign Affairs Interest and Public Knowledge', Journalism Studies, 14 (3), 387-406.

Adorno, T. and Horkheimer, M. (2002) Dialectic of Enlightenment, Stanford: Stanford University Press.

Adorno, T.W. (2001) The Culture Industry: Selected Essays on Mass Culture, London: Routledge.

Agustín, Ó.G. and Jørgensen, M.B. (2018) Solidarity and the 'Refugee Crisis' in Europe, Basingstoke: Palgrave.

Albahari, M. (2015) Crimes of Peace: Mediterranean Migrations at the World's Deadliest Border, Philadelphia: University of Pennsylvania Press.

Alesina, A.F. and Glaeser, E.L. (2004) Fighting Poverty in the US and Europe: A World of Difference, Oxford: Oxford University Press.

Allen, W. (2016) 'A Decade of Immigration in the British Press', Migration Observatory Report, University of Oxford: COMPAS. Available at: https://migrationobservatory. ox.ac.uk/resources/reports/decade-immigration-british-press/.

Alliance pour les Chiffres de la Presse et des Médias (2017) Report on 'Classement Diffusion Presse Quotidienne Nationale 2019'. Available at: https://www.acpm.fr/ Les-chiffres/Diffusion-presse/Presse-Payante/Presse-Quotidienne-Nationale.

Altheide, D.L. (2004) 'Media Logic and Political Communication', Political Communication, 21, 293-296.

Ambrosini, M., Cinalli, M. and Jacobson, D. (eds) (2020), Migration, Borders and Citizenship: Between Policy and Public Spheres, Basingstoke: Palgrave Macmillan.

Andersen, R. and de Silva, P.L. (2017) Routledge Companion to Media and Humanitarian Action, London: Taylor \& Francis.

Anderson, P.J. and Weymouth, T. (1999) Insulting the Public?: The British Press and the European Union, London: Longman.

Armstrong, K. (2002) 'Rediscovering Civil Society: The European Union and the White Paper on Governance', European Law Journal, 8 (1), 102-132.

Balme, R., Chabanet, D. and Wright, V. (eds) (2002) L'action collective en Europe, Paris: Presses de la Fondation Nationale des Sciences Politiques.

Banting, K. and Kymlicka, W. (2017) 'Introduction: The Political Sources of Solidarity in Diverse Societies', in K. Banting and W. Kymlicka (eds), The Strains of Commitment. 
The Political Sources of Solidarity in Diverse Societies (pp. 1-58), Oxford: Oxford University Press.

Baringhorst, S. (1998) Politik als Kampagne: Zur medialen Erzengung von Solidarität, Opladen/Wiesbaden: Westdeutscher Verlag.

Barlai, M., Fähnrich, B., Griessler, C. and Rhomberg, M. (eds) (2017) The Migrant Crisis: European Perspectives and National Discourses, Berlin: Lit Verlag.

Barnes, R. (2018) Uncovering Online Commenting Culture: Trolls, Fanboys and Lurkers, Basingstoke: Palgrave.

Bauböck, R. (2018) 'Europe's Commitments and Failures in the Refugee Crisis', European Political Science, 17 (1), 140-150.

Baumard, M. (2016) 'Calais: le démantèlement de la «jungle» touche à sa fin', Le Monde. Available at: http://www.lemonde.fr/societe/article/2016/10/26/pres-d-un-millier-de-p ersonnes-sont-toujours-dans-la-jungle-de-calais_5020709_3224.html (26 October 2016).

Bayertz, K. (1999) 'Four Uses of "Solidarity", in K. Bayertz (ed.), Solidarity. Philosophical Studies in Contemporary Culture, vol. 5 (pp. 3-28), Dordrecht: Springer.

Bell, B. (2020) 'Greece Migrant Crisis: Islanders Strike over Crowded Camps', BBC News, 22 January 2020. Available at: https://www.bbc.com/news/world-europe-51204084.

Bellamy, R. (2017) 'A European Republic of Sovereign States: Sovereignty, Republicanism and the European Union', European Journal of Political Theory, 16 (2), 188-209.

Benhabib, S. (2004) The Rights of Others: Aliens, Residents, and Citizens, Cambridge: Cambridge University Press.

Bennett, W.L. and Segerberg, A. (2013) The Logic of Connective Action: Digital Media and the Personalization of Contentious Politics, Cambridge: Cambridge University Press.

Bentele, G. and Nothhaft, H. (2010) 'Strategic Communication and the Public Sphere from a European Perspective', International Journal of Strategic Communication, 4 (2), 93-116.

Berry, M., Garcia-Blanco, I. and Moore, K. (2015) 'Press Coverage of the Refugee and Migrant Crisis in the EU: A Content Analysis of Five European Countries', Project Report, United Nations High Commissioner for Refugees, Geneva. Available at: http s://www.unhcr.org/56bb369c9.html.

Best, J. (2001) How Claims Spread: Cross-National Diffusion of Social Problems, New York: Aldine de Gruyter.

Beyers, J. (2004) 'Voice and Access: Political Practices of European Interest Associations', European Union Politics, 5 (2), 211-240.

Bigo, D., Carrera, S. and Guild, E. (eds) (2013) Foreigners, Refugees or Minorities?: Rethinking People in the Context of Border Controls and Visas, London: Ashgate.

Bigot, G. and Fella, S. (2008) 'The Prodi Government's Proposed Citizenship Reform, and the Debate on Immigration and its Impact in Italy', Modern Italy, 13 (3), 305315.

Birkland, T.A. (1998) 'Focusing Events, Mobilization and Agenda Setting', Journal of Public Policy, 18 (1), 53-74.

Blinder, S. and Allen, W.L. (2016) 'Constructing Immigrants: Portrayals of Migrant Groups in British National Newspapers, 2010-2012', International Migration Review, 50 (1), 3-40.

Bochsler, D., Gerber, M. and Zumbach, D. (2015) 'Switzerland: A Landslide Election, which only Shifts $4 \%$ of the Votes', Party Systems and Government Observatory Blog, University of Nottingham, 22 Oct 2015. Available at: https://whogoverns.eu/switzerlanda-landslide-election-which-only-shifts-4-of-the-votes/. 
Bohman, J. (1998) 'The Globalization of the Public Sphere', Philosophy and Social Criticism, 24, 199-216.

Boin, A., 't Hart, P. and McConnell, A. (2009) 'Crisis Exploitation: Political and Policy Impacts of Framing Contests', Journal of European Public Policy, 16, 81-106.

Boltanski, L. (1999) Distant Suffering: Morality, Media and Politics, Cambridge: Cambridge University Press.

Bonfadelli, H. (2017) 'Media and Immigration: Communication Research in Switzerland', in M. Barlai, B. Fähnrich, C. Griessler and M. Rhomberg (eds), The Migrant Crisis: European Perspectives and National Discourses (pp. 297-320), Zürich: LIT Verlag.

Bonizzoni, P. (2020) 'The Border(S) Within: Formal and Informal Processes of Status Production, Negotiation and Contestation in a Migratory Context', in M. Ambrosini, M. Cinalli and D. Jacobson (eds), Migration, Borders and Citizenship: Between Policy and Public Spheres, Basingstoke: Palgrave Macmillan.

Boomgaarden, H.G. and Vliegenthart, R. (2009) 'How News Content Influences Antiimmigration Attitudes: Germany, 1993-2005', European Journal of Political Research, 48 (4), 516-542.

Brändle, V.K., Trenz, H.J., Adler Berg, F.S. and Rosenberg, A.S. (2018) 'Solidarity Contestation in Danish Media: A National Escape from Transnational Crisis', in M. Cinalli and H.J. Trenz (eds), Integrated Report on Transnational Solidarity in the Public Domain (WP5) Deliverable 5.1. (pp. 165-192). Available at: https://transsol.eu/ files/2018/05/deliverable-5-1.pdf.

Brändle, V.K. and Eisele, O. (2019) 'Sharing Is Caring? Exploring the Relationship between Preferences for Online Participation and Support for Solidarity between EU Member States', American Behavioral Scientist, 63 (4), 523-537.

Brändle, V.K., Eisele, O. and Trenz, H.-J. (2019) 'Contesting European Solidarity during the 'Refugee Crisis': A Comparative Investigation of Media Claims in Denmark, Germany, Greece and Italy', Mass Communication and Society, 22 (6), 708-732.

Brier, R. (2009) 'The Roots of the "Fourth Republic": Solidarity's Cultural Legacy to Polish Politics', East European Politics \& Societies, 23 (1), 63-85.

Brüggemann, M., Engesser, S., Büchel, F., Humprecht, E. and Castro, L. (2014) 'Hallin and Mancini Revisited: Four Empirical Types of Western Media Systems', Journal of Communication, 64 (6).

Brunkhorst, H. (2005) Solidarity: From Civic Friendship to a Global Legal Community, Cambridge, MA: MIT Press.

Brunkhorst, H. (2007) 'Globalizing Solidarity: The Destiny of Democratic Solidarity in the Times of Global Capitalism, Global Religion, and the Global Public', Journal of Social Philosophy, 38, 93-111.

Bruns, A. (2010) 'From reader to writer: Citizen Journalism as News Produsage', in J. Hunsinger, L. Klastrup and M. Allen (eds), The International Handbook of Internet Research (pp. 119-133), Dordrecht/London: Springer.

Bundeszentrale für politische Bildung (2019) 'Bevölkerung mit Migrationshintergrund I', Bundeszentrale für politische Bildung. Available at: https://www.bpb.de/nachschlagen/ zahlen-und-fakten/soziale-situation-in-deutschland/61646/migrationshintergrund-i.

Calabrese, A. and Burke, B.R. (1992) 'American Identities: Nationalism, the Media, and the Public Sphere', Journal of Communication Inquiry, 16 (2), 52-73.

Calhoun, C. (2002) 'Imagining Solidarity: Cosmopolitanism, Constitutional Patriotism, and the Public Sphere', Public Culture, 14 (1), 147-171. 
Calhoun, C. (2005) 'Constitutional Patriotism and the Public Sphere: Interests, Identity, and Solidarity in the Integration of Europe', International Journal of Politics, Culture, and Society, 18(3-4), 257-280.

Cappella, J.N. and Jamieson, K. (1997) Spiral of Cynicism: The Press and the Public Good, Oxford: Oxford University Press.

Castelli Gattinara, P., Cinalli, M., Giugni, M. and Morales, L. (2015) LOCALMULTIDEM and MDE Discursive Political Opportunities: Description of Study, Released Data and Codebook. Leicester: University of Leicester.

Chabanet, D. (2008) 'When the Unemployed Challenge the European Union: The European Marches as a Mode of Externalization of Protest', Mobilization, 13 (3), 311-322.

Chadwick, A. (2013) The Hybrid Media System: Politics and Power, Oxford: Oxford University Press.

Chaudhry, I. and Gruzd, A. (2020) 'Expressing and Challenging Racist Discourse on Facebook: How Social Media Weaken the "Spiral of Silence" Theory', Policy \& Internet, 12 (1), 88-108.

Chen, G.M. (2017) 'Nasty Talk Online', in G.M. Chen, Online Incivility and Public Debate (pp. 57-77), Basingstoke: Palgrave.

Chen, G.M. and Lu, S. (2017) 'Online Political Discourse: Exploring Differences in Effects of Civil and Uncivil Disagreement in News Website Comments', Journal of Broadcasting \& Electronic Media, 61 (1), 108-125.

Chouliaraki, L. (2006) The Spectatorship of Suffering, London: SAGE Publications.

Chouliaraki, L. (2013) The Ironic Spectator. Solidarity in the Age of Post-Humanitarianism, Cambridge: Polity.

Chouliaraki, L. and Stolic, T. (2017) 'Rethinking Media Responsibility in the Refugee “Crisis": A Visual Typology of European News', Media, Culture \& Society, 39 (8), $1162-1177$.

Cinalli, M. (2004) 'Horizontal Networks vs. Vertical Networks in Multi-Organisational Alliances: A Comparative Study of the Unemployment and Asylum Issue-Fields in Britain', EurPolCom, 8 (4), 1-31.

Cinalli, M. (2007) 'Between Horizontal Bridging and Vertical Governance: Pro-Beneficiary Movements in New Labour Britain', in D. Purdue (ed.), Civil Societies and Social Movements: Potentials and Problems (pp. 88-108), Houndmills: Routledge.

Cinalli, M. (2017) Citizenship and the Political Integration of Muslims: The Relational Field of French Islam, Basingstoke: Palgrave Macmillan.

Cinalli, M. and Giugni, M. (2013a) 'Public Discourses about Muslims and Islam in Europe', Ethnicities, 13 (2), 131-146.

Cinalli, M. and Giugni, M. (2013b) 'Political Opportunities, Citizenship Models and Political Claim-making over Islam', Ethnicities, 13 (2), 147-164.

Cinalli, M. and O'Flynn, I. (2014) 'Public Deliberation, Network Analysis and the Political Integration of Muslims in Britain', British Journal of Politics and International Relations, 16 (3), 428-451.

Cinalli, M. and Giugni, M. (2016a) 'Citizens' Responses to the European Economic Crisis in the Public Domain', Politics \& Policy 44 (3), 388-399.

Cinalli, M. and Giugni, M. (2016b) 'Collective Responses to the Economic Crisis in the Public Domain: Myth or Reality?' Politics \& Policy 44 (3), 427-446.

Cinalli, M. and Jacobson, D. (2020) 'From Borders to Seams: The Role of Citizenship', in M. Ambrosini, M. Cinalli and D. Jacobson (eds), Migration, Borders and Citizenship: Between Policy and Public Spheres (pp. 27-45), Basingstoke: Palgrave Macmillan. 
Cinalli, M., De Nuzzo, C., Lechuga, R. and Sanhueza, M.J. (2018) 'France', in M. Cinalli and H.J. Trenz (eds), Integrated Report on Transnational Solidarity in the Public Domain (WP5) Deliverable 5.1. (pp. 49-96). Available at: https://transsol.eu/ files/2018/05/deliverable-5-1.pdf.

Colombo, M. (2013) 'Discourse and Politics of Migration in Italy: The Production and Reproduction of Ethnic Dominance and Exclusion', Journal of Language and Politics, 12 (2), 157-179.

Colombo, M. (2017) 'The Representation of the "European Refugee Crisis" in Italy: Domopolitics, Securitization, and Humanitarian Communication in Political and Media Discourses', Journal of Immigrant \& Refugee Studies, 16 (1-2),1-18.

Connor, P. (2016) 'Number of Refugees to Europe Surges to Record 1.3 Million in 2015', Pew Research Center. Available at https://www.pewresearch.org/global/wpcontent/uploads/sites/2/2016/08/Pew-Research-Center-Europe-Asylum-Report-FINALAugust-2-2016.pdf.

Conrad, M. and Aðalsteinsdóttir, H. (2017) 'Understanding Germany's Short-Lived "Culture of Welcome" - Images of Refugees in Three Leading German Quality Newspapers', German Politics and Society, 125 (4), 1-21.

Costello, C. and Hancox, E. (2014) 'The UK, EU Citizenship and Free Movement of Persons', Migration Observatory Policy PrimerMay 2014, COMPAS, University of Oxford. Available at https:/migrationobservatory.ox.ac.uk/wp-content/uploads/2016/ 04/PolicyPrimer-UK_EU_Asylum_Law.pdf.

Cottle, S. (2003) News, Public Relations and Power, London: Sage.

Cottle, S. (2006) Mediatized Conflict: Developments in Media and Conflict Studies, Maidenhead: Open University Press.

Couldry, N. (2012) Media, Society, World. Social Theory and Digital Media Practice, Cambridge: Polity.

Couldry, N., Hepp, A. and Krotz, F. (2010) Media Events in a Global Age, London/New York: Routledge.

Curtin, D. (2006) 'Framing Public Deliberation and Democratic Legitimacy in the European Union', in S. Besson and J.L. Martì (eds) Deliberative Democracy and its Discontents (pp. 133-158), Aldershot: Ashgate.

Daddow, O. (2012) 'The UK Media and "Europe": from Permissive Consensus to Destructive Dissent', International Affairs, 88 (6), 1219-1236.

Dahlgren, P. (2013) The Political Web: Media, Participation and Alternative Democracy, Basingstoke: Palgrave Macmillan.

Damstra, A., Jacobs, L., Boukes, M. and Vliegenthart, R. (2019) 'The Impact of Immigration News on Anti-immigrant Party Support: Unpacking Agenda-setting and Issue Ownership Effects over Time', Journal of Elections, Public Opinion and Parties, 1-22. https://doi.org/10.1080/17457289.2019.1607863.

Dayan, D. and Katz, E. (1992) Media Events: The Live Broadcasting of History, Cambridge, MA/London: Harvard University Press.

De Bùrca, G. (2005) EU Law and the Welfare State: in Search of Solidarity, Oxford: Oxford University Press.

De Swert, K. (2012) Calculating Inter-coder Reliability in Media Content Analysis using Krippendorff's Alpha. CPC Center for Politics and Communication Manual. Available at https://www.polcomm.org/wp-content/uploads/ICR01022012.pdf.

De Vreese, C.H. (2003) Framing Europe: Television News and European Integration, Amsterdam: Askant. 
De Wilde, P. (2011) 'No Polity for Old Politics? A Framework for Analyzing the Politicization of European Integration', Journal of European Integration, 33 (5), 559-575.

De Wilde, P. (2013) 'Representative Claims Analysis: Theory Meets Method', Journal of European Public Policy, 20 (2), 278-294.

De Wilde, P. and Zürn, M. (2013) 'Debating Globalization: Cosmopolitanism and Communitarianism as Political Ideologies', unpublished manuscript, Berlin: WZB.

De Wilde, P., Michailidou, A. and Trenz, H.-J. (2013) Contesting Europe. Exploring Euroscepticism in Online Media Coverage, Colchester: ECPR Press.

De Wilde, P., Koopmans, R., Merkel, W., Strijbis, O. and Zürn, M. (2019) The Struggle Over Borders: Cosmopolitanism and Communitarianism, Cambridge: Cambridge University Press.

Deken, J.J.D., Ponds, E. and Riel, B.V. (2009) 'Social Solidarity', in G.L. Clark, A.H. Munnell and J.M. Orszag (eds), The Oxford Handbook of Pensions and Retirement Income (pp. 141-160), Oxford: Oxford University Press.

Delanty, G. (2008) 'Fear of Others: Social Exclusion and the European Crisis of Solidarity', Social Policy \& Administration, 42 (6), 676-690.

Della Porta, D. (2008) 'The Emergence of European Movements? Civil Society and the EU', European Journal of Legal Studies, 1 (3), 1-37.

Della Porta, D. (2009) Democracy in Social Movements, Basingstoke: Palgrave Macmillan.

Della Porta, D. (2018) Solidarity Mobilizations in the 'Refugee Crisis': Contentious Moves, Basingstoke: Palgrave.

Della Porta, D. and Tarrow, S. (2005) Transnational Protest and Global Activism, Lanham: Rowman \& Littlefield.

Della Porta, D. and Caiani, M. (2007) 'Europeanization from Below? Social Movements and Europe', Mobilization, 12 (1), 1-20.

Della Porta, D. and Caiani, M. (2009) Social Movements and Europeanization, Oxford: Oxford University Press.

Dinas, E., Matakos, K., Xefteris, D. and Hangartner, D. (2019) 'Waking Up the Golden Dawn: Does Exposure to the Refugee Crisis Increase Support for Extreme-Right Parties?', Political Analysis, 27 (2), 244-254.

Ditlmann, R., Koopmans, R., Michalowski, I., Rink, A. and Veit, S. (2016) 'Verfolgung vor Armut ausschlaggebend für die Offenheit der Deutschen ist der Fluchtgrund', WZB Mitteilungen Heft, 151. Available at: https:/www.wzb.eu/sites/default/files/ publikationen/wzb_mitteilungen/veits24-27151-webpdf-2.pdf.

Dolezal, M., Helbling, M. and Hutter, S. (2010) 'Debating Islam in Austria, Germany and Switzerland: Ethnic Citizenship, Church-State Relations and Right-Wing Populism', West European Politics, 33 (2), 171-190.

Doudaki, V. and Boubouka, A. (2019) Discourses of Legitimation in the News: The Case of the Economic Crisis in Greece, London: Routledge.

Duru, D.N., Sejersen, T. and Trenz, H.J. (2021) 'The Best Welfare System in the World? The Danish Welfare State, Transnational Solidarity, and Civil Society in Times of Crisis', in M. Kousis (ed.), Transnational Solidarity in Times of Crises: Citizen Organisations and Collective Learning in Europe, Basingstoke: Palgrave.

Eberl, J.-M., Meltzer, C.E., Heidenreich, T., Herrero, B., Theorin, N., Lind, F., Berganza, R., Boomgaarden, H.G., Schemer, C. and Strömbäck, J. (2018) 'The European Media Discourse on Immigration and its Effects: A Literature Review', Annals of the International Communication Association, 42 (3), 207-223. 
Eilders, C. (2000) 'Media as Political Actors? Issue Focusing and Selective Emphasis in the German Quality Press', German Politics, 9 (3), 181-206.

Eisele, O. and Perfler, P. (2018) 'The Quest for Solidarity with Refugees: Investigating the Case of Germany Reflected in Public Claims and Comments during the "Refugee Crisis", in M. Cinalli and H.J. Trenz (eds), Integrated Report on Transnational Solidarity in the Public Domain (WP5) Deliverable 5.1. (pp. 70-92). Available at: https:// transsol.eu/files/2018/05/deliverable-5-1.pdf.

Eising, R. (2004) 'Multilevel Governance and Business Interests in the European Union', Governance: An International Journal of Policy, Administration, and Institutions, 17 (2), 211-245.

Enjolras, B. (2017) 'Boundary Work in the Public Sphere', in A.H. Midtbøen, K. SteenJohnsen and K. Thorbjørnsrud (eds), Boundary Struggles: Contestations of Free Speech in the Norwegian Public Sphere. Available at: https://press.nordicopenaccess. no/index.php/noasp/catalog/book/16.

Entman, R.M. (2007) 'Framing Bias: Media in the Distribution of Power', Journal of Communication, 57 (1), 163-173.

Eriksen, E.O. (2017) 'Structural Injustice: The Eurozone Crisis and the Duty of Solidarity', in A. Grimmel and M.S. Giang (eds), Solidarity in the European Union (pp. 97118), Berlin: Springer.

Eriksen, E.O. and Fossum, J.E. (2004) 'Europe in Search of Legitimacy: Strategies of Legitimation Assessed', International Political Science Review, 25 (4), 435-459.

Escafré-Dublet, A., Lelévrier, C. and Tenfiche, S. (2014) Assessment of Urban Policies in Paris, Créteil, France: Lab’Urba, University Paris Est.

Eurostat (2018) 'Asylum and First Time Asylum Applicants by Citizenship, Age and Sex Monthly Data (rounded) [migr_asyappctzm]', extracted on 22.03.2018.

Evangelinidis, A. (2016) 'The Greek State's Response to the Refugee Crisis and the Solidarity Movement', Contemporary Southeastern Europe, 3 (1), 32-36.

Evangelinidis, A. (2018) 'Global Injustice Symbols and Social Movements', Social Movement Studies, 17 (4), 486-487.

Evans, M. (2010) 'Framing International Conflicts: Media Coverage of Fighting in the Middle East', International Journal of Media \& Cultural Politics, 6 (2), 209-233.

Facebook (2020) 'What Does Most Relevant Mean on a Facebook Page Post?', Facebook Help Centre.

Faist, R., (1994) 'How to Define a Foreigner? The Symbolic Politics of Immigration in German Partisan Discourse', West European Politics, 17 (2), 50-71.

Favell, A. (1998) Philosophies of Integration: Immigration and the Idea of Citizenship in France and Britain, Basingstoke: Palgrave Macmillan.

Favell, A. (2014) 'The Fourth Freedom: Theories of Migration and Mobilities in "Neoliberal” Europe', European Journal of Social Theory, 17 (3), 275-289.

Federico, V. and Lahusen, C. (eds) (2018) Solidarity as a Public Virtue?: Law and Public Policies in the European Union, Baden-Baden: Nomos.

Feinstein, A. and Storm, A. (2017) The Emotional Toll on Journalists Covering the Refugee Crisis, Oxford: Reuters Institute for the Study of Journalism. Available at: https://reutersinstitute.politics.ox.ac.uk/sites/default/files/2017-07/Storm \%20and $\%$ 20Feinstein \% 20-\%20Emotional\%20Toll.pdf.

Fernández G. G., E. (2018a) 'Civic and Political Solidarity Practices in Switzerland', in C. Lahusen and M.T. Grasso (eds), Solidarity in Europe (pp. 195-226), Basingstoke: Palgrave Macmillan. 
Fernández, G. G., E (2018b) 'Discursive Opportunities Country Report Transnational Solidarity Action Claims - Switzerland', in M. Cinalli and H.J. Trenz (eds), Integrated Report on Transnational Solidarity in the Public Domain (WP5) Deliverable 5.1 (pp. 193-216). Available at: https:/transsol.eu/files/2018/05/deliverable-5-1.pdf.

Ferree, M.M., Gamson, W., Gerhards, J. and Ruchts, D. (2002) 'Four Models of the Public Sphere in Modern Democracies', Theory and Society, 31 (1), 35.

Fiske, J. (1994) Media Matters: Everyday Culture and Political Change, Minneapolis: University of Minnesota Press.

Fitzgerald, I.A.N. and Smoczynski, R. (2015) 'Anti-Polish Migrant Moral Panic in the UK: Rethinking Employment Insecurities and Moral Regulation’, Sociologický Časopis /Czech Sociological Review, 51 (3), 339-361.

Fitzgerald, J. and Jorde, C. (2018) 'Dynamic Political Attitudes in Partisan Context', in R. Tillmann, V. Voorpostel and P. Farago (eds), Social Dynamics in Swiss Society. Empirical Studies based on the Swiss Household Panel (pp. 189-201), Wiesbaden: Springer.

Fletcher, R. and Nielsen, R.K. (2017) 'Are News Audiences Increasingly Fragmented? A Cross-National Comparative Analysis of Cross-Platform News Audience Fragmentation and Duplication', Journal of Communication, 67 (4), 476-498.

Fotopoulos, S. and Kaimaklioti, M. (2016) 'Media Discourse on the Refugee Crisis: On What Have the Greek, German and British Press Focused?', European View, 15 (2), 265-279.

Franzosi, R. (2004) From Words to Numbers. Narrative, Data and Social Science, Cambridge: Cambridge University Press.

Freeman, G. (1998) 'The Decline of Sovereignty? Politics and Immigration Restriction in Liberal States', in C. Joppke (ed.), Challenge to the Nation State. Immigration in Western Europe and the United States, Oxford: Oxford University Press.

Freeman, G.P. (2002) 'Winners and Losers: Politics and the Costs and Benefits of Migration', in A.M. Messina (ed.), Western European Immigration and Immigration Policy (pp. 77-96), Westport CT: Praeger.

Galpin, C. and Trenz, H.-J. (2017) 'The Spiral of Euroscepticism: Media Negativity, Framing and Opposition to the EU', in M. Caiani and S. Guerra (eds), Euroscepticism, Democracy and the Media: Communicating Europe, Contesting Europe (pp. 4972) Houndsmills: Palgrave Macmillan.

Galpin, C. and Trenz, H.-J. (2018) 'Converging towards Euroscepticism? Negativity in News Coverage during the 2014 European Parliament Elections in Germany and the UK', European Politics and Society, 1-17.

Galpin, C. and Trenz, H.-J. (2019) 'Participatory Populism: Online Discussion Forums on Mainstream News Sites During the 2014 European Parliament Election', Journalism Practice, 13 (7), 781-798.

Gammeltoft-Hansen, T. (2017) 'Refugee Policy as 'Negative Nation Branding': The Case of Denmark and the Nordics', in K. Fischer and H. Mouritzen (eds), Danish Foreign Policy Yearbook (pp. 99-125), Copenhagen: Danish Institute for International Studies.

Gaus, D. (2011) 'The Dynamics of Legitimation. Why the Study of Political Legitimacy Needs More Realism', RECON Online Working Paper 2011/15. Available at: http:// www.reconproject.eu/main.php/RECON_wp_1115.pdf?fileitem=50512026.

Geddes, A. (2005) 'Getting the Best of Both Worlds? Britain, the EU and Migration Policy', International Affairs, 81 (4), 723-740.

Geddes, A. and Scholten, P. (2016) The Politics of Migration and Immigration in Europe, London: SAGE. 
Gemi, E., Ulasiuk, I. and Triandafyllidou, A. (2013) 'Migrants and Media Newsmaking Practices', Journalism Practice, 7 (3), 266-281.

Georgiou, M. and Zaborowski, R. (2017) 'Council of Europe Report: Media Coverage of the 'Refugee Crisis': A Cross-European Perspective', DG1, March 2017. Available at: https://rm.coe.int/1680706b00.

Gerbaudo, P. (2014) 'Populism 2.0: Social Media Activism, the Generic Internet User and Interactive Direct Democracy', in D. Trottier and C. Fuchs (eds), Social Media, Politics and the State: Protests, Revolutions, Riots, Crime and Policing in the Age of Facebook, Twitter and YouTube (pp. 67-87), New York and London: Taylor and Francis.

Gerhards, J. and Schafer, M.S. (2010) 'Is the Internet a Better Public Sphere? Comparing Old and New Media in the US and Germany', New Media \& Society, 12 (1), 143-160.

Gerhards, J, Lengfeld, H., Ignácz, Z., Kley, F.K. and Priem, M. (2019). European Solidarity in Times of Crisis. Insights from a Thirteen-Country Survey. London: Routledge.

Gifford, C. and Wellings, B. (2017) 'Referendums and European Integration: The Case of the United Kingdom', in B. Leruth, N. Startin and S. Usherwood (eds), The Routledge Handbook of Euroscepticism (pp. 268-279), London: Routledge.

Giugni, M. and Passy, F. (2000) 'Resistance to Europeanization: National Barriers to Supranational Changes in Migration Policy', La Lettre de la Maison Française d'Oxford, 12, 83-206.

Giugni, M. and Passy, F. (eds) (2001) Political Altruism?: Solidarity Movements in International Perspective, Lanham: Rowman \& Littlefield Publishers.

Giugni, M. and Passy, F. (2002) 'Le champ politique de l'immigration en Europe: Opportunités, mobilisations et héritage de l'Etat national', in Balme R., Chabanet, D. and V. Wright (eds), L'action collective en Europe (pp. 433-460), Paris: Presses de la Fondation Nationale des Sciences Politiques.

Givskov, C. and Trenz, H.-J. (2014) 'Civic Engagement through Mainstream Online Newspapers: Possibilities and Shortcomings', MedieKultur, 30 (566), 44-60.

Gleeson, S. (2009) 'From Rights to Claims: The Role of Civil Society in Making Rights Real for Vulnerable Workers', Law \& Society Review, 43 (3), 669-700.

Glowacki, M. (2015) 'Governance of Public Service Media in Poland: The Role of the Public', Media and Communication, 3 (4), 26-34.

Goffman, E. (1974) Frame Analysis: An Essay on the Organization of Experience, London: Harper and Row.

Gonçalves, J. (2018) 'Aggression in News Comments: How Context and Article Topic Shape User-generated Content', Journal of Applied Communication Research, 46 (5), 604-620.

Gora, A. and de Wilde, P. (2019) 'Handbook for Representative Claims Analysis', Project Deliverable: RECONNECT - Reconciling Europe with its Citizens through Democracy and Rule of Law. Available at: https://reconnect-europe.eu/wp-content/ uploads/2019/09/D2.2-update-July-2019.pdf.

Gormsen, C. (2015) 'Støjbergs flygtninge-annoncer indrykket i Libanon', Altinget.dk, 7 September 2015. Available at: https://www.altinget.dk/artikel/stoejbergs-flygtninge-a nnoncer-indrykket-i-libanon.

Gray, E. and Statham, P. (2005), 'Becoming European? The Transformation of the British Pro-Migrant NGO Sector in Response to Europeanization', Journal of Common Market Studies, 43 (4), 877-898. 
Graham, R. (2019) 'Race, Social Media, and Deviance', in The Palgrave Handbook of International Cybercrime and Cyberdeviance (pp. 1-24), Basingstoke: Palgrave.

Grande, E., Schwarzbözl, T. and Fatke, M. (2019) 'Politicizing Immigration in Western Europe', Journal of European Public Policy, 26 (10), 1444-1463.

Grasso, M. (ed.) (2017) Integrated Report on Individual Forms of Solidarity (WP3) Deliverable 3.1, Available at: http://blogs.uni-siegen.de/transsol/files/2017/07/D3.1-inte grated-WP3-report.pdf.

Green-Pedersen, C. and Krogstrup, J. (2008) 'Immigration as a Political Issue in Denmark and Sweden', European Journal of Political Research, 47 (5), 610-634.

Greenslade, R. (2005) Seeking Scapegoats: The Coverage of Asylum in the UK Press (Vol. 5), Institute for Public Policy Research.

Greussing, E. and Boomgaarden, H.G. (2017) 'Shifting the Refugee Narrative? An Automated Frame Analysis of Europe's 2015 Refugee Crisis', Journal of Ethnic and Migration Studies, 43 (11), 1749-1774.

Grimmel, A. and Giang, S.M. (2017) Solidarity in the European Union: A Fundamental Value in Crisis, Berlin: Springer International Publishing.

Guasti, P. and Geissel, B. (2019) 'Rethinking Representation: Representative Claims in Global Perspective', Politics and Governance, 7 (3).

Gusfield, J.R. (1984) The Culture of Public Problems: Drinking-Driving and the Symbolic Order, Chicago: University of Chicago Press.

Habermas, J. (1985) The Theory of Communicative Action: Reason and the Rationalization of Society, Boston: Beacon Press.

Habermas, J. (1989) The Structural Transformation of the Public Sphere: An Inquiry into a Category of Bourgeois Society. Trans. Thomas Burger with the assistance Of Frederick Lawrence, Cambridge: Polity.

Habermas, J. (1996) Between Facts and Norms: Contributions to a Discourse Theory of Law and Democracy, Cambridge: Polity Press.

Hall, S. (1973) Encoding and Decoding in the Television Discourse, Centre for Cultural Studies, University of Birmingham.

Haller, M. (2019) 'Zwischen "Flüchtlingskrise" und "Migrationspakt". Mediale Lernprozesse auf dem Prüfstand', OBS-Arbeitspapier 37, Otto Brenner Stiftung. Available at: https:// www.otto-brenner-stiftung.de/fileadmin/user_data/stiftung/02_Wissenschaftsportal/03_ Publikationen/AP37_Fluechtlingskrise_II_Haller.pdf.

Hallin, D.C. and Mancini, P. (2004) Comparing Media Systems: Three Models of Media and Politics, Cambridge: Cambridge University Press.

Hamann, U. and Karakayali, S. (2017) 'Practicing Willkommenskultur: Migration and Solidarity in Germany. Intersections', East European Journal of Society and Politics, 2 (4), 69-86.

Hamilton, J. (2004) All the News That's Fit to Sell: How the Market Transforms Information into News, Princeton: Princeton University Press.

Hanitzsch, T. and Vos, T.P. (2018) 'Journalism beyond Democracy: A New Look into Journalistic Roles in Political and Everyday Life', Journalism: Theory, Practice \& Criticism, 19 (2), 146-164.

Hanitzsch, T. and Lauerer, C. (2019) 'Berufliches Rollenverständnis', in T. Hanitzsch, J. Seethaler and V. Wyss (eds), Journalismus in Deutschland, Österreich und der Schweiz (pp. 135-161), Berlin: Springer.

Hanke, P., Wieruszewski, M. and Panizzon, M. (2019) 'The 'Spirit of the Schengen Rules', the Humanitarian Visa, and Contested Asylum Governance in Europe - The Swiss Case', Journal of Ethnic and Migration Studies, 45 (8), 1361-1376. 
Hannerz, U. (2004) Foreign News. Exploring the World of Foreign Correspondents, Chicago: University of Chicago Press.

Harding, L., Oltermann, P. and Watt, N. (2015) 'Refugees Welcome? How UK and Germany Compare on Migration'. The Guardian, 2 September 2015. Available at: https://www.theguardian.com/world/2015/sep/02/refugees-welcome-uk-germa ny-compare-migration.

Haunss, S. (2007) 'Challenging Legitimacy: Repertoires of Contention, Political ClaimsMaking, and Collective Action Frames', in A. Hurrelmann, S. Schneider and J. Steffek (eds), Legitimacy in an Age of Global Politics. Transformations of the State (pp. 156172), Basingstoke: Palgrave Macmillan.

Heath, R. L. (2010) 'Introduction', in T.E. Cook and S.J. Hollady (eds), The Handbook of Crisis Communication (pp. 1-40), Chichester: Blackwell Publishing.

Hedetoft, U. (2010) 'Denmark versus Multiculturalism', in S. Vertovec and S. Wessendorf (eds), The Multiculturalism Backlash: European Discourses, Policies and Practices (pp. 111-130), London: Routledge.

Helbling, M. (2014) 'Framing Immigration in Western Europe', Journal of Ethnic and Migration Studies, 40 (1), 21-41.

Helmig, B., Gmür, M., Bärlocher, C., von Schnurbein, G., Degen, B., Nollert, M., Sokolowski, S.W. and Salamon, L.M. (2017) 'Switzerland: A Liberal Outlier for Europe', in L.M. Salamon, S.W. Sokolowski, M.A. Haddock and Associates (eds), Explaining Civil Society Development: A Social Origins Approach (pp. 131-142), Baltimore: Johns Hopkins University Press.

Hepp, A. (2014) Mediatized Worlds, Culture and Society in a Media Age, Basingstoke: Palgrave Macmillan.

Hille, S. and Bakker, P. (2013) 'I like news. Searching for the "Holy Grail" of Social Media: The Use of Facebook by Dutch News Media and their Audiences', European Journal of Communication, 28 (6), 663-680.

Hille, S. and Bakker, P. (2014) 'Engaging the Social News User', Journalism Practice, 8 (5), 563-572.

Hjarvard, S. (2007) 'Den politiske presse: En analyse af danske avisers politiske orientering', Journalistica. Tidsskrift for forskning $i$ journalistic, No.5, 27-53.

Hjarvard, S., Mortensen, M. and Fugl Eskjær, M. (2015) 'Introduction: Three Dynamics of Mediatized Conflicts', in M. Fugl Eskjær, S. Hjarvard and M. Mortensen (eds), The Dynamics of Mediatized Conflicts (pp. 1-27), New York: Peter Lang.

Holmes, S.M. and Castañeda, H. (2016) 'Representing the "European Refugee Crisis" in Germany and Beyond: Deservingness and Difference, Life and Death', American Ethnologist, 43 (1), 12-24.

Hooghe, M. (2008) 'The Political Opportunity Structure for Civil Society Organizations in a Multilevel Context: Social Movement Organizations and the European Union', in W. A. Maloney and J.W. Van Deth (eds), Civil Society and Governance in Europe: From National to International Linkages (pp. 71-90), Cheltenham: Edward Elgar Publishing.

Hooghe, L. and Marks, G. (2018) 'Cleavage Theory Meets Europe’s Crises: Lipset, Rokkan, and the Transnational Cleavage', Journal of European Public Policy, 25 (1), 109-135.

Hovden, J.F. and Mjelde, H. (2019) 'Increasingly Controversial, Cultural, and Political: The Immigration Debate in Scandinavian Newspapers 1970-2016', Javnost - The Public, 26 (2), 138-157.

Hughey, M.W. and Daniels, J. (2013) 'Racist Comments at Online News Sites: A Methodological Dilemma for Discourse Analysis', Media, Culture \& Society, 35 (3), 332-347. 
Hurrelmann, A. (2007) 'Multilevel Legitimacy: Conceptualizing Legitimacy Relationships between the EU and National Democracies', in J. DeBardeleben and A. Hurrelmann (eds), Democratic Dilemmas of Multilevel Governance: Legitimacy, Representation and Accountability in the European Union (pp. 17-37), Basingstoke: Palgrave Macmillan.

Hurrelmann, A., Krell-Laluhová, Z., Nullmeier, F., Schneider, S. and Wiesner, A. (2009) 'Why the Democratic Nation-state Is Still Legitimate: A Study of Media Discourses', European Journal of Political Research, 48 (4), 483-515.

Husbands, C.T. (1994) 'Crises of National Identity as the New Moral Panics: Political Agenda-setting about Definitions of Nationhood', New Community, 20 (2), 191-206.

Hutter, S., Grande, E. and Kriesi, H. (2016) Politicising Europe: Integration and Mass Politics, Cambridge: Cambridge University Press.

Iosifidis, P. and Boucas, D. (2015) 'Media Policy and Independent Journalism in Greece', Open Society Foundations. Available at: https://www.opensocietyfoundations.org/p ublications/media-policy-and-independent-journalism-greece.

Jones, E. (2012) 'The JCMS Annual Review Lecture: European Crisis, European Solidarity', JCMS: Journal of Common Market Studies, 50, 53-67.

Johnston, H. (1995) 'A Methodology for Frame Analysis: From Discourse to Cognitive Schemata', in H. Johnston and B. Klandermans (eds), Social Movements and Culture (pp. 217-246), London: UCL Press.

Imig, D. and Tarrow, S. (eds) (2001). Contentious Europeans. Protest and Politics in an Emerging Polity, Lanham: Rowman \& Littlefield.

Joppke, C. (1996), 'Multiculturalism and Immigration: A Comparison of the United States, Germany and Great Britain', Theory and Society, 25 (4), 449-500.

Kadianaki, I. and Andreouli, E. (2017) 'Essentialism in Social Representations of Citizenship: An Analysis of Greeks' and Migrants' Discourse', Political Psychology, 38 (5), 833-848.

Kaitatzi-Whitlock, S. and Kenterelidou, C. (2017) 'The Greek Paradigm on the Migrant and Refugee Crisis', in M. Barlai, B. Fähnrich, C. Griessler and M. Rhomberg (eds), The Migrant Crisis: European Perspectives and National Discourses (pp. 127-146), Berlin: Lit Verlag.

Kalogeraki, S. (2018) 'Volunteerig for Refugees and Asylum Seekers in Greece', in C. Lahusen and M. Grasso (eds), Solidarity in Europe. Citizens' Responses to Crisis (pp. 169-194), Basingstoke: Palgrave.

Kalogeropoulos, A., Negredo, S., Picone, I. and Nielsen, R.K. (2017) 'Who Shares and Comments on News? A Cross-national Comparative Analysis of Online and Social Media Participation', Social Media + Society, 3 (4), 1-12.

Kanellopoulos, K., Duru, D.N., Zschache, U., Loukakis, A., Kousis, M. and Trenz, H.J. (2020) 'Transnational Solidarity, Migration, and the Refugee Crisis: (In)Formal Organising and Political Environments in Greece, Germany, and Denmark', Sociological Research Online, doi:1360780420937030.

Kępińska, E. and Kindler, M. (2014) 'Poland', in A. Triandafyllidou and R. Gropas (eds), European Immigration. A Sourcebook, 2nd edition (pp. 273-286), Surrey: Ashgate.

Kingdon, J.W. (1984) Agendas, Alternatives, and Public Policies, Boston: Little, Brown.

Kinski, L. (2018) 'Whom to Represent? National Parliamentary Representation during the Eurozone Crisis', Journal of European Public Policy, 25 (3), 346-368.

Kinski, L. and Crum, B. (2020) 'Transnational Representation in EU National Parliaments: Concept, Case Study, Research Agenda'. Political Studies, 68 (2), 370-388. Available at: https://doi.org/10.1177/0032321719848565. 
Kitschelt, H. (1986) 'Political Opportunity Structures and Political Protest', British Journal of Political Science, 16, 57-85.

Kleinsteuber, H.J. (2004) 'Comparing Mass Communication Systems: Media Formats, Media Contents, and Media Processes', in F. Esser and B. Pfetsch (eds) Comparing Political Communication. Theories, Cases, and Challenges (pp. 64-86), Cambridge: Cambridge University Press.

Klimkiewicz, B. (2017) 'State, Media and Pluralism: Tracing Roots and Consequences of Media Policy Change in Poland', Publizistik, 62 (2), 197-213.

Kluknavská, A., Bernhard, J. and Boomgaarden, H.G. (2019) 'Claiming the Crisis: Mediated Public Debates about the Refugee Crisis in Austria, the Czech Republic and Slovakia', Journal of Refugee Studies, published first: doi:10.1093/jrs/fez022.

Komter, A.E. (2005) Social Solidarity and the Gift, Cambridge: Cambridge University Press.

Koopmans, R. (2002) 'Codebook for the Analysis of Political Mobilisation and Communication in European Public Spheres', Europub.com Project. Available at: http:// europub.wz-berlin.de.

Koopmans, R. (2007) 'Who Inhabits the European Public Sphere? Winners and Losers, Supporters and Opponents in Europeanised Political Debates', European Journal of Political Research, 46 (2), 183-210.

Koopmans, R. (2010) 'Winners and Losers, Supporters and Opponents in Europeanized Public Debates', in R. Koopmans and P. Statham (eds), The Making of a European Public Sphere: Media Discourse and Political Contention (pp. 97-121), Cambridge: Cambridge University Press.

Koopmans, R. and Statham, P. (1999) 'Political Claim Analysis: Integrating Protest Event and Political Discourse Approaches', Mobilization, 4 (1), 203-222.

Koopmans, R. and Statham, P. (eds) (2010) The Making of a European Public Sphere: Media Discourse and Political Contention, Cambridge: Cambridge University Press.

Koopmans, R., Statham, P., Giugni, M. and Passy, F. (2005) Contested Citizenship. Immigration and Cultural Diversity in Europe, Minneapolis: University of Minnesota Press.

Kousis, M., Kalogeraki, S. and Cristancho, C. (2018) 'Alternative Action Organizations During Hard Economic Times: A Comparative European Perspective', American Behavioral Scientist, 62 (6), 733-738.

Kousis, M., Loukakis, A., Paschou, M. and Lahusen, C. (2020) 'Waves of Transnational Solidarity Mobilisations in Times of Crisis: Actions, Obstacles and Opportunities in Europe', in C. Lahusen (ed.), Citizens' Solidarity in Europe. Civic Engagement and Public Discourse in Times of Crises (pp. 55-84), Cheltenham: Edgar Elgar.

Krämer, B. (2017) 'Populist Online Practices: The Function of the Internet in Right-wing Populism', Information, Communication \& Society, 20 (9), 1293-1309.

Krastev, I. (2017a) After Europe, Philadelphia: University of Pennsylvania Press.

Krastev, I. (2017b) 'The Refugee Crisis and the Return of the East-West Divide in Europe', Slavic Review, 76 (2), 291-296.

Krastev, I. and Holmes, S. (2019) The Light That Failed: A Reckoning, London: Penguin Books, Limited.

Kriesi, H.P. (1992) 'Öffentlichkeit und soziale Bewegungen in der Schweiz - ein Musterfall?', in B. Schäfers (ed.), Lebensverhältnisse und soziale Konflikte im neuen Europa. Verhandlungen des 26. Deutschen Soziologentages (pp. 576-585), Frankfurt a.M.: Campus.

Kriesi, H.P. and Trechsel, A.H. (2008) The Politics of Switzerland: Continuity and Change in a Consensus Democracy, Cambridge: Cambridge University Press. 
Kriesi, H., Grande, E., Dolezal, M., Helbling, M., Höglinger, D., Hutter, S. and Wüest, B. (2012) Political Conflict in Western Europe, Cambridge: Cambridge University Press.

Kriesi, H., Koopmans, R., Duyvendak, J.W. and Giugni, M. (1995) New Social Movements in Western Europe: A Comparative Analysis, Minneapolis: University of Minnesota Press.

Krzyżanowski, M. and Wodak, R. (2009) The Politics of Exclusion. Debating Migration in Austria, New Brunswick, NJ: Transaction.

Krzyżanowski, M. (2018) 'Discursive Shifts in Ethno-Nationalist Politics: On Politicization and Mediatization of the "Refugee Crisis" in Poland', Journal of Immigrant \& Refugee Studies, 16 (1-2),76-96.

Krzyżanowski, M. (2020) 'Discursive Shifts and the Normalisation of Racism: Imaginaries of Immigration, Moral Panics and the Discourse of Contemporary Right-wing Populism', Social Semiotics, online first: https://doi.org/10.1080/10350330.2020. 1766199.

Ksiazek, T.B., Peer, L. and Zivic, A. (2015) 'Discussing the News. Civility and Hostility in User Comments', Digital Journalism, 3 (6), 850-870.

Kyriakidou, M. (2009) 'Imagining Ourselves Beyond the Nation? Exploring Cosmopolitanism in Relation to Media Coverage of Distant Suffering', Studies in Ethnicity and Nationalism, 9 (3), 481-496.

Kyriakidou, M. (2015) 'Media Witnessing: Exploring the Audience of Distant Suffering', Media, Culture \& Society, 37 (2), 215-231.

Lahusen, C. (ed.) (2020) Citizens' Solidarity in Europe. Civic Engagement and Public Discourse in Times of Crises, Cheltenham: Edward Elgar.

Lahusen, C. (2021) The Political Attitudes of Divided European Citizens. Public Opinion and Social Inequalities in Comparative and Relational Perspective, London: Routledge.

Lahusen, C. and Grasso, M. (eds) (2018) Solidarity in Europe. Citizens' Responses in Times of Crisis, Basingstoke: Palgrave Macmillan.

Lahusen, C., Zschache, U. and Kousis, M. (eds) (2021) Transnational Solidarity in Times of Crises: Citizen Organisations and Collective Learning in Europe, Basingstoke: Palgrave Macmillan.

Lasswell, H. (1948) The Structure and Function of Communication in Society, New York: Harper and Row.

Lindekilde, L. (2013) 'Claims-Making', in D.H. Snow, D. Della Porta, B. Klandermans and D. McAdam (eds), The Wiley-Blackwell Encyclopedia of Social and Political Movements, John Wiley and Sons.

Löffelholz, M. and Weaver, D.H. (2008) Global Journalism Research: Theories, Methods, Findings, Future, Chichester: Blackwell Pub.

Loseke, D. (2017) Thinking about Social Problems: An Introduction to Constructionist Perspectives, London: Taylor \& Francis.

Lucassen, L. (2018) 'Peeling an Onion: The "Refugee Crisis" from a Historical Perspective', Ethnic and Racial Studies, 41 (3), 383-410.

Maggini, N. (2018) 'Italy', in M. Cinalli and H.J. Trenz (eds), Integrated Report on Transnational Solidarity in the Public Domain (WP5) Deliverable 5.1. (pp. 115-142). Available at: https://ranssol.eu/files/2018/05/deliverable-5-1.pdf.

Magnette, P. (2003) 'European Governance and Civic Participation: Beyond Elitist Citizenship?', Political Studies, 52 (1), 139-156.

Malcolm, N. (1995) 'The Case against Europe', Foreign Affairs 74 (2), 52-68. 
Maloney, W.A. and van Deth, J.W. (eds) (2008) Civil Society and Governance in Europe: From National to International Linkages, Cheltenham: Edward Elgar Publishing.

Mancini, P. (2012) 'Media Fragmentation, Party System, and Democracy', The International Journal of Press/Politics, 18 (1), 43-60.

Matthijs, M. (2016) 'The Three Faces of German Leadership', Survival, 58 (2), 135-154.

McCombs, M.E. and Shaw, D.L. (1972) 'The Agenda-Setting Function of Mass Media', Public Opinion Quarterly, 36 (2), 176-187.

McCright, A.M. and Dunlap, R.E. (2000) 'Challenging Global Warming as a Social Problem: An Analysis of the Conservative Movement's Counter-Claims', Social Problems, 47 (4), 499-522.

McNair, B. (2000) Journalism and Democracy, London/New York: Routledge.

McQuail, D. (2013) Journalism and Society, London: SAGE Publications.

Mellon, J. and Prosser, C. (2017) 'Twitter and Facebook are not Representative of the General Population: Political Attitudes and Demographics of British Social Media Users', Research and Politics, 1-9.

Menéndez, A.J. (2016) 'The Refugee Crisis: Between Human Tragedy and Symptom of the Structural Crisis of European Integration', European Law Journal, 22 (4), 388-416.

Mertens, T. (1996), 'Cosmopolitanism and Citizenship: Kant against Habermas', European Journal of Philosophy 4 (3), 328-347.

Mexi, M. (2018) 'Greece in Times of Multiple Crises: Solidarity under Stress?', in V. Federico and C. Lahusen (eds), Solidarity as a Public Virtue. Law and Public Policies in the European Union (pp. 337-360), Baden Baden: Nomos.

Meyer, J.W. (2000) 'Globalization: Sources and Effects on National States and Societies', International Sociology, 15 (2), 233-248.

Michailidou, A. and Trenz, H.-J. (2010) 'Mediati(zi)ng EU politics: Online News Coverage of the 2009 European Parliamentary Elections', Communications, 35 (3), 327346.

Michailidou, A. and Trenz, H.-J. (2014) 'The Mediatisation of politics. From the National to the Transnational', Partecipazione e Conflitto. Journal of Sociopolitical Studies, 7 (3), 469-498.

Michailidou, A. and Trenz, H.-J. (2015) 'The European Crisis and the Media: Media Autonomy, Public Perceptions and New Forms of Political Engagement', in V. Guiraudon, C. Ruzza and H.-J. Trenz (eds), Europe's Prolonged Crisis, The Making or the Unmaking of a Political Union (pp. 232-250), Basingstoke: Palgrave Macmillan.

Michailidou, A. and Trenz, H.J. (2019) 'European Solidarity in Times of Crisis: Towards Differentiated Integration', in J. Batora and J.E. Fossum (eds), Crises, EU Trajectories and the Question of Resilience (pp. 132-151), London: Routledge.

Michailidou, A., Trenz, H.J. and De Wilde, P. (2014) The Internet and European Integration. Pro- and anti-EU Debates in Online News Media, Opladen: Barbara Budrich Publisher.

Miller, D. (2007) National Responsibility and Global Justice, Oxford: Oxford University Press.

Moffitt, B. (2016) The Global Rise of Populism: Performance, Political Style, and Representation, Stanford: Stanford University Press.

Mono, R. (2009) Ein Politikraum, viele Sprachen, welche Öffentlichkeit?: Fragen zu Potenzial und Restriktionen von Öffentlichkeit in transnationalen Politikräumen am Beispiel der Europäischen Union, Münster: Lit.

Montgomery, T. (2017) 'United Kingdom. Voices from the Frontline: Organising Solidarity in Austerity Britain', TransSOL - Transnational Solidarity at Times of Crisis 
Report (WP4) Deliverable 4.2 (pp. 190-215), October 2017. Available at: https:/tra nssol.eu/files/2017/12/WP4-Integrated-report-final.pdf.

Montgomery, T. and Baglioni, S. (2018a) 'The United Kingdom', in V. Federico, and C. Lahusen (eds), Solidarity as a Public Virtue? Law and Public Policies in the European Union (pp. 179-191), Baden-Baden: Nomos.

Montgomery, T. and Baglioni, S. (2018b) 'Solidarity in Austerity Britain: The Cases of Disability, Unemployment and Migration', in V. Federico, and C. Lahusen (eds), Solidarity as a Public Virtue? Law and Public Policies in the European Union (pp. 469-494), Baden-Baden: Nomos.

Montgomery, T., Calò, F. and Baglioni, S. (2018) 'Claims Making and the Construction of the Refugee Crisis in Britain', in M. Cinalli and H.J. Trenz (eds), Integrated Report on Transnational Solidarity in the Public Domain (WP5) Deliverable 5.1, (pp. 217243). Available at: https://transsol.eu/files/2018/05/deliverable-5-1.pdf.

Mortensen, M. and Trenz, H.J. (2016) 'Media Morality and Visual Icons in the Age of Social Media: Alan Kurdi and the Emergence of an Impromptu Public of Moral Spectatorship', Javnost. The Public, 23 (4), 343-362.

Müller-Hofstede, S. and Butterwegge, C. (2007) 'Grundlagen-Dossier Migration: Neue Integrationsdebatten und Politik', Bundeszentrale für Politische Bildung. Available at: https://www.bpb.de/gesellschaft/migration/dossier-migration-ALT/56349/integrations debatten-und-politik.

Mylonas, Y. (2012) 'Media and the Economic Crisis of the EU: The 'Culturalization' of a Systemic Crisis and Bild-Zeitung's Framing of Greece', tripleC. Cognition, Communication, Co-ooperation, 10 (2), 646-671.

Nash, K. (2008) 'Global Citizenship as Show Business: The Cultural Politics of Make Poverty History', Media, Culture \& Society, 30 (2), 167-181.

Neidhardt, F. (1994) Öffentlichkeit, öffentliche Meinung, soziale Bewegungen, Opladen: Westdeutscher Verlag.

Nelson, T.E., Clawson, R.A. and Oxley, Z.M. (1997) 'Media Framing of a Civil Liberties Conflict and its Effect on Tolerance', The American Political Science Review, 91 (3), 567-583.

Nestoras, A. (2015) 'The Gatekeeper's Gambit: SYRIZA, Left Populism and the European Migration Crisis', Institute of European Democrats Working Paper. Available at: https:// www.iedonline.eu/download/2015/IED-Antonios-NestorasWorking-Greece.pdf.

Newman, N. (with Fletcher, R., Levy, D.A.L. and Nielsen, R.K.) (2016) Reuters Institute Digital News Report 2016, Oxford: Reuters Institute for the Study of Journalism/ University of Oxford.

Nicolaïdis, K. and R. Howse (2001), The Federal Vision: Legitimacy and Levels of Governance in the United States and the European Union, Oxford: Oxford University Press.

Olsen, T.L. (2015) 'Derfor registrerer Danmark ikke flygtninge. Dr.dk. 10th of September 2015'. Available at: https://www.dr.dk/nyheder/politik/overblik-derfor-registrererdanmark-ikke-flygtninge.

O’Neill, D. and Harcup, T. (2009) 'News Values and Selectivity', in K. Wahl-Jorgensen and T. Hanitzsch (eds), The Handbook of Journalism Studies (pp. 181-194), New York: Routledge.

Örnebring, H. and Jönsson, A.M. (2004) 'Tabloid Journalism and the Public Sphere: A Historical Perspective on Tabloid Journalism', Journalism Studies, 5 (3), 283-295.

Page, B. (1996) Who Deliberates? Mass Media in Modern Democracy, Chicago: University of Chicago Press. 
Pallotta, D. (2012) Charity Case: How the Nonprofit Community Can Stand Up For Itself and Really Change the World, London: Wiley.

Papathanassopoulos, S. (2015) 'European Media Views of the Greek Crisis', in S. Schifferes and R. Roberts (eds), The Media and the Financial Crises. Comparative and Historical Perspectives (pp. 103-118), London: Routledge.

Paschou, M. and Loukakis, A. (2018) 'Greece', in M. Cinalli and H.J. Trenz (eds), Integrated Report on Transnational Solidarity in the Public Domain (WP5) Deliverable 5.1 (pp. 93-114). Available at: https://ranssol.eu/files/2018/05/deliverable-5-1.pdf.

Petelczyc, J. (2018a) 'Disability, Unemployment, Immigration: Does Solidarity Matter in Times of Crisis. The Polish Case', in V. Federico and C. Lahusen (eds), Solidarity as a Public Virtue?: Law and Public Policies in the European Union (pp. 395-420), BadenBaden: Nomos.

Petelczyc, J. (2018b) 'Poland', in V. Federico and C. Lahusen (eds), Solidarity as a Public Virtue?: Law and Public Policies in the European Union (pp. 129-146), Baden-Baden: Nomos.

Pfetsch, B. (2007) 'National Media in Europeanized Public Sphere: The Openness and Support of the Press for European Integration', in C. de Vreese and H. Schmitt (eds), A European Public Sphere: How much of it do we have and how much do we need? (pp. 401-425), Connex Report Series No. 2.

Philo, G., Briant, E. and Donald, P. (2013) Bad News for Refugees, London: Pluto Press.

Piłat, A. and Potkańska, D. (2017) 'Local Responses to the Refugee Crisis in Poland. Reception and Integration', Migration Policy Programme, Warsaw: Institute of Public Affairs. Available at: http://www.forintegration.eu/pl/pub/local-responses-to-the-r efugee-crisis-in-poland/dnl/17.

Ponsford, D. (2016) 'National Newspaper ABCs: i, Times and Telegraph titles all Gain Print Sales after Independent Closure', Press Gazette, 19 May 2016. Available at: http s://www.pressgazette.co.uk/national-newspaper-abcs-i-times-and-telegraph-titles-all-ga in-print-sales-after-independent-closure/.

Prosser, C., Mellon, J. and Green, J. (2016) 'What Mattered Most to you when Deciding How to Vote in the EU referendum?', British Election Study, 11 July 2017. Available at: https://www.britishelectionstudy.com/bes-findings/what-mattered-most-to-youwhen-deciding-how-to-vote-in-the-eu-referendum/\#.XjQdchNKhTY.

Punch, K.F. (2014) Introduction to Social Research: Quantitative and Qualitative Approaches, London: SAGE Publications.

Rackaway, C. (2014) 'Online News Consumption', in Communicating Politics Online (pp. 68-77), New York: Palgrave Macmillan US.

Rasmussen, T. (2014) 'Internet and the Political Public Sphere', Sociology Compass, 8 (12), 1315-1329.

Rauchfleisch, A. and Kovic, M. (2016) 'The Internet and Generalized Functions of the Public Sphere: Transformative Potentials From a Comparative Perspective', Social Media + Society, 2 (2), 1-15.

Reagle, J.M. (2015) Reading the Comments, Cambridge, MA: MIT Press.

Richardson, J.E. and Colombo, M. (2013) 'Continuity and Change in Anti-immigrant Discourse in Italy: An Analysis of the Visual Propaganda of the Lega Nord', Journal of Language and Politics, 12 (2), 180-202.

Risse, T. (2014) European Public Spheres, Cambridge: Cambridge University Press.

Rokkan, S. (1999) State Formation, Nation Building and Mass Politics in Europe, Oxford: Oxford University Press. 
Roose, J., Kousis, M. and Sommer, M. (2014) 'Discursive Actor Attribution Analysis: A Tool to Analyze How People Make Sense of the Eurozone Crisis', Institute of Sociology Publication, Berlin: Freie Universität Berlin. Available at: https://www. polsoz.fu-berlin.de/en/soziologie/arbeitsbereiche/europa/ggcrisi/publications/Articles_ Papers/2014_Roose_et_al_Discursive_Actor_Attribution_Analysis/index.html.

Rucht, D., Koopmans, R. and Neidhardt, F. (1999) Acts of Dissent: New Developments in the Study of Protest, Lanham: Rowman \& Littlefield.

Ruzza, C. (2006) 'European Institutions and the Policy Discourse of Organised Civil Society', in S. Smismans (ed.), Civil Society and Legitimate European Governance, Cheltenham: Edward Elgar Press.

Rydgren, J. (2007) 'The Sociology of the Radical Right', Annual Review of Sociology, 33 (1), 241-262.

Sadowski, P. and Sczzaviska, K. (2019) 'Poland's Response to the EU Migration Policy', in M. Barlai, B. Fähnrich, C. Griessler and M. Rhomberg (eds), The Migrant Crisis: European Perspectives and National Discourses (pp. 211-234), Zürich: Lit.

Sand, T. (2015) 'Danskerne står i kø for at hjælpe flygtninge', Berlingske.dk, 9 September 2015. Available at: https://www.b.dk/nationalt/danskerne-staar-i-koe-for-at-hjaelp e-flygtninge.

Sarrasin, O., Kuhn, T. and Lancee, B. (2018) 'What Explains Increasing Euroscepticism in Switzerland? A Longitudinal Analysis' in R. Tillmann, M. Voorpostel and P. Farago (eds), Social Dynamics in Swiss Society (pp. 203-214), Wiesbaden: Springer.

Sassen, S. (1999) Guests and Aliens, New York: The New Press.

Saurugger, S. (2008), 'Interest Groups and Democracy in the EU', West European Politics, 31 (6), 1274-1291.

Saward, M. (2006) 'The Representative Claim', Contemporary Political Theory, 5 (3), 297-318.

Saward, M. (2010) The Representative Claim, Oxford: Oxford University Press.

Schmitz Weiss, A. and De Macedo Higgins Joyce, V. (2009) 'Compressed Dimensions in Digital Media Occupations - Journalists in Transformation', Journalism, 10 (5), 587-603.

Schneider, S., Nullmeier, F. and Hurrelmann, A. (2007) 'Exploring the Communicative Dimension of Legitimacy: Text Analytical Approaches', in A. Hurrelmann, S. Schneider and J. Steffek (eds), Legitimacy in an Age of Global Politics (pp. 126-155), Basingstoke: Palgrave Macmillan.

Severs, E. (2012) 'Substantive Representation through a Claims-making Lens: A Strategy for the Identification and Analysis of Substantive Claims', Representation, 48 (2), 169181.

Siapera, E. (2019) 'Refugee Solidarity in Europe: Shifting the Discourse', European Journal of Cultural Studies, 22 (2), 245-266.

Siapera, E. and Veglis, A. (2012) The Handbook of Global Online Journalism, Oxford: Wiley.

Siapera, E., Papadopoulou, L. and Archontakis, F. (2015) 'Post-Crisis Journalism', Journalism Studies, 16 (3), 449-465.

Signer, S., Puppis, M. and Piga, A. (2011) 'Minorities, Integration and the Media: Media Regulation and Media Performance in Multicultural and Multilingual Switzerland', International Communication Gazette, 73 (5), 419-439.

Silveira, A., Canotilho, M. and Froufe, P.M. (2013) Citizenship and Solidarity in the European Union: From the Charter of Fundamental Rights to the Crisis, the State of the Art, P.I.E. Peter Lang. 
Silverstone, R. (2006) Media and Morality: On the Rise of the Mediapolis, Malden, MA: Polity.

Slots- og Kulturstyrelsen (2017) Mediernes udvikling 2017, Kulturministeriet, pp. 1-23. Available at: https:/mediernesudvikling.slks.dk/fileadmin/user_upload/dokumenter/ medier/Mediernes_udvikling/2017/Overblik_og_perspektivering/Overblik_og_persp ektivering_2017.pdf.

Smismans, S. (ed.) (2006) Civil Society and Legitimate European Governance, Cheltenham: Edward Elgar Press.

Smith, J., Chatfield, C. and Pagnucco, R. (eds) (1997). Transnational Social Movements and Global Politics. Solidarity beyond the State, Syracuse, NY: Syracuse University Press.

Soysal, Y. (1994) Limits of Citizenship: Migrant and Postnational Membership in Europe, Chicago: University of Chicago Press.

Sparks, C. (2008) 'Media Systems in Transition: Poland, Russia, China', Chinese Journal of Communication, 1 (1), 7-24.

Statham, P. (2008) 'Making Europe News: How Journalists View their Role and Media Performance', Journalism, 9 (4), 398-422.

Statham, P. and Geddes, A. (2006) 'Elites and the 'Organised Public': Who Drives British Immigration Politics and in Which Direction?', West European Politics, 29 (2), 248-269.

Statham, P. and Trenz, H.-J. (2013) The Politicization of Europe. Contesting the Constitution in the Mass Media, Abingdon: Routledge.

Stjernø, S. (2012) Solidarity in Europe: The History of an Idea, Cambridge: Cambridge University Press.

Stråth, B. (2017) 'Identity and Social Solidarity: An Ignored Connection. A Historical Perspective on the State of Europe and its Nations', Nations and Nationalism, 23 (2), 227-247.

Streeck, W. (2014) Buying Time, London: Verso.

Studer, S., Schweizer, C., Puppis, P.M. and Künzler, M. (2014) Darstellung der Schweizer Medienlandschaft, Bericht zuhanden des Bundesamtes für Kommunikation (BAKOM) Fribourg.

Sunstein, C.R. (2009) Going Extremes. How Like Minds Unite and Divide, Oxford: Oxford University Press.

Szczerbiak, A. (2012) Poland Within the European Union: New Awkward Partner or New Heart of Europe?, London: Routledge.

Szczerbiak, A. (2019) 'Why is Poland's Law and Justice Party Still So Popular?', EUROPP - European Politics and Policy or the London School of Economics. Available at: https://blogs.lse.ac.uk/europpblog/2019/10/01/why-is-polands-law-and-justiceparty-still-so-popular.

Szczupak, K., Petelczyc, J. and Theiss, M. (2018) 'Poland', in M. Cinalli and H.-J. Trenz (eds), Integrated Report on Transnational Solidarity in the Public Domain (WP5) Deliverable 5.1 (pp. 143-164). Available at: https://transsol.eu/files/2018/05/deliverable5-1.pdf.

Szylko-Kwas, J., Gajlewicz-Korab, K., Grutza, A. and Jupowicz-Ginalska, A. (2017). 'Immigrants in Polish and German Online Media: A Comparative Analysis', Journalism Research, 12: 39-72.

Teney, C., Lacewell, O. and De Wilde, P (2014) Winners and Losers of Globalization in Europe: Attitudes and Ideologies, European Political Science Review, 6 (4), 575-595.

The Right Honourable Lord Justice Leveson (2012) An Inquiry into the Culture, Practices and Ethics of the Press. Report November, London: The Stationery Office. 
Thielemann, E. (2004), "Why Asylum Policy Harmonization Undermines Refugee Burden-Sharing', European Journal of Migration \& Law, 6 (1), 47-71.

Thomas, E.F., Cary, N., Smith, L.G.E., Spears, R. and McGarty, C. (2018) 'The Role of Social Media in Shaping Solidarity and Compassion Fade: How the Death of a Child Turned Apathy into Action but Distress Took it Away', New Media \& Society, 20 (10), 3778-3798.

Thomaß. B. and Horz, C. (n.d.) 'Germany. Media Landscapes - Expert Analyses of the State of the Media', retrieved from: https://medialandscapes.org/country/germany/ media/print.

Toepfl, F. and Piwoni, E. (2015) 'Public Spheres in Interaction: Comment Sections of News Websites as Counterpublic Spaces', Journal of Communication, 65 (3), 465-488.

Tönnies, F. (2002) Community and Society, East Lansing: Michigan State University Press.

Trebbe, J. and Schönhagen, P. (2011) 'Ethnic Minorities in the Mass Media: How Migrants Perceive their Representation in Swiss Public Television', Journal of International Migration and Integration, 12 (4), 411-428.

Trechsel, A. (2007) 'Direct Democracy and European Integration: A Limited Obstacle', in C. Church (ed.), Switzerland and the European Union: A Close, Contradictory and Misunderstood Relationship (pp. 36-51), London: Routledge.

Trenz, H.-J. (2005) Europa in den Medien. Das Europäische Integrationsprojekt im Spiegel nationaler Öffentlichkeit, Frankfurt a.M., New York: Campus.

Trenz, H.-J. (2015) 'Europeanising the Public Sphere - Meaning, Mechanism, Effects', in U. Liebert and J. Wolff (eds), Interdisziplinäre Europastudien (pp. 233-251), Berlin: Springer.

Trenz, H.-J. (2016) Narrating European Society: Toward a Sociology of European Integration, Lanham: Rowman and Littlefield, Lexington Books.

Trenz, H.-J. (2020) 'New Opportunities for European Solidarity Mobilization: The Role of the Media', in H. Krunke, I. Manners and H. Petersen (eds), Cross-border Solidarity - Concept, Challenges and Opportunities, Cambridge: Cambridge University Press.

Trenz, H.-J. and Grasso, M. (2018) 'Towards a New Conditionality of Welfare? Reconsidering Solidarity in the Danish Welfare State', in M. Grasso and C. Lahusen (eds), Solidarity in Europe. Citizens Responses in Times of Crisis, Basingstoke: Palgrave.

Trenz, H.-J., Brändle, V.K., Cinalli, M. and Eisele, O. (2020) 'Taking Voice and Taking Sides: The Role of Social Media Commenting in Solidarity Contestation', in C. Lahusen (ed.), Citizens' Solidarity in Europe. Civic Engagement and Public Discourse in Times of Crises (pp. 149-176), Edward Elgar.

Trenz, H.-J., Conrad, M. and Rosén, G. (2009) 'Impartial Mediator or Critical Watchdog? The Role of Political Journalism in EU-constitution-making', Comparative European Politics, 7 (3), 342-363.

Triandafyllidou, A. (2009) 'Greek Immigration Policy at the Turn of the 21st Century. Lack of Political Will or Purposeful Mismanagement?', European Journal of Migration and Law, 11(2), 159-177.

Triandafyllidou, A. (2018) 'A "Refugee Crisis" Unfolding: "Real" Events and their Interpretation in Media and Political Debate', Journal of Immigrant \& Refugee Studies, 16 (1-2),198-216.

Tuck, R. (2016) 'The Left Case for Brexit', Dissent Magazine. Available at: https://www. dissentmagazine.org/online_articles/left-case-brexit. 
Van der Brug, W., D’Amato, G., Ruedin, D., Berkhout, J., D’Amato, G., Ruedin, D. and Berkhout, J. (2015) The Politicisation of Migration. Available at: https://doi.org/10. 4324/9781315723303.

Van Dijk, T. (1988) News Analysis. Case Studies of International and National News in the Press, London: Routledge.

Van Oorschot, W. (2000) 'Who Should Get What, and Why', Policy and Politics, 28 (1), 33-48.

Van Oorschot, W. (2006) 'Making the Difference in Social Europe: Deservingness Perceptions among Citizens of European Welfare States', Journal of European Social Policy, 16 (1), 23-42.

Van Prooijen, J.-W., Krouwel, A.P.M. and Emmer, J. (2017) 'Ideological Responses to the EU Refugee Crisis: The Left, the Right, and the Extremes', Social Psychological and Personality Science, 9 (2), 143-150.

Velentza, C. (2018) 'The Greek Response to the Refugee Crisis in Eastern Mediterranean (the period of 2015-2016): An Overview', MiReKoc Working Papers (Migration Research Center at Koc University). Available at: https://mirekoc.ku.edu.tr/wp-content/ uploads/2019/01/Mirekoc_Report_The-Greek-response-to-the-refugee-crisis-in-EasternMediterranean-web.pdf.

Vetters, R., Jentgens, E. and Trenz, H.-J. (2009) 'Whose Project is it? Media Debates on the Ratification of the EU Constitutional Treaty', Journal of European Public Policy, 16 (3), 412-430.

Vissers, S. and Stolle, D. (2014) 'Spill-Over Effects Between Facebook and On/Offline Political Participation? Evidence from a Two-Wave Panel Study', Journal of Information Technology \& Politics, 11 (3), 259-275.

Vollmer, B. and Karakayali, S. (2017) 'The Volatility of the Discourse on Refugees in Germany', Journal of Immigrant and Refugee Studies, 16 (1-2),118-139.

Wagner-Pacifici, R. (1986) The Moro Morality Play: Terrorism as Social Drama, Chicago: University of Chicago Press.

Wagschal, U. (2007) 'Diskurs oder Machtpolitik: Welche Interessen setzen sich in der Direktdemokratie am erfolgreichsten durch?', in M. Freitag and U. Wagschal (eds), Direkte Demokratie: Bestandsaufnahmen und Wirkungen im internationalen Vergleich (pp. 303-330), Berlin: LIT.

Wahl-Jorgensen, K., Williams, A., Sambrook, R., Harris, J., Garcia-Blanco, I., Dencik, L., Cushion, S., Carter, C. and Allan, S. (2016) 'The Future of Journalism', Digital Journalism, 4 (7), 809-815.

Waisbord, S. (2004) 'Media and the Reinvention of the Nation', in J.D. Downing, D. McQuail and P. Schlesinger (eds), The SAGE Handbook of Media Studies, Thousand Oaks: Sage.

Waisbord, S. (2013) Reinventing Professionalism: Journalism and News in Global Perspective, Oxford: Wiley.

Wallaschek, S. (2017) 'Notions of Solidarity in Europe's Migration Crisis; The Case of Germany's Media Discourse', EuropeNow Journal. Available at: https://www. europenowjournal.org/2017/09/30/notions-of-solidarity-in-europes-migration-crisis-thecase-of-germanys-media-discourse/

Walzer, M. (1994) Thick and Thin. Moral Argument at Home and Abroad, Notre Dame: University of Notre Dame Press.

Weber, B. (2016a) 'The German Refugee "Crisis" after Cologne: The Race of Refugee Rights', English Language Notes, 54 (2), 77-92.

Weber, B. (2016b) “"We must talk about Cologne” - Race, Gender, and Reconfigurations of "Europe", German Politics and Society, 34 (4), 68-86. 
Weber-Menges, S. (2008) 'Die Rolle der Massenmedien bei der Integration von Migranten', Ringvorlesung Universität Siegen. Available at: https:/www.uni-siegen.de/ phil/sozialwissenschaften/soziologie/mitarbeiter/geissler/weber-menges_ringvorlesung 2008_migranten_und_medien.pdf.

Wessler, H., Peters, B., Brüggemann, M., Kleinen-von Köningslöw, K. and Sifft, S. (2008) Transnationalization of Public Spheres, Basingstoke: Palgrave Macmillan.

Williams, A.E. and Toula, C.M. (2017) 'Solidarity Framing at the Union of National and Transnational Public Spheres', Journalism Studies, 18 (12), 1576-1592.

Wodak, R. (2015) The Politics of Fear: What Right-Wing Populist Discourses Mean, London: Sage.

Wright, C.R. (1960) 'Functional Analysis and Mass Communication', Public Opinion Quarterly, 24 (4), 605-620.

Zarycki, T., Smoczyński, R. and Warczok, T. (2017) 'The Roots of Polish CultureCentered Politics: Toward a Non-Purely Cultural Model of Cultural Domination in Central and Eastern Europe', East European Politics and Societies, 31 (2), 360-381.

Zaun, N. (2018) 'States as Gatekeepers in EU Asylum Politics: Explaining the Nonadoption of a Refugee Quota System', Journal of Common Market Studies, 56, 44-62.

Zschache, U., Theiss, M. and Paschou, M. (2020) 'What is Solidarity About? Views of Transnational Solidarity Activists in Germany, Poland and Greece', Sociological Research Online.

Zürn, M. and de Wilde, P. (2016) 'Debating Globalization: Cosmopolitanism and Communitarianism as Political Ideologies', Journal of Political Ideologies, 21 (3), 280-301. 


\section{Index}

Page numbers in italics denote figures, those in bold denote tables.

accountability of journalism 2

action(s) 43, 44; collective 33, 87, 168;

connective 33 ; forms of 45 ; humanitar-

ian $25,26,46,64,96$; protest 44 ;

solidarity 20,44

actors 37-38, 45; object 45-46; positions see positions; primary and secondary

46; see also protagonists of solidarity

contestations

addressees 45, 46

advocacy groups 15, 70, 131, 140, 147

agenda-setting 19, 22, 27, 49; news media

28, 34, 63, 65, 149; political and media

logics in 39-40; and social media 86

anonymity 14

argumentative dimension of

claims-making 46

assimilation of refugees 46

asylum applications 67-68; Denmark 68,

121; France 68 ; Germany 61, 68, 113; Greece 68, 135; Italy 68, 143; Poland 68, 151; Switzerland 68, 108; United Kingdom (UK) 68, 158, 159

audiences 22; activation of 29-30

background of refugees 70, 71, 92-93, 96, 97, 146, 161

belongingness 3

Berlingske 122

Bild 52, 58, 115

blaming 28

Blick 58, 109

border management 46, 70, 123, 124

bottom-up mobilisation of solidarity 86 ; see also social media commenting

Bratislava EU summit (2016) 140, 175

Britain see United Kingdom (UK) broadsheet newspapers $33,51,65,79,86$, 100, 173; Germany 115; UK 159, 160, 164; see also titles of individual newspapers

BT 123

Calais refugee camp 128, 159, 161

Cameron, D. 159, 160

care-taking 30

Castelli Gattinara, P. 32

categorical rejection, culture of 62,82 , 152-153, 154-155

Catholic church, Poland 152

charity/charities $4,14,19,22,126,166$, 168, 175

Charlie Hebdo shooting (2015) 128

churches 14, 69; Catholic, Poland 152

citizenship 4, 13, 21, 166, 174

Civic Platform, Poland 155

civic/public initiatives 70, 71, 92, 96, 97, 110, 161, 170

civil rights 77

civil society $6,15,17,25,33,34,35,37$, 64, 69, 70, 73, 76, 77, 78, 82, 83, 86, 110, 167, 170, 173; Denmark 75, 123, 125, 126, 127; France 75, 129, 130, 131, 133; Germany 75, 116, 117; Greece 75, 136, 139, 140; Italy 75, 146, 147; Poland 75, 154; Switzerland 75, 110-111, 112; United Kingdom (UK) 75, 160, 162; see also churches; NGOs; trade unions

claimants see protagonists of solidarity contestations

claims: as basic speech acts 34 ; as communicative acts 34,35 ; justifications in see justifications; as strategic communication 34, 35; see also negative 
claims; neutral/ambivalent claims; positive claims

claims-making 2, 18-19, 62

claims-making analysis 5-6, 7-8, 9, 32-60, 63-64, 119; and argumentative practices 46 ; basic claims grammar 45-50; challenges and opportunities 53-59; claims sample size across countries and newspapers 52; codebooks 33, 38, 49-50, 55, 59; coding instructions 44-45, 50, 59; coding processes $32-33,41,42,50$, 53-56; comparison as aspect of 38 ; and context of claim 47-49; examples for coding 48; frame analysis 46-47; as hybrid quantitative-qualitative approach 39, 41, 42, 54; identification of a claim $42-45,55$; inter-coder reliability 32-33, 54-56; interpretative elements 42, 54; language factors 53; measurement aspect of 38; meta-variables 47-49; methodological expansions 33-34; origins of 33, 41; pilot studies 50, 57, 59; protest-centric nature of 33; and public opinion formation 32, 34, 35-37, 40-41, $54,59,84$; 'purpose' of a claim 43; reliability of claims coding $50,53-56,59$; sampling strategies 50-51; social media commenting analysis as supplement to 56-59; standardisation in 39, 41-42; statistical significance considerations 51 ; sub-category coding 55 ; training of coders 56,59 ; validity of claims coding $53-54$, $55-56$

collective action $33,87,168$

collective commitment 87

collective responsibility 168

Cologne sexual assaults (New Year 2015/

16) $66,81,113,115,116,119,161,174$ commitment 16; collective 87 ; moral 14 ,

23, 96; mutual 23; shared 18

Common European Asylum System 159,170

communicative action, theory of 34

communicative acts $34,35,42$

communitarianism 4, 82, 122, 126, 171

comparison 38

compassion 19, 22, 26, 40, 71

concern, shared 18

conditionality 4, 103

connective action 33

consequences of the 'refugee crisis' 70, 71, 92, 96, 117, 119

Conservative Party, UK 159

constructivist paradigm 38 contentious politics $7,17,18,33,35,82$ contestation(s): public sphere as locus of 13-14, 15; see also solidarity contestation

Corriere della Sera, Il 52, 58, 144, 145,148

cosmopolitanism 3, 4, 27, 82, 171

Couldry, N. 26

courts 69, 143

'crisis' frame 25-26, 27

crisis management 71, 73, 112, 116, 119

critical junctures 49

critical theory 13

cross-country comparisons 38

cross-sectoral comparisons 38

cultural positions 62,82

cultural studies 34,54

culture industry 13

Daily Express, The 52, 58, 160, 161, 162

Danish People's Party (Dansk Folkeparti, DF) 122, 123-124

Dayan, D. 26

De Wilde, P. 32

democracy 2, 13, 14, 77; direct, Switzerland 107, 109

Democratic Party, Italy 145

denial, culture of 62, 82; Denmark 123-125; United Kingdom (UK) 163

Denmark 5, 61, 62, 66, 67, 121-127, 140, 169, 171; actors of claims 69, 123-125; asylum applicants 68,121 ; border controls 123,124 ; civil society $75,123,125$, 126, 127; denial of transnational solidarity 123-125; immigration debates 121-122; immigration policy 121 ; issues of claims about the 'refugee crisis' 71, 76, 124; issues discussed in articles posted on Facebook 92; issues in social media comments 92, 97; 'jewellery law' 67, 123; justifications for claims/ positions $77,125,126$; news media (newspapers) 52, 58, 89, 90, 95, 122-123, 126; polarisation of solidarity contestation 126, 127; political actors 125, 127; political parties 75,122 , 123-124; positions of claimants 72,73 , $74,75,125$; positions of claimants by territorial scope 81 ; public opinion 122 ; public sphere 122-123; social media comments 91, 92, 94, 95, 96, 97, 125-126, 172; state actors 75, 123-125, 170; supranational actors 75 ; tone in news posted on Facebook 89, 90, 95; 
tone of social media comments 95,96 , 125-126, 172; welfare chauvinism 126

deservingness/undeservingness of refugees $28,64,79,85,117,173$

diagnostic frames 46

direct democracy, Switzerland 107, 109

Discursive Actor Attribution Analysis (DAAA) 43

disruptive event(s), Syrian civil war as 28-29

distance 14

distant others 4, 16

Dublin Regulation 121, 135, 159, 170; suspension of $61,66,70,113$

East-West cleavage 169

Eastern Europe 151-152, 160

economic actors, Italy 149

economic crisis 4, 166

Ekstrabladet 123

emotions 23, 40, 87, 94, 98, 101, 173; see also fear; pity

empathy 16, 29, 71

engagement 14; solidarity 15, 20, 21, 25

Enhedslisten 122, 124

equality 2, 4, 143

Erdoğan, R. 131

European integration 18, 83, 166, 170, 171, 174-175

European public sphere 17, 18, 70, 167

European Social Model 166

European solidarity $1-2,6,7,9,15,16$, $28,63,66,83,166,167-176$

European Union (EU) 17-18, 61, 65, 70, $81,83,110,166$; Bratislava summit (2016) 140,175; as a community of values 2-3; Eastern enlargement 160; Germany and 171, 175; institutions/ organisations $69,70,73,83$; as intergovernmental organisation 168; power relationships within 169, 171; Swiss relationship with 107-108; as transnational body 168; and Turkey cooperation agreement (2016) 67, 138,146; United Kingdom (UK) and 158-159, 160, 164

Europeanisation of solidarity debates $80-81$

EUROPUB project $32,41,55,70$

Euroscepticism 107-108, 159, 163, 169, 171

evaluative frames 46

exclusive notion of solidarity 170-171 externalisation of refugee crisis: Greece 136, 138-140, 141, 142; United

Kingdom (UK) 160-161, 164

extreme right-wing parties 20, 80, 108, $110,129,131,135,141,149$

Facebook see social media commenting

fairness 77

Fakt 52, 58

far-right politics see extreme-right wing parties

fear, politics of 19, 29-30, 94, 96, 98, 101, 170-171

Figaro, Le 52, 58, 129, 130, 131, 132

fiscal solidarity 4

Five Star Movement 145

focusing event(s) 22, 27; refugee crisis' as 64

Forza Italia 145

framing 19, 46-47, 62, 65

France 5, 61, 66, 67, 96, 128-134, 172; actors of claims 69, 130-131; asylum applicants 68; Calais refugee camp 128, 159, 161; Charlie Hebdo shooting (2015) 128; civil society $75,129,130$, 131, 133; extreme-right support 129, 131 ; immigration policy 128 ; integration of migrants 128,129 ; issues of claims about the 'refugee crisis' 71, 76; issues discussed in articles posted on Facebook 92; issues in social media comments 92, 97; justifications for claims/positions 77, 131, 132, 132, 133; news media (newspapers) 52, 58, 90, 95, 129-130, 131, 132; Paris attacks (November 2015) 66, 81, 113, 128; political actors 133; political parties $75,129,131$; positions of claimants 72 , $73,75,131$; positions of claimants by territorial scope 81 ; public sphere 129-130; social media comments 91, 92, 94, 95, 96, 97, 130, 132-133, 133-134; state actors 75, 130-131, 169-170; supranational actors 75 ; tone of claims in news articles 90, 95; tone of social media comments 95, 96

Frankfurter Allgemeine Zeitung (FAZ) $52,58,115$

free movement, principle of 170

freedom 2

friendship relations 15 
Gazeta Wyborcza 52, 58, 156

Germany 5, 25, 66, 67, 70, 89, 113-120, 123, 130, 133, 140, 152, 169, 171, 172, 174; actors of claims $69,70,116,119$; asylum applicants $61,68,113$; civil society 75, 116, 117; Cologne sexual assaults (New Year 2015/16) 66, 81, 113, 115, 116, 119, 161, 174; Dublin Regulation suspension 61, 66, 113; and European Union (EU) 171, 175; immigration debate 115-116; immigration policy 113-114; issues of claims about the 'refugee crisis' $71,76,116,118-119$; issues discussed in articles posted on Facebook 92; issues in social media comments 92, 97, 117; justifications for claims/positions 77, 116-117, 119; news media (newspapers) 52, 58, 89, 90, 95, 114-116, 116-117, 118, 119; open borders policy 103, 113, 114, 175; political actors 116, 119; political parties 75; positions of claimants $72,73,74,75$, $116-117,119$; positions of claimants by territorial scope 81 ; public opinion 114; public sphere 114-116; social media comments 90, 91, 92, 94, 95, 96, 97, $115,117-118,119$; state actors 116,119 , 169-170; supranational actors 75; tone of claims in news articles 89, 90, 95, $116,117,119$; tone of social media comments 95, 96, 118; 'welcoming culture' $29,62,65,76,96,103,113$, $114,116,117,119,121,168,169$

Giornale, Il 144, 145

global justice 21, 166

global solidarity see transnational (global) solidarity

Gora, A. 32

governance, EU 17

governments see national governments

Great Recession 4

Greece 4, 5, 25, 61, 66, 67, 89, 90, 135-142, 169; actors of claims 69, 139-140; asylum applicants 68,135 ; civil society 75, 136, 139, 140; externalisation/ Europeanisation of crisis 136, 138-140, 141, 142; extreme right 135,141 ; humanitarian agenda 137-138; immigration policy $135,136,138$; issues of claims about the 'refugee crisis' 71,76 ; issues discussed in articles posted on Facebook 92; issues in social media comments 92, 97; justifications in claims 77; news media (newspapers) 52,
58, 89, 90, 95, 137-138; open borders policy 136; political actors 140; political parties $75,135,139,140,141$; positions of claimants $72,73,74,75,140$; positions of claimants by territorial scope 81; public opinion 136-138; public sphere 137-138; securitisation agenda $138,140,141,142$; social media comments 91, 92, 94, 95, 96, 97, 102, 140-141, 172; state actors 75, 139-140, 169-170; supranational actors 75 ;

SYRIZA-ANEL government 135; tone in news posted on Facebook 89, 90, 95; tone of social media comments 95,96 , 102, 141, 172

grievance 7

Guardian, The 52, 58, 160, 162, 163

Habermas, J. 13, 34

Handbook for the Analysis of

Representative Claims 32

hatred/hate speech $23,86,95,96,102$, 155,156

Hollande, F. 130

Horizon 2020 programme 5

hospitality 29, 174; moral obligations of 30

human rights $2,19,21,77,99,111$, 117, 132, 133, 143, 149, 166

human rights organisations 70 , 147,154

humanitarian, humanitarianism 82, 99, 117, 124, 137-138, 139, 146, 147, 148, $149,166,168,170,173$; action 25, 26, 46, 64, 96; campaigning 22; disaster 27, 28; solidarity 3, 6, 126

Hungary 61, 169

identity-based justifications 77, 78, 79, 83, 111, 125, 131, 132, 133, 146, 147

immigration debates 28, 175; Denmark 121-122; Germany 115-116;

Switzerland 108

immigration policy: Denmark 121; France 128; Germany 113-114; Greece 135, 136, 138; Switzerland 108; United Kingdom (UK) 158, 159

inclusive notion of solidarity $6,27,62$, 122, 126, 170, 171

indignation 23

individual citizens/activists 69, 70, 75

inequality 4

insider/outsider distinction 16, 18 
integration: European 18, 83, 166, 170, 171, 174-175; of public sphere 79-80, 102; of refugees/migrants 46, 70, 71, 97, $114,129,161$

interest-based justifications $77,78,79,83$, 111, 116, 125, 131, 132, 146, 147, 162

International Organisation of Migration (IOM) 136

interpretations: in claims-making analysis 42,54 ; collective, through social media $86-87,88$; news media provision of 20 , 28,65

issues of concern in refugee solidarity debates $64,70-71,73,76$; social media commenters 91-93, 96, 97; see also under individual countries

Italy 5, 25, 61, 66, 67, 90, 143-150; actors of claims 69, 145-146; asylum applicants 68,143 ; civil society $75,146,147$; courts as actors for solidarity protection 143; economic actors 149; humanitarian positions $146,147,148,149$; issues of claims about the 'refugee crisis' 71, 76, 146, 149; issues discussed in articles posted on Facebook 92; issues in social media comments $92, \mathbf{9 7}$; justifications for claims/positions 77 , 146-147, 148; news media (newspapers) 52, 58, 90, 95, 144-145, 146, 148, 149; political actors 147, 149; political parties $75,144,145,147,149$; positions of claimants $72,74,75,145-146,147$; public sphere $144-145$; security concerns 144, 149; social media comments 91, 92, 94, 95, 96, 97, 102, 147-148, 148-149, 172; state actors $75,146,149$, 170 ; supra-national actors 75 ; tone in news posted on Facebook 90, 95; tone of social media comments $95,96,102$, 172; welfare chauvinism 146, 148

'jewellery law', Denmark 67, 123 journalism 2, 9, 14, 18, 20, 39, 41, 101, 165 justice 17, 21, 77, 166, 168, 176; global 21, 166 ; social 14,16

justification(s) 18, 62, 63, 83; identitybased $77,78,83,111,125,131,132$, 133, 146, 147; interest-based 77, 78, 83, 111, 116, 125, 131, 132, 146, 147, 162; logics of 47 ; for positions $77-78,79,83$, 111, 116-117, 119, 125, 131, 132, 133; rights-based $77,78,83,111,117,125$, 131, 132, 146, 147, 162; social media commenting 89, 98-100, 103, 111, 119,126

Jyllands-Posten 52, 58, 122-123

Kaczynski, J. 152

Kathimerini 52, 58, 137, 142n4

Katz, E. 26

kinship relations 15

Konservative Folkeparti, Det 122

Koopmans, R. 32

Krippendorff's Alpha 54, 55

Kruskal-Wallis test 73

Kurdi, Alan 29, 65-66, 85, 93

language 53

Law and Justice Party see Prawo i Sprawiedliwość, PiS

Lega Nord see Northern League

legitimacy, political 36, 40, 42

Liberal Alliance party, Denmark 122

Libero Quotidiano 52, 58, 144, 145, 148

live coverage 29

LOCALMULTIDEM project 32

mass media 165-166, 173-174; as

agenda-setters 28; Janus face of 21, 166;

organisations 22; selective attention of

19,22 ; and solidarity contestation

3-5, 13-18, 35, 165; transnationalising

mechanism in 21; see also news media; social media

Matin, Le 52, 58, 109, 110, 111

media events 26-27; agenda-setting function 27; refugee crisis as media event 20-31, 67, 68, 173; as 'routines' 27;

staging or orchestrating of 26

media logics 39-40

mediapolis 165

Merkel, A. 66, 113, 119, 130, 175

migration management $70-71,73,76,92$, $96,97,110,116,117,118,123,124,146$, 149, 161

Monde, Le 52, 58, 129, 130, 131, 132

moral commitment 14, 23, 96

moral obligation 14,30

moral panics $26,28,163$

moral spectatorship 23, 85

multiculturalism 109, 112, 115, 121, 122, $147,152,170$

nation state 20-21, 165

nation-building 3

National Front, France 131 


\section{Index}

national governments $64,69,70,76-77$,

81; see also state actors

national identity 3; Poland 152

national public sphere 17, 21, 167

national scope, and solidarity positions $80,81,83,124$

national solidarity $3,6,15,63,165$

national sovereignty, defence of 151,152 , 158, 159, 169

nationalistic tendencies $6,18,19,85,122$, 170, 171

negative claims $72,73,76,77,78,79,81$, 83, 168; Denmark 125; France 131;

Germany 116-117, 119; Greece 140;

Italy 146; Poland 155; Switzerland 110,

111; United Kingdom (UK) 160-161, 162,163

negative consequences, internalisation of 30

negative social media comments 91,95 , 96, 97, 98, 99, 102, 172; Denmark 125, 126, 172; France 132, 133; Germany 118; Italy 147, 148; Poland 155-156, 172; Switzerland 111; United Kingdom (UK) 162, 163, 164, 172

Neue Züricher Zeitung 52, 58, 109

neutral/ambivalent claims 72, 73, 76, 78, 125,131

neutral/ambivalent social media comments 91, 95, 125-126, 132, 133, 141, 148

New Democracy party 140

news media 171; agenda-setting 28, 34, 63,

65,149 ; claims-making in 62 , see also claims-making analysis contentiousness of solidarity towards refugees in 18-20; as crisis actors 298; framing processes 62,65 ; as interpreters 20 , 28, 65; positionality of claims across newspaper types 78-80; and public sphere relationship 65; see also titles of individual newspapers; and under individual countries

news-making 34, 49

NGOs (non-governmental organisations)

$14,19,33,37,69,70,129$

non-elected representatives 37

norms 17,27

North Macedonia 138

Northern League (Lega Nord) 144, 145, 147

Norway 122

object actors 45-46

obligations 15-16; moral 14, 30; mutual

23; shared 16 online commenting see social media commenting

online sampling 50-51

open borders advocates 19

open borders policy 170; Germany 103, 113, 114, 175; Greece 136

opportunity 7

Orbán, V. 131

Paris attacks (November 2015) 66, 81, 113, 128

Parisien, Le 52, 58, 129, 130, 131, 132

particularistic solidarity $3-4,16$

performers/performances 26

pilot studies 50, 57, 59

pity $26,40,87$; horizon of 19,22 ; politics of $19,29,94,95,96,98,101,104$, 168,173

pluralism 14, 86, 100, 101

Poland 5, 61, 62, 66, 67, 70, 89, 90, 151-157, 169; actors of claims 69; asylum applicants 68,151 ; categorical rejection of solidarity 152-153, 154-155, 156; Catholic church 152; civil society 75,154 ; human rights organisations 154; issues of claims about the 'refugee crisis' 71, 76; issues discussed in articles posted on Facebook 92; issues in social media comments 92, 97; justifications in claims 77 ; national identity, defence of 152 ; news media (newspapers) 52, 58, 89, 90, 95, 153154, 156, 157; political parties 75,151 , 152, 153, 154, 155, 156-157; positions of claimants $72,73,74,75,54-155$; positions of claimants by territorial scope 81 ; public opinion 152-153; public sphere 153-154; response patterns to posted articles on Facebook 91; social media comments 92, 94, 95, 96, 97, 155-156, 172; state actors 75, 154, 155, 156, 170; supranational actors 75 ; tone in news posted on Facebook 89, 90, 95; tone of social media comments 95, 96, 155-156, 172; trade union movements (Solidarność) 152

polarisation of solidarity debates 94 , 102-103; Denmark 126, 127; United Kingdom (UK) 163-164

policy actors/elites 17, 20, 166

policy spheres $13,14,17,18$

political actors $19,21,36,38,39,40,49$, 54, 59, 78, 82-83, 87, 169; Denmark 125, 127; France 133; Germany 116, 
119; Greece 140; Italy 147, 149; Switzerland 110, 112; United Kingdom (UK) 161,163

political decisions 44

political discourse analysis 41

political legitimation 36, 40, 42

political logics 39-40

political parties $14,33,64,69,73,169$,

173; Denmark 75, 122; extreme-right 20, 80, 108, 110, 129, 131, 135, 141, 149; France 75, 129, 131; Germany 75;

Greece 75, 135, 139, 140, 141; Italy 75, 144, 145, 147, 149; Poland 75, 151, 152, $153,154,155,156-157$; populist 6,20 , 88, 110, 114, 144, 149, 151; right-wing 72, 85, 110, 114, 144, 145, 147, 151, 156, 158, 170; Switzerland 75, 108, 110, 111; United Kingdom (UK) 75, 158-159, 160, 161 see also names of individual parties

political representation 36-37

Politiken 52, 58, 122-123

populists/populist parties $6,20,64,88$, 110, 114, 144, 149, 151-152, 171, 174

position(s) 18-19, 45, 46, 63, 82-83; country differences in 72-78; cultural 62,82 ; differences across newspaper types 78-80; justifications for 77-78, 79, 83, 111 ; and territorial scope of actors 80-81, 83; see also under individual countries

positive claims $72,76,78,79,81,82,83$, 168; Denmark 125; France 131; Germany 116, 117, 119; Greece 140; Italy 146; Poland 154-155; Switzerland 110, 111 positive social media comments 91, 95, 96, 97, 98, 99, 102, 172; France 132, 133; Germany 118; Greece 141, 172; Italy 148, 172; Switzerland 111

positivist paradigm 38

power politics, EU 169, 171

Prawo i Sprawiedliwość, PiS 151, 152, 153, 154, 155, 156-157

prognostic frames 46

protagonists of solidarity contestations 64 , 68-70; see also civil society; state actors; supranational actors

protest actions 44

protest event analysis 41

Proto Thema 52, 58, 137, 142n6

public opinion: Denmark 122; formation of $32,34,35-37,40-41,54,59,84,85$, 100-101, 172, 173, 174; Germany 114;
Greece 136-138; Poland 152-153; Switzerland 108; United Kingdom (UK) 158 public sphere 1, 2, 3, 5, 7, 13, 18, 62, 165, 166-167, 171-172; Denmark 122-123;

European 17, 18, 70, 167; France 129-130; Germany 114-116; Greece 137-138; integration of 79-80, 102, 172; as locus of contestations $13-14,15,40$; national 17,21,167; and news media relationship 65; social media and pluralisation of 86; Switzerland 108-110; United Kingdom (UK) 159-160 public/civic initiatives 70, 71, 92, 96, 97, 110, 161, 170 publicity 19,20

quantitative-qualitative approach in claims-making analysis $39,41,42,54$ quotas, refugee 130, 145, 146, 152, 169, 175

racism 85,155

radicalisation 96, 141, 148, 155, 156-157, 171,173

rare phenomena 51,54

reciprocal solidarity 4,22

reciprocity 16

RECONNECT project 32, 41

Red-Green Alliance (Enhedslisten) 122, 124 refugee crisis $1-3,4,5,7,8,18,19-20$; as focusing events 64; as media event 20-31, 67, 68, 173

Regione Ticino, La 52, 58, 109

reliability of claims coding $50,53-56,59$

religiosity 98-99, 152

Reporters without Borders 153

Repubblica, La 52, 58, 144, 145, 148

Republicans, France 131

responsibility 9,23 ; collective 168 ; of journalism 2; shared 16, 175

right-wing actors $72,85,110,114,130$, 137, 144, 145, 147, 151, 169, 170, 174; see also extreme right-wing

rights 4, 15-16, 17, 170; civil 77; human 2, 19, 21, 77, 99, 111, 117, 132, 133, 143, 149 , 166; shared 16; social 21,77

rights-based justifications $77,78,79,83$, $111,117,125,131,132,146,147,162$ rule of law 2

Rzeczpospolita 52, 58

salience of solidarity debate $64,65-68$ sampling strategies: claims-making analysis $50-51$; social media commenting analysis 57 


\section{Index}

Saward, M. 36

Schengen area $61,72,107,159,170$

securitisation 138, 140, 141, 142

security $64,70,71,82,124,144,149,174$;

management 46; threats $26,27,28,113$

segmentation of solidarity contentions 31 , $133,134,148,149,162-163,167,173$

selective issue attention $19,22,64$

Slovakia 169

Social Democrats (Socialdemokratier, SD) 122, 124

social justice 14,16

social media 7, 22, 23, 33, 35

social media commenting (Facebook) 5, 6, 7, 8, 9, 47-48, 56-58, 59, 84-104, 172-173; civic culture scenario 86, 87-88, 93; civicness of citizen's commentary 88-93; contribution to democratic politics 100-101; destabilising effects of 86; engagement with refugee solidarity 93-100; interpretative work 86-87, 88; issue agendas 91-93, 96,97 ; issues in comments with negative/positive stance 97; justifications 89 , 98-100, 103, 111, 119, 126; negative/ opposing comments see negative social media comments; neutral/ambivalent comments 91, 95, 125-126, 132, 133, 141; positive (affirmative) comments see positive social media comments; response patterns to posted articles 90-91; sampling strategy 57; and tone of articles posted 89-90; tone of commenters 89, 94-97, 98, 99, 102, 172; uncivic culture scenario 86,88 ; see also under individual countries

social movement research 17, 33, 39

social movements $14,19,37$

social rights 21,77

Socialist Party, France 131

Söder, M. 113

solidarity 166 ; action 20,44 ; definition of 15; differentiated 175; with distant others 4; engagement 15, 20, 21, 25; European 1-2, 6, 7, 9, 15, 16, 28, 63, 66, 83, 166, 167-176; exclusive notion of 170-171; fiscal 4; flexible 175; humani$\operatorname{tarian} 3,6,126$; inclusive notion of 6 , 27, 62, 122, 126, 170, 171; national 3, 6, $15,63,165$; objects of 35,87 ; particularistic 3-4, 16; targets of 22; thick or reciprocal 4, 22; thin 4; transnational see transnational (global) solidarity; universalistic $3,4,16$ solidarity contestation 40; European field of $3-6,82$; mass media and $3-5,13-18$, 35,165

Solidarność 152

spectatorship, moral 23, 85

speech acts 33, 34

Spiegel, Der 115, 118

standardisation in claims-making analysis $39,41-42$

state actors $69-70,73,76-77,78,79$, 82-83, 110, 169-170; Denmark 75, 123-125, 170; France 75, 130-131, 133, 169-170; Germany 75, 116, 119, 169-170; Greece 75, 139-140, 169-170; Italy 75, 146, 149, 170; Poland 75, 154, 155, 156, 170; Switzerland 75, 110, 111, 170; United Kingdom (UK) 75, 161, 170; see also national governments; political parties

statements 43 ; legitimation 42 ; verbal 44 stigmatisation 23

strangers 16,165

strategic communications 34,35

sub-national scope, and solidarity

positions 80,81

Süddeutsche Zeitung (SZ) 52, 58, 115, 118 supranational actors $69,70,75,110,111$, 124, 139, 161; see also European Union (EU), institutions; United Nations (UN) supranational scope, and solidarity positions $80,81,83$

Sweden 25, 121, 122, 123

Swiss People's Party (SVP) 108, 110

Switzerland 5, 61, 66, 67, 70, 107-112, 172; actors of claims 69, 110; asylum applicants 68,108 ; civil society 75 , 110-111, 112; direct democratic participation 107, 109; and EU relationship 107-108; fragmentation, political/ cultural/ linguistic 107; immigration debate 108; immigration policy 108 ; issues of claims about the 'refugee crisis' 71, 76, 110-111; issues discussed in articles posted on Facebook 92; issues in social media comments $\mathbf{9 2}$, 97; justifications for claims/positions 77, 111; linguistic divisions 107,108 , 109-110, 111, 112; migration debate before refugee crisis 109-110; news media (newspapers) 52, 58, 90, 95, 108-110; political actors 110, 112; positions of claimants $72,74,75,110,111$; positions of claimants by territorial scope 81 ; public opinion 108; public 
sphere 108-110; social media comments 91, 92, 94, 95, 96, 97, 111-112; state actors 110, 111, 170; supranational actors 75 ; tone of claims in news articles 90, 95; tone of social media comments 95, 96, 111-112

Syrian civil war, as disruptive event 28-29

Szydło, B. 152

Ta Nea 52, 58, 137, 142n5

tabloid newspapers 49, 51, 65, 79, 99, 100, 173; Denmark 123; France 129, 131; Germany 115; Greece 137; Italy 144, 145; Poland 153; United Kingdom (UK) 159, 160, 163, 164; see also titles of individual newspapers

Tages Anzeiger 52, 58, 109

targets of solidarity 22

Telegraph, The 52, 58, 160, 161, 162

temporal analyses 38

Temps, Le 52, 58, 109, 111

territorial scope of actors, and solidarity positions $80-81,83,139$

terror threats/attacks 113, 128; Charlie

Hebdo shooting (2015) 128; Paris

attacks (November 2015) 66, 81, 113,128

thick and thin solidarity 4

threat 27, 62, 170-171, 173, 174; perceptions of $22,23,26$; security $26,27,28$

tonality of claims and statements: news articles 79, 89, 90, 95, 172; social media comments 89, 94-97, 98, 99, 102, 172; see also negative claims; negative social media comments; neutral/ambivalent claims; neutral/ambivalent social media comments; positive claims; positive social media comments: and under individual countries

Tönnies, F. 4

trade unions 14, 69, 70; Poland 152

transnational (global) solidarity 4, 5, 6, 7, $15,18,21,22,23,28,63,82,87,165$, 166; Danish denial of 123-125; UK denial of 163

transnational scope, and solidarity positions 80, 81, 139

'Transnational Solidarity in Times of Crisis' (TranSol) project 5-6

transnationalisation of solidarity debates $80-81$

Treaty on European Union 2
Turkey, and EU cooperation agreement (2016) 67, 138, 146

UKIP (United Kingdom Independence Party) $158-159,160$

United Kingdom (UK) 5, 61, 62, 66, 67, 90, 158-164; actors of claims 69; asylum applicants $68,158,159$; civil society 75, 160, 162; and EU 158-159, 160, 164; externalisation of refugee crisis 160-161, 164; immigration policy 158, 159; issues of claims about the 'refugee crisis' $71,76,161,163$; issues discussed in articles posted on Facebook 92; issues in social media comments 92, 97; justifications in claims 77 , 162; news media (newspapers) 52, 58, 90, 95, 159, 160-162, 163-164; polarisation of solidarity debates 163-164; political actors 161, 163; political parties 158-159, 160, 161; positions of claimants $72-73,74,75,160-161$; positions of claimants by territorial scope 81; public opinion 158; public sphere 159-160; response patterns to posted articles on Facebook 91; social media comments 92, 94, 95, 96, 97, 162-163, 164, 172; state actors 161, 162, 170; supranational actors 75, 161; tone in news posted on Facebook 90, 95, 160, 161; tone of social media comments 95 , 96, 162, 172

United Nations High Commissioner for Refugees (UNHCR) 135, 136

United Nations (UN) 69, 73, 110

universalistic solidarity $3,4,16$

validity of claims coding $53-54,55-56$

values $2-3,170$

Venstre 122, 124

verbal statements 44, 94

volunteers/volunteering $76,111,117$, 119, 136

Walzer, M. 4

'welcoming culture' 29, 62, 65, 70, 76, 82, $96,103,113,114,116,117,119,121$, 168,169

welfare chauvinism 98, 126, 132, 146, 148

welfare states 15

witnessing of human suffering 23

xenophobia $6,65,85,95,96,102,140$, 144, 151-152, 156, 171 


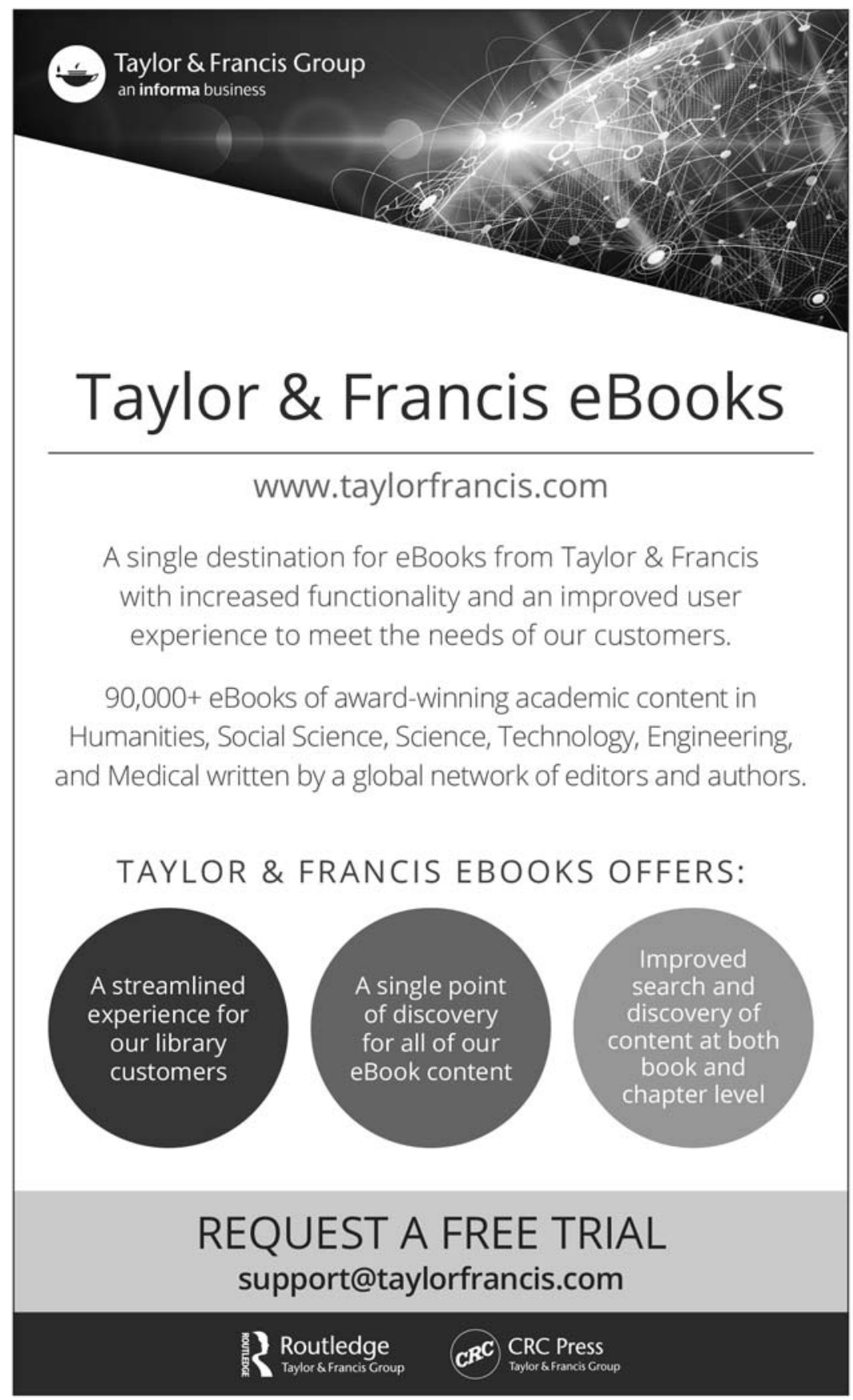

